NBSIR 76-1133

\title{
Skid Resistance Measurement Tests of FHWA Reference Systems at the Western Field Test Center
}

R. W. Kearns and J. F. Ward

Engineering Mechanics Section

Mechanics Division

Institute for Basic Standards

National Bureau of Standards

Washington, D. C. 20234

March - April 1975

Final

Issued October 1976

Prepared for

Federal Highway Administration

Office of Development

Washington, D. C. 



\section{SKID RESISTANCE MEASUREMENT \\ TESTS OF FHWA REFERENCE \\ SYSTEMS AT THE WESTERN FIELD \\ TEST CENTER}

R. W. Kearns and J. F. Ward

Engineering Mechanics Section

Mechanics Division

Institute for Basic Standards

National Bureau of Standards

Washington, D. C. 20234

March - April 1975

Final

Issued October 1976

Prepared for

Federal Highway Administration

Office of Development

Washington, D. C. 20590

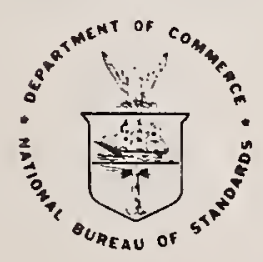

U.S. DEPARTMENT OF COMMERCE, Elliot L. Richardson, Secretary

Edward O. Vetter, Under Secretary

Dr. Betsy Ancker-Johnson, Assistant Secretary for Science and Technology

NATIONAL BUREAU OF STANDARDS, Ernest Ambler, Acting Director 
Federal Highway Administration Policy

The opinions, findings and conclusions expressed in this publication are those of the authors and not necessarily those of the Federal Highway Administration. 
1. INTRODUCTION

2. PREPARATION, MEASUREMENT AND ADJUSTMENT OF SUBSYSTEMS 3

2.1 Test Preparations 3

2.1.1 Auxiliary Test Equipment 3

2.1.2 Test T'ires 5

2.2 Skid Trailer Weight Distribution 5

2.3 Tow Vehicle Displacements 5

2.4 Speed Measuring Subsystem 7

2.5 Pavement Wetting Subsystem 7

2.5.1 Flow Räte Measurement 7

2.5.2 Water Distribution - Static Measurements 9

2.5.3 Water Distribution - Dynamic Measurements 15

2.5.4 Wetted Width Measurement 20

2.6 Force Measuring Subsystem 27

2.6.1 WARS Transducer 27

2.6.2 WARS Transducer Evaluation 31

2.6.3 On-Board Signal Generator Equivalent Value 31

2.6.4 Transducer Response to Changes in Operating 31 Variables

2.6.5 Transducer Response to Changes in Wheel. Radius 31

2.6.6 Transducer Response to Changes in Inflation 35

2.6.7 Transducer Response to Changes in Hitch Height 35

2.7 Suspension Subsystems 35

2.7.1 Experimental Determination of the Effective 38 Unloading Constant

2.7.2 Tow Vehicle and Trailer Displacements under 40 Static Traction Load

2.7.2.1 Displacement of the Test Wheel Hub 40

2.7.2.2 Displacement of the Test Tire Interface 40

2.7.2.3 Displacement of the Trailer Body through 40 Roll Axis Rotation

2.7.3 Suspension Characteristics under Transient 44 Loading 
3. THE DYNAMIC SKID RESISTANCE MEASUREMENT OF SELECTED SURFACES AND WARS-IRS CORREIAATION

3.1 Surfaces Solected

3.2 lests planned

3.3 The Test Matrix

3.4 Tests Accomplished

3.5 Control of Test Variables 70

3.6 Test Tire Inflation Pressure Tests 71

3.7 Measurement of Uncontrolled Test Variables 76

3.8 The Correlation Test Plan 94

3.9 Test Matrix Results 98

3.10 Ranking of the Sources of Dispersion

3.11 Skid Resistance Speed Gradient 122

3.12 The Correlation Equation 129

3.13 Use of the Correlation Equation 129

4. THE IRS GROUND STATION 132

4.1 Introduction 132

4.2 Features of the Ground Station 132

4.3 Evaluation of the Ground Station

5. RECOMMENDAT IONS

6. REFERENCES

Appendix A. General Description of the Western Area Reference System (Tow Vehicle and Trailer).

Appendix B. Operating Parameters of the Western Area Reference System.

Appendix C. The Test Matrix. 
1. WARS Engine Tachometer Readings (Second Gear).

2. WARS Flow Rates, 8.1 Inch Wetted Width.

3. Comparison of Average Flow Rates Determined by Two Methods.

4. Wetted Width Measurements.

5. Effect of Test Tire Inflation Pressure on WARS Transducer Output.

6. Tests Planned and Accomplished.

7. Test Plan Sequence.

8. Weather During Test Plan Time Periods.

9. Ranking of Possible Sources of Dispersion in WARS Results.

10. Ranking of Possible Sources of Dispersion in IRS Results.

11. Dispersion Sample Standard Deviations.

12. Correlation Summary.

13. Skid Number Values Computed by the Ground Station. 


\section{ILLUSTRATIONS}

1. Tosl 'lire Radlal Spring Rale 'Test Set-Up.

2. WARS Tow Vehicle Displacements with Load.

3. WARS Piping Modified for Flowmeter and 3 Sets of Adjusting Values.

4. Verification of WARS Flow Rates.

5. SDG Sight Tube Array.

6. Static Water Distribution at $20 \mathrm{mph}(32 \mathrm{~km} / \mathrm{h})$.

7. Static Water Distribution at $40 \mathrm{mph}(64 \mathrm{~km} / \mathrm{h})$.

8. Static Water Distribution at $60 \mathrm{mph}(97 \mathrm{~km} / \mathrm{h})$.

9. WARS Dynamic Pavement Wetting at $60 \mathrm{mph}(97 \mathrm{~km} / \mathrm{h})$.

10. Measurement of Water Trace Width after the Trailer has Passed.

11. Wetted Width by Delayed Measurement on Pavement, WARS at $20 \mathrm{mph}(32 \mathrm{~km} / \mathrm{h})$.

12. WARS Pavement Wetting During a Locked Wheel Skid at $20 \mathrm{mph}(32 \mathrm{~km} / \mathrm{h})$.

13. WARS Pavement Wetting During a Locked Wheel Skid at $40 \mathrm{mph}(64 \mathrm{~km} / \mathrm{h})$.

14. WARS Pavement Wetting During a Locked Wheel Skid at $60 \mathrm{mph}(97 \mathrm{~km} / \mathrm{h})$.

15. Effect of Bubble Formation on WARS Pavement Wetting at $20 \mathrm{mph}(32 \mathrm{~km} / \mathrm{h})$.

16. Side View of WARS Pavement Wetting at $40 \mathrm{mph}(64 \mathrm{~km} / \mathrm{h})$.

17. A Simulated Traction Force Being Applied to a Locked Test Wheel Through an Air-Bearing Force Plate.

18. WARS Transducer Performance.

19. Adjustable Radius Test Wheel.

20. Variation in WARS Transducer Output with Test Wheel Radius. 
21. Variation in WARS Transducer Output with Hitch Height.

22. Experimental Determination of WARS Effective Unloading Constant.

23. Displacement of the WARS Test Wheel Hub Due to Static Traction.

24. Displacement of the WARS Test Tire Interface Due to Static Traction.

25. Roll Displacement of the WARS Trailer Body Due to Static Traction.

26. Effect of Different Damping Factors on Second-Order Linear Systems.

27. Trailer Transient Drop Test Equipment.

28. IRS Transient Drop Test Set-Up.

29. IRS Displacement Response to Center-of-Gravity Drop Test.

30. WARS Displacement Response to a Center-of-Gravity Type Drop Test Before Modification.

31. WARS Displacement Response to a Center-of-Gravity Type Drop Test After Modification.

32. IRS Force Response to a Center-of-Gravity Drop Test.

33. IRS Force Response to an Axle Drop Test.

34. WARS Force Response to a Center-of-Gravity Type Drop Tést.

35. WARS Force Response to an Axle Drop Test.

36. Delay in the Drying of a Wet Pavement when Deicing Agents are Present.

37. Histogram of Test Tire Inflation Pressure After a 5 Mile $(8 \mathrm{~km})$ Drive.

38. Histogram of Test Tire Inflation Pressure After Skid Test.

39. Change in Test Tire Carcass Temperature Versus Inflation Pressure.

40. Thermometer Locations.

41. Temperature Versus Time of Day, April 29, 1975.

42. Temperature Versus Time of Day, May 3, 1975. 
43. Surface 3 North End Temperature Minus Base Temperature Versus Time of Day, April 23 - May 8, 1975.

44. Surface 3 North End Temperature Minus Base, Temperature Versus Wind Direction, April 23 - May 8, 1975.

45. Surfaces 1, 2, 3 North End Temperature Minus Base Temperature Versus Time of Day, Wind $\mathrm{Ca} / \mathrm{m}$ at Time of Measurement. Various Days.

46. Surface 3 North End Temperature Minus Surface 3 South End Temperature Versus Wind Direction, April 23 - April 26, 1975.

47. Observations of Wind Direction, April 23 - May 8, 1975.

48. Texture of Skid Resistance Surface Number 1.

49. Texture of Skid Resistance Surface Number 2.

50. Texture of Skid Resistance Surface Number 3.

51. Texture of Tire Wear on Surface Number 1.

52. Texture of Tire Wear on Surface Number 2.

53. Texture of Tire Wear on Surface Number 3.

54. Tire Wear on Surface 1.

55. Tire Wear on Surface 2 .

56. Tire Wear on Surface 3 .

57. Confidence Interval Versus Number of Measurements.

58. WARS Measurement Results at WFTC - Spring, 1975, Single Time Period Measurements.

59. IRS Measurement Results at WFTC - Spring, 1975, Single Time Period Measurements.

60. WARS Measurement Results at WFTC - Spring, 1975, Multiple Time Period Measurements.

61. IRS Measurement Results at WFTC - Spring, 1975, Multiple Time Period Measurements.

62. Deviation from the Mean Skid Number Measured by the WARS on Surface 1 at the WFTC as a Function of Test Tire. 
63. Deviation from the Mean Skid Number Measured by the IRS on Surface 1 at the WFTC as a Function of Test Tire.

64. Deviation from the Mean Skid Number Measured by the WARS on Surface 2 at the WFTC as a Function of Test Tire.

65. Deviation from the Mean Skid Number Measured by the IRS on Surface 2 at the WFTC as a Function of Test Tire.

66. Deviation from the Mean Skid Number Measured by the WARS on Surface 3 at the WFTC as a Function of Test Tire.

67. Deviation from the Mean Skid Number Measured by the IRS on Surface 3 at the WFTC as a Function of Test Tire.

68. Deviation from the Mean Skid Number Measured by the WARS on Surface 1 at the WFTC as a Function of Lane.

69. Deviation from the Mean Skid Number Measured by the IRS on Surface 1 at the WFTC as a Function of Lane.

70. Deviation from the Mean Skid Number Measured by the WARS on Surface 2 at the WFTC as a Function of Lane.

71. Deviation from the Mean Skid Number Measured by the IRS on Surface 2 at the WFTC as a Function of Lane.

72. Deviation from the Mean Skid Number Measured by the WARS on Surface 3 at the WFTC as a Function of Lane.

73. Deviation from the Mean Skid Number Measured by the IRS on Surface 3 at the WFTC as a Function of Lane.

74. Deviation from the Mean Skid Number Measured by the WARS at the WFTC as a Function of Time Period.

75. Deviation from the Mean Skid Number Measured by the IRS at the WFTC as a Function of Time Period.

76. Skid Resistance Characteristic, Surface 2 at FHWA, WFTC.

77. Skid Gradient Characteristic, Surface 2 at FHWA, WFTC.

78. Skid Resistance Characteristic, Surface 3 at FHWA, WFTC.

79. Skid Gradient Characteristic, Surface 3 at FHWA WFTC.

80. WARS-IRS Correlation, Single Time Period Results. 
81. IRS Ground Station.

82. Ground Station Plot.

83. Measured Location of Surface Within the Pad Corresponding to SN Data.

84. Variation in $\mathrm{SN}_{40}$ with Starting Point.

85. Second Degree Polynomial Fitted to Data in Interval.

86. Differential Radar System Plot of Test Speed.

87. Plot On-Board Tow Vehicle.

88. Ground Station Response to Known Inputs.

A-1. Sequence of Events. 


\author{
at the \\ Western Field Test Center \\ March and April, 1975
}

R. W. Kearns and J. F. Ward

\begin{abstract}
The Federal Highway Administration (FHWA) is developing a program to improve the method of measuring wet weather pavement skid resistance (SN) and to reduce the variation in results. At the national level, an interim reference system (IRS) is maintained and operated by the National Bureau of Standards. At the regional level, an area reference system (ARS) is maintained and operated at each FHWA field test center. Intercomparisons between these reference systems and the highway measuring systems at the state level, provide measurement assurance.
\end{abstract}

In this report, the first correlation results between the IRS and the Western ARS (WARS) are given:

$$
\mathrm{SN}_{\text {WARS }}=4.55+0.99 \mathrm{SN}_{\text {IRS }}
$$

where the computed standard deviation of a mid-range predicted value is $1 \mathrm{SN}$. SN is described as a function of test speed, $V$, in $\mathrm{mph}$ ( $1 \mathrm{mph}=1.609 \mathrm{~km} / \mathrm{h}$ ): for surface 2 ;

$$
\mathrm{SN}(\mathrm{V})=76.5-0.71 \mathrm{~V}+0.0070 \mathrm{~V}^{2}
$$

and the speed gradient is

$$
\frac{\mathrm{d}(\mathrm{SN})}{\mathrm{dV}}=-0.71+0.014 \mathrm{~V}
$$

The test program is explained from test preparations, tuning and calibration of subsystems, thru dynamic measurement of the surfaces. Controlled and uncontrolled variables are identified, discussed, 
and in some cases, experimentally verified. A ranking of the sources of dispersion is given. A discontinuity in $\mathrm{SN}$ of surface 1 is identified due to the unique test plan. A ground station for improved SN calculation precision and on-site statistical analysis is found to meet design objectives.

Key Words: Accident reduction, skidding; correlation skid resistance; highway safety; measurement, skid resistance; pavement, skid resistance; pavement wetting system; tire-pavement interface forces; wet pavement.

\section{INTRODUCTION}

The measurement of the skid resistance of highways under wet weather conditions is part of the Federal Highway Administration (FHWA) skid accident reduction program. Currently, the majority of state highway departments measure pavement skid resistance with locked-wheel skid measurement systems, which are reported to be in substantial compliance with the requirements of ASTM Designation E-274-70 [1]*. To reduce the variability between measurement results from different designs of systems meeting these requirements and to improve the precision of the measurements made by a given system, FHWA is developing a hierarchical. system for the measurement of pavement skid resistance [2]. At the national level, the FHWA program provides for an interim reference system (IRS) maintained by the National Bureau of Standards (NBS). At the regional level, the program provides for area reference systems (ARS) maintained at FHWA Field Test Centers (FTC). At the state level, skid resistance measuring systems are maintained to inventory and rank the condition of the highways in accordance with their skid resistance. The plan to assure measurement consistency between the state reports includes the monitoring and development of test procedures and equipment by NBS to relate the measurements made within the hierarchial system to the national measurement system.

The measurement assurance program for the FTC and ARS includes the periodic evaluation of test facilities and procedures, determination of the performance characteristics of the ARS and its subsystems, measurement of selected reference surfaces maintained at the FTC with the IRS, and correlation of the measurements made by the ARS and IRS. The program also includes the evaluation of new test equipment and procedures, and experimental studies for the development of numerical data, where appropriate, to identify and quantify sources of difference in the skid number measurements. As a result, improvements in procedure and equipments are expected as the program develops with the increased measurement capabilities being transferred to the highway measurement systems at the FTC.

*Figures in brackets indicate the literature references at the end of this report. 
This report describes tests conducted under the direction of NBS personnel at the FHWA Western FTC (WFTC) during periods in March and April 1975.

\section{PREPARATION, MEASUREMENT AND ADJUSTMENT OF SUBSYSTEMS}

Previous results from skid trailer correlation test programs indicated the measurements lacked precision, agreement among trailers using self-watering systems was poor, and the causes for the differences between trailer measurements was difficult to define [3]. To identify sources of these differences certain preparations were made and auxiliary equipment and experiments were designed to measure, and intercompare with the IRS, the performance characteristics of the components and subsystems. When conditions were found to be outside the ASTM requirements or conditions were found that would adversely affect the performance of the total WARS system, adjustments and modifications were made or recommended.

\subsection{Test Preparations}

Auxiliary test equipment and the facilities of the WFTC were used to prepare the WARS for test. Test tires were prepared for test.

\subsubsection{Auxiliary Test Equipment}

Skid resistance is reported in terms of skid number (SN) which is determined from the force required to slide a locked test tire at a stated speed in the presence of a water layer applied to the pavement ahead of the test tire divided by the effective wheel load and multiplied by 100. The thickness of the water layer, the speed, and forces at the tire-pavement interface are the principal quantities to be measured. To relate these measurements to the national measurement system auxiliary test equipment was designed using component types which are routinely calibrated in various NBS laboratories.

Two load cells, calibrated to a 0.25 pounds-force ( $1 \mathrm{bf}$ ) ( 1.1 newtons (N)) uncertainty in the Engineering Mechanics Section, were utilized in a test fixture to apply simultaneously known traction and load forces to a force plate during its calibration [4]. The force plate was used subsequently to calibrate the force transducers of the trailers (sec. 2.6).

A turbine flow rate meter was calibrated to a 0.6 gallons per minute $(\mathrm{gpm})$ (2 liters per minute $(1 / \mathrm{min})$ ) uncertainty in the Fluid Meters Section. Calibrations were obtained for the turbine both alone and as part of a digital differential flow rate system having a 0.1 gpm $(0.4 \mathrm{l} / \mathrm{min})$ resolution. The system is part of the on-board IRS instrumentation, but is adaptable to measuring the flow rate in the ARS (sec. 2.5). 


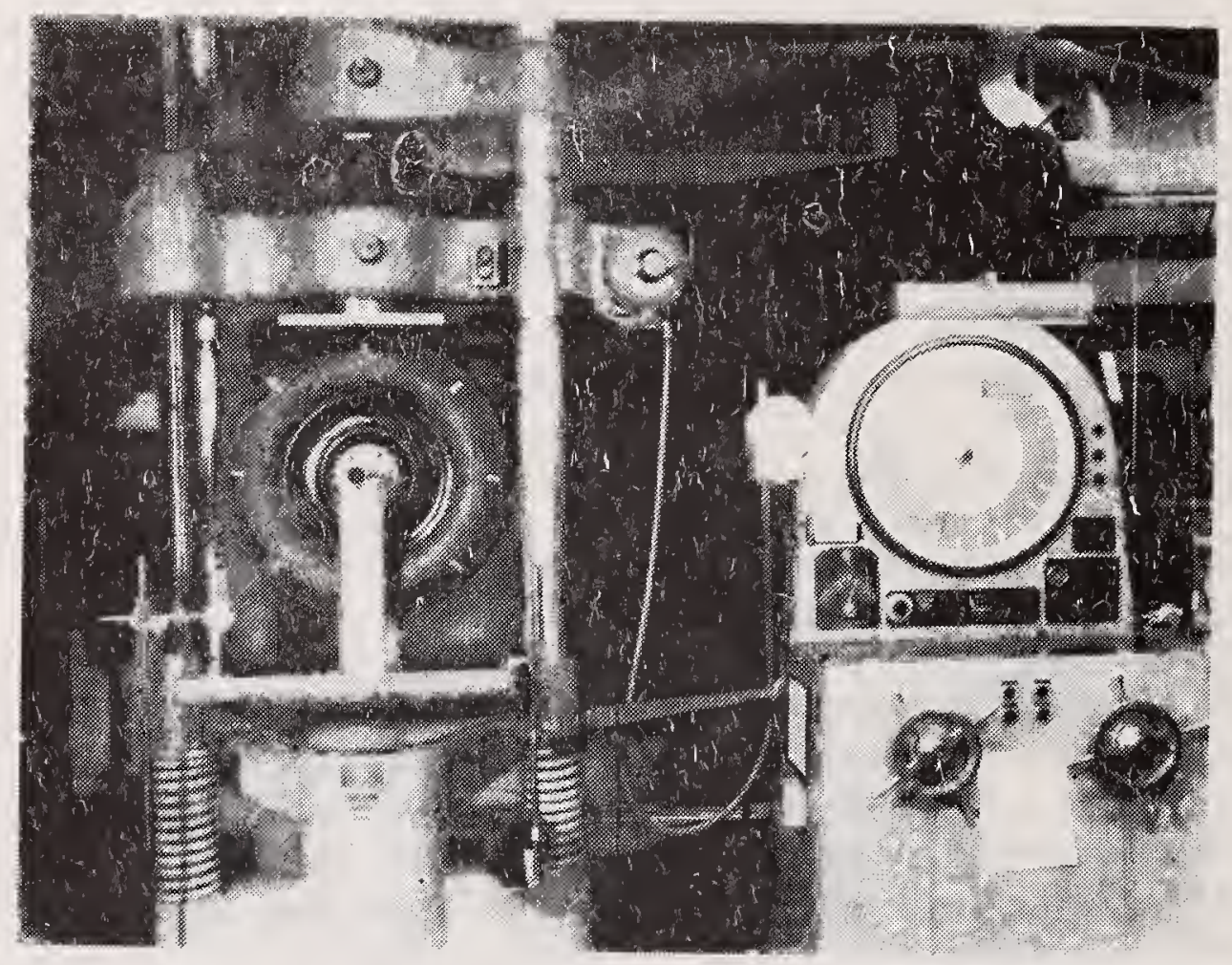

Figure 1. Test tire radial spring rate test set-up. 
A differential radar speed meter, whose time base was calibrated against a standard frequency and whose radiated frequency is specified to be well within limits required for its $0.1 \mathrm{mph}(0.16 \mathrm{~km} / \mathrm{h})$ resolution was used to record the speed of the system during a skid resistance measurement (sec. 2.4).

Other auxiliary equipment included a voltmeter, calibrated to one milivolt uncertainty by the Electrical Instruments Section; and inflation pressure gage, calibrated to 0.05 pounds-force per square inch (psi) (345 pascals $(\mathrm{Pa})$ ) uncertainty by the Pressure and Vacuum Section; and an automatic sequential displacement recording system (sec. 2.7).

\section{1 .2 Test Tires}

In preparation for the testing at the WFTC, each of the ASTM E501 test tires to be used was mounted on a wheel, balanced, and broken in with a 200 mile $(320 \mathrm{~km})$ drive. In additton, the nominal radial spring rate was determined at NBS. The value was $12801 \mathrm{bf} / \mathrm{In}(224 \mathrm{kN} / \mathrm{m})$ at 24 psi (165 Pa) inflation pressure under 1085 lbf $(4800 \mathrm{~N})$ load after break in. This value was determined from radial load versus deflection data obtained with the test setup in Figure 1.

\subsection{Skid Trailer Weight Distribution}

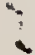

To measure the static vertical wheel loads of the test trailer, a force plate was placed under each trailer tire and a vertical load cell was placed under the hitch. The air bearings of the force plates were inflated, water placed in the trailer hose, and the trailer leveled. Readings were then taken simultaneously. The initlal test wheel load was $1098 \mathrm{lbf}(4880 \mathrm{~N})$. After adjustment the distribution was:

$\begin{array}{ll}\text { Left (test) side wheel load } & =1087 \text { lbf }(4830 \mathrm{~N}) \\ \text { Right side wheel load } & =1083 \text { lbf }(4820 \mathrm{~N}) \\ \text { Hitch vertical load } & =178 \text { lbf }(792 \mathrm{~N})\end{array}$

\subsection{Tow Vehicle Displacements}

Changes in the tow vehicle hitch height and rear wheel radius were measured as a function of occupant weight and water load. Changes in hitch height affect the skid number measurement in two ways; the vertical load reduction factor is altered and the transducer is rotated such that a component of the vertical load may be measured as traction (sec. 2.6). Changes in rear wheel radius change the water pump rate. In Figure 2, points 1 correspond to the removal of $75 \mathrm{gal}(2801)$ of water. Polnts 2 correspond to the removal of $80 \mathrm{gal}$ (300 1) of water and a $1501 \mathrm{~b}$ (330 $\mathrm{kg}$ ) deadweight representing the driver's weight. The driver is the only occupant of the WARS. 

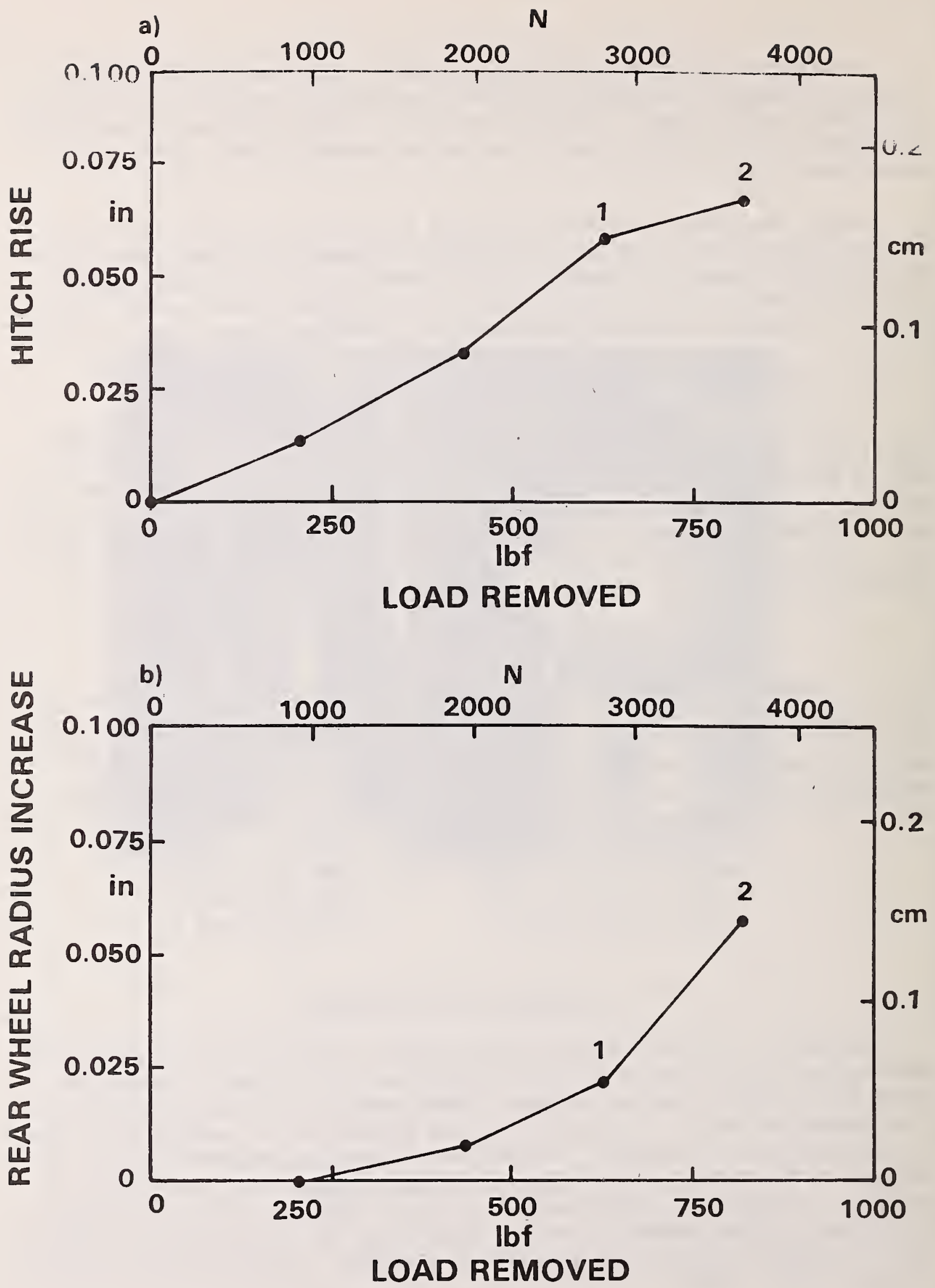

Figure 2. WARS tow vehicle displacements with load. 


\subsection{Speed Measuring Subsystem}

The WARS speed signal was generated by a fifth wheel mounted within the wheelbase of the tow vehicle. Two electronic circuits with separate calibration adjustments were operated from a single tachometer generator.

One circuit provided a full range readout which was recorded on the tow vehicle strip chart recorder. The second circuit displayed an expanded scale signal to the driver on a center-zero analog meter. The null point corresponded to any desired setting preselected by the driver.

WFTC personnel adjusted the speed system while the fifth wheel was rotated by the surface of rotating drums driven by a synchronous motor. The system was then checked by driving over a measured mile at near constant speed while the traverse time was measured with a stop watch. When checked against the IRS radar, which has a $0.1 \mathrm{mph}(0.2 \mathrm{~km} / \mathrm{h}) \mathrm{re}-$ solution, the difference was less than $0.5 \mathrm{mph}(0.8 \mathrm{~km} / \mathrm{h})$ at speeds of 20, 40, and $60 \mathrm{mph}(32,64$, and $97 \mathrm{~km} / \mathrm{h})$. Corresponding engine tachometer readings were noted (Table 1 ), while driving in second gear as in skid testing.

During each day of dynamic skid testing, both the WARS and IRS speed systems were checked against the radar. It was found that the WARS preselected null settings necessary for agreement with the radar were not constant. After repairs to the null circuit, setting variations were reduced from a few miles per hour to a few tenths of a mile per hour.

Records obtained with the IRS radar system during the correlation testing were used for the reduction of the speed data of both the WARS and the IRS.

\subsection{Pavement Wetting Subsystem}

The pavement wetting subsystem was tested for water flow rate, uniformity of water distribution, and width of the water trace on the pavement. The dynamic distribution measurements are considered to be unreliable for reasons to be mentioned later.

\section{5 .1 Flow Rate Measurement}

To measure flow rate with a resolution of $0.1 \mathrm{gpm}(0.4 \mathrm{l} / \mathrm{min})$ the WARS water system was modified to allow replacement of a straight pipe section in the tow vehicle with the flow meter assembly normally installed in the IRS. The modification included valves and pressure measuring ports so that the back pressure of the flow meter assembly could be duplicated when the pipe section was reinstalled. 
Table 1 - WARS Engine Tachometer Readings

(Second Gear)

\begin{tabular}{cc} 
Speed & Tachomeler \\
$\mathrm{mph}^{\mathrm{a}}$ & $\mathrm{rpm}$ \\
20 & 1425 \\
40 & 2600 \\
60 & 3800 \\
\hline
\end{tabular}

a $1 \mathrm{mph}=1.609 \mathrm{~km} / \mathrm{h}$. 
The water pump is driven from the tow vehicle drive shaft. During stationary tests, this shaft is driven with the transmission in second gear at the engine tachometer readings noted during the speed system testing (Table 1). Initial tests showed that the flow rate was insufficient for the desired 8.1 inch $(21 \mathrm{~cm})$ wetted width. The pump drive pulley ratio was changed and the piping converted to the design utilized in the IRS (Fig. 3). The flow rate was then trimmed to the desired values corresponding to test speeds of 20,40 , and $60 \mathrm{mph}$ (32, 64, and $97 \mathrm{~km} / \mathrm{h}$ ). The pressure readings measured at the ends of the flow meter assembly under each flow condition are given in Table 2.

Normally, to measure an average flow rate, WFTC personnel operate a water system at nearly constant speed while collecting the water in a 55 gallon (203 1) tank and measuring the time of collection. Results of tests using this method are compared in Table 3 with the average turbine output. In one case, the results differ by nearly five percent.

After the turbine assembly was removed from the WARS, the upstream pressure at the pipe section was adjusted to $8.5 \mathrm{psi}$ ( $58 \mathrm{kPa}$ ) and the downstream pressure to $4 \mathrm{psi}(27 \mathrm{kPa}$ ) (downstream valve fully open) for the $40 \mathrm{mph}(64 \mathrm{~km} / \mathrm{h})$ condition. To check the system flow rate after these adjustments the IRS force plate was sealed in a waterproof bag, placed under the tank and the water discharged was weighed versus time (Fig. 4). These results confirmed that the system was properly adjusted to within three percent of the desired values.

\subsubsection{Water Distribution - Static Measurements}

The objective of static distribution gage (SDG) pavement wetting system measurements is to determine the distribution of water across the width of the water trace at the point where it would normally contact the pavement surface. The SDG includes a basin divided into equal width slots mounted at floor level. The basin is equipped with a sliding cover that is used to divert the water flow except during the time that a sample is being collected. When the cover is removed, the incident stream is divided by the slots and displayed in sight tubes arranged to form a bar graph (Fig. 5).

The stationary trailer was positioned with a normal hitch height and with the test tire centered on the basin such that water issuing from the nozzle entered the slots. The tow vehicle drive wheels were placed on dynamometer rollers. To obtain a sample of the water distribution, the drive wheels were turned at the desired speed with water flowing from the nozzle, and the sliding cover was removed until water rose to a predetermined approximate level in the sight tubes. Then the cover was quickly replaced. The basin size is such that the time required to fill to the predetermined level was comparable to, or longer than, the duration of a skid test. The relative distribution of water was then noted from the sight tubes. 


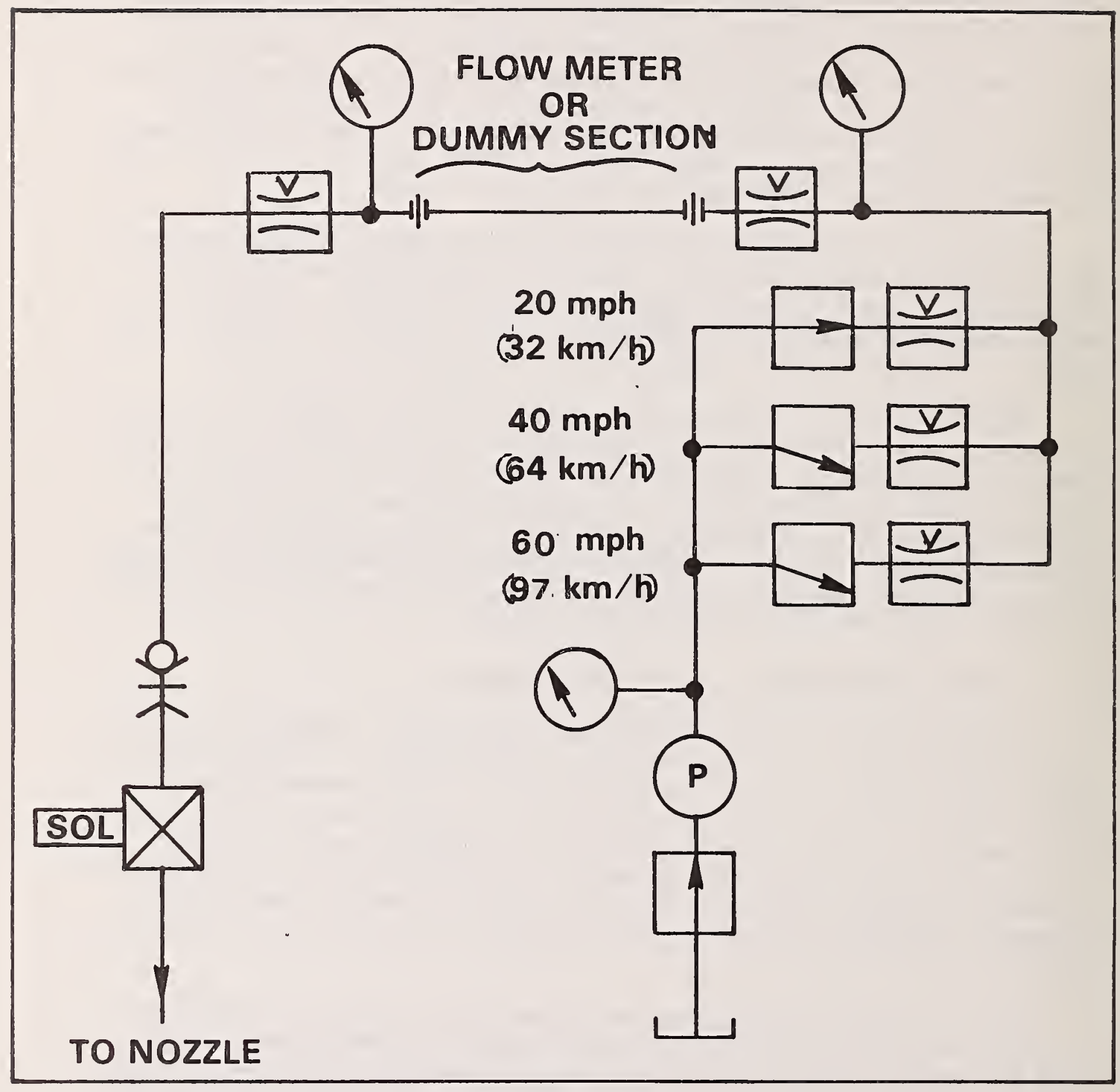

Figure 3. WARS piping modified for flowmeter and 3 sets of adjusting valves. 
Table 2 - WARS Flow Rates, 8.1 Inch $(20.6 \mathrm{~cm})$ wetted width

\begin{tabular}{|c|c|c|c|c|}
\hline Speed & Flow rate & $\begin{array}{c}\text { Pump } \\
\text { outlet } \\
\text { pressure }\end{array}$ & $\begin{array}{l}\text { Flowmeter } \\
\text { upstream } \\
\text { pressure }\end{array}$ & $\begin{array}{l}\text { Flowmeter } \\
\text { downstream } \\
\text { pressure }\end{array}$ \\
\hline $\mathrm{mph}^{\mathrm{a}}$ & $\mathrm{gpm}^{\mathrm{b}}$ & psic & psic & $p s i^{C}$ \\
\hline${ }_{\left(1425^{20} \mathrm{rpm}\right)^{d}}^{d}$ & 14.6 & 19 & $31 / 4$ & 2 \\
\hline$(2600 \mathrm{rpm})^{\mathrm{d}}$ & 29.2 & 32 & $81 / 2$ & $31 / 4$ \\
\hline$(3800 \mathrm{rpm})^{60}$ & 43.9 & 260 & $\sim 18$ & 6 \\
\hline
\end{tabular}

a $1 \mathrm{mph}=1.609 \mathrm{~km} / \mathrm{h}$.

b $1 \mathrm{gpm}=3.71 / \mathrm{min}$.

c 1 psi $=6.9 \mathrm{kPa}$.

d Engine tachometer readings correspond to 2nd gear, the WARS automatic transmission setting where 3 rd gear is locked out. 
Table 3 Comparison of Average Flow Rates Determined By Two Methods

\begin{tabular}{ccc}
\hline Flowmeter & Flow Tank & Difference \\
\hline $\mathrm{gpm}^{\mathrm{a}}$ & $\mathrm{gpm}^{\mathrm{a}}$ & percent \\
14.4 & 14.2 & -1.4 \\
28.7 & 27.3 & -4.9 \\
44.2 & 44.1 & -0.2 \\
\hline
\end{tabular}

a $1 \mathrm{gpm}=3.71 / \mathrm{min}$. 


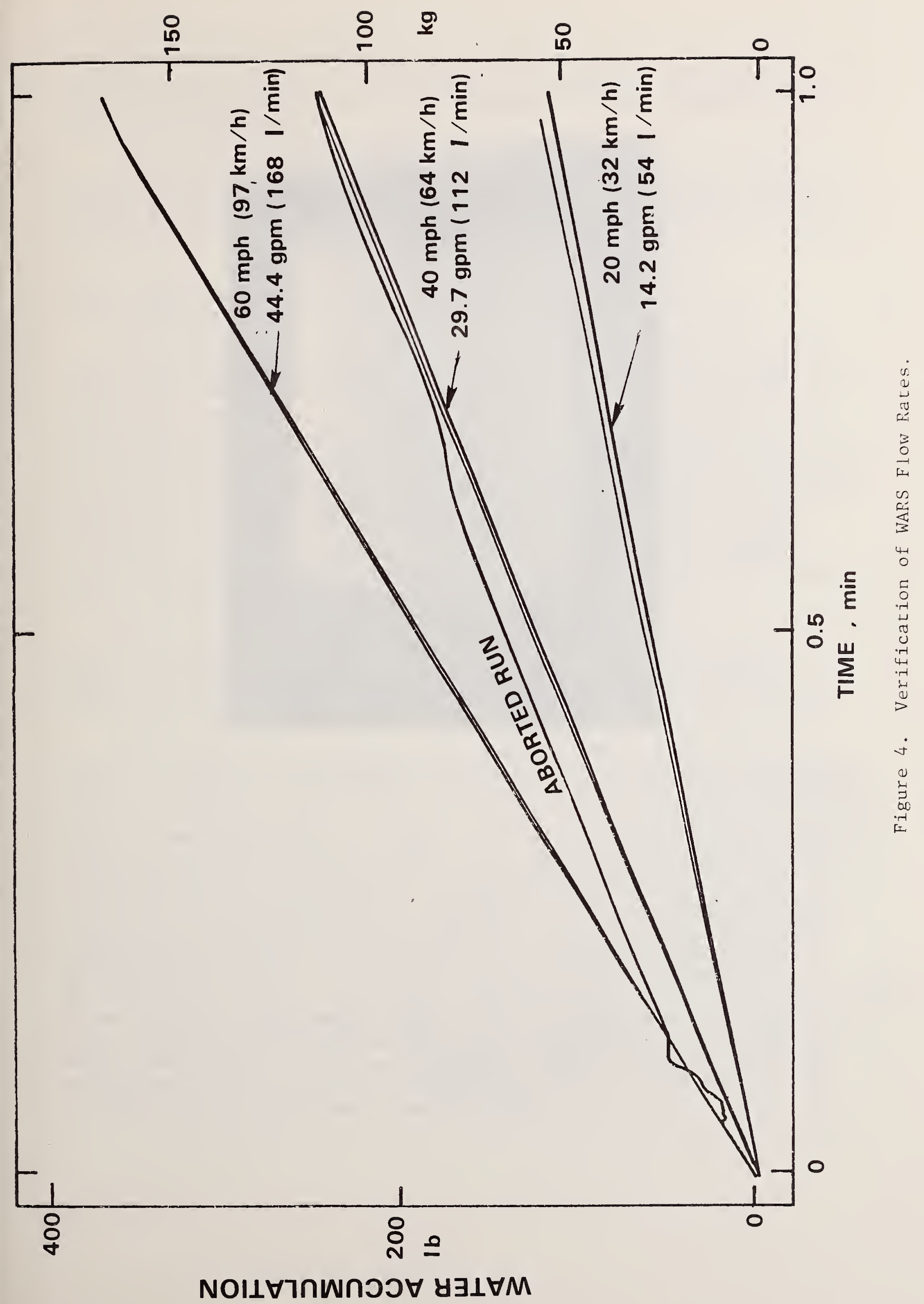




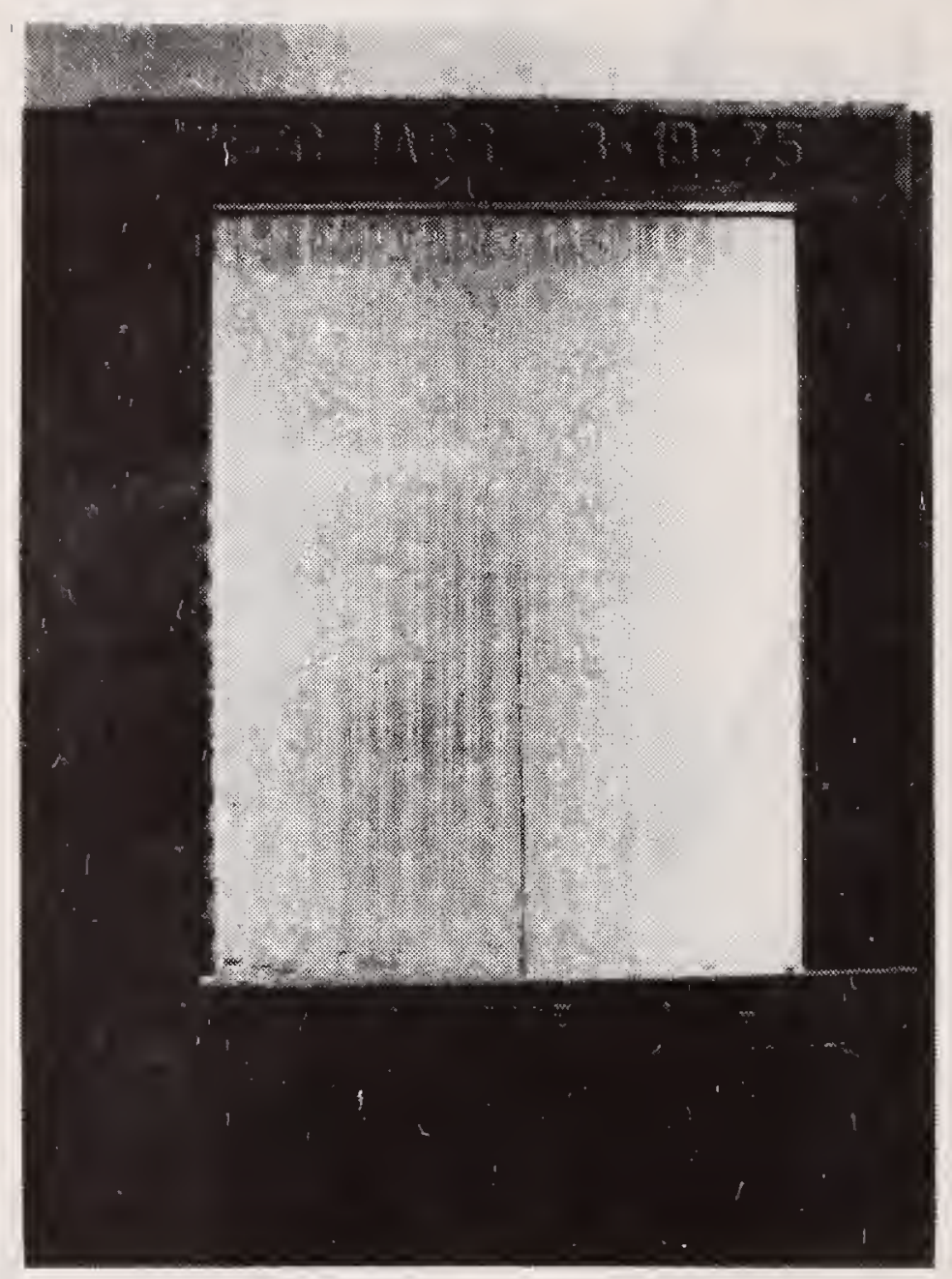

Figure 5. SDG sight tube array. 
The location of the test tire relative to the slots filled was noted to check the lateral positioning of the nozzle. The number of slots collecting water was noted as a measure of wetted width a the point of surface contact.

Testing of the WARS revealed a partial obstruction of the flow nozzle. After the obstruction was removed, the distributions shown in Figures 6,7 , and 8 were obtained for flow rates corresponding to speeds of 20,40 , and $60 \mathrm{mph}(32,64$, and $97 \mathrm{~km} / \mathrm{h})$ respectively.

\subsubsection{Water Distribution - Dynamic Measurements}

The objective of dynamic distribution gage (DDG) pavement wetting system measurements is to determine the distribution of water across the width of the water trace at the surface contact line under actual aerodynamic conditions. A receiving basin equipped with slots is used but remains uncovered after passage of the trailer. Since the test speed, flow rate, and length of the basin are known, the expected quantity to be collected can be calculated. Prior measurements made with the DDG at the Eastern FTC (EFTC) showed the collections averaged 70 percent larger than expected. The additional water collected distorted the distribution, thereby negating the objective of the test. Observed sources of additional water collected included water splashed from the gage structure and the spray that follows the trailer.

Since the DDG at the WFTC is of a design similar to the gage at the EFTC, no dynamic distribution measurements were made. Until proper sampling of the water trace can be demonstrated consistently, the DDG should not be used to characterize pavement wetting system performance.

NBS personnel discussed the problems with WFTC representatives and suggested some steps to minimize splashing over the DDG. They recommended that the receiving basin be kept dry, that the grate and gage be secured against wobbling, and that the grate be flush filled to cover the crossbars. These recommendations were followed in tests involving operation of the WARS over the DDG conducted by WFTC after the departure of NBS personnel. Photographs made during the tests by a high frame-rate cine camera mounted on the WARS trailer were forwarded to NBS. These photographs recorded the dispersal of water from the pavement wetting nozzle. The photographs showed that the nozzle position was higher than intended, approximately 6 inches $(15 \mathrm{~cm})$ above the pavement. Films made at 20, 40 , and $60 \mathrm{mph}(32,64$, and $97 \mathrm{~km} / \mathrm{h})$ showed no splashing directly attributable to the presence of the gage or grate. Dynamic effects on the nozzle stream were greatest at $60 \mathrm{mph}(97 \mathrm{~km} / \mathrm{h})$. Typical frames at $60 \mathrm{mph}$ (97 $\mathrm{km} / \mathrm{h}$ ) showing flow onto the solid pavement ahead of the grate and over the DDG are shown in Figure 9. No gage samples were reported so it is not known whether excess water was collected. 

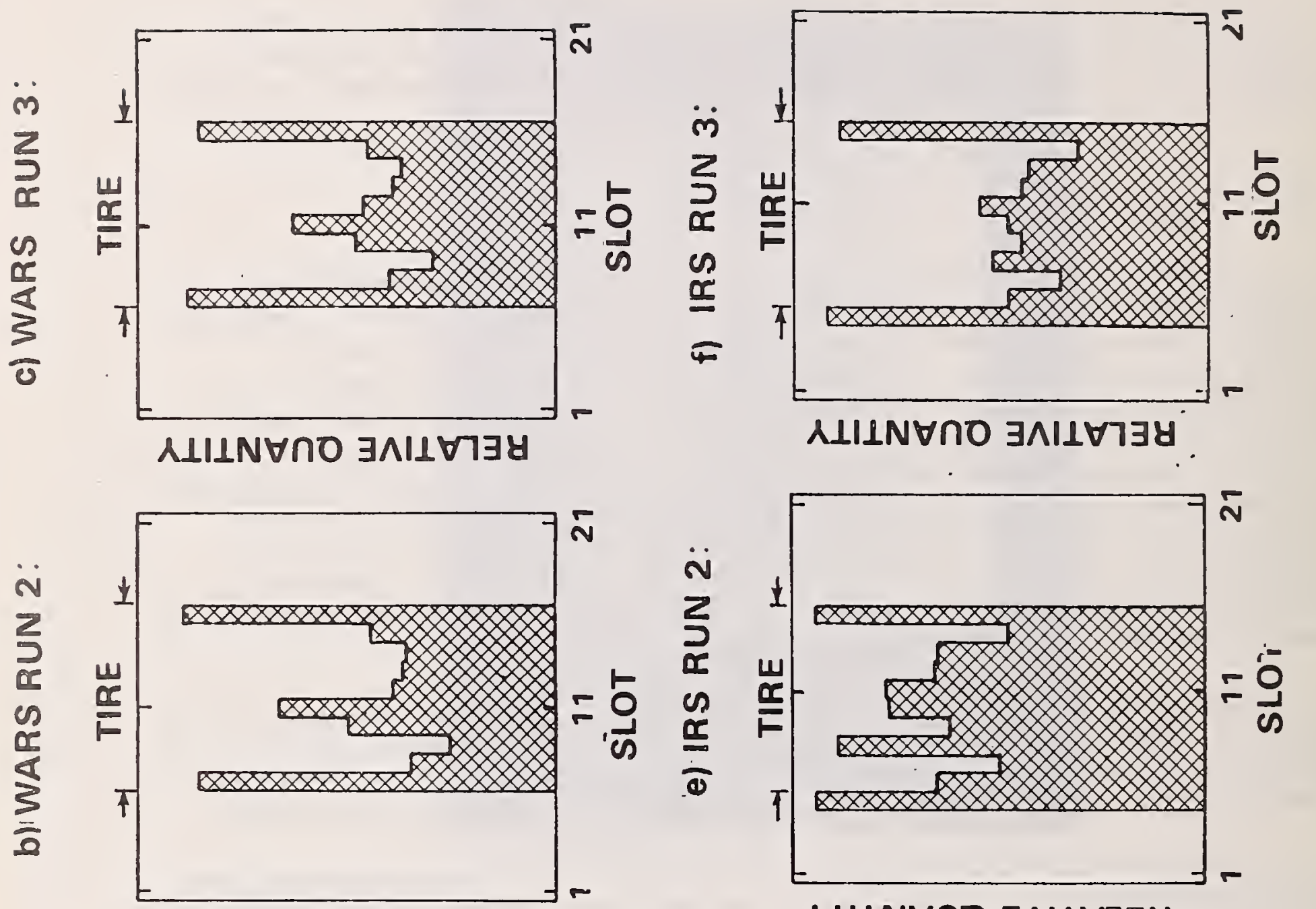

\section{ᄉ $\perp \perp N \forall \cap O \exists \wedge I \perp \forall 7 \exists \forall$}

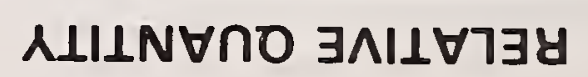
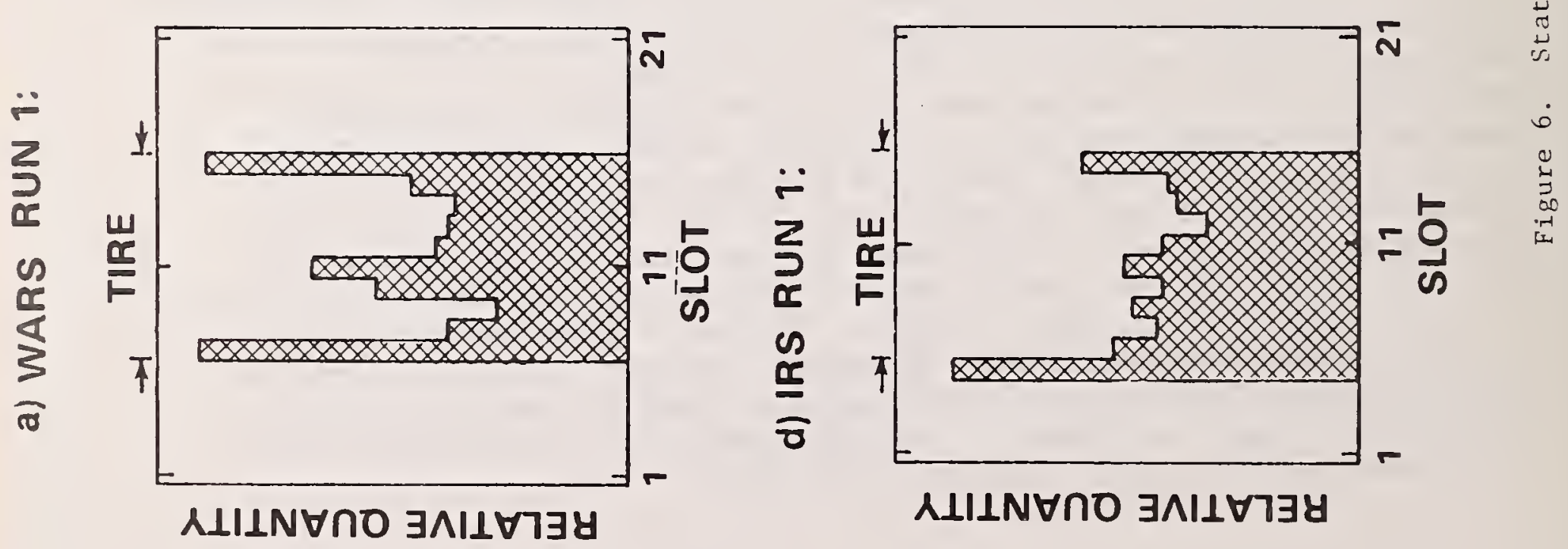


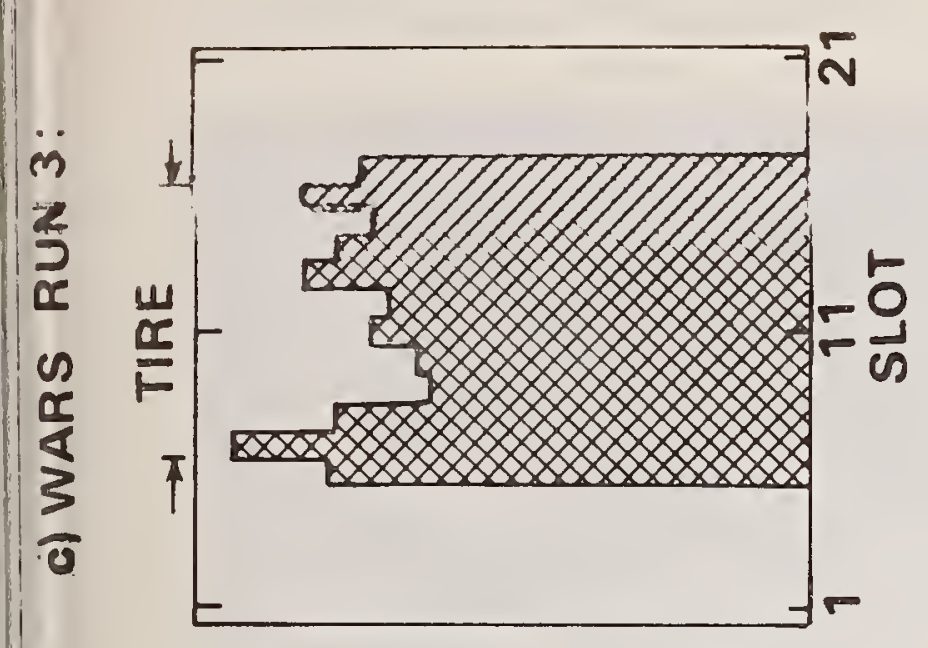

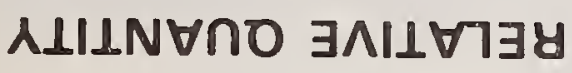

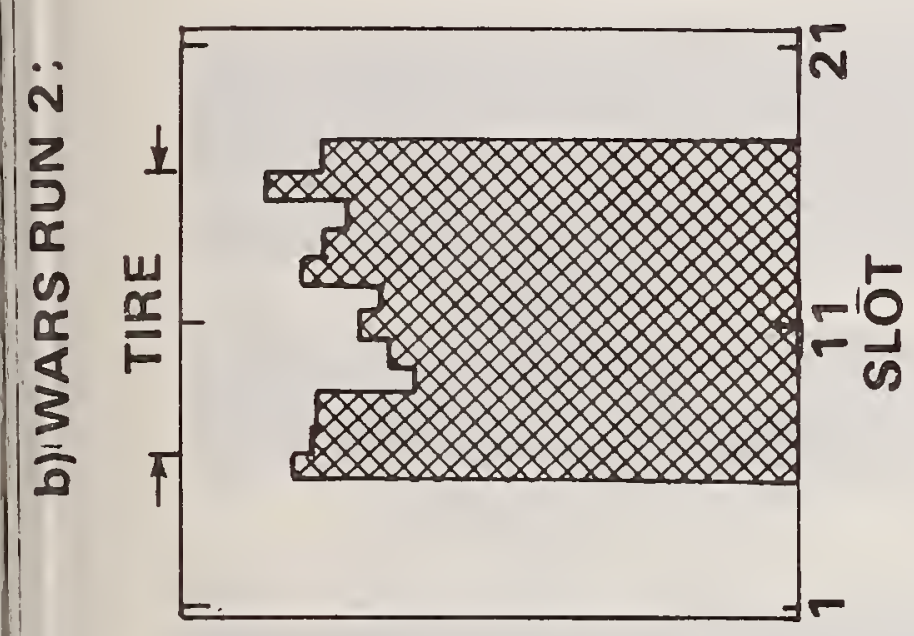

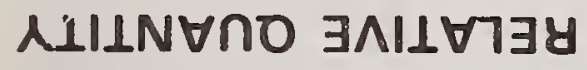

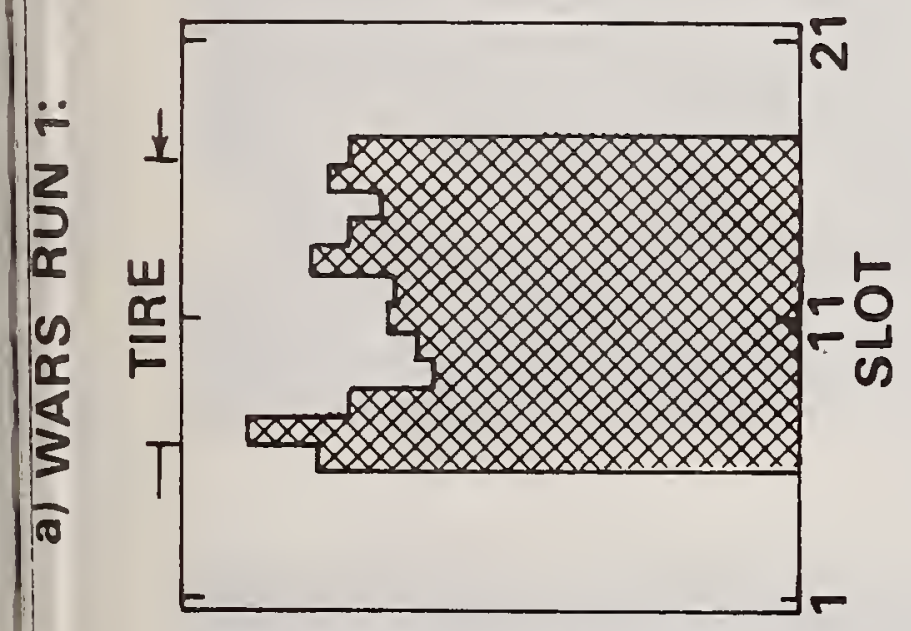

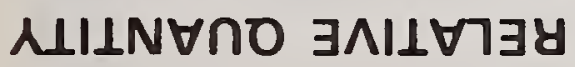
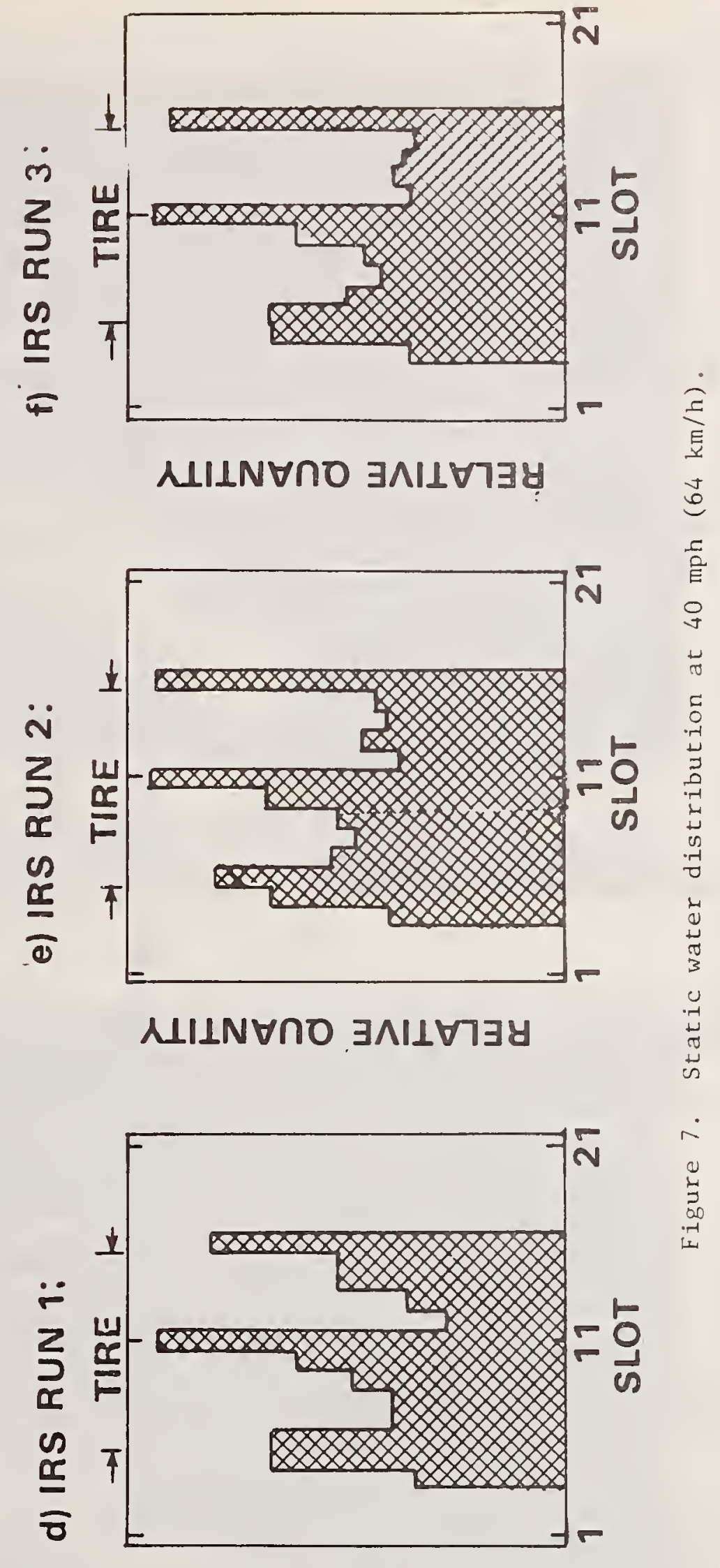

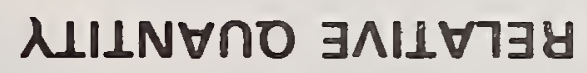



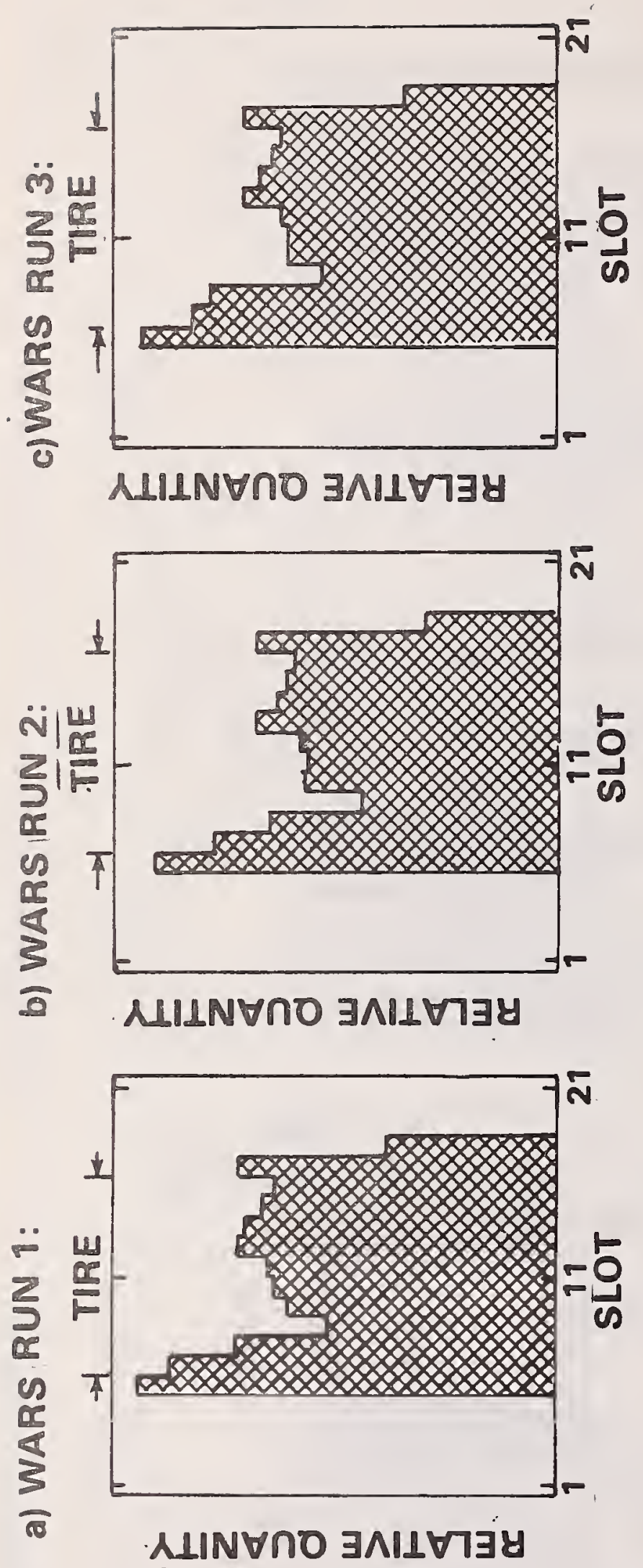
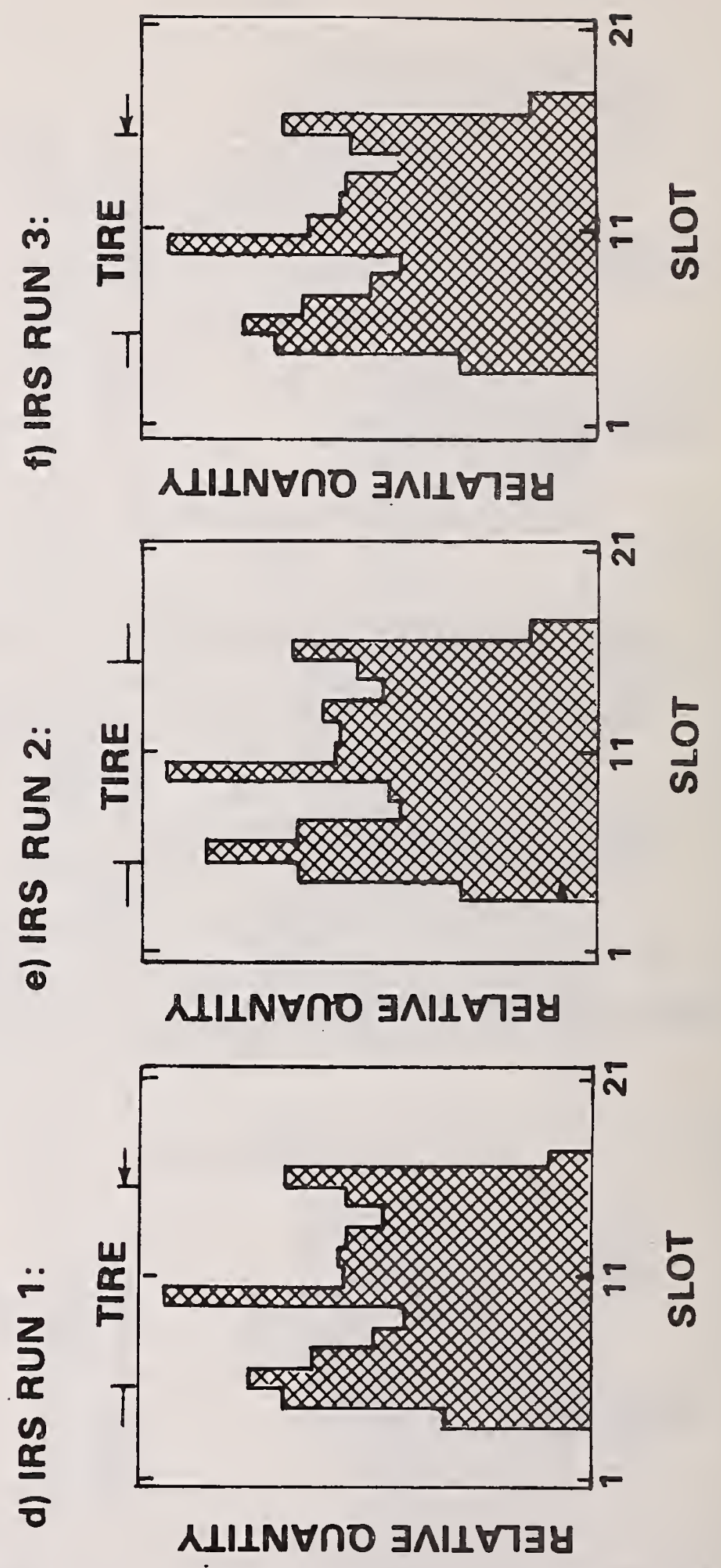
(a) ON SOLID PAVEMENT:

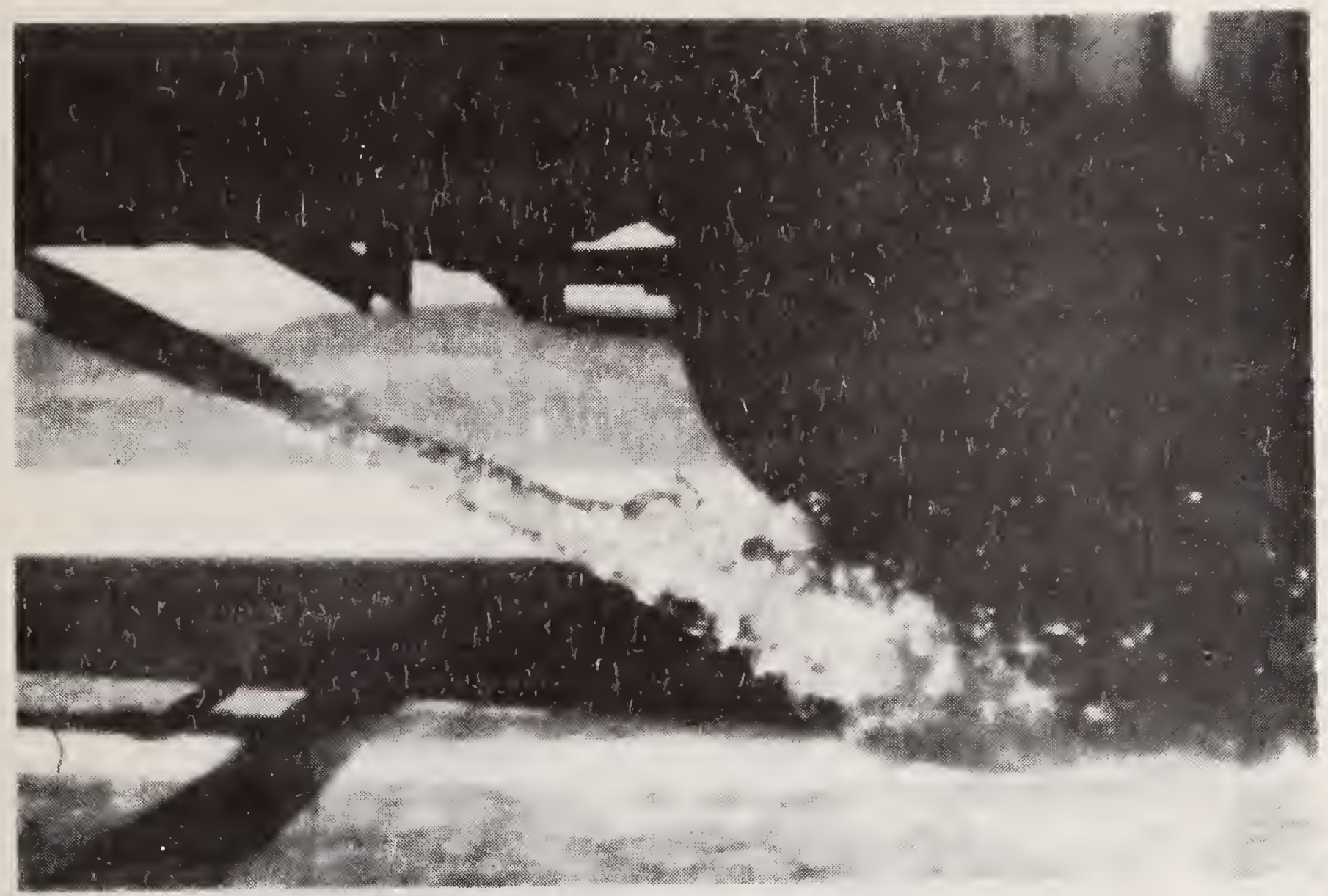

\section{(b) OVER THE DDG:}

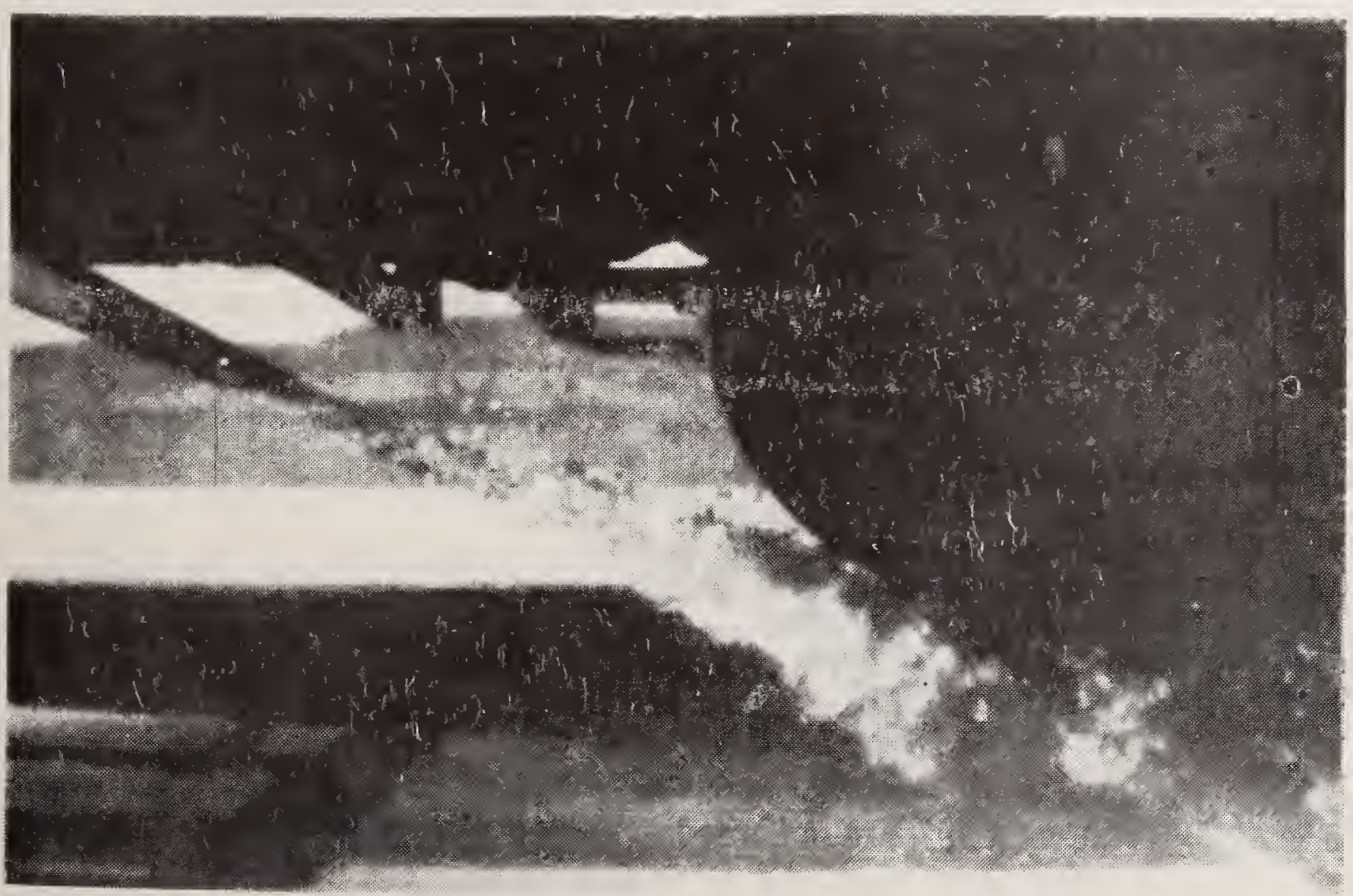

Figure 9. WARS dynamic pavement wetting at $60 \mathrm{mph}(97 \mathrm{~km} / \mathrm{h})$. 


\subsubsection{Wetted Width Measurement}

In order to lay the desired water film thickness, the flow rate must be adjusted as a function of the width of the water trace at the leading edge of the tire-pavement interface. The various ways of measuring wetted width include using SDG and DDG distribution widths, measuring the water trace on the pavement after the passage of the skid tester, and photographing the pavement from the moving skid tester showing the water trace width at the position of the interface of the test tire.

Each measurement technique has known sources of error. Width readings of both distribution gages do not include the spreading that begins when the water contacts the pavement. The SDG reading does not include dynamic effects. Water traces laid down on pavement contain an additional increment of width due to spreading and lose resolution, necessitating assumptions about the width at the desired time. Measurements from photographs of the wetted width from the moving skid tester involve the use of geometry to account for changes in scale with distance from the camera. At this point, an optimal camera arrangement has not been prepared.

In this evaluation, the span of slots collecting water during the SDG tests (shown in section 2.5.2) was used as a measure of wetted width. DDG measurements were not made (see section 2.5.3).

In making direct measurements on the pavement (Fig. 10), the test wheel was extended beyond the water trace and the test brake was not applied. Three measurements were made with increasing delay times after passage of the test vehicle by an observer with a scale. From these measurements, the width at the time of passage was estimated using linear extrapolation.

Data was obtained for the WARS at $20 \mathrm{mph}(32 \mathrm{~km} / \mathrm{h})(\mathrm{Fig} .11)$. At higher speeds traces were too diffuse to measure. Large amounts of spray were generated. Coarse pavement and $10 \mathrm{mph}(16 \mathrm{~km} / \mathrm{h})$ winds contributed to the scatter.

The results obtained from SDG and pavement measurements are given in Table 4. The extrapolation to obtain the pavement measurement values is shown in Figure 11 .

A high frame-rate cine camera was installed temporarily on the WARS skid trailer with a downward view of the water trace. Examples of photographs obtained in motion from which the wetted width could be estimated are shown in Figures 12, 13, and 14. These photographs were made during locked wheel skids. 


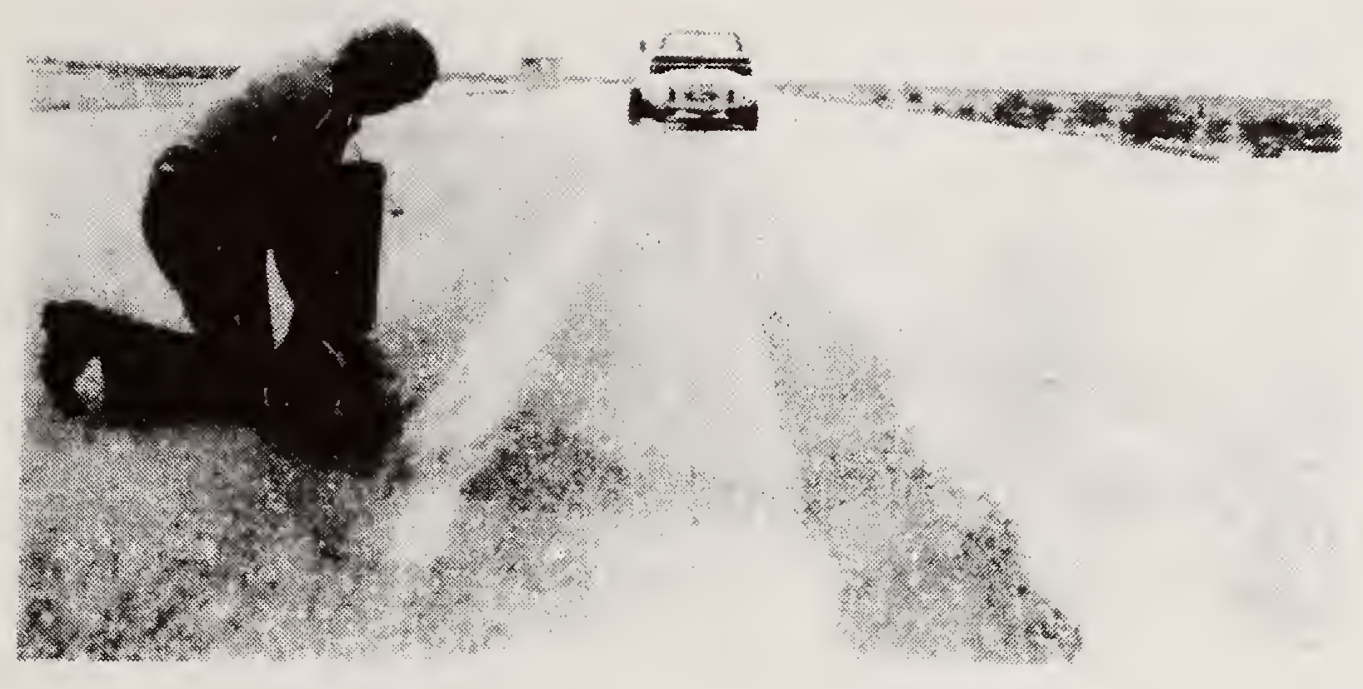

Figure 10. Measurement of water trace width after the trailer has passed. 


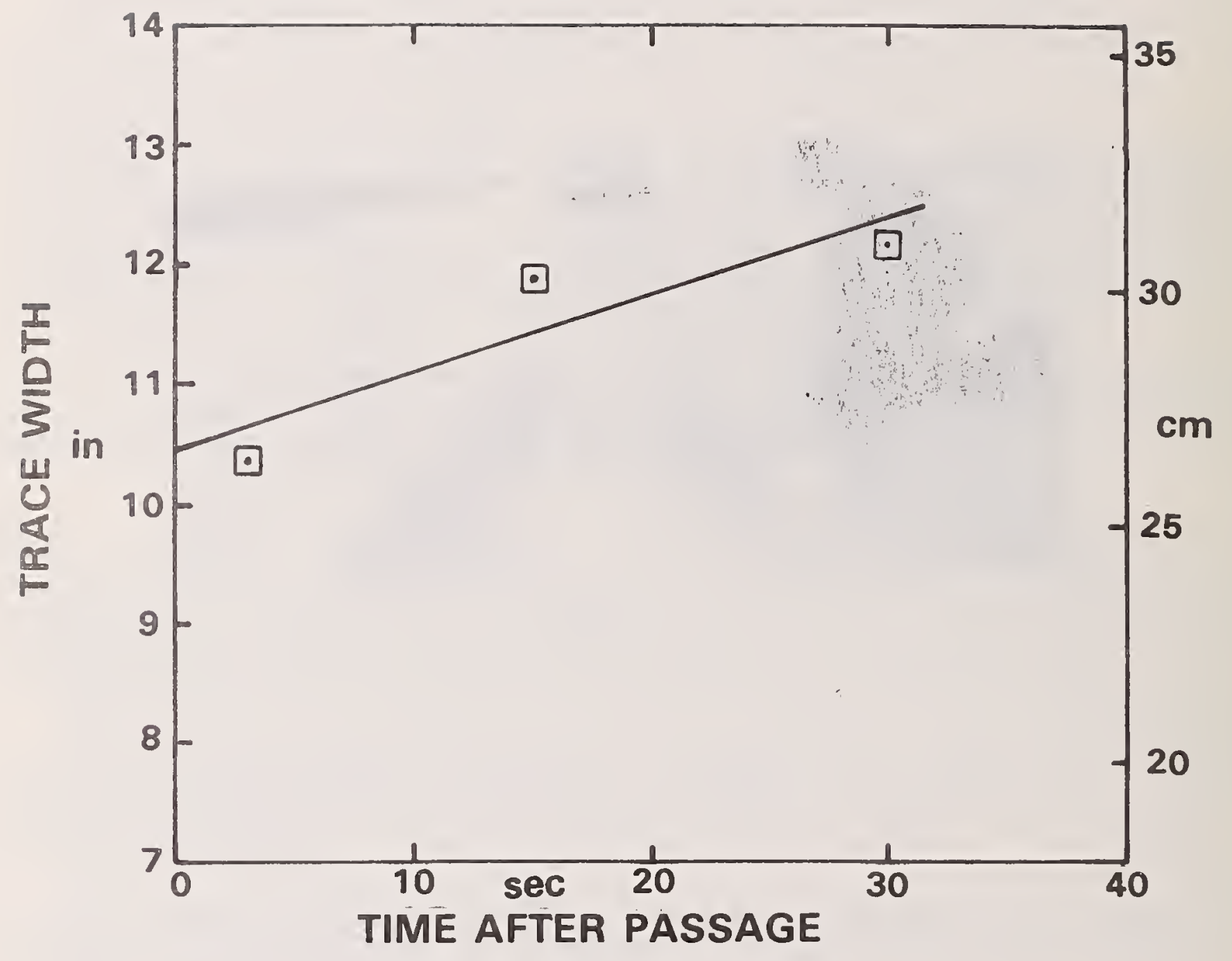

Figure 11. Wetted width by delayed measurement on pavement, WARS at $20 \mathrm{mph}(32 \mathrm{~km} / \mathrm{h})$. 


\begin{tabular}{|c|c|c|c|c|}
\hline Speed & Unit & $\begin{array}{c}\text { Nominal } \\
\text { Flow Rate } \\
\end{array}$ & Method & Wetted Width \\
\hline $\mathrm{mph}^{\mathrm{a}}$ & & $g \mathrm{pm}^{\mathrm{b}}$ & & in $\mathrm{c}$ \\
\hline 20 & WARS & 14.6 & SDG & 6.2 \\
\hline 20 & WARS & 14.6 & Pavement & 10.5 \\
\hline 20 & WARS & 14.6 & Photo & $\sim 12$ \\
\hline 20 & IRS & 14.2 & SDG & 6.9 \\
\hline 40 & WARS & 29.2 & SDG & 7.5 \\
\hline 40 & WARS & 29.2 & Photo & $\sim 14$ \\
\hline 40 & IRS & 29.3 & SDG & 8.1 \\
\hline 60 & WARS & 43.9 & SDG & 8.1 \\
\hline 60 & WARS & 43.9 & Photo & 214 \\
\hline 60 & IRS & 43.3 & SDG & 8.8 \\
\hline
\end{tabular}
a $1 \mathrm{mph}=1.609 \mathrm{~km} / \mathrm{h}$.
b $1 \mathrm{gpm}=3 . \dot{7} 1 / \mathrm{min}$.
c 1 in $=2.54 \mathrm{~cm}$. 


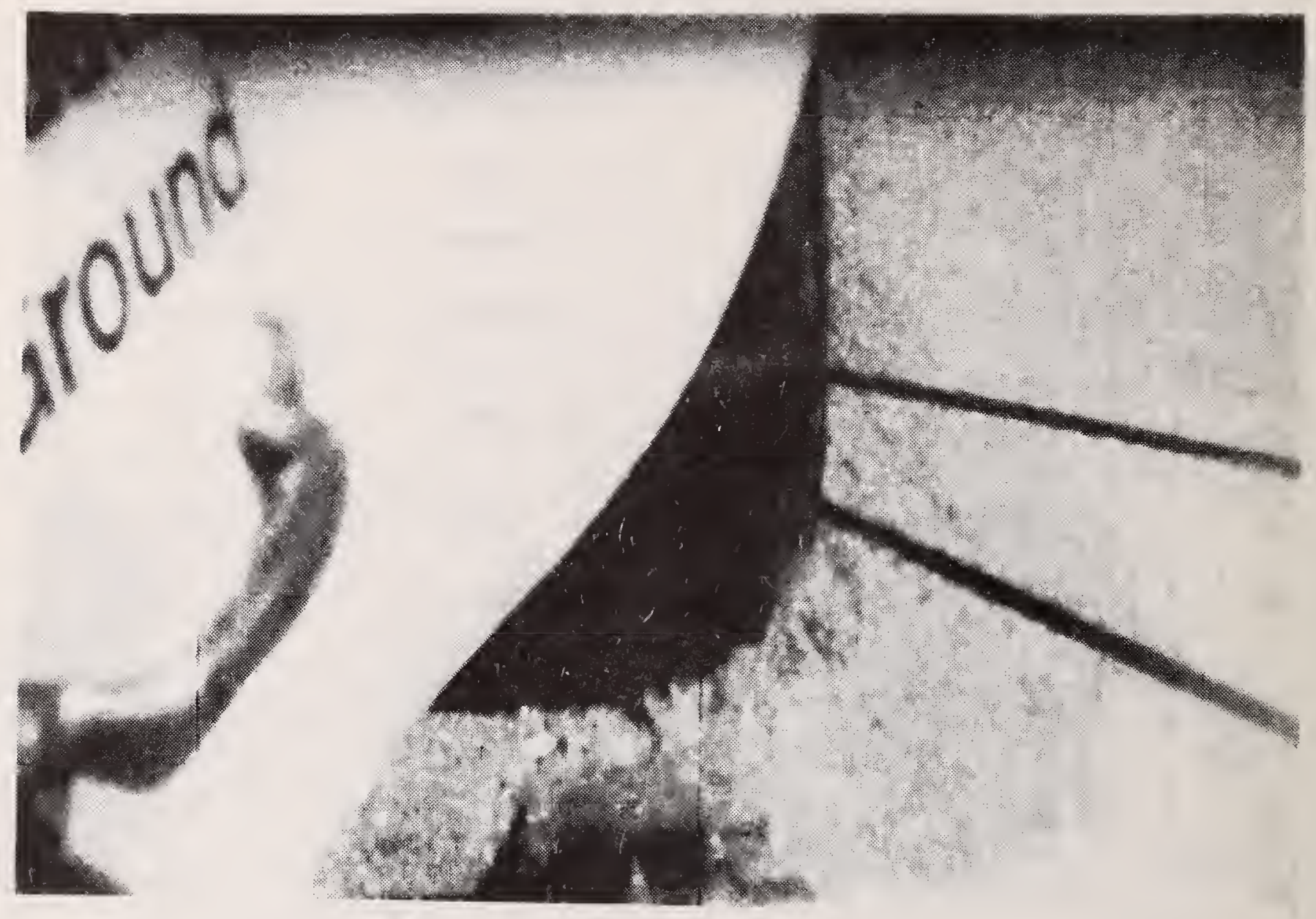

Figure 12. WARS pavement wetting during a locked wheel skid at $20 \mathrm{mph}(32 \mathrm{~km} / \mathrm{h})$. 


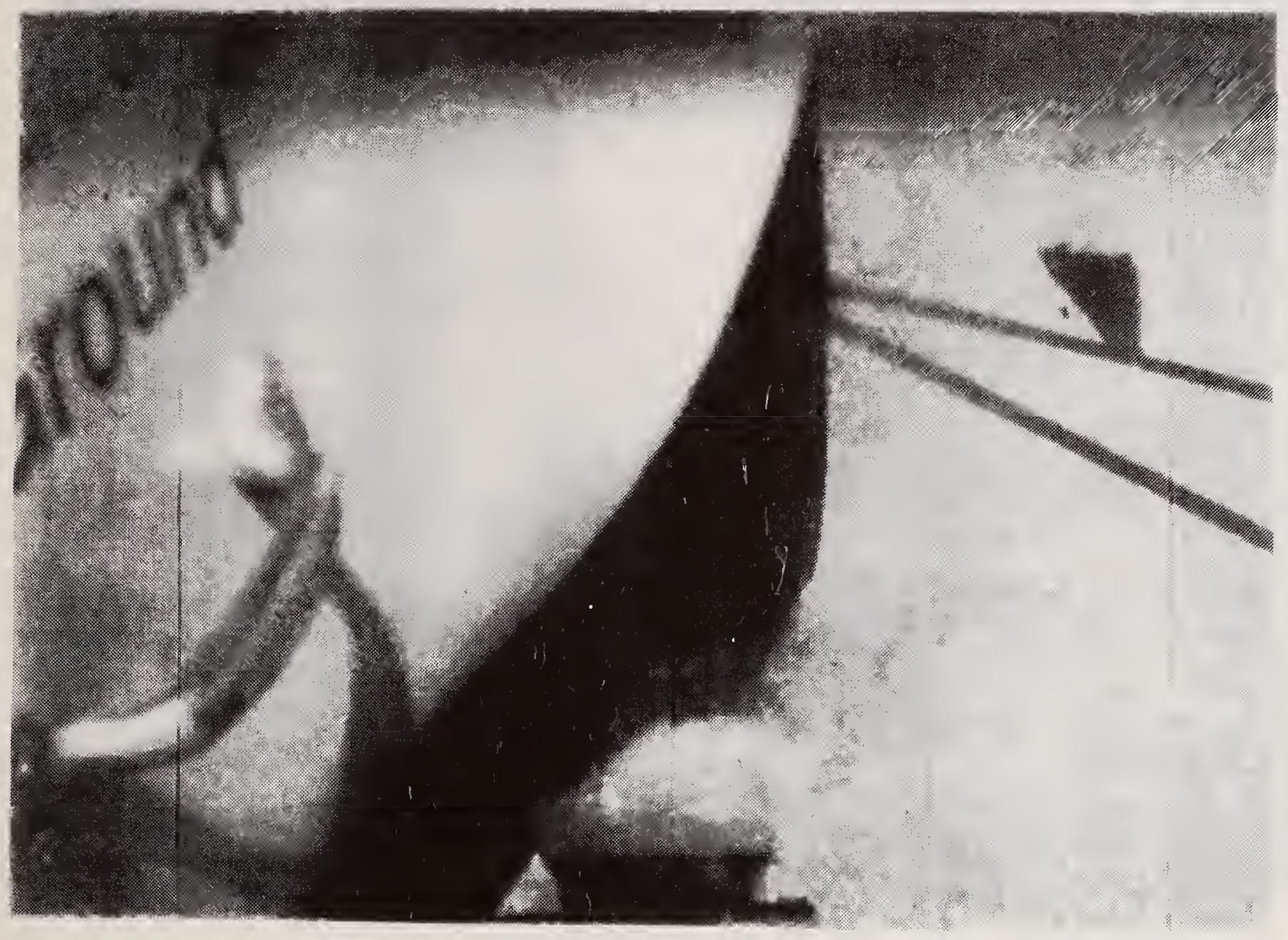

Figure 13. WARS pavement wetting during a locked wheel skid at $40 \mathrm{mph}(64 \mathrm{~km} / \mathrm{h})$. 


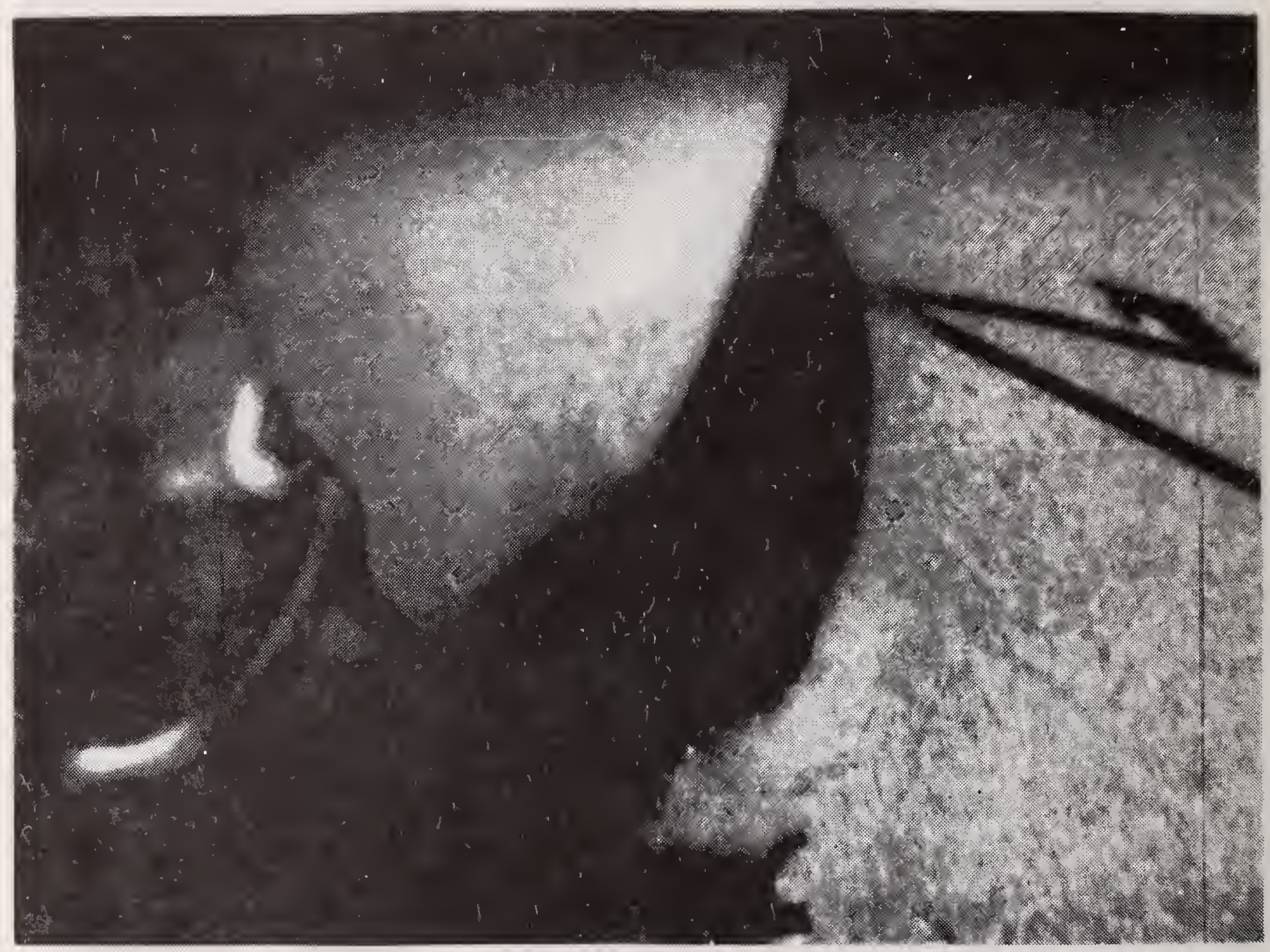

Figure 14. WARS pavement wetting during a locked wheel skid at $60 \mathrm{mph}(97 \mathrm{~km} / \mathrm{h})$. 
A large amount of spray was observed following the WARS nozzle at all speeds. Spray formed both when the test wheel was normally positioned and when the wheel extender was used. Much of the pumped water was still in the air at the position of the test tire. At $20 \mathrm{mph}(32 \mathrm{~km} / \mathrm{h})$, photographs showed formation of large bubbles in the water stream which burst and left dry areas ahead of the test tire (Fig. 15).

Side view photographs (Fig. 16) showed that the stream reached ground level near the leading edge of the tire-pavement interface with little time to settle on the pavement before meeting the tire.

Since the WARS photographs show mostly spray, the measured values of wetted width from the photographs are unrealistically high. However, the photographs do demonstrate the poor coupling between the stream and the pavement which left the wetted width undefined.

\subsection{Force Measuring Subsystem}

The transducer of the force measuring subsystem is located inboard on the axle, remote from the force it is to measure at the tire-pavement interface. This force at the interface is equivalent to a moment and force acting along vectors in three-dimensional space with respect to the centroid of the transducer. Displacements occurring within the system may alter these vectors acting at the transducer. Many effects due to these displacements are minimized by using the tow vehicle and trailer system as a fixture while calibrating the transducer "in situ". Known forces are applied at the tire-pavement interface by means of an air-bearing force plate and calibration box. A locked test wheel is shown on a force plate during such a test in Figure 17. However, some effects are not accounted for, such as the transverse force at the tirepavement interface and the yawing orientation of the trailer usually present during skid testing. Displacements of the interface are larger when the tire is "hot" as in a running condition. The tests described here were conducted with the tires at room temperature. However, the tires were previously broken-in with at least 200 miles $(322 \mathrm{~km})$ of use which provides some additional flexibility.

\subsubsection{WARS Transducer}

The WARS utilizes a torque transducer to measure traction at the interface. Torque readings are converted to traction by assuming a constant test wheel radius of $1215 / 16$ inches $(32.9 \mathrm{~cm})$. Variations in readout of up to $20 \mathrm{ft} .1 \mathrm{bf}(27 \mathrm{~N} . \mathrm{m})$ occurred under vertical load with no traction applied. Variations in readout of up to $8 \mathrm{ft.lbf}(10.8 \mathrm{~N} . \mathrm{m})$ occurred with the test tire lifted from the pavement when the brake was energized as compared to de-energized. The results of additional tests indicated the variations were smaller when the test wheel hub was dithered by an impact wrench before placing the test tire on the pavement. 
(a) EXPANDING BUBBLE ABOUT TO BURST:

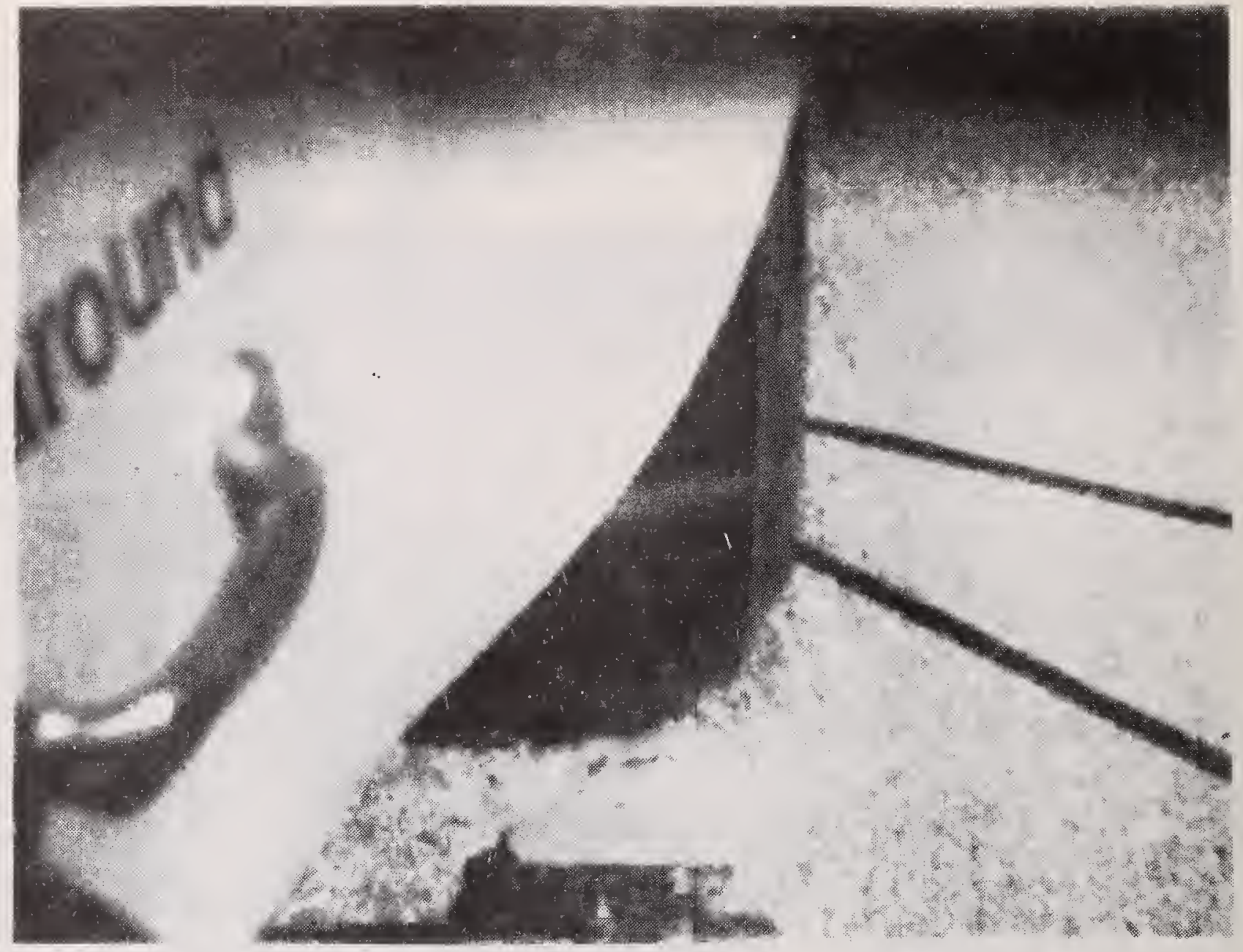

(b) GAP LEFT BY SAME BUBBLE:

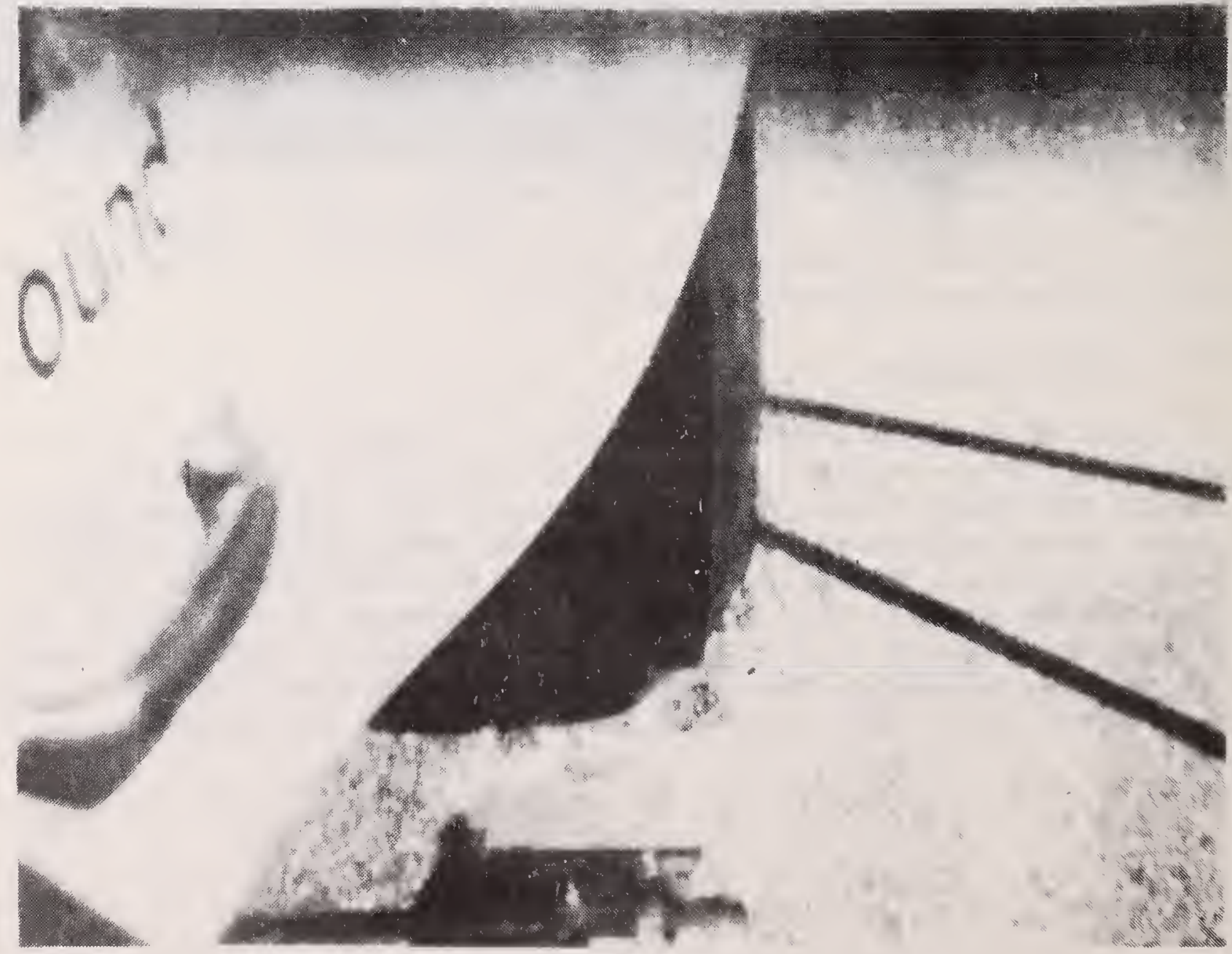

Figure 15. Effect of bubble formation on WARS payement: wetting at $20 \mathrm{mph}(32 \mathrm{~km} / \mathrm{h})$. 


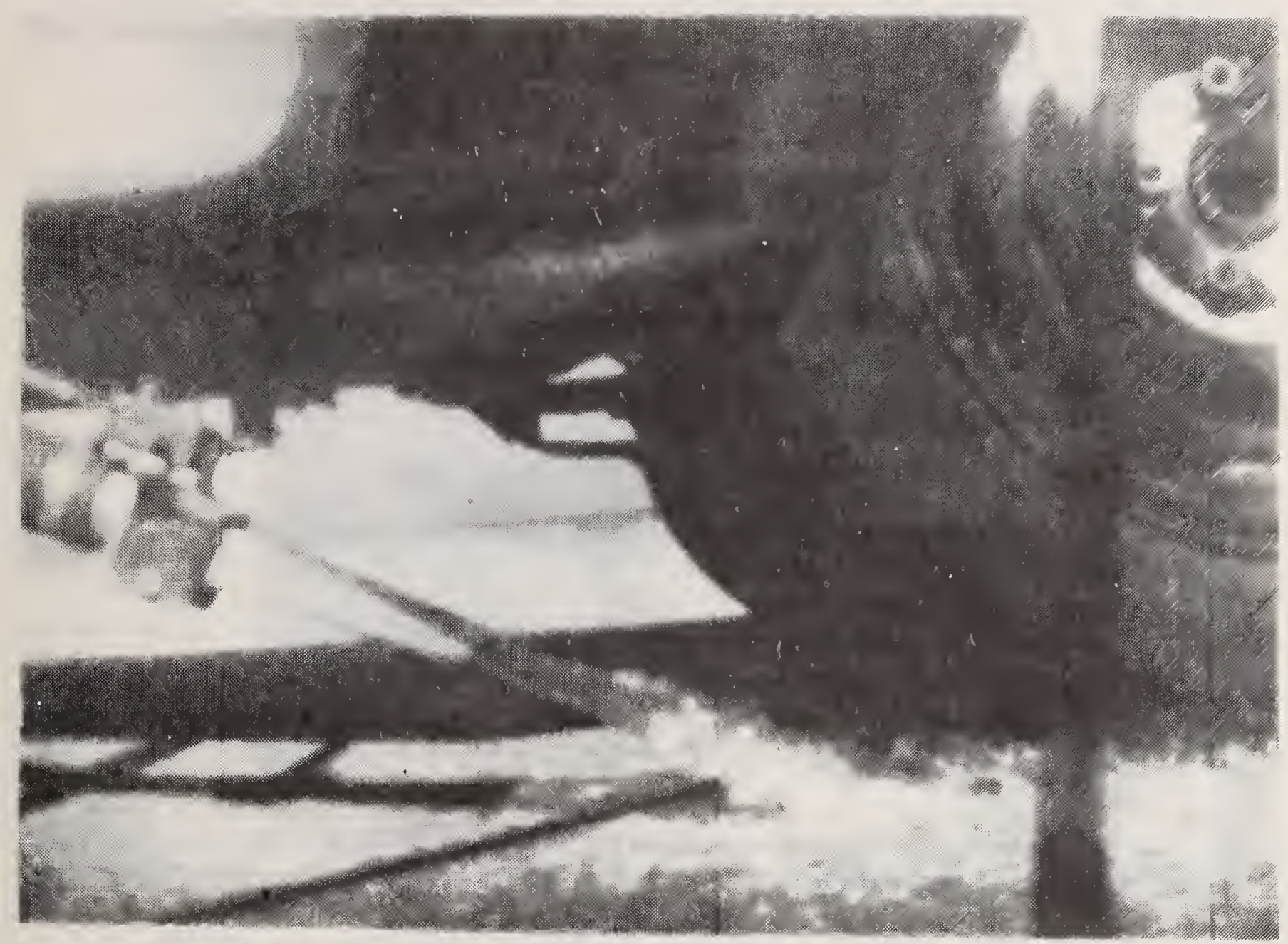

Figure 16. Side view of WARS pavement wetting at $40 \mathrm{mph}(64 \mathrm{~km} / \mathrm{h})$. 


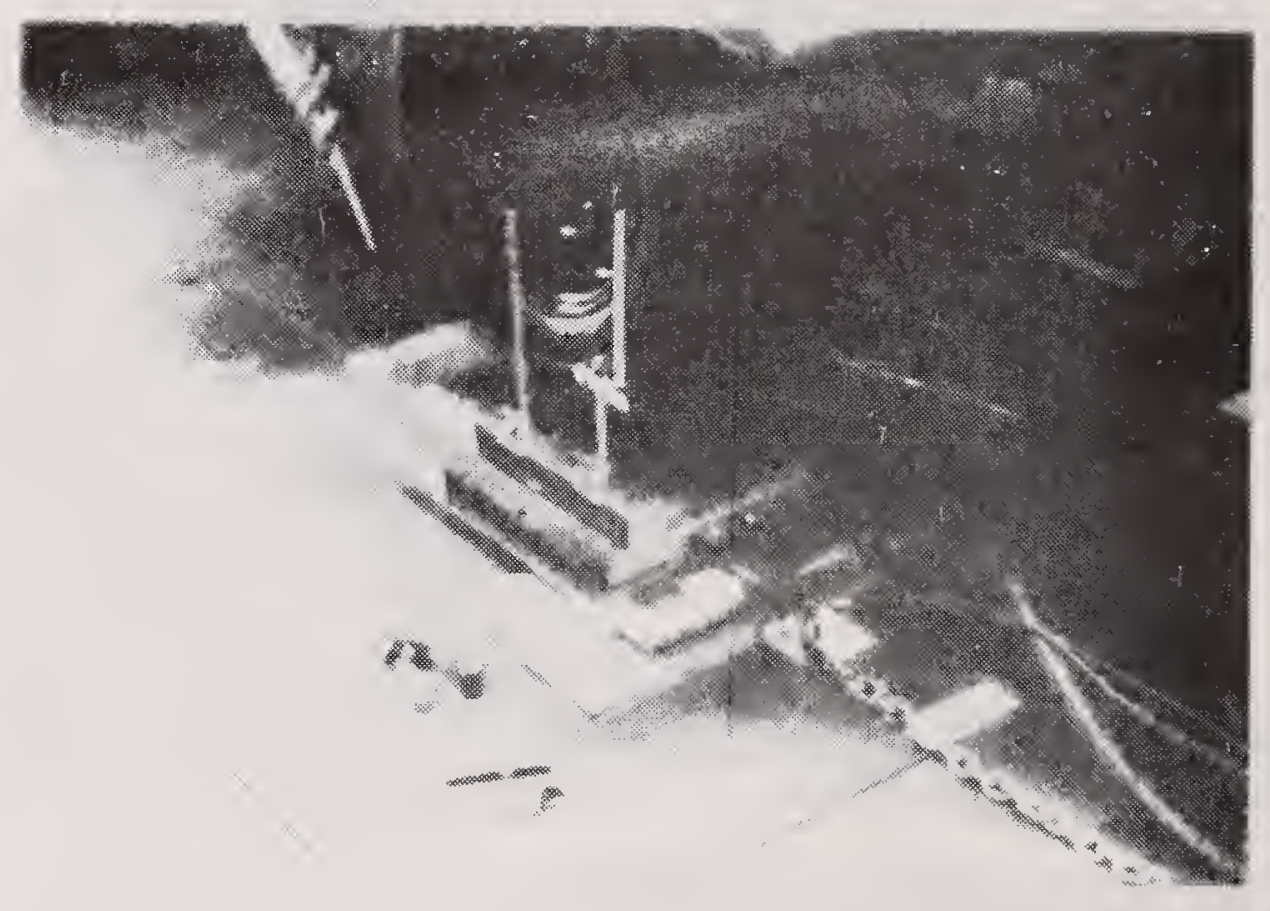

Figure 17. A simulated traction force being applied to a locked test wheel through an air-bearing force plate. 
The trailer was alined with the tow vehicle with the test (left) wheel resting on the force plate. A $150 \mathrm{lb}(330 \mathrm{~kg})$ weight was placed in the seat of the tow vehicle. The hitch height was leveled which corresponded to $143 / 8$ inches $(36.5 \mathrm{~cm})$ from a level pavement to the bottom of a welded flange under the trailer hitch assembly. A force plate test was conducted using the WARS on-board electronics for the transducer signal and the IRS electronics for the force plate signal. The transducer signal was scaled on the $X-Y$ recorder with the test wheel in the air. Dither was applied and then the wheel was carefully set on the force plate. The signal of the floating level force plate was then scaled. The results were plotted point-by-point as shown in Figure 18. The data points alternated on either side of a stralght line under increasing traction load and alternated, under decreasing load, on either side of another line which was parallel and $121 \mathrm{bf}(53.4 \mathrm{~N})$ under the first line.

\subsubsection{On-Board Signal Generator Equivalent Value}

The value of the resistor used for the calibration signal generator was determined to be equivalent to a change of $8651 \mathrm{bf}(3850 \mathrm{~N}$ ) under these test conditions. This corresponds to the $933 \mathrm{ft.lbf}$ torque (1265 N.m) value used by WFTC personnel when the wheel radius is $1215 / 16$ inches $(32.9 \mathrm{~cm})$.

\subsubsection{WARS Transducer Response to Changes in Operating Variables}

To evaluate the stability of these results, supplementary force plate tests were conducted which included changes in wheel radius, changes in test tire inflation pressure, and changes in hitch height.

\subsubsection{Response to Changes in Wheel Radius}

The test wheel and tire were removed from the trailer and replaced with a wheel on which an adjustable radius arm, containing a cavity at its end, had been welded (Fig. 19). A flat plate containing a similar cavity was placed on the force plate. The brake of the test wheel was then locked with a ball bearing located between the cavities and directly under the center line of the axle.

A traction force plate test was conducted at a nominal value of radius followed by a higher and lower value of radius. The results shown in Figure 20 confirm that the transducer output, and hence calibra-tion, varies directly with the wheel radius. 


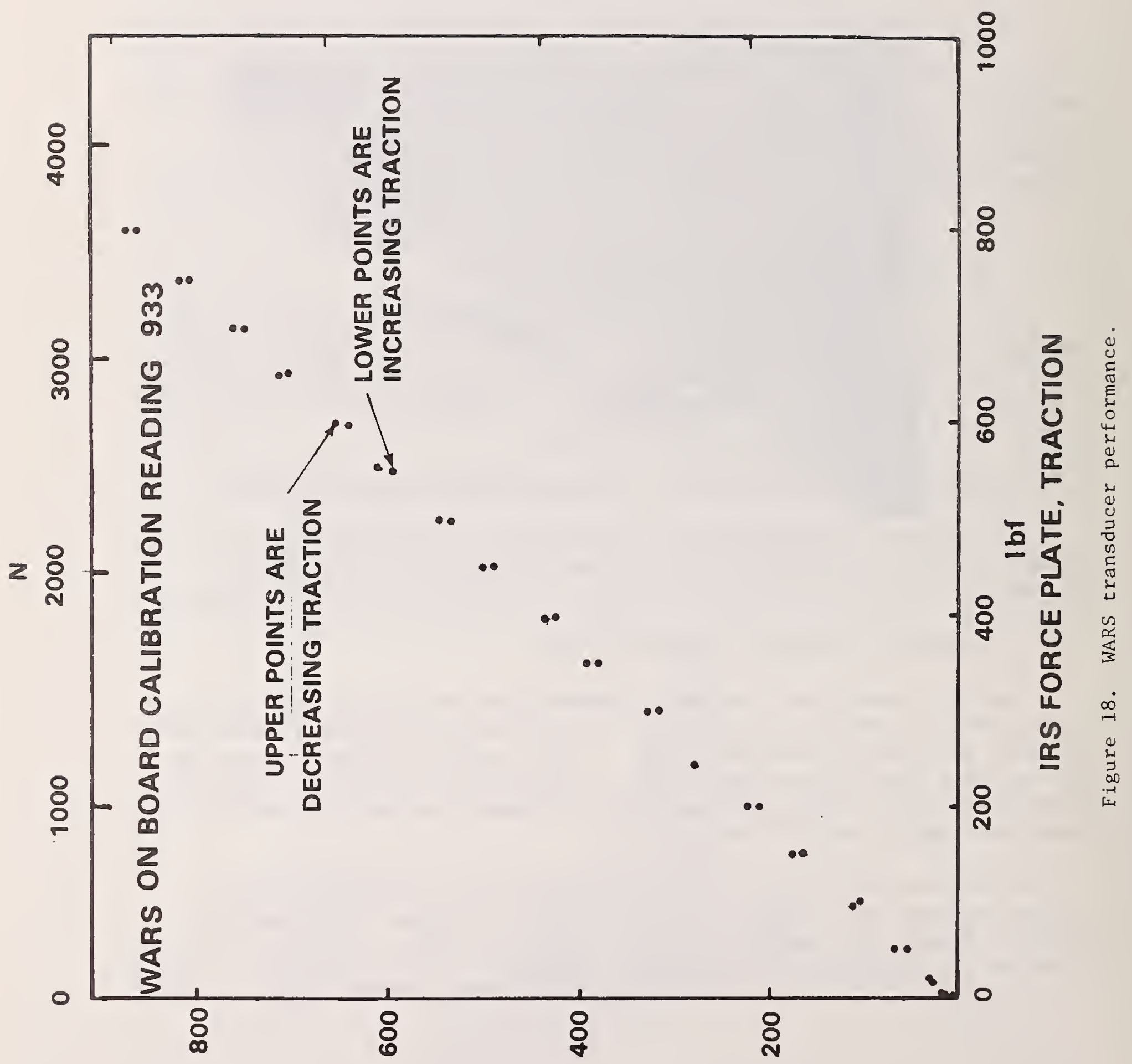

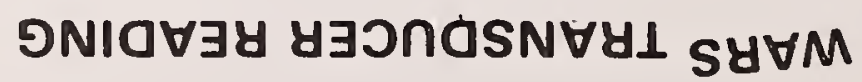




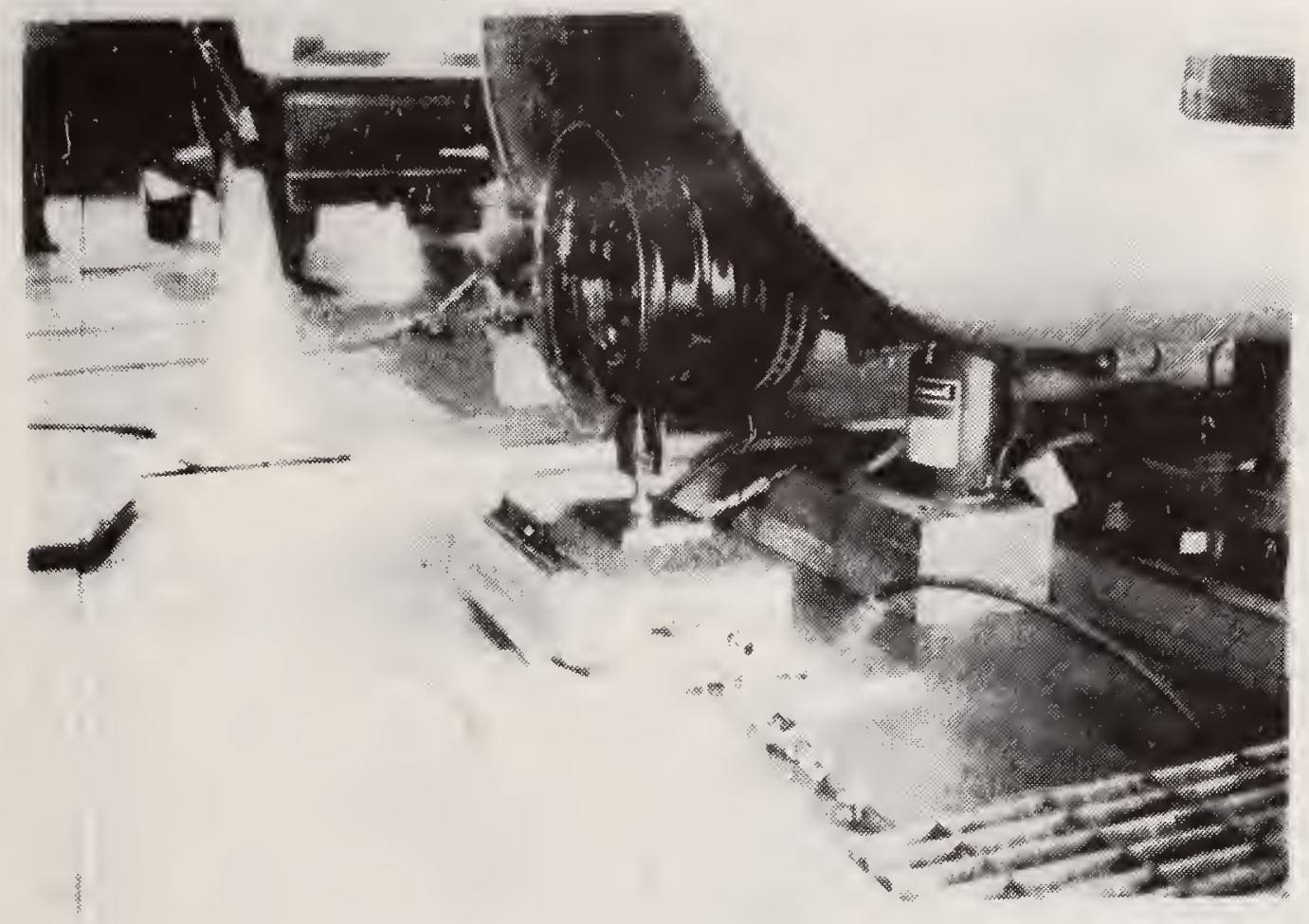

Figure 19. Adjustable radius test wheel. 


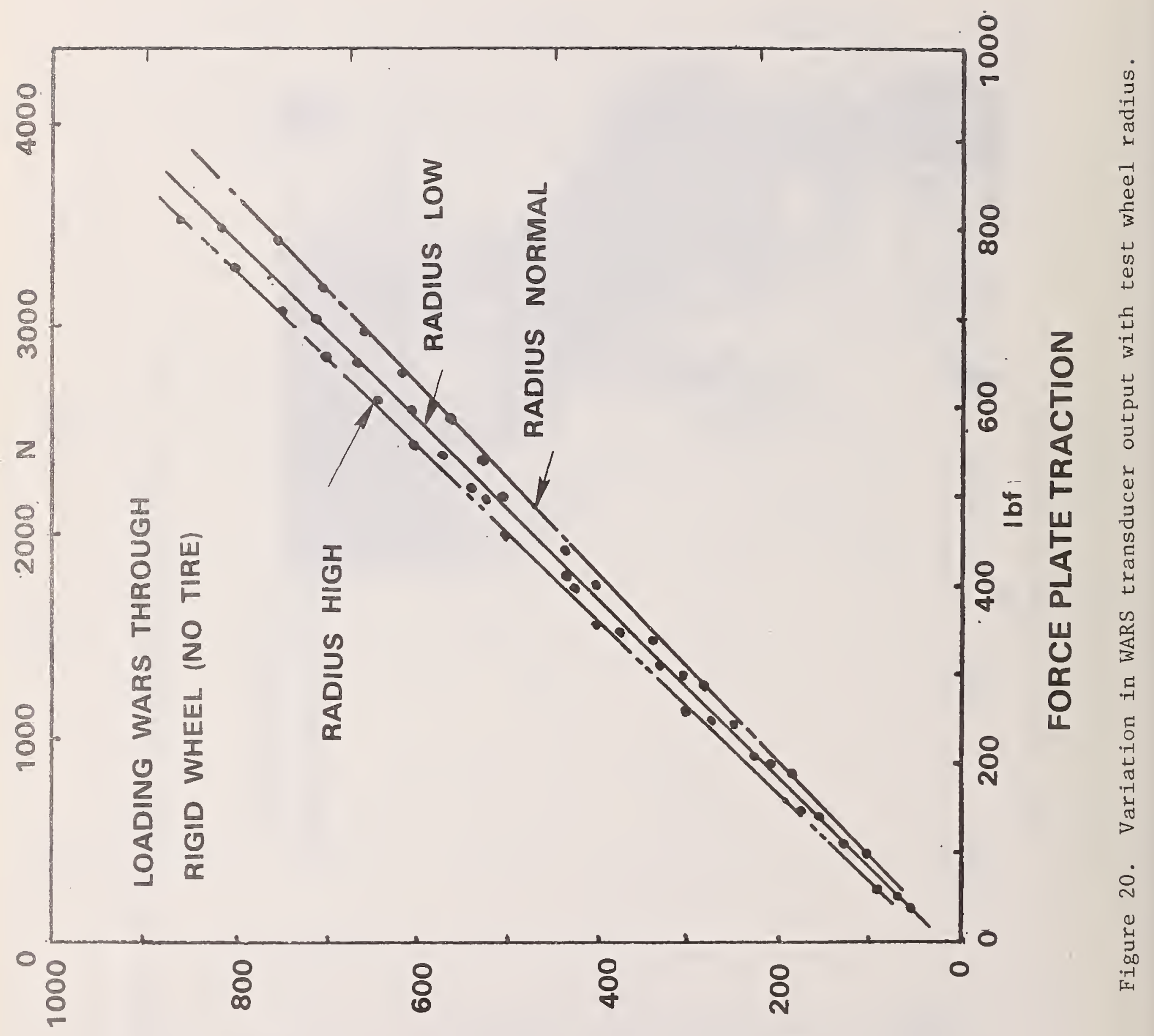

SNIA 
Force plate tests with test tire inflation pressure as the operating variable were conducted by WFTC personnel. The results are summarized in Table 5. They indicate the WARS transducer calibration is a function of test tire inflation pressure varying in excess of one percent over the range from 22 to $30 \mathrm{psi}$ (152 to $207 \mathrm{kPa}$ ).

\subsubsection{Transducer Response to Changes in Hitch Height}

Force plate tests were conducted with hitch height as the operating variable. No change in transducer output was measured over the range from $15 / 8$ inches $(4.1 \mathrm{~cm})$ below to $13 / 8$ inches $(3.5 \mathrm{~cm}$ ) above normal hitch height (Fig. 21).

Note however that skid number is a function of hitch height, because the vertical load changes with changing hitch height (see sec. 2.7.1).

\subsection{Suspension Subsystems}

The measurement of pavement skid resistance at normal traffic speeds is a dynamic test. While the data of interest is to occur during a period of steady state friction, the fact is that transient oscillations dominate the entire trace. Trailer motions introduce transient dynamic forces into the system and vice versa. The effective dynamic characteristics of the suspension subsystems need to be measured and reported in analytical form so that dynamic analyses of the system can be performed for comparison with experimental results and for use in design parameter studies.

Further, measurements made by systems of similar or even the same design differ. Consequently, in an attempt to document the dynamic characteristics that might affect measuring performance and account for these differences, the effective spring rates, natural frequencies, and viscous friction of the suspension systems were determined. Measurements of certain static displacements were also made as the traction force at the tire-pavement interface was increased to approximately $800 \mathrm{lbf}(3560 \mathrm{~N})$ and then decreased to zero.

The dynamic characteristics of the trailer suspension system were obtained while the trailer was connected to a ball hitch on a stationary fixture. The displacements of the trailer test wheel under static load were measured with the trailer alined and connected to the tow vehicle with the tow vehicle drive wheels and trailer test wheel locked. Consequently, part of the motion occurring under traction force is due to motion between the ball hitch and the tow vehicle tire-pavement interface.

Since optimum design values have not been demonstrated at this time, results from some tests conducted on the IRS are presented with those of the WARS for intercomparison purposes. 
Table 5 - Effect of Test Tire Inflation Pressure on WARS Transducer output

\begin{tabular}{ccc}
$\begin{array}{c}\text { Test tire } \\
\text { inflation pressure }\end{array}$ & $\begin{array}{c}\text { Traction force } \\
\text { applied }\end{array}$ & $\begin{array}{c}\text { WARS } \\
\text { transducer } \\
\text { output }\end{array}$ \\
\hline psia $^{\mathrm{a}}$ & $1 \mathrm{ff}^{\mathrm{b}}$ & volts \\
30 & 800 & 8.65 \\
28 & 800 & 8.63 \\
26 & 800 & 8.60 \\
24 & 800 & 8.58 \\
22 & 800 & 8.55 \\
\hline
\end{tabular}

a $1 \mathrm{psi}=6.9 \mathrm{kPa}$.

b $11 \mathrm{bf}=4.45 \mathrm{~N}$. 


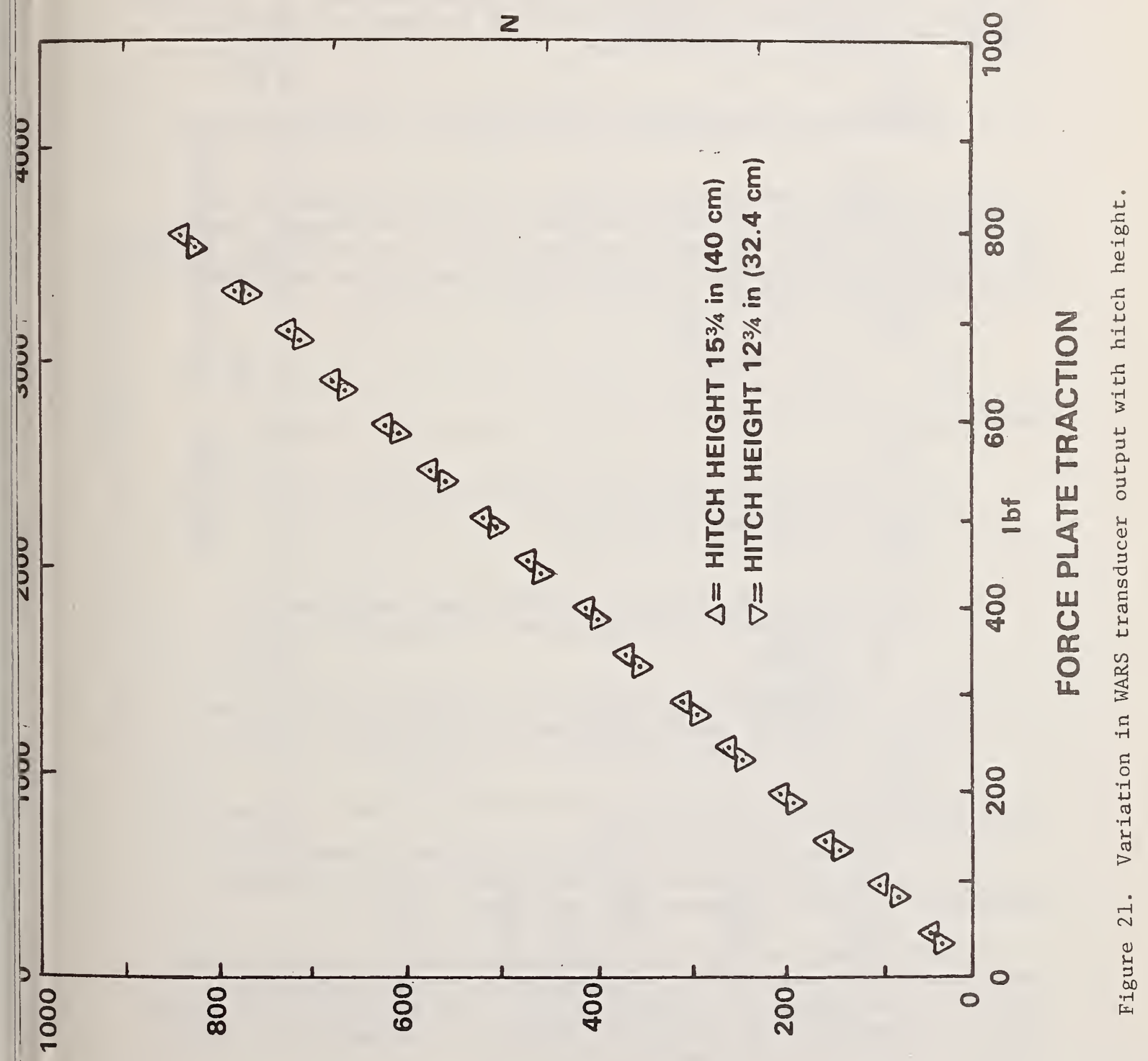

ONIO $\forall \exists y$ y 
Since the WARS transducer is a torque instrument, an instantaneous measurement of the test wheel vertical load is not avallable. As the test wheel locks, the traction force generates a moment about the hitch which reduces the vertical load on the test tires. This abrupt unloading excites a transient response in the suspension subsystem. The unloading constant is an important parameter in the dynamic analysis of the trailer. Further, the variation in vertical load must be known to correctly reduce traction data to skid number.

\subsubsection{Experimental Determination of the Effective Unloading Constant}

The vertical load on the test wheel of a towed two-wheeled skid trailer is reduced as the traction force at the tire-pavement interface is increased. This reduction in vertical load can be described in terms of an effective unloading constant [4] which can then be experimentally determined. The reduction in vertical load is given by:

$$
F_{W L}=F_{W L}-F_{Z_{0}}\left(\frac{H}{\mathrm{~L}}\right)
$$

where $\quad \mathrm{F}_{\mathrm{WL}_{\mathrm{x}}}=$ the longitudinal traction force on the left wheel.

$\mathrm{F}_{\mathrm{WL}}=$ the total normal force on the left wheel acting at the
tire-pavement interface. $\begin{aligned} \mathrm{F}_{W L}= & \text { The normal force on the left wheel acting at the } \\ z_{0} & \text { tire-pavement interface when the applied traction } \\ & \text { is zero. }\end{aligned}$

$\underline{\mathrm{H}}=$ the effective normal force unloading constant where $\mathrm{H}$ is the hitch height and $\mathrm{L}$ is the length from the hitch to the center line of the axle.

There is an uncertainty in the measurement of $\mathrm{H}$ and $\mathrm{L}$ because of the shape and size of the ball hitch.

The effective normal force unloading constant for the IRS was measured at the WFTC to demonstrate the method.

The transducer vertical load signal was amplified and applied to the $Y$-axis of the recorder while the amplified traction signal was applied to the X-axis. The unloading occurs linearly as shown in Figure 22. At a traction force of $8001 \mathrm{bf}(3560 \mathrm{~N})$ the unloading is $85 \mathrm{lbf}$ $(378 \mathrm{~N})$. The effective unloading constant is 


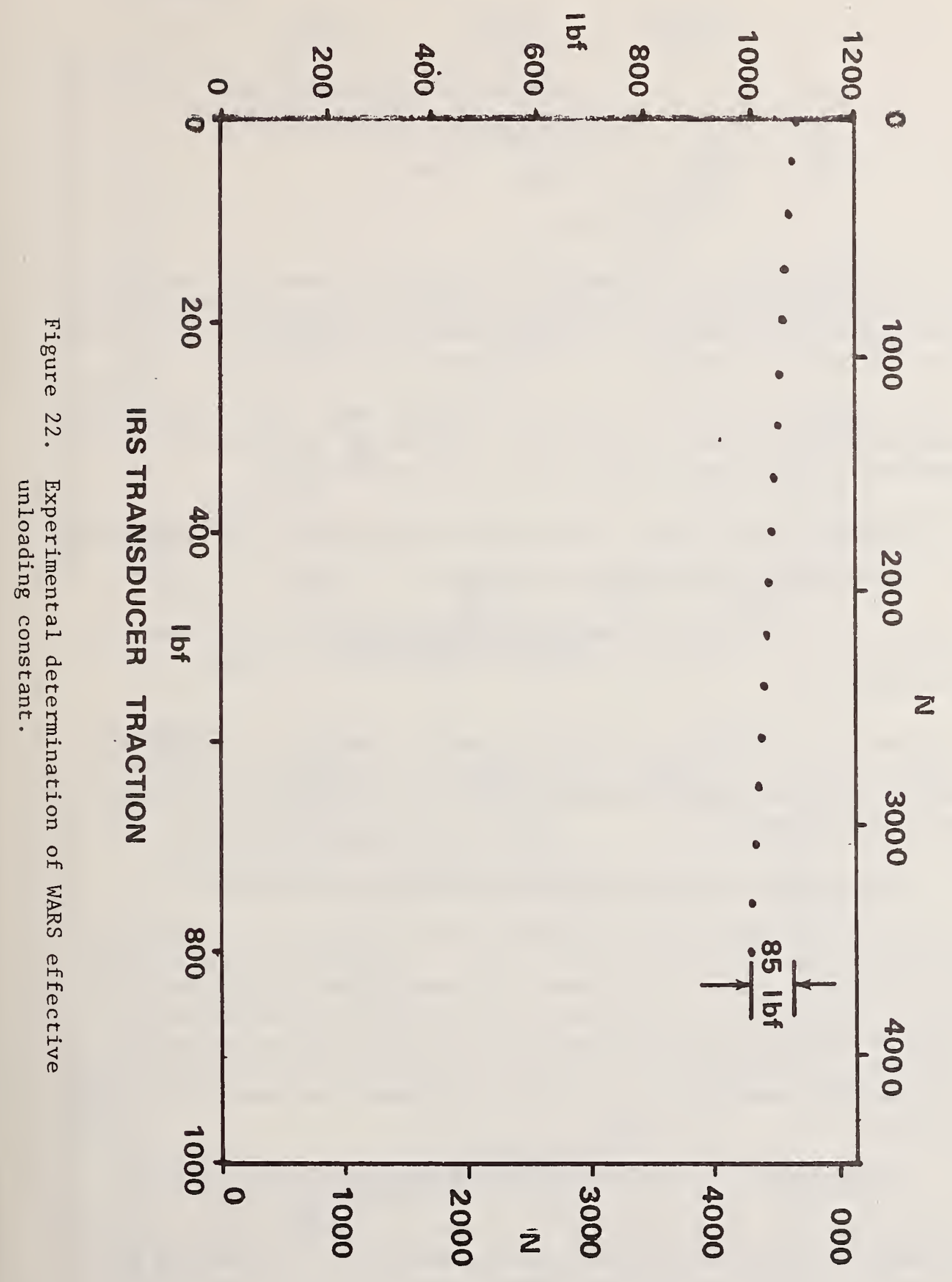




$$
\frac{H}{L}=\frac{{ }_{W L}{ }_{z_{0}}-{ }_{W L}{ }_{z}}{F_{W L}}=\frac{85}{800}=0.106
$$

On skid trailers not instrumented for vertical load, the vertical load and traction channels of the force plate may be used. WFTC personnel used the force plate channels to experimentally determine the effective unloading constant of the WARS. It was reported to be 0.143 .

This value was used in the reduction of the WARS data. The effective unloading constant was not used in the reduction of the IRS data, rather, the measured vertical loads and traction forces were used.

\subsubsection{Tow Vehicle and Trailer Displacements under Static Traction Load}

\subsubsection{Displacement of the Test Wheel Hub}

Under a static traction load of $742 \mathrm{lbf}(3300 \mathrm{~N})$ the test wheel hub moves backward 1.2 inches $(3.0 \mathrm{~cm})$ with respect to the pavement, as shown in Figure 23.

Although the decreasing traction data is incomplete, the existence of a large hysteresis loop is indicated. This displacement includes the tow vehicle tire and suspension deflections, trailer yaw and trailer suspension deflections.

\subsubsection{Displacement of the Test Tire Interface}

The test tire-force plate interface moves rearward with respect to the hub due to the distortion of the tire. No slippage of the tire on the force plate was noted. The interface displacement is plotted in Figure 24. Displacement measurements in the loading cycle beyond 370 lbf $(1650 \mathrm{~N})$ of increasing traction are not valid because the sensor went off scale. The shape of the plot at the lower loads indicates that a displacement of about $0.5 \mathrm{in}(1.2 \mathrm{~cm})$ would have been measured at 800 lbf $(3560 \mathrm{~N})$.

\subsubsection{Displacement of the Trailer Body Through Roll Axis Rotation}

Angular displacement about the roll axis was measured with respect to the pavement using two vertical sensors mounted at the rear of the trailer with an effective lateral separation of 46 in $(117 \mathrm{~cm})$.

The displacements are shown in Figure 25. Initially, the sensors were off scale. The displacement measurements between 263 and $5551 \mathrm{bf}$ $(1170$ and $2470 \mathrm{~N})$ have been extrapolated to zero traction to establish the origin of the displacement scale. The corresponding roll angle was two minutes of arc. 

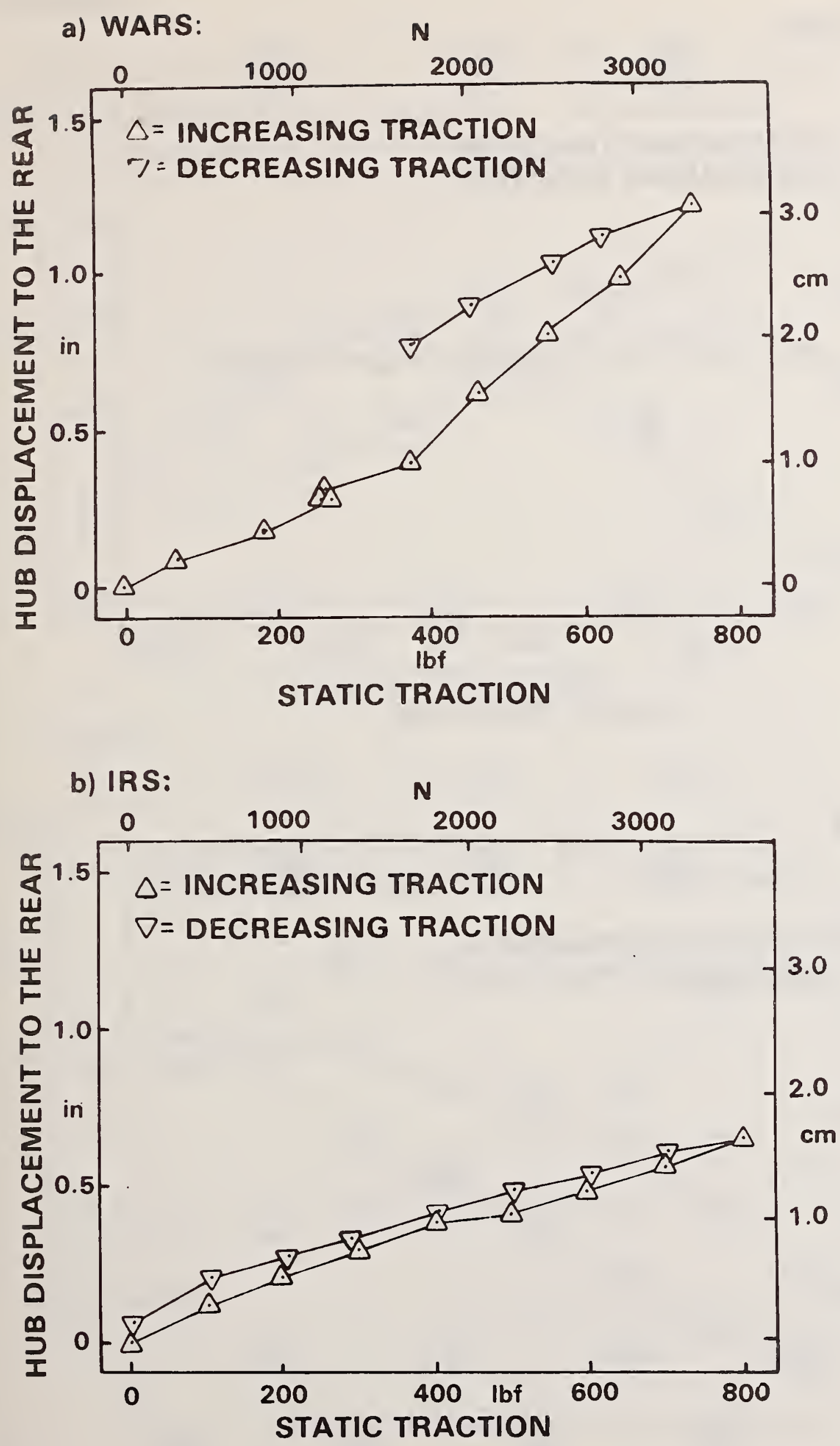

Figure 23. Displacement of the test wheel hub due to static traction. 


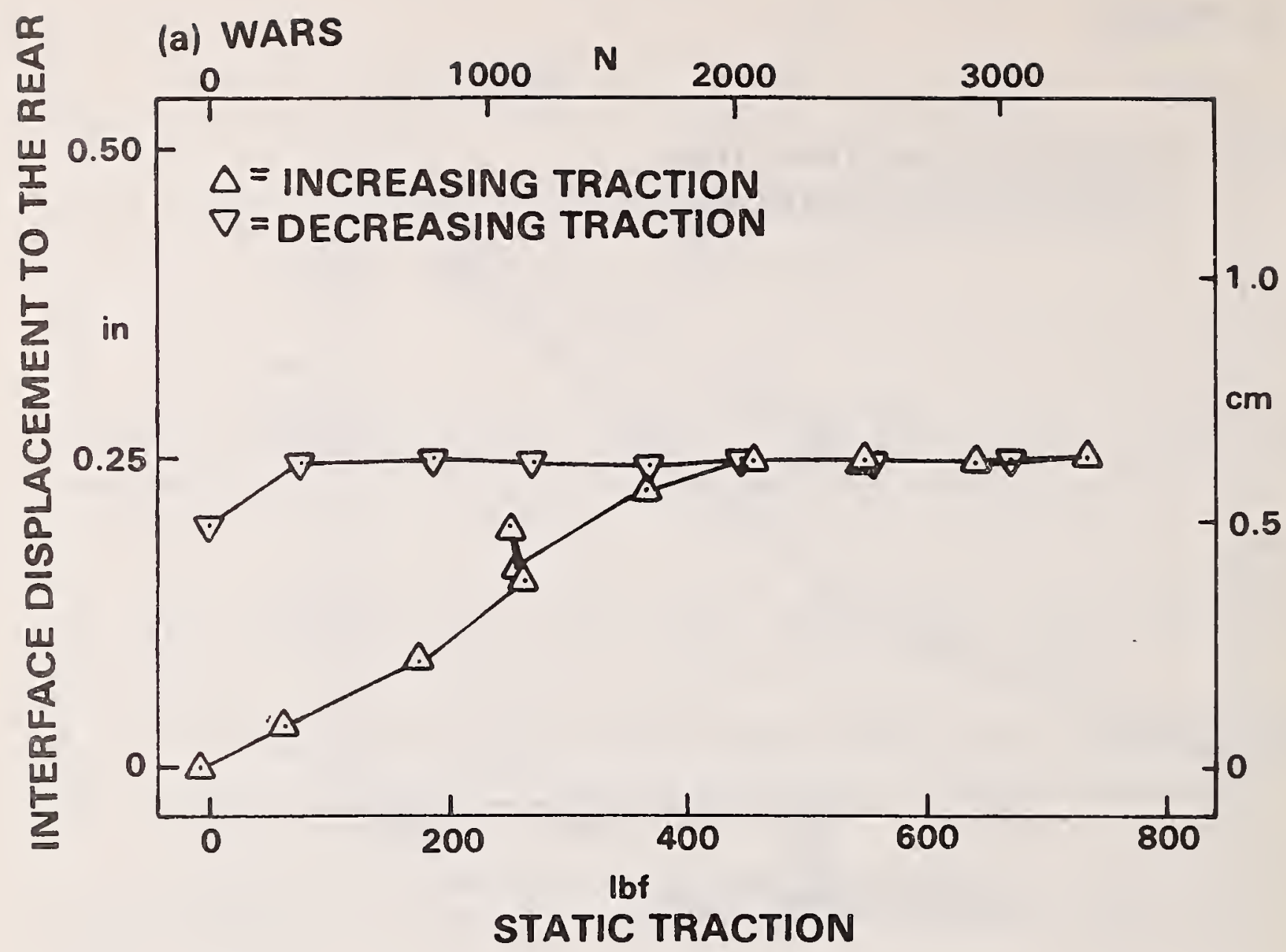

(b) IRS

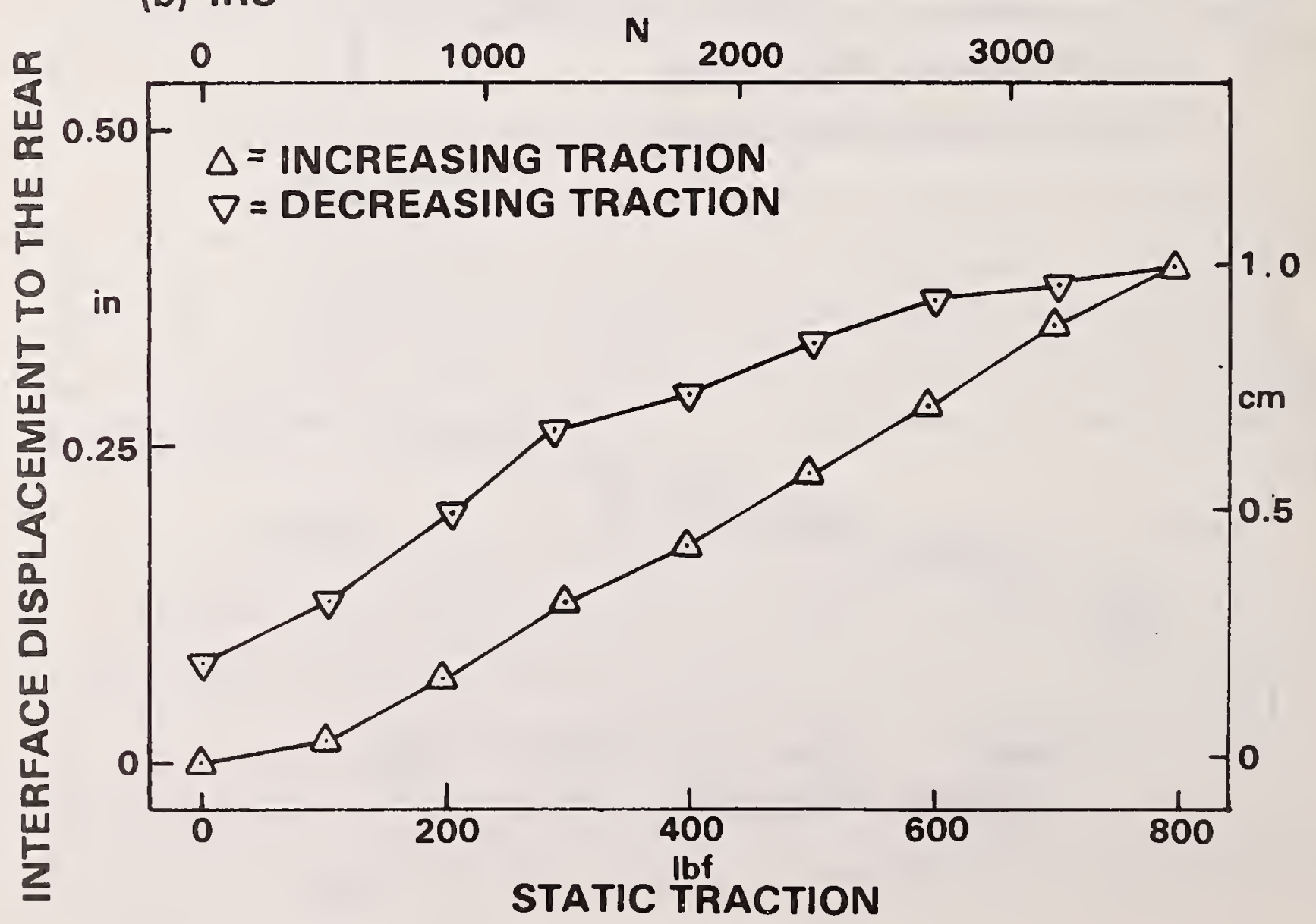

Figure 24. Displacement of the test tire interface due to static traction. 


\subsubsection{Suspension Characteristics under Transient Loading}

The effert lve dyonmid rharacterist fos of the suspenston subsystem

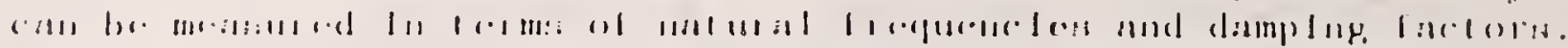

l'here are three thatual frequedeles ot interest. Onte occurs under conditions of small variations in vertical load where there is no relative movement within the suspension subsystem. The axle and body are free to rotate in a vertical plane about the hitch within a small range of displacement of the tires (section 2.1.2). The other two natural frequencies occur under conditions of larger variations in vertical load where there is relative movement within the suspension system and the shock absorbers are active. In this case there are two degrees of freedom:

a) the body can rotate in a vertical plane about the hitch, while

b) the axle can rotate in a vertical plane about the trailing arm hinge in suspension designs of the IRS type, and about the leaf springs in suspension designs of the WARS type.

There is a mode of operation associated with each degree of freedom. Each mode may be produced independently by starting the system oscillation under the proper initial conditions. A dynamic analysis of the IRS suspension design revealed two dynamic tests which are easy to conduct which approximate the independent modes such that the measurement of each natural frequency is enhanced. The enhancement is more evident under the condition that the shock absorbers are deactivated [5]. The first test is to raise the trailer by the rear bumper and to drop it abruptly. With this initial condition, an oscillation occurs where the angular displacement of the body and axle trailing arm are out of phase. In this mode, the low frequency is enhanced. The second test is to raise the trailer at the axle and to drop it abruptly. With this initial condition, an oscillation occurs where the angular displacement of the body and axle trailing arm are in phase. In this mode, the high frequency is enhanced. A dynamic analysis of suspension system designs of the WARS type may reveal a better set of tests to conduct to obtain its characteristics.

A nondimensional family of plots which can be used to estimate the amount of damping in systems representative of second order systems is shown in Figure 26 [6]. The curves indicate that a system with a damping factor, $\zeta$, of 0.8 reaches near equilibrium before a system with either a damping factor of 0.6 or 1.0 . A more optimum value (not shown) is 0.7 . A measuring system which is subject to disturbing transients will measure the near equilibrium value more often with a damping factor of 0.7 . 


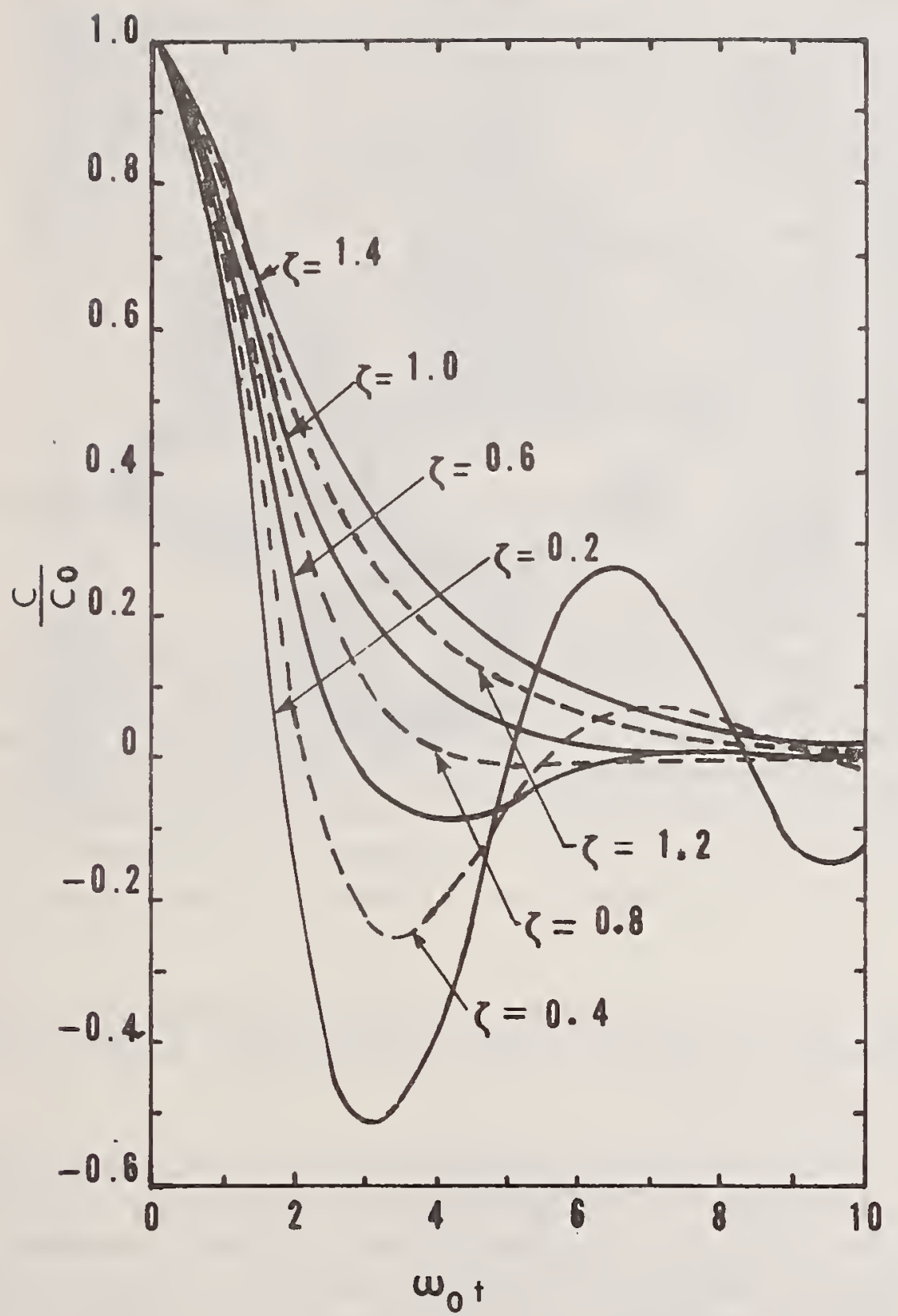

Figure 26. Effect of different damping factors on second-order linear systems (Reference 6). 
A special air cylinder assembly was designed so a trailer could be raised at its center-of-gravity or at its axle and dropped abruptly. The air cylinder system is shown in Figure 27. The large diameter air cylinder is used to lift the body. The small air cylinder is used to raise a trailer by its axle. The IRS test set-up is shown in Figure 28.

The IRS was lifted at its center-of-gravity 0.56 in $(1.4 \mathrm{~cm})$ and dropped abruptly. The body-to-axle displacement, measured at the axle, versus time is shown in Figure 29. By comparing the form of the response with the family of curves of Figure 26, the effective damping factor between the body and axle is estimated to be 0.57 . The body-to-ground displacement response, measured at the rear bumper, is also shown. This response includes the displacement of the tires which are only lightly damped. The effective body-to-ground displacement response damping factor is estimated to be 0.45 . The damped low frequency F , is estimated to be $3.2 \mathrm{~Hz}$. Since the low natural frequency, $F_{n}$, is related to $F_{d}$, by

$$
F_{d}=F_{n} \sqrt{1-\zeta^{2}}
$$

the low natural frequency is approximately $3.6 \mathrm{~Hz}$. The small amplitude natural frequency on the tires is approximately $4 \mathrm{~Hz}$.

The WARS was subjected to a similar drop test, by lifting it 0.7 in $(1.8 \mathrm{~cm})$ at the rear bumper and dropping it abruptly. The body-to-axle response is shown in Figure 30. The damping factor was estimated to be 0.45. At the recommendation of NBS personnel, a second set of shock absorbers was installed on the WARS. The test was repeated with the result shown in Figure 31. After this modification the body-to-axle damping factor was increased to 0.65 . The damped low frequency, $F_{d}$, is estimated to be $3.7 \mathrm{~Hz}$. The low natural frequency is approximately 4.9 $\mathrm{Hz}$.

The IRS suspension system consists of parallelogram arms trailing from the body to the axle assembly with coiled springs mounted vertically between the arms and upper body.

The response of the IRS force measurements to a center-of-gravity drop test is shown in Figure 32. The effective transducer and force plate damping factors are 0.4. The damped low frequency response is 2.9 $\mathrm{Hz}$. There is a natural frequency associated with the trailer body and a second natural frequency associated with the axle. The natural frequency associated with the axle is a higher frequency. The damped high frequency response is estimated at $8 \mathrm{~Hz}$.

A response curve consists of both the low and high frequency components. The amount and relative phase of each depends upon the initial conditions. When the initial conditions are changed by lifting the 


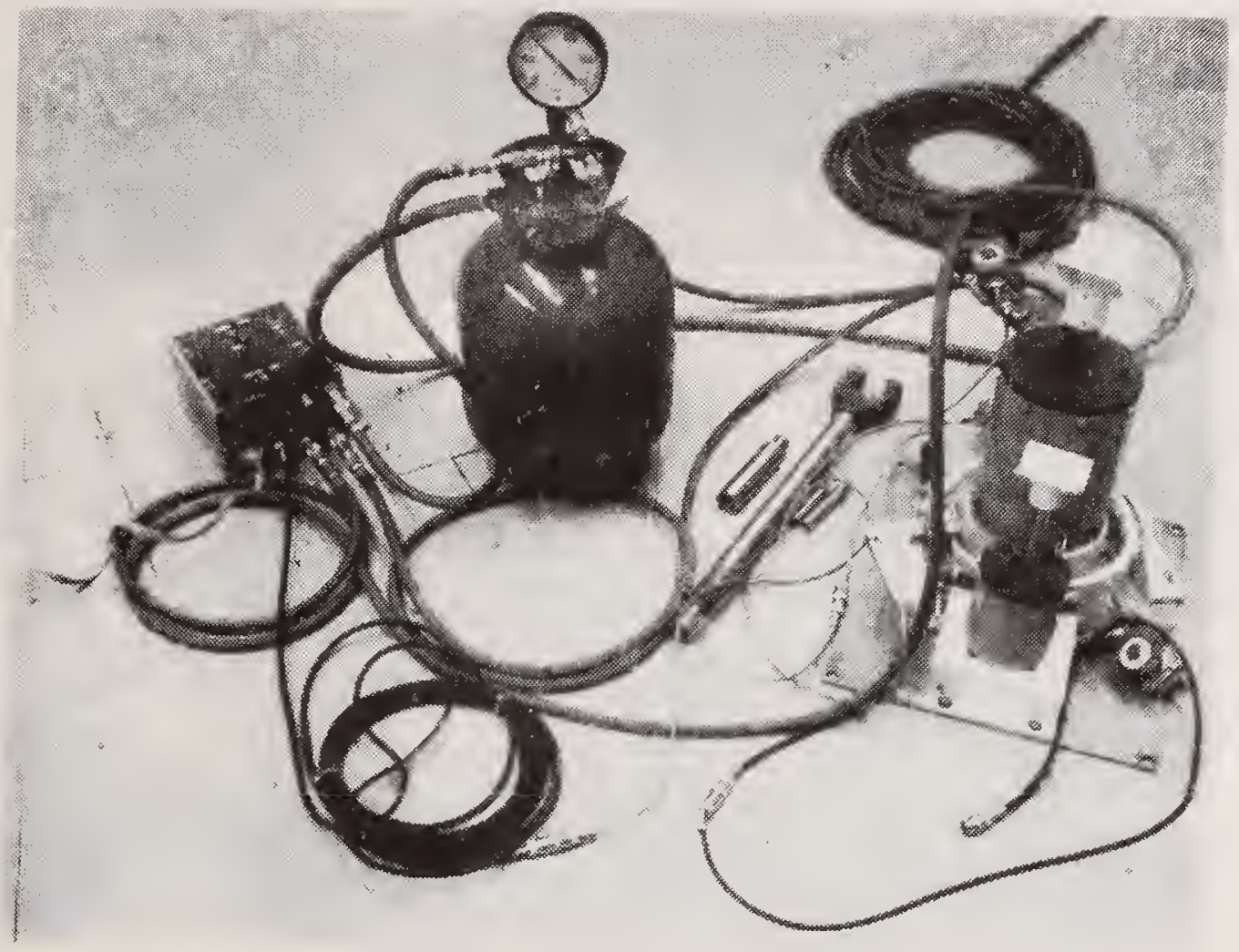

Figure 27. Trailer transient drop test equipment. 


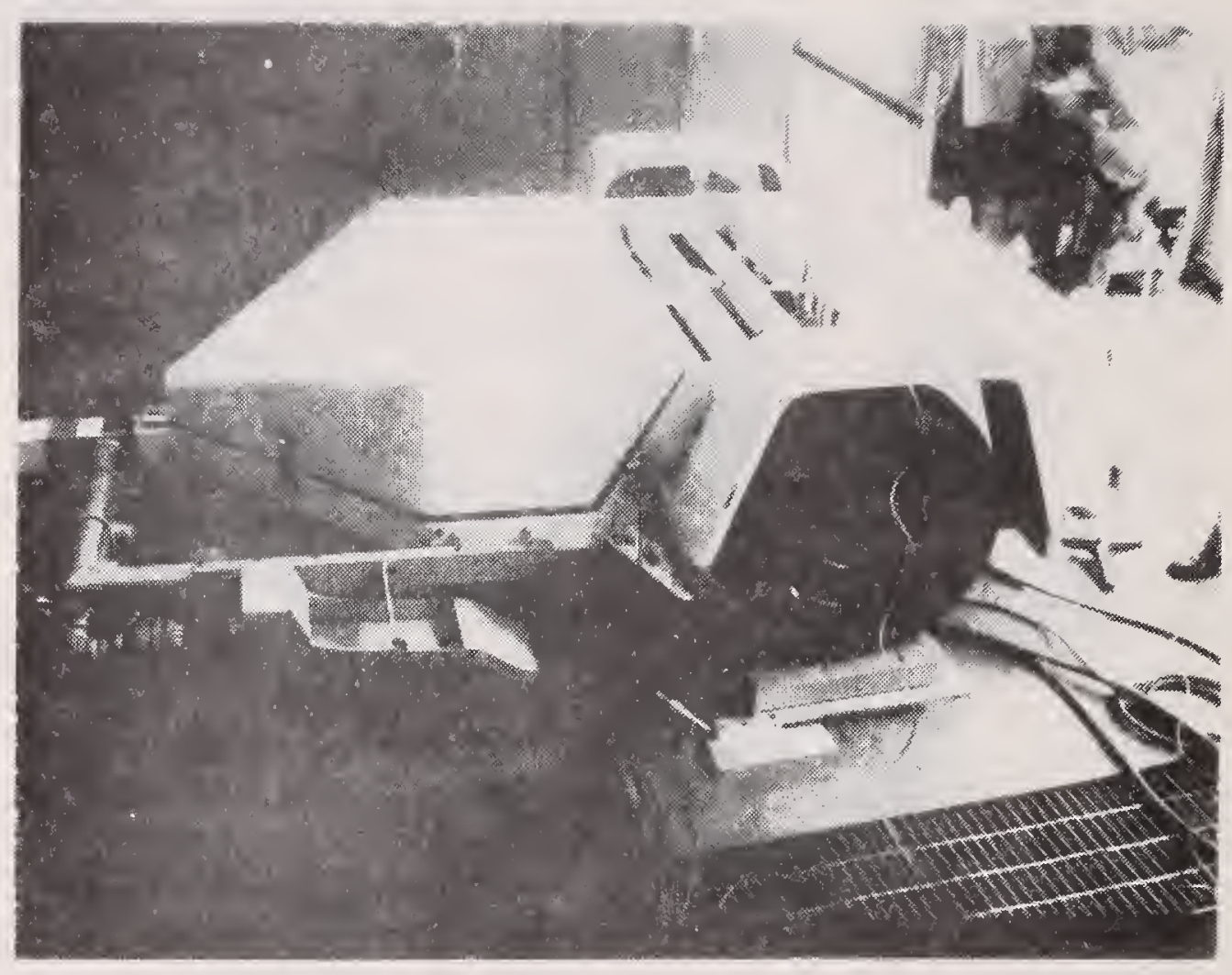

Figure 28. IRS transient drop test set-up. 


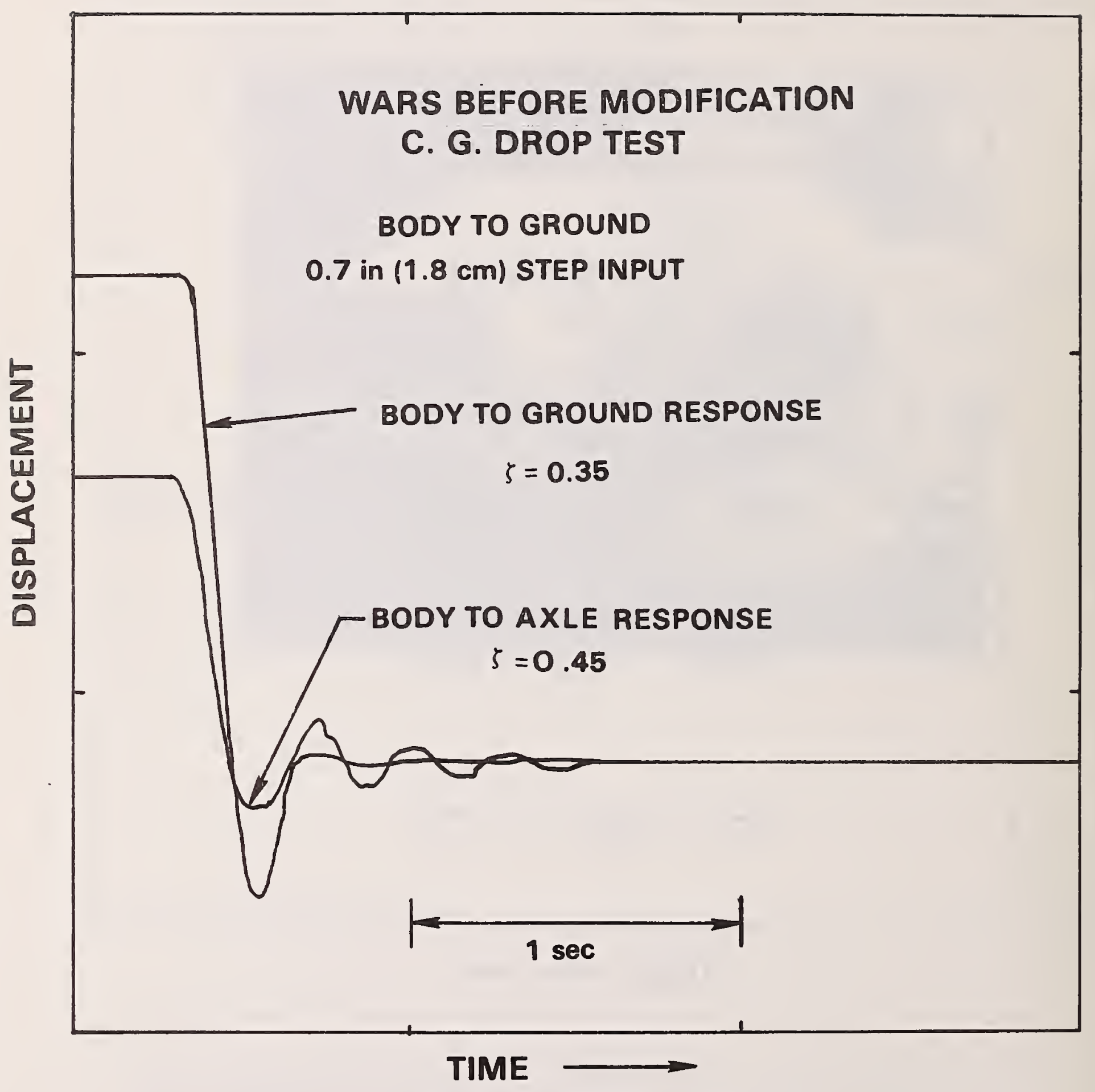

Figure 30. WARS displacement response to a center-of-gravity type drop test - before modification. 


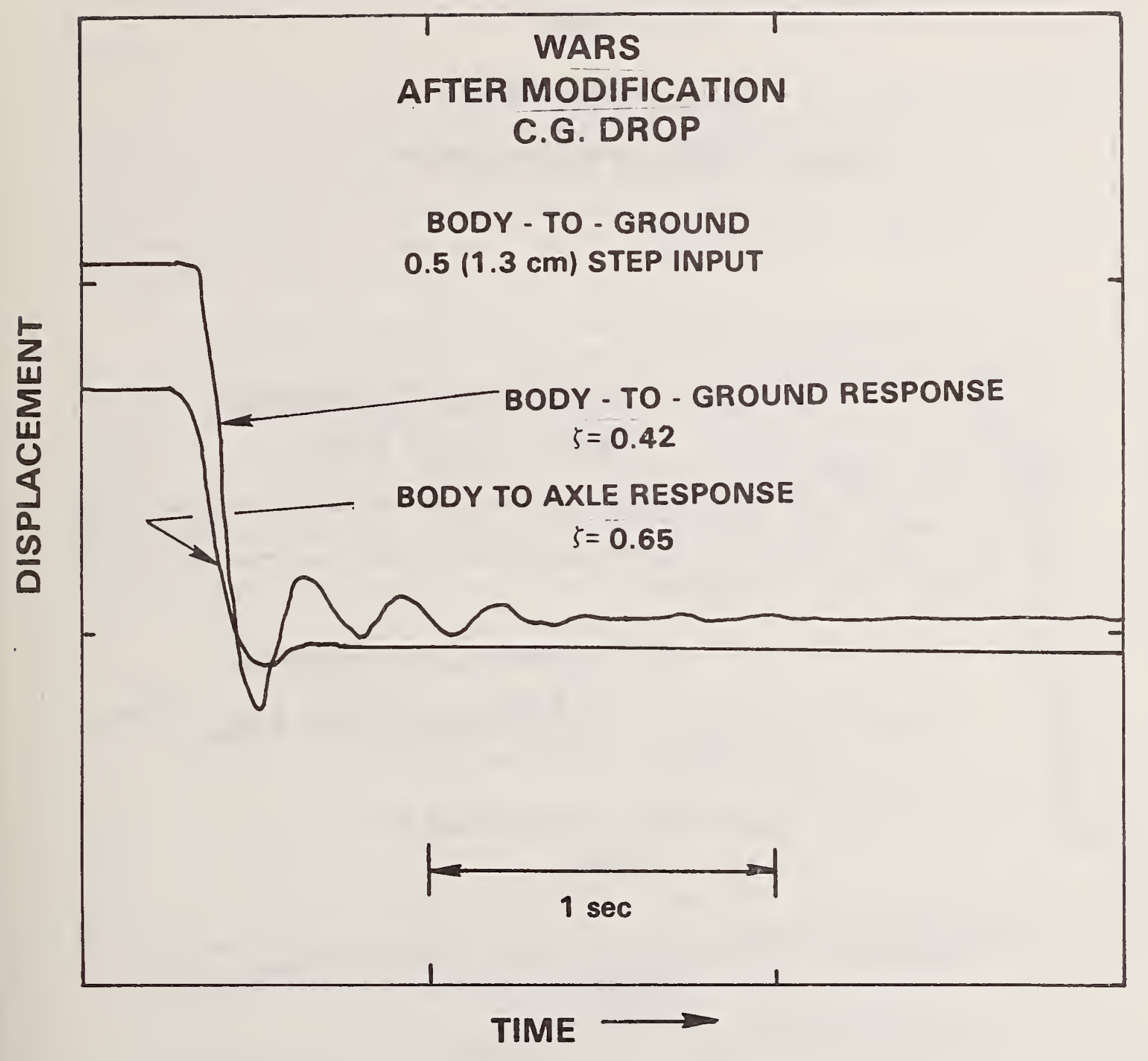

Figure 31. WARS displacement response to a center-of-gravity type drop test - after modification. 


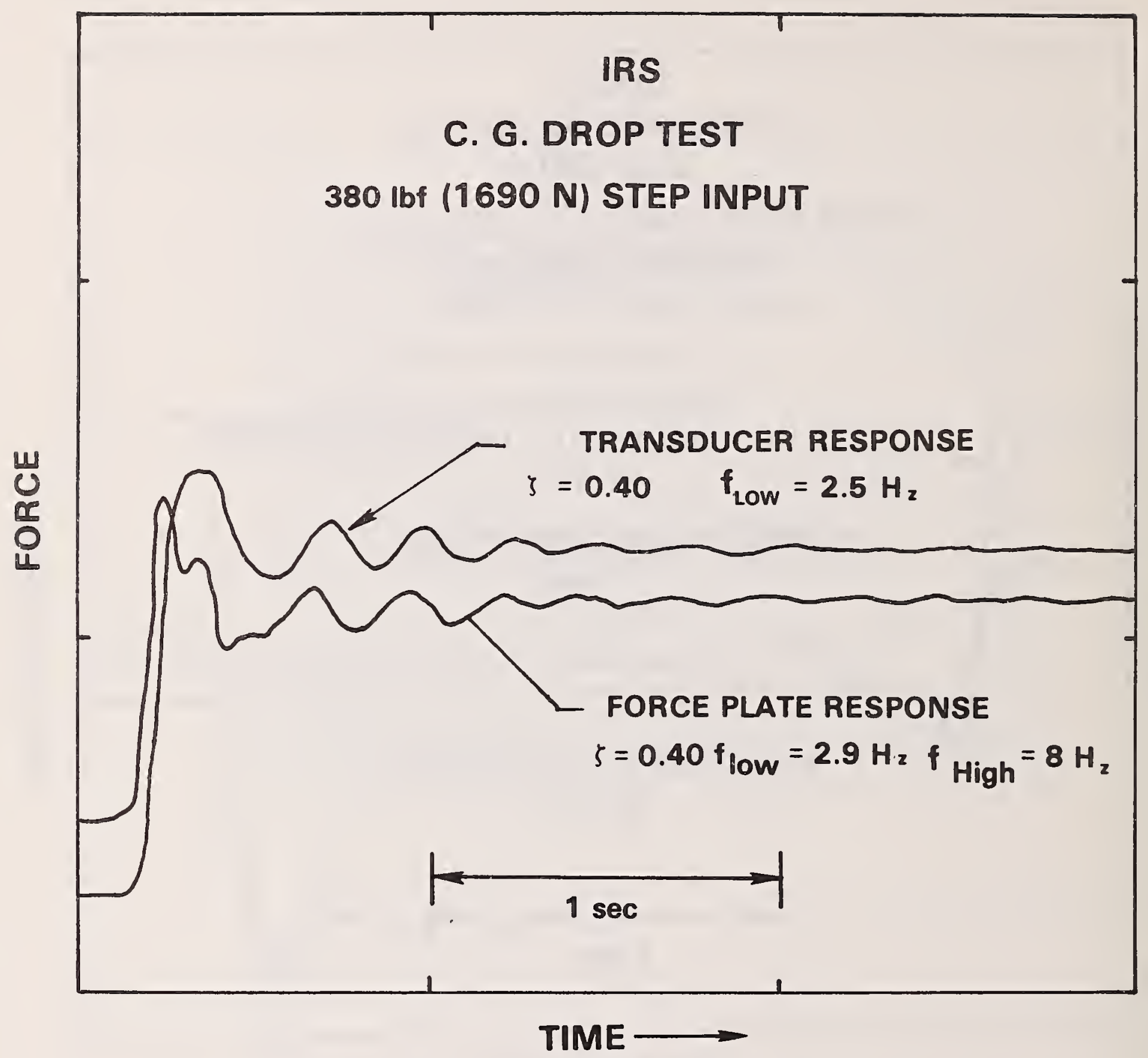

Figure 32. IRS force response to a center-of-gravity drop test. 
trailer by the axle (Fig. 33) and dropping the axle abruptly, the damping factor is estimated at 0.46 with a damped low frequency component of $2.5 \mathrm{~Hz}$ and a damped high frequency component of $9 \mathrm{~Hz}$.

The WARS suspension consists of an axle assembly mounted on leaf springs.

The response of the WARS force measurements to a center-of-gravity type drop test is shown in Figure 34. The transducer responds to torque inputs. There is a transducer response to the varying vertical force. The vertical force plate response is also shown. The damping factor associated with this response is estimated to be 0.21 . The damped low frequency response is nominally $3.3 \mathrm{~Hz}$. Due to the low damping factor, the undamped low natural frequency is the same value.

The response of the WARS force measurements to an axle-1ift drop test is shown in Figure 35. Again the torque transducer responds to the varying vertical force with the high frequency component more apparent. The high frequency component is also more apparent in the force plate response. The damping factor associated with the axle-lift drop test force plate response is estimated to be 0.35 . The damped high natural frequency is estimated to be in the range from 6 to $8 \mathrm{~Hz}$. The corresponding undamped high natural frequency would be 6.4 to $8.5 \mathrm{~Hz}$.

The WARS sma11 amplitude natural frequency on the tires is approximately $4 \mathrm{~Hz}$.

\section{THE DYNAMIC SKID RESISTANCE MEASUREMENT OF SELECTED SURFACES AND WARS-IRS CORRELATION}

The purpose of the dynamic skid resistance measurement test program was:

1) to measure selected surfaces at the WFTC,

2) to measure the consistency and precision in the measure ments of both the WARS and the IRS, and

3) to correlate the degree of match in the measurements be tween the IRS and the WARS.

\subsection{Surfaces Selected}

The surfaces selected were a 100 foot $(30 \mathrm{~m})$ longitudinal section of lanes 1 through 7 of surfaces identified as 1,2 , and 3 at the WFTC. So that the reduced data would all be within the same 100 foot ( $30 \mathrm{~m}$ ) 


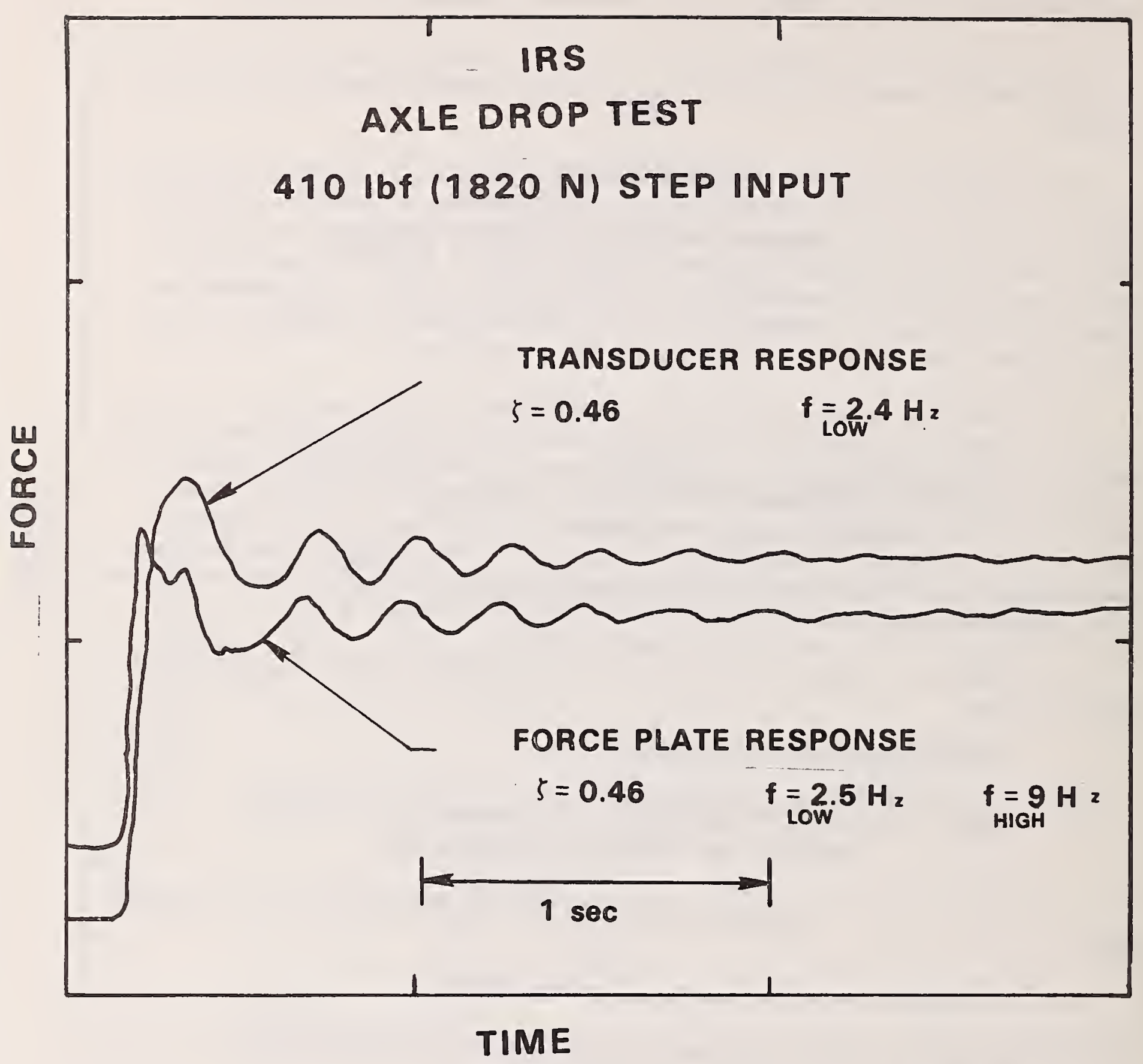

Figure 33. IRS force response to an axle drop test. 
AFTER MODIFICATION

C.G. DAOP TEST

$390 \mathrm{lbf}(1730 \mathrm{~N})$ STEP INPUT

U
뜬

FORCE PLATE RESPONSE

$$
\zeta=0.21
$$

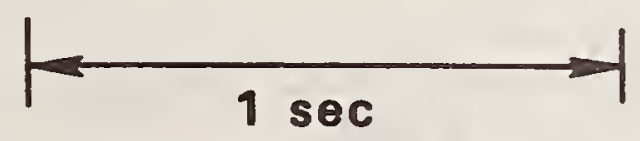

TRANSDUCER RESPONSE

TIME

Figure 34. WARS force response to a center-of-gravity type drop test. 


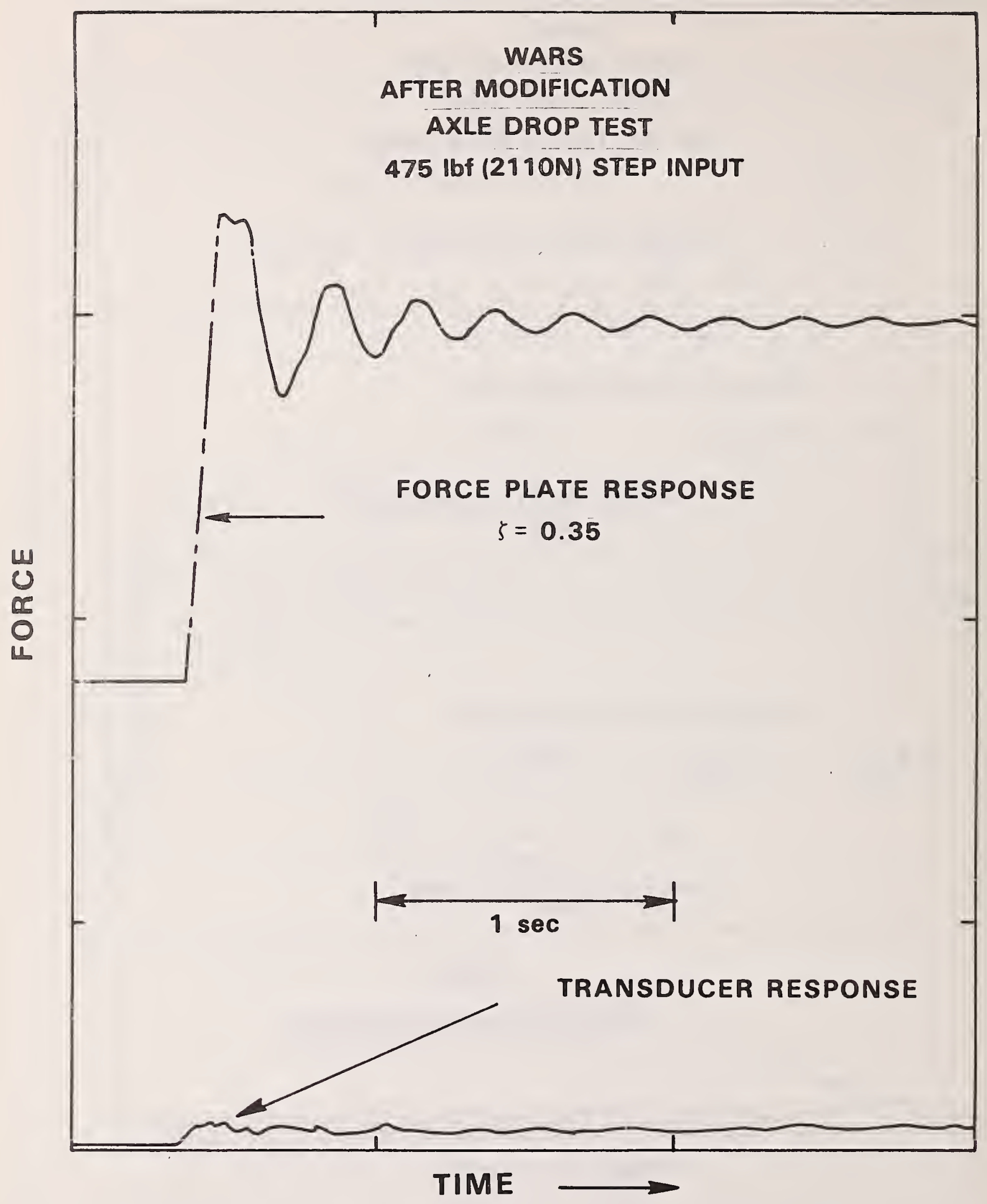

Figure 35. WARS force response to an axle drop test. 
section at all test speeds, pylons were set out where the operator would start the automatic test sequence for each test speed. The location of the selected surfaces was the first 100 feet $(30 \mathrm{~m})$ at the southern end of each surface.

\subsection{Tests Planned}

The test program is designed to yield the following information:

1) Skid resistance, $S N$, of a surface as a function of test speed.

2) Skid resistance - test speed gradient, $\theta$, as a function of test speed.

3) Variability in SN with choice of time period for the test.

4) Variability in SN with choice of test tire.

5) Variability in SN with choice of lane within the surface.

The test plan included the control of the following operating variables:

a) hitch height,

b) inflation pressure of the test tire,

c) Inflation pressure of the tow vehicle rear tires,

d) inflation pressure of the shock absorbers,

e) surface cleanliness,

f) surface degree-of-dryness,

g) test speed, and

h) wear texture of the test tires.

The test plan included the measurement of the following uncontrolled variables:

a) weather,

b) surface temperature,

c) test tire lock-up position, and

d) test tire tread depth.

The planned test program is contained in Table 6 . 


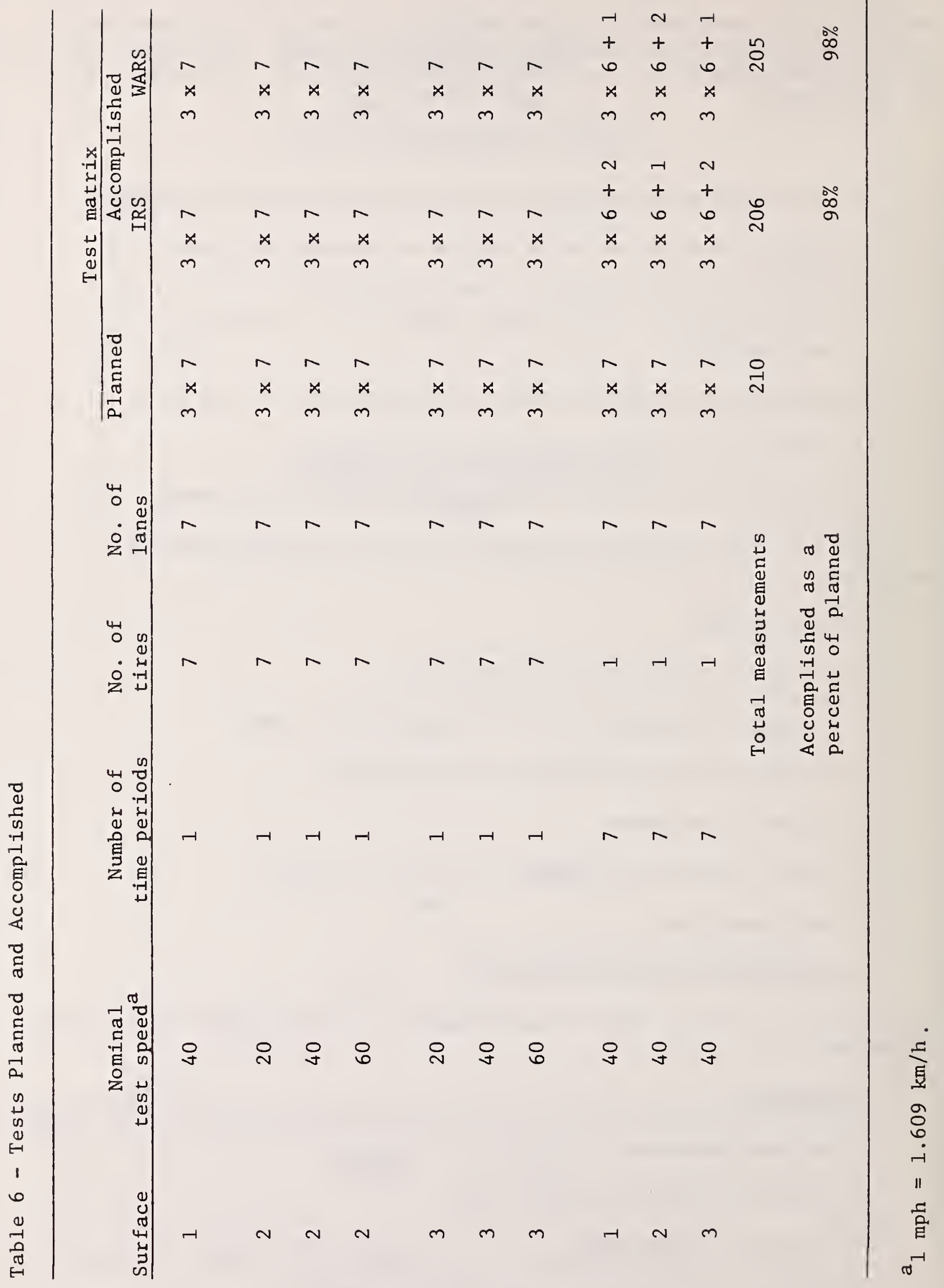


The test sequence within each time period is given in Table 7 . In general, at least two tests are conducted in other lanes before a test is repeated in a given lane. At a spacing of 20 minutes between tests, a minimum of one hour is allowed for the surface to dry before measuring the lane again [7].

In the NBS tests conducted the previous fall at the EFTC [5] it was noted that each surface textured the test tire in a different pattern. Since the water in the interface can fill the texture previously worn in the tire, as well as fill the texture of the surface, each tire was assigned to a specific surface. The same test tire was then used on both the IRS and the WARS. Seven tires were used on each of three surfaces ( 21 tires) for the single time period tests. One tire was used on each of three surfaces ( 3 tires) for the multiple time period tests. Twenty-four (24) test tires were used in the program.

\subsection{The Test Matrix} matrix:

A subdivision of the test plan consists of the following test

Time Period

Surface

Tires

\begin{tabular}{cccccccc}
\cline { 2 - 7 } Speed & A & B & C & D & E & F & G \\
\cline { 2 - 7 }$S-\Delta S$ & 1 & 2 & 3 & 4 & 5 & 6 & 7 \\
$S$ & 2 & 3 & 4 & 5 & 6 & 7 & 1 \\
$S+\Delta S$ & 4 & 5 & 6 & 7 & 1 & 2 & 3
\end{tabular}

Letters A thru G designated 7 tires while numbers 1 thru 7 identify the 7 lanes comprising the surface [7]. The nominal test speed is $S$, while $\Delta S$ is an incremental change in the speed. Since $\Delta S$ is small, the slope over the range $2 \Delta S$ approaches the speed gradient at $S$. Another subdivision of the test plan given in Table 6 consists of a test matrix where the variables are lanes within a surface and time period of the test. The same test tire and wheel was always used on the same surface and all tests were conducted at $40 \mathrm{mph}(64 \mathrm{~km} / \mathrm{h})$.

The mean of the 21 skid number measurements represents the skid number of the surface measured during the time period using the average tire at the nominal test speed. The novelty of the test matrix is that it yields the skid gradient of the surface, as well as a measure of the surface and tire nonuniformities. The test matrix is explained further in Appendix B. 

Table 7 - WFTC Test Plan Sequence

\section{Surfaces}

24 Tires

210 Skid Measurements - IRS

210 Skid Measurements - ARS 

TIME PERIOD 非

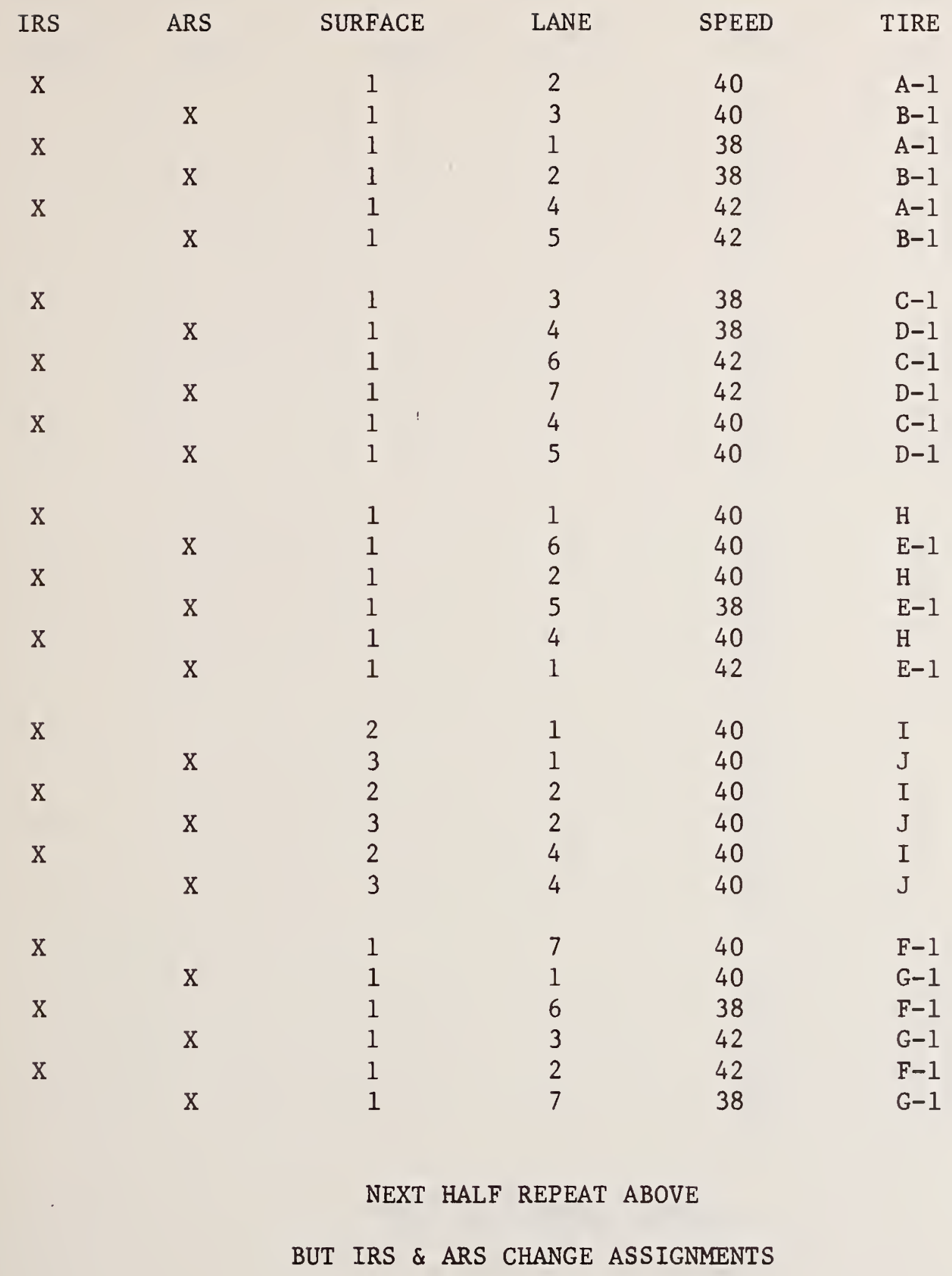





\begin{tabular}{|c|c|c|c|c|c|}
\hline IRS & ARS & SURFACE & LANE & SPEED & 'TIRE \\
\hline \multirow[t]{2}{*}{$\mathrm{x}$} & & 2 & 2 & 40 & $A-2$ \\
\hline & $\mathrm{x}$ & 2 & 3 & 40 & B-2 \\
\hline \multirow[t]{2}{*}{$\mathrm{x}$} & & 2 & 1 & 38 & $A-2$ \\
\hline & $\mathrm{X}$ & 2 & 2 & 38 & B-2 \\
\hline \multirow[t]{2}{*}{$\mathrm{x}$} & & 2 & 4 & 42 & $A-2$ \\
\hline & $\mathrm{x}$ & 2 & 5 & 42 & B-2 \\
\hline \multirow[t]{2}{*}{$\mathrm{x}$} & & 2 & 3 & 38 & $C-2$ \\
\hline & $\mathrm{X}$ & 2 & 4 & 38 & $D-2$ \\
\hline \multirow[t]{2}{*}{$\mathrm{x}$} & & 2 & 6 & 42 & $C-2$ \\
\hline & $\mathrm{x}$ & 2 & 7 & 42 & D-2 \\
\hline \multirow[t]{2}{*}{$\mathrm{x}$} & & 2 & 4 & 40 & $C-2$ \\
\hline & $\mathrm{x}$ & 2 & 5 & 40 & $D-2$ \\
\hline \multirow[t]{2}{*}{$\mathrm{x}$} & & 1 & 2 & 40 & $\mathrm{H}$ \\
\hline & $\mathrm{x}$ & 2 & 6 & 40 & $E-2$ \\
\hline \multirow[t]{2}{*}{$\mathrm{x}$} & & 1 & 3 & 40 & $\mathrm{H}$ \\
\hline & $\mathrm{x}$ & 2 & 5 & 38 & $E-2$ \\
\hline \multirow[t]{2}{*}{$\mathrm{x}$} & & 1 & 5 & 40 & $\mathrm{H}$ \\
\hline & $\mathrm{x}$ & 2 & 1 & 42 & $E-2$ \\
\hline \multirow[t]{2}{*}{$\mathrm{x}$} & & 2 & 2 & 40 & I \\
\hline & $\mathrm{x}$ & 3 & 2 & 40 & $\mathrm{~J}$ \\
\hline \multirow[t]{2}{*}{$\mathrm{x}$} & & 2 & 3 & 40 & I \\
\hline & $\mathrm{x}$ & 3 & 3 & 40 & $\mathrm{~J}$ \\
\hline \multirow[t]{2}{*}{$\mathrm{x}$} & & 2 & 5 & 40 & I \\
\hline & $\mathrm{x}$ & 3 & 5 & 40 & $\mathrm{~J}$ \\
\hline \multirow[t]{2}{*}{$\mathrm{x}$} & & 2 & 7 & 40 & $\mathrm{~F}-2$ \\
\hline & $\mathrm{x}$ & 2 & 1 & 40 & G-2 \\
\hline \multirow[t]{2}{*}{$\mathrm{X}$} & & 2 & 6 & 38 & $F-2$ \\
\hline & $\mathrm{x}$ & 2 & 3 & 42 & $G-2$ \\
\hline \multirow[t]{2}{*}{$\mathrm{X}$} & & 2 & 2 & 42 & $F-2$ \\
\hline & $\mathrm{x}$ & 2 & 7 & 38 & $G-2$ \\
\hline
\end{tabular}

NEXT HALF REPEAT ABOVE

BUT IRS \& ARS CHANGE ASSIGNMENTS 


\begin{tabular}{|c|c|c|c|c|c|}
\hline IRS & ARS & SURFACE & LANE & SPEED & TIRE \\
\hline \multirow[t]{2}{*}{$\mathrm{X}$} & & 3 & 2 & 40 & $A-3$ \\
\hline & $\mathrm{X}$ & 3 & 3 & 40 & $B-3$ \\
\hline \multirow[t]{2}{*}{$\mathrm{X}$} & & 3 & 1 & 38 & $A-3$ \\
\hline & $\mathrm{X}$ & 3 & 2 & 38 & $B-3$ \\
\hline \multirow[t]{2}{*}{$\mathrm{X}$} & & 3 & 4 & 42 & $A-3$ \\
\hline & $\mathrm{X}$ & 3 & 5 & 42 & $B-3$ \\
\hline \multirow[t]{2}{*}{$\mathrm{X}$} & & 3 & 3 & 38 & $C-3$ \\
\hline & $\mathrm{X}$ & 3 & 4 & 38 & $D-3$ \\
\hline \multirow[t]{2}{*}{$\mathrm{X}$} & & 3 & 6 & 42 & $C-3$ \\
\hline & $\mathrm{X}$ & 3 & 7 & 42 & $D-3$ \\
\hline \multirow[t]{2}{*}{$\mathrm{x}$} & & 3 & 4 & 40 & $C-3$ \\
\hline & $\mathrm{X}$ & 3 & 5 & 40 & $D-3$ \\
\hline \multirow[t]{2}{*}{$\mathrm{X}$} & & 1 & 3 & 40 & $\mathrm{H}$ \\
\hline & $\mathrm{X}$ & 3 & 6 & 40 & $E-3$ \\
\hline \multirow[t]{2}{*}{$\mathrm{X}$} & & 1 & 4 & 40 & $\mathrm{H}$ \\
\hline & $\mathrm{X}$ & 3 & 5 & 38 & $E-3$ \\
\hline \multirow[t]{2}{*}{$\mathrm{X}$} & & 1 & 6 & 40 & $\mathrm{H}$ \\
\hline & $\mathrm{X}$ & 3 & 1 & 42 & $E-3$ \\
\hline \multirow[t]{2}{*}{$\mathrm{x}$} & & 2 & 3 & 40 & $\mathrm{I}$ \\
\hline & $\mathrm{X}$ & 3 & 3 & 40 & $\mathrm{~J}$ \\
\hline \multirow[t]{2}{*}{$\mathrm{X}$} & & 2 & 4 & 40 & I \\
\hline & $\mathrm{X}$ & 3 & 4 & 40 & $\mathrm{~J}$ \\
\hline \multirow[t]{2}{*}{$\mathrm{x}$} & & 2 & 6 & 40 & I \\
\hline & $\mathrm{X}$ & 3 & 6 & 40 & $\mathrm{~J}$ \\
\hline \multirow[t]{2}{*}{$\mathrm{X}$} & & 3 & 7 & 40 & $F-3$ \\
\hline & $\mathrm{X}$ & 3 & 1 & 40 & G-3 \\
\hline \multirow[t]{2}{*}{$\mathrm{x}$} & & 3 & 6 & 38 & $F-3$ \\
\hline & $\mathrm{X}$ & 3 & 3 & 42 & $G-3$ \\
\hline \multirow[t]{2}{*}{$\mathrm{X}$} & & 3 & 2 & 42 & $F-3$ \\
\hline & $\mathrm{X}$ & 3 & 7 & 38 & $G-3$ \\
\hline
\end{tabular}

NEXT HALF REPEAT ABOVE

BUT IRS \& ARS CHANGE ASSIGNMENTS 
TIME PERIOD 非

\begin{tabular}{|c|c|c|c|c|c|}
\hline IRS & ARS & SURFACE & LANE & SPEED & TIRE \\
\hline \multirow[t]{2}{*}{$\mathrm{X}$} & & 3 & 2 & 20 & $A-3$ \\
\hline & $\mathrm{X}$ & 3 & 3 & 20 & $B-3$ \\
\hline \multirow{2}{*}{$\mathrm{X}$} & & 3 & 1 & 18 & $A-3$ \\
\hline & $\mathrm{X}$ & 3 & 2 & 18 & $B-3$ \\
\hline \multirow[t]{2}{*}{$\mathrm{X}$} & & 3 & 4 & 22 & $A-3$ \\
\hline & $X$ & 3 & 5 & 22 & $B-3$ \\
\hline \multirow[t]{2}{*}{$\mathrm{X}$} & & 3 & 3 & 18 & $C-3$ \\
\hline & $\mathrm{X}$ & 3 & 4 & 18 & $D-3$ \\
\hline \multirow[t]{2}{*}{$X$} & & 3 & 6 & 22 & $C-3$ \\
\hline & $\mathrm{X}$ & 3 & 7 & 22 & $D-3$ \\
\hline \multirow[t]{2}{*}{$\mathrm{X}$} & & 3 & 4 & 20 & $C-3$ \\
\hline & $\mathrm{X}$ & 3 & 5 & 20 & $D-3$ \\
\hline \multirow[t]{2}{*}{$X$} & & 1 & 4 & 40 & $\mathrm{H}$ \\
\hline & $X$ & 3 & 6 & 20 & $E-3$ \\
\hline \multirow[t]{2}{*}{$\mathrm{X}$} & & 1 & 5 & 40 & $\mathrm{H}$ \\
\hline & $\mathrm{X}$ & 3 & 5 & 18 & $E-3$ \\
\hline \multirow[t]{2}{*}{$\mathrm{X}$} & & 1 & 7 & 40 & $\mathrm{H}$ \\
\hline & $\mathrm{X}$ & 3 & 1 & 22 & $E-3$ \\
\hline \multirow[t]{2}{*}{$\mathrm{X}$} & & 2 & 4 & 40 & $I$ \\
\hline & $\mathrm{X}$ & 3 & 4 & 40 & $\mathrm{~J}$ \\
\hline \multirow[t]{2}{*}{$\mathrm{X}$} & & 2 & 5 & 40 & $I$ \\
\hline & $\mathrm{X}$ & 3 & 7 & 40 & $\mathrm{~J}$ \\
\hline \multirow[t]{2}{*}{$\mathrm{X}$} & & 2 & 7 & 40 & $I$ \\
\hline & $\mathrm{X}$ & 3 & 5 & 40 & $\mathrm{~J}$ \\
\hline \multirow[t]{2}{*}{$\mathrm{X}$} & & 3 & 7 & 20 & $F-3$ \\
\hline & $\mathrm{X}$ & 3 & 1 & 20 & $G-3$ \\
\hline \multirow[t]{2}{*}{$\mathrm{X}$} & & 3 & 6 & 18 & $F-3$ \\
\hline & $\mathrm{X}$ & 3 & 3 & 22 & $G-3$ \\
\hline \multirow[t]{2}{*}{$\mathrm{X}$} & & 3 & 2 & 22 & $\mathrm{~F}-3$ \\
\hline & $\mathrm{X}$ & 3 & 7 & 18 & $G-3$ \\
\hline
\end{tabular}

NEXT HALF REPEAT ABOVE

BUT IRS \& ARS CHANGE ASSIGNMENTS 
TIME PERIOD 非

\begin{tabular}{|c|c|c|c|c|c|}
\hline IRS & ARS & SURFACE & LANE & SPEED & TIRE \\
\hline \multirow[t]{2}{*}{$\mathrm{x}$} & & 3 & 2 & 60 & $A-3$ \\
\hline & $\mathrm{X}$ & 3 & 3 & 60 & $B-3$ \\
\hline \multirow[t]{2}{*}{$\mathrm{X}$} & & 3 & 1 & 58 & $A-3$ \\
\hline & $X$ & 3 & 2 & 58 & $B-3$ \\
\hline \multirow[t]{2}{*}{$\mathrm{X}$} & & 3 & 4 & 62 & $A-3$ \\
\hline & $\mathrm{X}$ & 3 & 5 & 62 & $B-3$ \\
\hline \multirow[t]{2}{*}{$\mathrm{X}$} & & 3 & 3 & 58 & $C-3$ \\
\hline & $\mathrm{X}$ & 3 & 4 & 58 & $D-3$ \\
\hline \multirow[t]{2}{*}{$\mathrm{X}$} & & 3 & 6 & 62 & $C-3$ \\
\hline & $X$ & 3 & 7 & 62 & $D-3$ \\
\hline \multirow[t]{2}{*}{$\mathrm{X}$} & & 3 & 4 & 60 & $C-3$ \\
\hline & $\mathrm{X}$ & 3 & 5 & 60 & $D-3$ \\
\hline \multirow[t]{2}{*}{$\mathrm{X}$} & & 1 & 5 & 40 & $\mathrm{H}$ \\
\hline & $X$ & 3 & 6 & 60 & $E-3$ \\
\hline \multirow[t]{2}{*}{$\mathrm{X}$} & & 1 & 6 & 40 & $\mathrm{H}$ \\
\hline & $\mathrm{X}$ & 3 & 5 & 58 & $E-3$ \\
\hline \multirow[t]{2}{*}{$\mathrm{X}$} & & ] & 1 & 40 & $\mathrm{H}$ \\
\hline & $X$ & 3 & 1 & 62 & $\mathrm{~F}-3$ \\
\hline \multirow[t]{2}{*}{$\mathrm{X}$} & & 2 & 5 & 40 & $I$ \\
\hline & $\mathrm{X}$ & 3 & 6 & 40 & $\mathrm{~J}$ \\
\hline \multirow[t]{2}{*}{$\mathrm{X}$} & & 2 & 6 & 40 & I \\
\hline & $X$ & 3 & 5 & 40 & $\mathrm{~J}$ \\
\hline \multirow[t]{2}{*}{$\mathrm{X}$} & & 2 & 1 & 40 & $I$ \\
\hline & $\mathrm{X}$ & 3 & 1 & 40 & $\mathrm{~J}$ \\
\hline \multirow[t]{2}{*}{$\mathrm{X}$} & & 3 & 7 & 60 & $F-3$ \\
\hline & $\mathrm{X}$ & 3 & 3 & 62 & $G-3$ \\
\hline \multirow[t]{2}{*}{$\mathrm{X}$} & & 3 & 6 & 58 & $F-3$ \\
\hline & $X$ & 3 & 1 & 60 & $G-3$ \\
\hline \multirow[t]{2}{*}{$\mathrm{X}$} & & 3 & 2 & 62 & $F-3$ \\
\hline & $X$ & 3 & 7 & 58 & $G-3$ \\
\hline
\end{tabular}

NEXT HALF REPEAT ABOVE

BUT IRS \& ARS CHANGE ASSIGNMENTS 
TIME PERIOD 非6

\begin{tabular}{|c|c|c|c|c|c|}
\hline IRS & ARS & SURFACE & LANE & SPEED & TIRE \\
\hline \multirow[t]{2}{*}{$\mathrm{X}$} & & 2 & 2 & 20 & $A-2$ \\
\hline & $\mathrm{X}$ & 2 & 3 & 20 & B-2 \\
\hline \multirow[t]{2}{*}{$\mathrm{X}$} & & 2 & 1 & 18 & $A-2$ \\
\hline & $\mathrm{X}$ & 2 & 2 & 18 & $B-2$ \\
\hline \multirow[t]{2}{*}{$\mathrm{X}$} & & 2 & 4 & 22 & $A-2$ \\
\hline & $\mathrm{X}$ & 2 & 5 & 22 & $B-2$ \\
\hline \multirow[t]{2}{*}{$\mathrm{X}$} & & 2 & 3 & 18 & $C-2$ \\
\hline & $\mathrm{X}$ & 2 & 4 & 18 & $\mathrm{D}-2$ \\
\hline \multirow[t]{2}{*}{$\mathrm{X}$} & & 2 & 6 & 22 & $C-2$ \\
\hline & $X$ & 2 & 7 & 22 & $D-2$ \\
\hline \multirow[t]{2}{*}{$\mathrm{X}$} & & 2 & 4 & 20 & $\mathrm{C}-2$ \\
\hline & $\mathrm{X}$ & 2 & 5 & 20 & $\mathrm{D}-2$ \\
\hline \multirow[t]{2}{*}{$\mathrm{X}$} & & 1 & 6 & 40 & $\mathrm{H}$ \\
\hline & $\mathrm{X}$ & 2 & 6 & 20 & $E-2$ \\
\hline \multirow[t]{2}{*}{$\mathrm{X}$} & & 1 & 7 & 40 & $\mathrm{H}$ \\
\hline & $\mathrm{X}$ & 2 & 1 & 22 & $E-2$ \\
\hline \multirow[t]{2}{*}{$\mathrm{X}$} & & 1 & 2 & 40 & $\mathrm{H}$ \\
\hline & $\mathrm{X}$ & 2 & 5 & 18 & $\mathrm{E}-2$ \\
\hline \multirow[t]{2}{*}{$\mathrm{X}$} & & 2 & 7 & 40 & $\mathrm{I}$ \\
\hline & $\mathrm{X}$ & 3 & 6 & 40 & $\mathrm{~J}$ \\
\hline \multirow[t]{2}{*}{$\mathrm{X}$} & & 2 & 6 & 40 & I \\
\hline & $\mathrm{X}$ & 3 & 7 & 40 & $\mathrm{~J}$ \\
\hline \multirow[t]{2}{*}{$\mathrm{X}$} & & 2 & 2 & 40 & I \\
\hline & $\mathrm{X}$ & 3 & 2 & 40 & $\mathrm{~J}$ \\
\hline \multirow[t]{2}{*}{$\mathrm{X}$} & & 2 & 7 & 20 & $\mathrm{~F}-2$ \\
\hline & $\mathrm{X}$ & 2 & 1 & 20 & G-2 \\
\hline \multirow[t]{2}{*}{$\mathrm{X}$} & & 2 & 6 & 18 & $F-2$ \\
\hline & $\mathrm{X}$ & 2 & 3 & 22 & $G-2$ \\
\hline \multirow[t]{2}{*}{$\mathrm{X}$} & & 2 & 2 & 22 & $\mathrm{~F}-2$ \\
\hline & $\mathrm{X}$ & 2 & 7 & 18 & $G-2$ \\
\hline
\end{tabular}

NEXT HALF REPEAT ABOVE

BUT IRS \& ARS CHANGE ASSIGNMENTS 


\begin{tabular}{|c|c|c|c|c|c|}
\hline IRS & ARS & SURFACE & LANE & SPEED & TIRE \\
\hline \multirow[t]{2}{*}{$\mathrm{X}$} & & 2 & 2 & 60 & $A-2$ \\
\hline & $\mathrm{X}$ & 2 & 3 & 60 & B-2 \\
\hline \multirow[t]{2}{*}{$\mathrm{X}$} & & 2 & 1 & 58 & $A-2$ \\
\hline & $\mathrm{X}$ & 2 & 2 & 58 & B-2 \\
\hline \multirow[t]{2}{*}{$\mathrm{X}$} & & 2 & 4 & 62 & $A-2$ \\
\hline & $\mathrm{X}$ & 2 & 5 & 62 & $B-2$ \\
\hline \multirow[t]{2}{*}{$\mathrm{X}$} & & 2 & 3 & 58 & $C-2$ \\
\hline & $\mathrm{X}$ & 2 & 4 & 58 & $D-2$ \\
\hline \multirow[t]{2}{*}{$\mathrm{X}$} & & 2 & 6 & 62 & $C-2$ \\
\hline & $\mathrm{X}$ & 2 & 7 & 62 & $D-2$ \\
\hline \multirow[t]{2}{*}{$\mathrm{X}$} & & 2 & 4 & 60 & $C-2$ \\
\hline & $\mathrm{X}$ & 2 & 5 & 60 & $D-2$ \\
\hline \multirow[t]{2}{*}{$\mathrm{X}$} & & 1 & 7 & 40 & $\mathrm{H}$ \\
\hline & $X$ & 2 & 6 & 60 & $\mathrm{E}-2$ \\
\hline \multirow[t]{2}{*}{$\mathrm{X}$} & & 1 & 1 & 40 & $\mathrm{H}$ \\
\hline & $\mathrm{X}$ & 2 & 5 & 58 & $\mathrm{E}-2$ \\
\hline \multirow[t]{2}{*}{$\mathrm{X}$} & & 1 & 3 & 40 & $\mathrm{H}$ \\
\hline & $\mathrm{X}$ & 2 & 1 & 62 & $\mathrm{E}-2$ \\
\hline \multirow[t]{2}{*}{$\mathrm{X}$} & & 2 & 7 & 40 & I \\
\hline & $\mathrm{X}$ & 3 & 7 & 40 & $\mathrm{~J}$ \\
\hline \multirow[t]{2}{*}{$\mathrm{X}$} & & 2 & 3 & 40 & $I$ \\
\hline & $\mathrm{X}$ & 3 & 1 & 40 & $\mathrm{~J}$ \\
\hline \multirow[t]{2}{*}{$\mathrm{X}$} & & 2 & 1 & 40 & $I$ \\
\hline & $\mathrm{X}$ & 3 & 3 & 40 & $\mathrm{~J}$ \\
\hline \multirow[t]{2}{*}{$\mathrm{X}$} & & 2 & 7 & 60 & $F-2$ \\
\hline & $\mathrm{X}$ & 2 & 1 & 60 & $G-2$ \\
\hline \multirow[t]{2}{*}{$\mathrm{X}$} & & 2 & 6 & 58 & $F-2$ \\
\hline & $\mathrm{X}$ & 2 & 3 & 62 & G-2 \\
\hline \multirow[t]{2}{*}{$\mathrm{X}$} & & 2 & 2 & 62 & $F-2$ \\
\hline & $\mathrm{X}$ & 2 & 7 & 58 & $G-2$ \\
\hline
\end{tabular}

NEXT HALF REPEAT ABOVE

BUT IRS \& ARS CHANGE ASSIGNMENTS 
PAD I TIRE H

\section{T IME}

\begin{tabular}{llllllll} 
SPEED & 1 & 2 & 3 & 4 & 5 & 6 & 7 \\
\hline 40 & 1 & 2 & 3 & 4 & 5 & 6 & 7 \\
40 & 2 & 3 & 4 & 5 & 6 & 7 & 1 \\
40 & 4 & 5 & 6 & 7 & 1 & 2 & 3
\end{tabular}

PAD 2 TIRE I

\begin{tabular}{llllllll} 
& TIME & & & & & & \\
SPEED & 1 & 2 & 3 & 4 & 5 & 6 & 7 \\
\hline & & 2 & 3 & 4 & 5 & 6 & 7 \\
40 & 1 & 3 & 4 & 5 & 6 & 7 & 1 \\
40 & 2 & 5 & 6 & 7 & 1 & 2 & 3
\end{tabular}

PAD 3 TIRE J

T IME

\begin{tabular}{llllllll} 
SPEED & 1 & 2 & 3 & 4 & 5 & 6 & 7 \\
\hline 40 & 1 & 2 & 3 & 4 & 5 & 6 & 7 \\
40 & 2 & 3 & 4 & 5 & 6 & 7 & 1 \\
40 & 4 & 5 & 6 & 7 & 1 & 2 & 3
\end{tabular}


PAD $1 \quad 40 \mathrm{MPH}$ TIME PERIOD \#1

\begin{tabular}{cccccccc} 
& TIRE & & & & & & \\
SPEED & A-1 & B-1 & C-1 & D-1 & E-1 & F-1 & G-1 \\
\hline 38 & 1 & 2 & 3 & 4 & 5 & 6 & 7 \\
40 & 2 & 3 & 4 & 5 & 6 & 7 & 1 \\
42 & 4 & 5 & 6 & 7 & 1 & 2 & 3
\end{tabular}

PAD $220 \mathrm{MPH}$ TIME PERIOD 非6

\begin{tabular}{|c|c|c|c|c|c|c|c|}
\hline \multicolumn{8}{|c|}{ TIRE } \\
\hline SPEED & $A-2$ & $B-2$ & $\mathrm{C}-2$ & $\mathrm{D}-2$ & $E-2$ & $F-2$ & G-2 \\
\hline 18 & 1 & 2 & 3 & 4 & 5 & 6 & 7 \\
\hline 20 & 2 & 3 & 4 & 5 & 6 & 7 & 1 \\
\hline 22 & 4 & 5 & 6 & 7 & 1 & & \\
\hline
\end{tabular}

PAD $240 \mathrm{MPH}$ TIME PERIOD \#2

\begin{tabular}{cccccccc} 
& TIRE & & & & & & \\
SPEED & A-2 & B-2 & C-2 & D-2 & E-2 & F-2 & G-2 \\
\hline 38 & 1 & 2 & 3 & 4 & 5 & 6 & 7 \\
40 & 2 & 3 & 4 & 5 & 6 & 7 & 1 \\
42 & 4 & 5 & 6 & 7 & 1 & 2 & 3
\end{tabular}

PAD $260 \mathrm{MPH}$ TIME PERIOD \# 7

\begin{tabular}{cccccccc} 
& TIRE & & & & & & \\
SPEED & A-2 & B-2 & C-2 & D-2 & E-2 & F-2 & G-2 \\
\hline & & & & & & & \\
58 & 1 & 2 & 3 & 4 & 5 & 6 & 7 \\
60 & 2 & 3 & 4 & 5 & 6 & 7 & 1 \\
62 & 4 & 5 & 6 & 7 & 1 & 2 & 3
\end{tabular}


PAD $320 \mathrm{MPH}$ TIME PERIOD 非

TIRF,

\begin{tabular}{|c|c|c|c|c|c|c|c|}
\hline SPEEL & $A-1$ & $11-1$ & $\therefore-1$ & $11-1$ & $t-1$ & r & U 1 \\
\hline 18 & 1 & 2 & 3 & 4 & 5 & 6 & 7 \\
\hline 20 & 2 & 3 & 4 & 5 & 6 & 7 & 1 \\
\hline 22 & 4 & 5 & 6 & 7 & 1 & 2 & 3 \\
\hline
\end{tabular}

PAD $340 \mathrm{MPH}$ TIME PERIOD 非 3

TIRE

\begin{tabular}{llllllll} 
SPEED & A-3 & B-3 & C-3 & D-3 & E-3 & F-3 & G-3 \\
\hline 38 & 1 & 2 & 3 & 4 & 5 & 6 & 7 \\
40 & 2 & 3 & 4 & 5 & 6 & 7 & 1 \\
42 & 4 & 5 & 6 & 7 & 1 & 2 & 3
\end{tabular}

PAD $360 \mathrm{MPH}$ TIME PERIOD 非 5

\section{TIRE}

\begin{tabular}{llllllll} 
SPEED & A-3 & B-3 & C-3 & D-3 & E-3 & F-3 & G-3 \\
\hline 58 & 1 & 2 & 3 & 4 & 5 & 6 & 7 \\
60 & 2 & 3 & 4 & 5 & 6 & 7 & 1 \\
62 & 4 & 5 & 6 & 7 & 1 & 2 & 3
\end{tabular}




\subsection{Tests Accomplished}

The test plan utilized seven time periods, with each time period containing two days. The plan required 14 extended working days of dynamic testing.

Except for a few periods of high wind speeds, during which dynamic testing was halted, the weather remained good. As shown in Table 6, both the WARS and NBS crews conducted 98 percent of the planned tests.

\subsection{Control of Test Variables}

Previous experiments with the IRS had shown that the operating variables listed in section 3.2 required control.

Variations in hitch height, as expected, change the unloading constant of the test wheel vertical load. Variations in hitch height which also rotate the two-axis force transducer used on the IRS cause a shift in the zero of the traction channel and change the unloading constant, as measured by the vertical load channel, from the expected value. The static tests had demonstrated (Fig. 21) that the WARS traction transducer output is rather insensitive to changes in hitch height. The static tests (sec. 2.3) had demonstrated that the hitch height depends on occupant and water weight.

Variations in inflation pressure of the WARS test tire change the transducer output signal as demonstrated in the subsystem tests (Table 5). Variations in inflation pressure of the IRS test tire shift the zero of the traction force instrumentation. Variations in inflation pressure of the test tires on both systems change the area of contact between the test tire and the surface. On dry pavements the variation in contact area changes the $2 \mathrm{mph}(3.2 \mathrm{~km} / \mathrm{h})$ skid resistance of smooth tires approximately one skid number per $2.5 \mathrm{psi}(17 \mathrm{kPa}$ ) in inflation pressure [9]. The $2 \mathrm{mph}(3.2 \mathrm{~km} / \mathrm{h})$ skid resistance is a measure of the first term of the skid resistance functional equation (sec. 3.9). Variations in the inflation pressure of the tow vehicle rear tires change the water laying system pump rate with test speed.

Each of ten tires were used for three tests during a test plan time period. Prior to the set of three tests, the test tire was conditioned with a five-mile drive. Immediately upon return to the test site, the inflation pressure of the test tire was readjusted to 24 psi (165 kPa). The hitch height was then readjusted to 10.5 in $(26.7 \mathrm{~cm})$ for the IRS and to 14.30 in $(36.5 \mathrm{~cm})$ for the WARS for the dimension from the surface to under the hitch flange at the same level location on the test site. The inflation pressure of the tow vehicle rear tires of both systems was readjusted to a nominal $45 \mathrm{psi}(310 \mathrm{kPa})$ four times per test day. The shock absorber pressure was checked at least once each day on the IRS. 
The shock absorber inflation pressure of the WARS was maintained at zero. Variations in shock absorber inflation pressure result in a shift in trailer body orientation which changes the static vertical test wheel load.

The surfaces were swept at the beginning of each test day. There is a considerable amount of rubber deposited on the surfaces as evidenced by the tire wear and "black residue" accumulated on the trailer fenders. There is also evidence that this sweeping was not sufficient to maintain a constant skid resistance value of the surface (sec. 3.10). Recommendations concerning surface cleanliness are made in another section of this report.

The degree-of-dryness of the surface was controlled above a minimum level. The test plan is designed for a 20 minute time interval between skid tests on a given surface. Also, the succeeding tests are not run on adjacent lanes but are spaced laterally in position and sequentially in time so sufficient time was available for surface drying before another test was conducted in a given lane. Figure 36 shows the delay in recovery from initial wetness with time for water [8]. Tests were delayed further, as required, until the test program director ruled a particular lane was dry.

The skid resistance of a surface is recognized to vary with test speed (sec. 3.9). A $1.0 \mathrm{mph}(1.6 \mathrm{~km} / \mathrm{h})$ difference in test speed on surface 3 at $20 \mathrm{mph}(32 \mathrm{~km} / \mathrm{h})$ changes the measurement result by approximately one percent. Test speed was recorded with a stationary differential radar system. The resolution of the system $1 . s 0.1 \mathrm{mph}(0.2 \mathrm{~km} / \mathrm{h})$.

\subsection{Test Tire Inflation Pressure T'ests}

Test tire inflation pressures were recorded throughout the testing day as described in section 3.5. The inflation pressures of two other test tires were also recorded. One was located in the shade and the other was located in the sun. The measurements are shown in Figures 37 , 38 , and 39 .

The largest variation occurs with ambient temperature. At the WFTC the mornings were $\operatorname{cool} 67^{\circ} \mathrm{F}\left(19^{\circ} \mathrm{C}\right)$ but the carcass temperature of the tire in the sun would reach $122^{\circ} \mathrm{F}\left(50^{\circ} \mathrm{C}\right)$ in the early afternoon. Pressure variations from $24 \mathrm{psi}(165 \mathrm{kPa}$ ) to $27.8 \mathrm{psi}$ (192 kPa) were recorded over this temperature range as shown in Figure 39. The test tires were stored in the sun during the day. After a tire was mounted on a trailer, the inflation pressure was adjusted to $24 \mathrm{psi}$ (165 $\mathrm{kPa}$ ) before starting the 5 mile $(8 \mathrm{~km})$ run. The range of variation measured upon the trailers return to the test site is shown in Figure 37 . The average inflation pressure was increased on the IRS by $1.7 \mathrm{psi}(12 \mathrm{kPa}$ ) and on the WARS by $1.4 \mathrm{psi}(10 \mathrm{kPa})$ during the warm-up run. The inflation pressure was readjusted to $24 \mathrm{psi}(165 \mathrm{kPa})$ before the skid test. The inflation pressure was then measured immediately after the skid test. The average inflation pressure was decreased on the IRS by $0.1 \mathrm{psi}(689 \mathrm{~Pa}$ ) and decreased on the WARS by 0.2 psi (1380 Pa) during a skid test. 


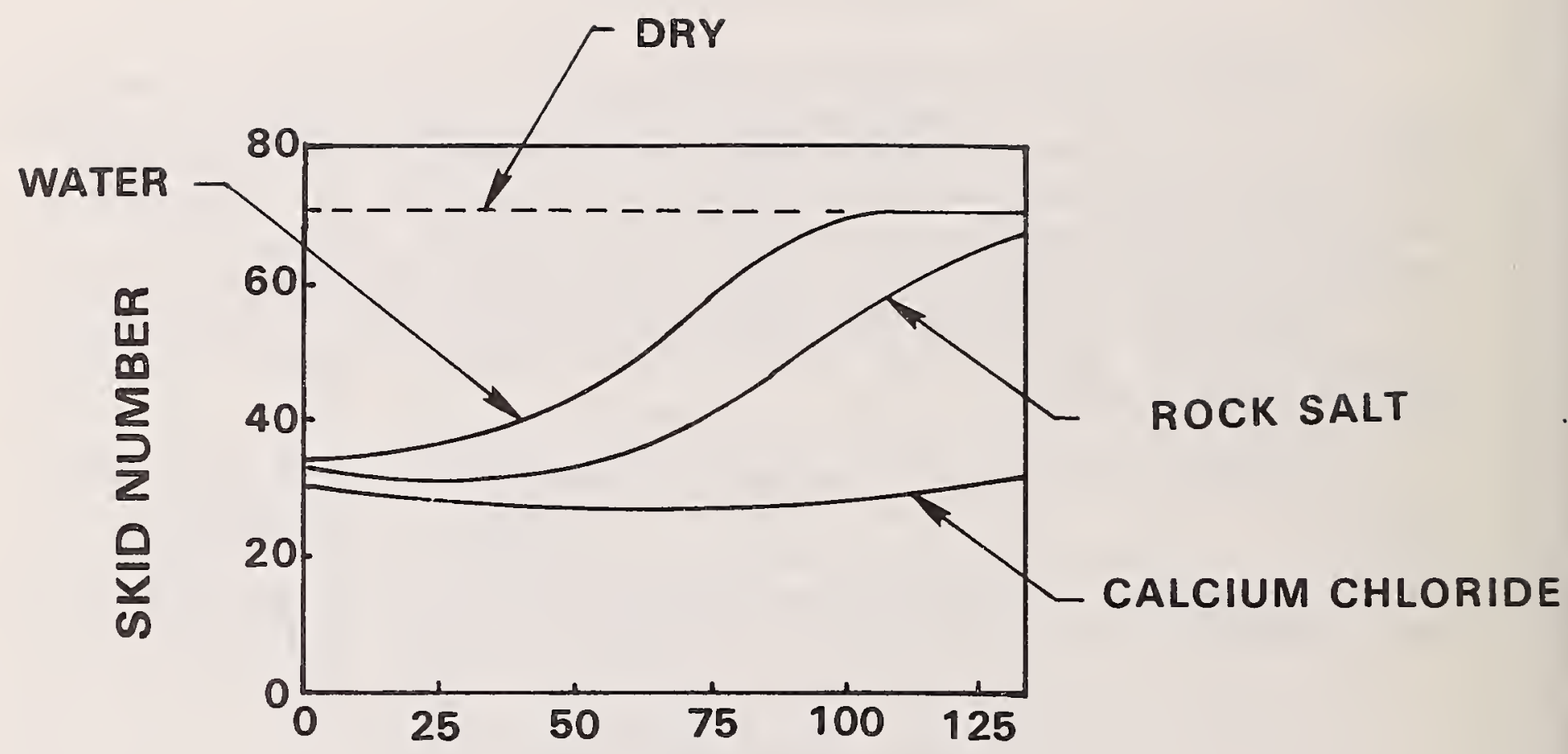

DRYING TIME, min.

Figure 36. Delay in the drying of a wet pavement when deicing agents are present (Reference 8 ). 


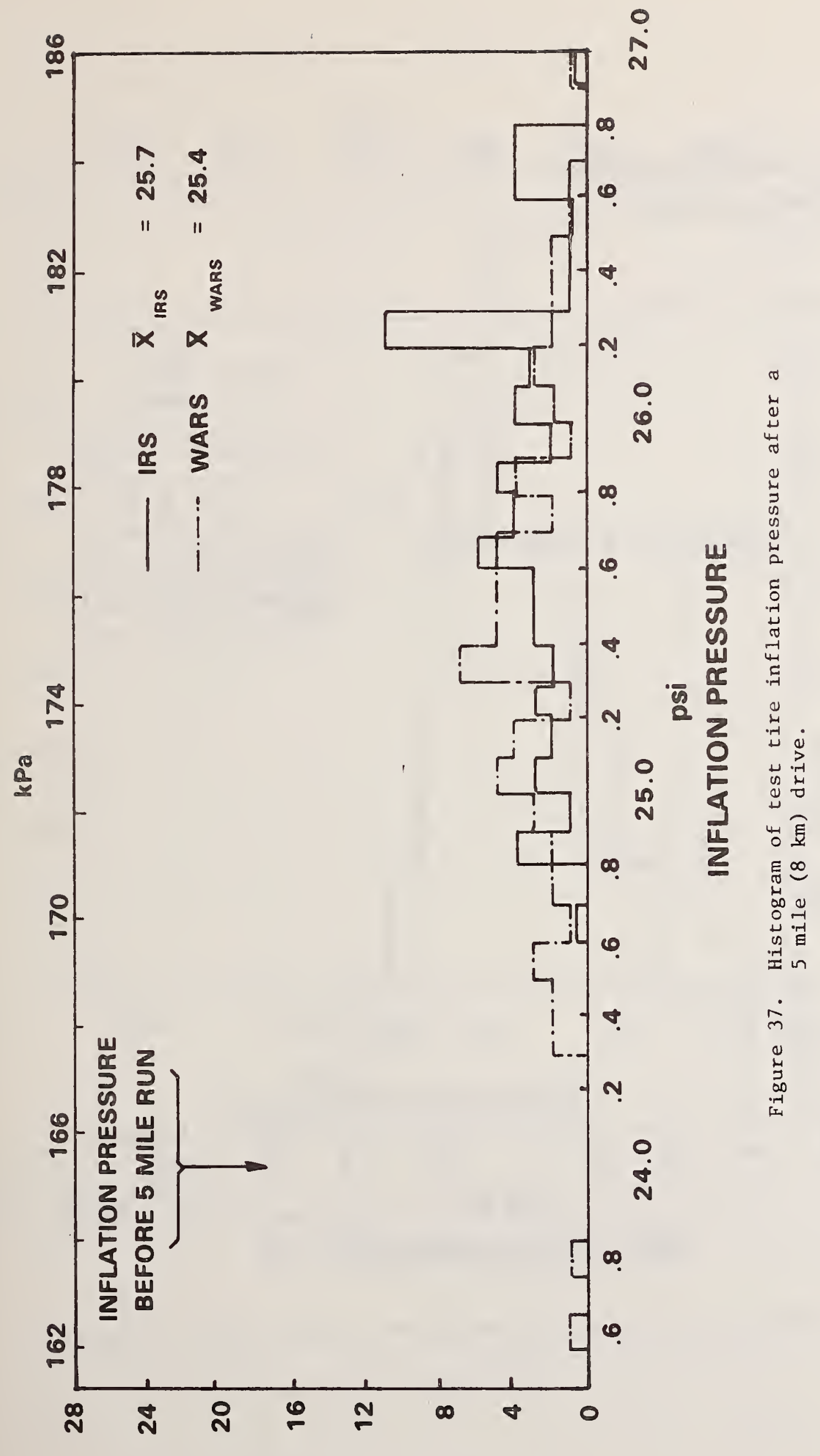

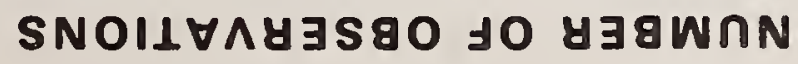




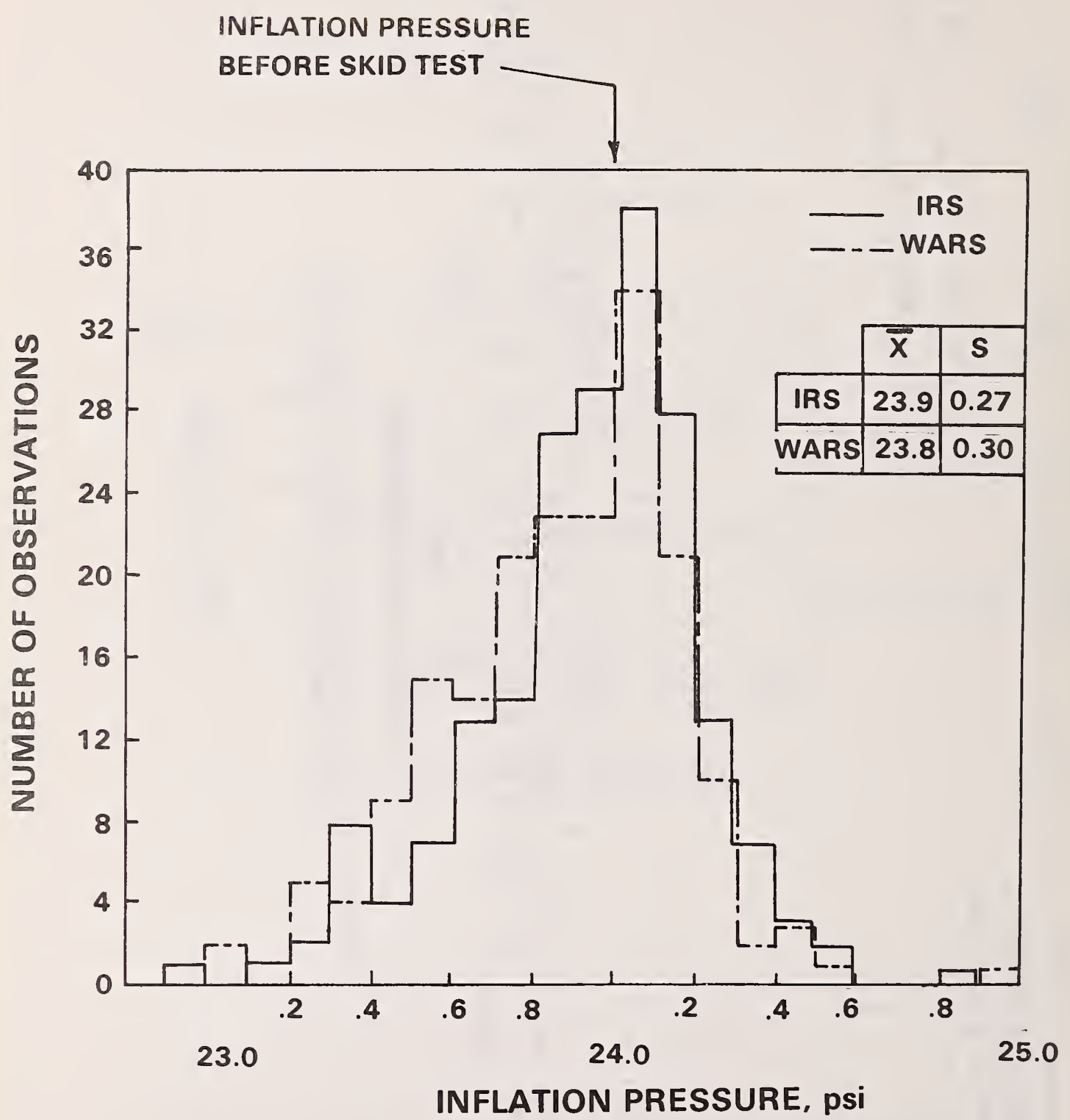

Figure 38. Histogram of test tire inflation pressure after skid test. 
Since variations in inflation pressure change the transducer outputs of both systems, and the weather conditions at the EFTC are quite different than those at the WFTC during the calibration period for state measuring systems, an estimate of the extreme differences which may occur when inflation pressure is not controlled follows.

Consider that the inflation pressure of the test tires to be used each day are set in the morning to $24 \mathrm{psi}(165 \mathrm{kPa}$ ) before leaving the garage. During the night and early morning the garage temperatures at the Eastern and Western FTC are maintained at $67^{\circ} \mathrm{F}\left(19^{\circ} \mathrm{C}\right)$. During the year, correlation tests are conducted in ambient temperatures of $60^{\circ} \mathrm{F}$ $\left(16^{\circ} \mathrm{C}\right)$ at the EFTC while others are conducted at $110^{\circ} \mathrm{F}\left(43^{\circ} \mathrm{C}\right)$ at the WFTC. Using Figure 39, the inflation pressure of a tire at the EFTC test surface is estimated to be $23.5 \mathrm{psi}(162 \mathrm{kPa})$ while a tire at the WFTC test surface is estimated to be $27 \mathrm{psi}(186 \mathrm{kPa})$. Because of the higher ambient temperature, the WFTC tire pressure may further increase by the larger values given in Figure 37 by the end of the five mile warm-up drive. The EFTC tire pressure may increase only by the smaller values. Under these assumptions, correlation tests at the WFTC may be conducted with test tires which are at $6 \mathrm{psi}(41 \mathrm{kPa})$ greater inflation pressure than those used at the EFTC.

The effect of this pressure difference would depend on the design of the measuring systems being correlated. One effect would be that the WARS transducer output at a traction force of $800 \mathrm{lbf}$ (3559N) would increase $0.8 \%$ (Table 6 ). Ideally, there should be no difference in the calibration result of a state measuring system conducted at either center. Recommendations concerning inflation pressure are made in another section of this report.

\subsection{Measurement of Uncontrolled Test Variables}

The weather conditions around the surfaces during the dynamic testing time period are given in Table 8.

The temperatures of the skid pad surfaces vary with environmental conditions. The surfaces used to provide a range of skid resistances vary in composition, coloration, roughness, etc. Their response to environmental changes depends on their characteristics of radiative, conductive, and aerodynamic heat transfer. In addition, pavement wetting may affect the surface temperature for some time following the pass of a skid tester.

The area of the skid surface is so large and the wheel tracks of the vehicles so varied that the temperature of the surfaces corresponding to the data reduction has to be measured indirectly. Surface thermometers were used to measure the temperatures of the dry skid pads, the base material on which the surfaces were inset, and the air in the shade at ground level. 

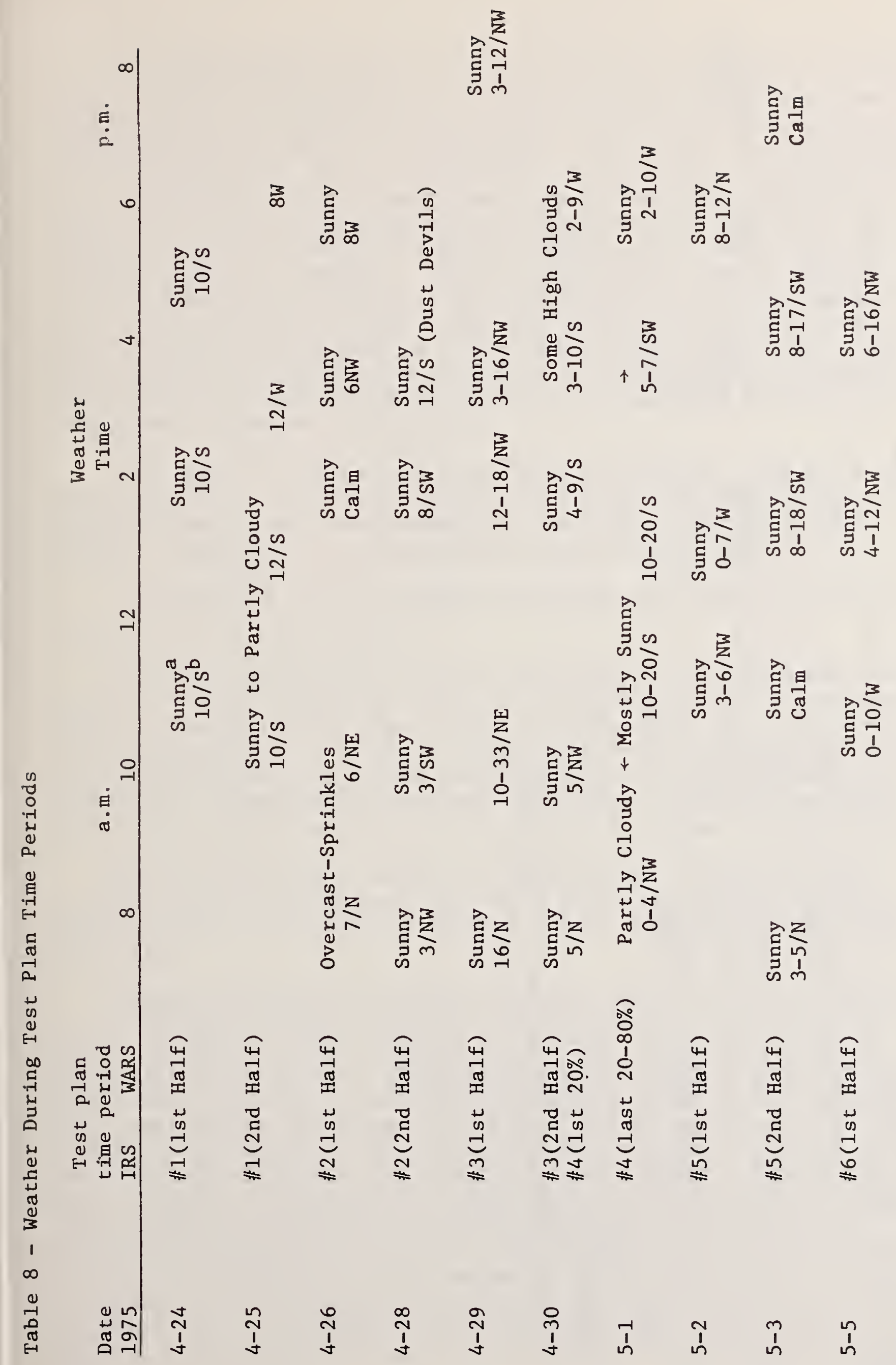


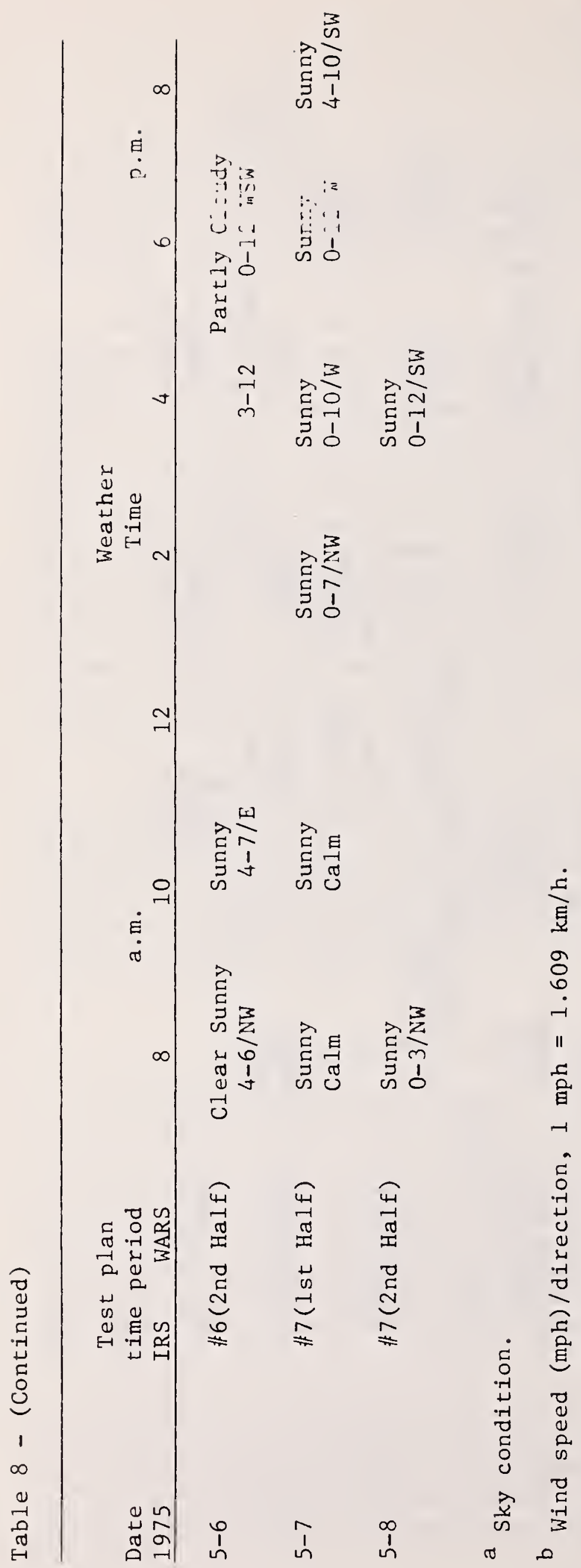


The temperature sensitive area of the sensor was placed in contact with the top of the aggregates. A conductive grease was used to provide thermal contact between the sensor and the sides of the protruding aggregates and the binder of the surface. The sensors were read throughout the testing period. The locations of the sensors are shown in Flgure 40. The surface temperatures measured are given versus time of day in Figure 41 . The surface temperatures ranged from $78^{\circ} \mathrm{F}\left(25^{\circ} \mathrm{C}\right)$ to $130^{\circ} \mathrm{F}$ $\left(54^{\circ} \mathrm{C}\right)$ during skid testing. Figures 41 and 42 show examples of the diurnal variations measured. The peak temperatures roughly correspond to solar heating, but note that the skid surfaces may appear warmer or cooler than the base pavement. When the temperature difference between a skid surface and the base is plotted versus time of day for 14 days data, the erratic tracking is evident (FIg. 43). Since the radiative and conductive properties of the pavements are unlikely to change, the aerodynamic component is suspected.

In Figure 44, temperature differences are grouped according to the wind direction at the time of each measurement. The line through the group averages shows correspondence to wind direction, the greatest positive temperature difference occurring with south winds.

In periods of calm, the three skid surfaces all tend to be hotter than the base pavement (Fig. 45).

If wind from the south travels the length of the skid surface and becomes warmer, its cooling effect will diminish, causing the temperature of the skid surface to increase from the south end to the north. The reverse gradient will result from north wind and, due to the location of the base thermometer during these tests, heated air from the skid surface will exaggerate the measured difference. Measured temperature differences between the ends of the surfaces are shown in Figure 46.

During these tests, north or northwest winds prevalled in the morning, often shifting toward the south by afternoon (Fig. 47). The wind direction thus tended to reinforce the sun angle in producing the daily peak.

Another uncontrolled variable monitored during the tests was tire wear. During each test an observer noted the test wheel lock-up position. The IRS crew would then measure and record the tread depth at each groove across the width of the tire at the lock-up position using the tire surface temperature as a further guide to position. Analysis of these data enable the amount of tire wear and the number of tests occurring at that tire location to be determined. The texture of surfaces 1, 2 , and 3 is shown in Figures 48, 49, and 50 respectively. A distinctive type of wear is associated with each surface. The surface of tire $H$, which skidded exclusively on surface 1 was "blistered" as shown in Figure 51. The surface of tire $I$, which skidded exclusively on surface 2, "carved" 0.1 inch $(0.2 \mathrm{~cm})$ diameter by 1 to 3 inch $(2$ to $7 \mathrm{~cm})$ long strands of rubber from the tire surface. The surface of tire $I$ is shown in Figure 52. The surface of tire $I$, which skidded exclusively on surface 3, was "grated" along the outer ribs and "lightly grated" on the inner ribs (Fig. 53). 


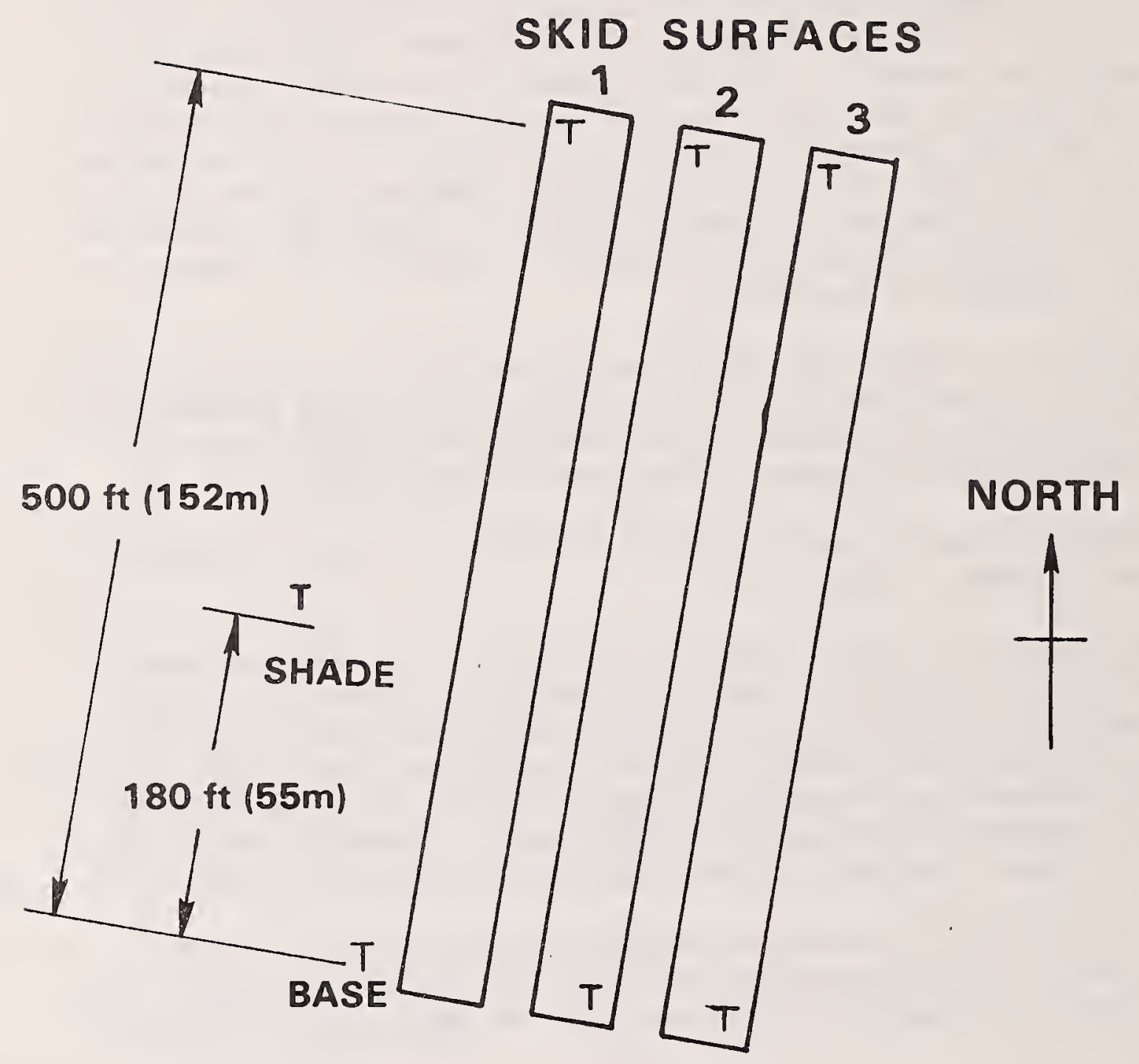

Figure 40. Thermometer locations. 


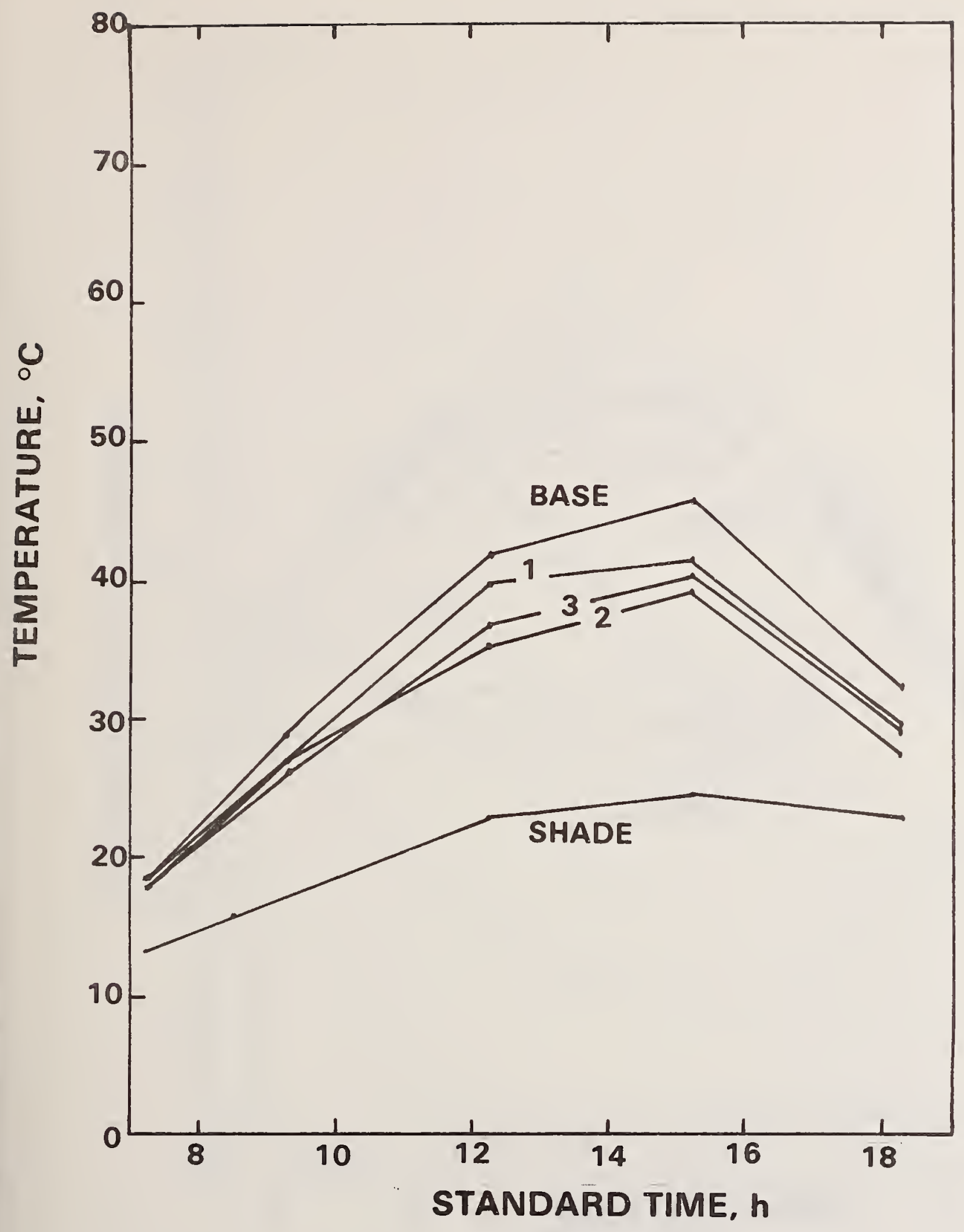

Figure 41. Temperature versus time of day, April 29, 1975. (Temperatures of surfaces $1,2,3$ measured at north end.) 


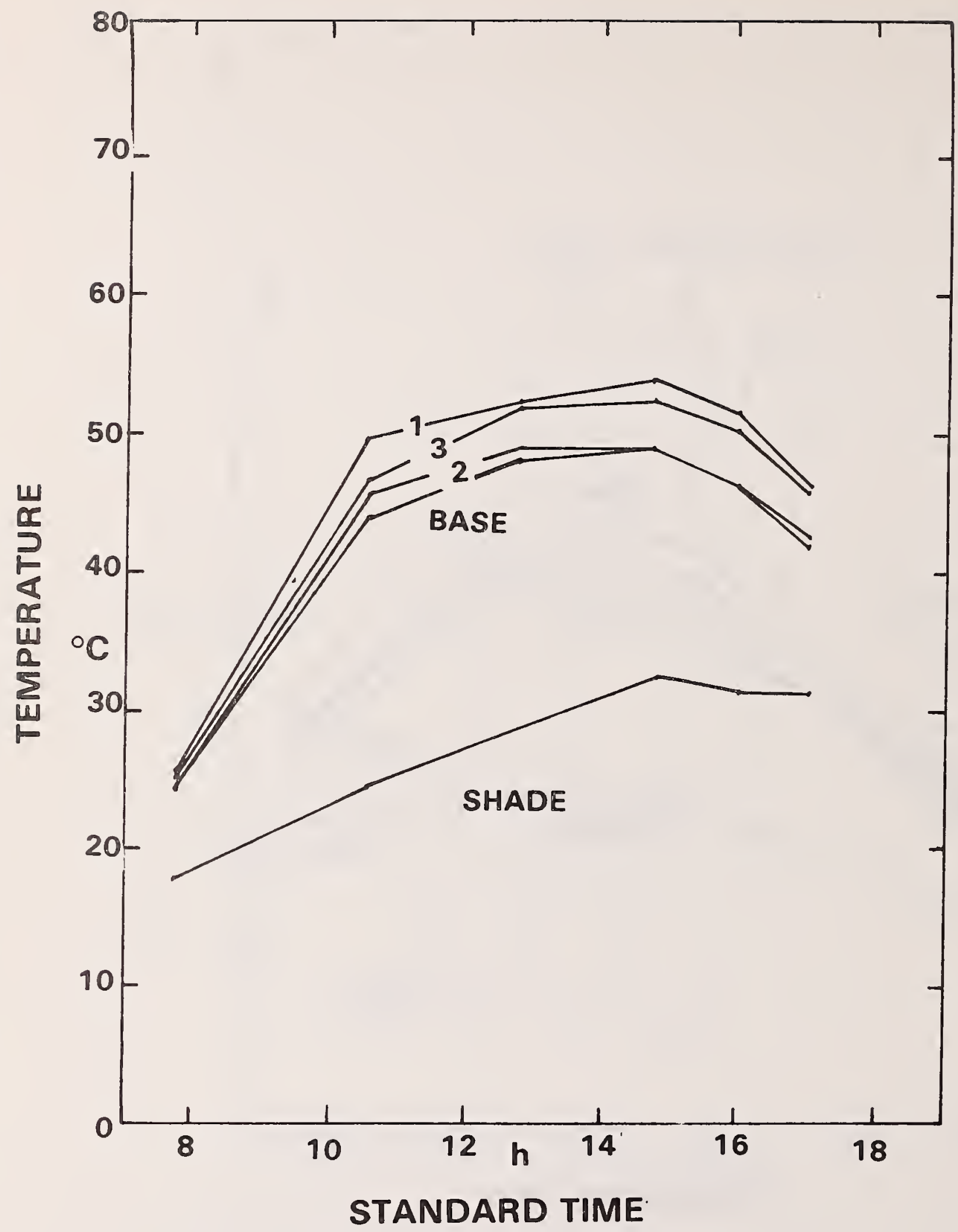

Figure 42. Temperature versus time of day, May 3, 1975. (Temperatures of surfaces $1,2,3$ measured at north end.) 


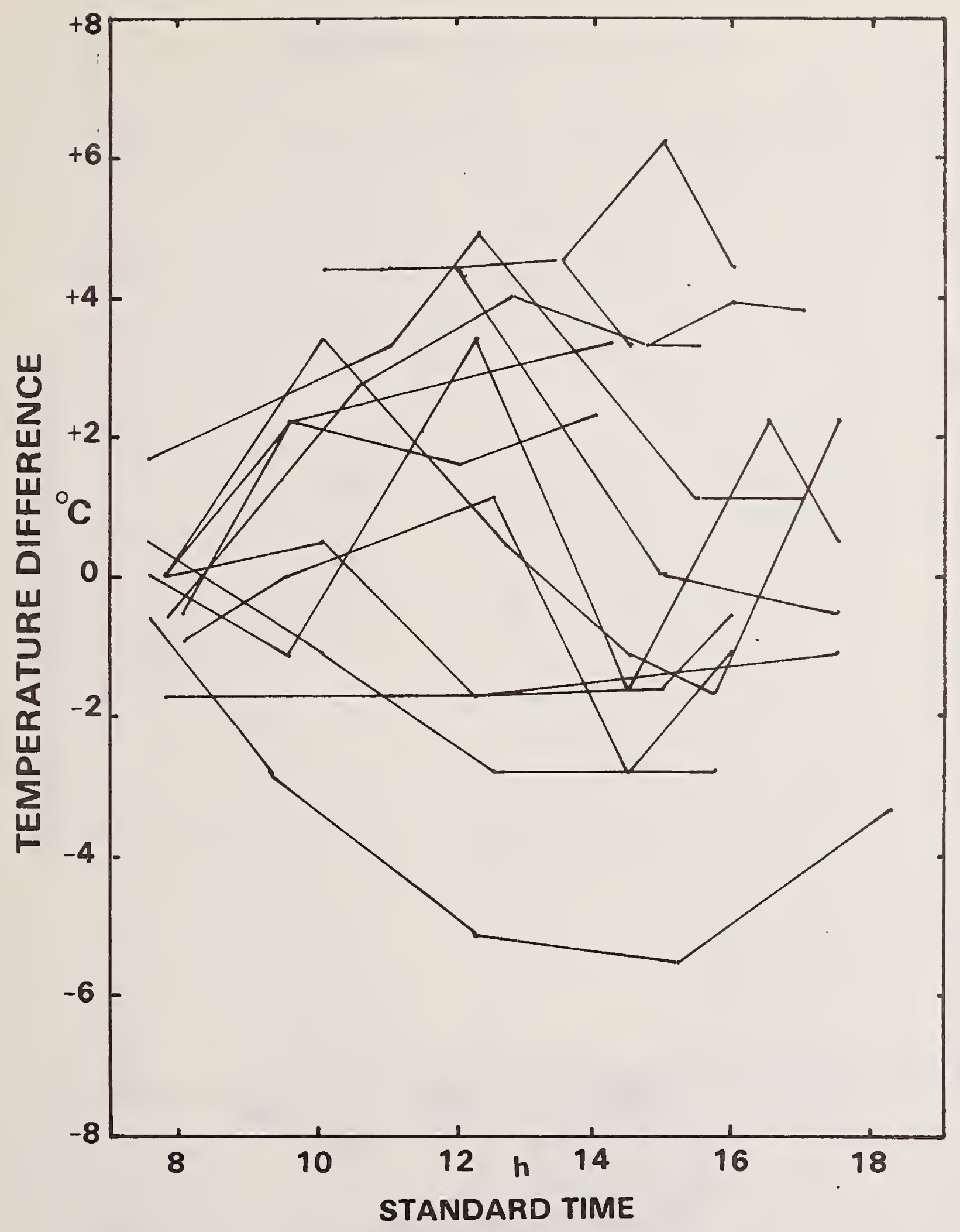

Figure 43. Surface 3 north end temperature minus base temperature versus time of day, Apri1 23 - May 8, 1975. 


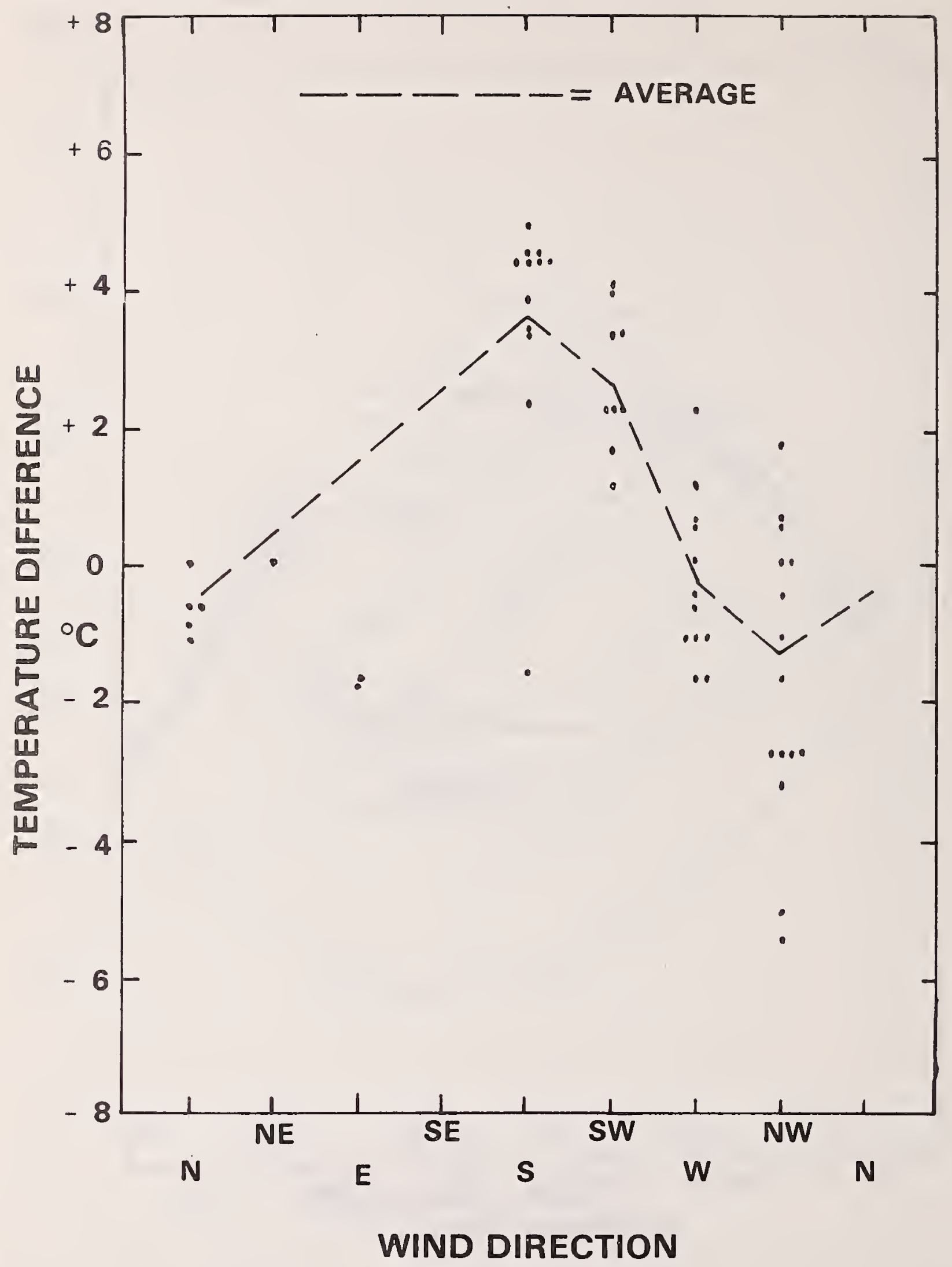

Figure 44. Surface 3 north end temperature minus base temperature versus wind direction, April 23 - May 8, 1975. 


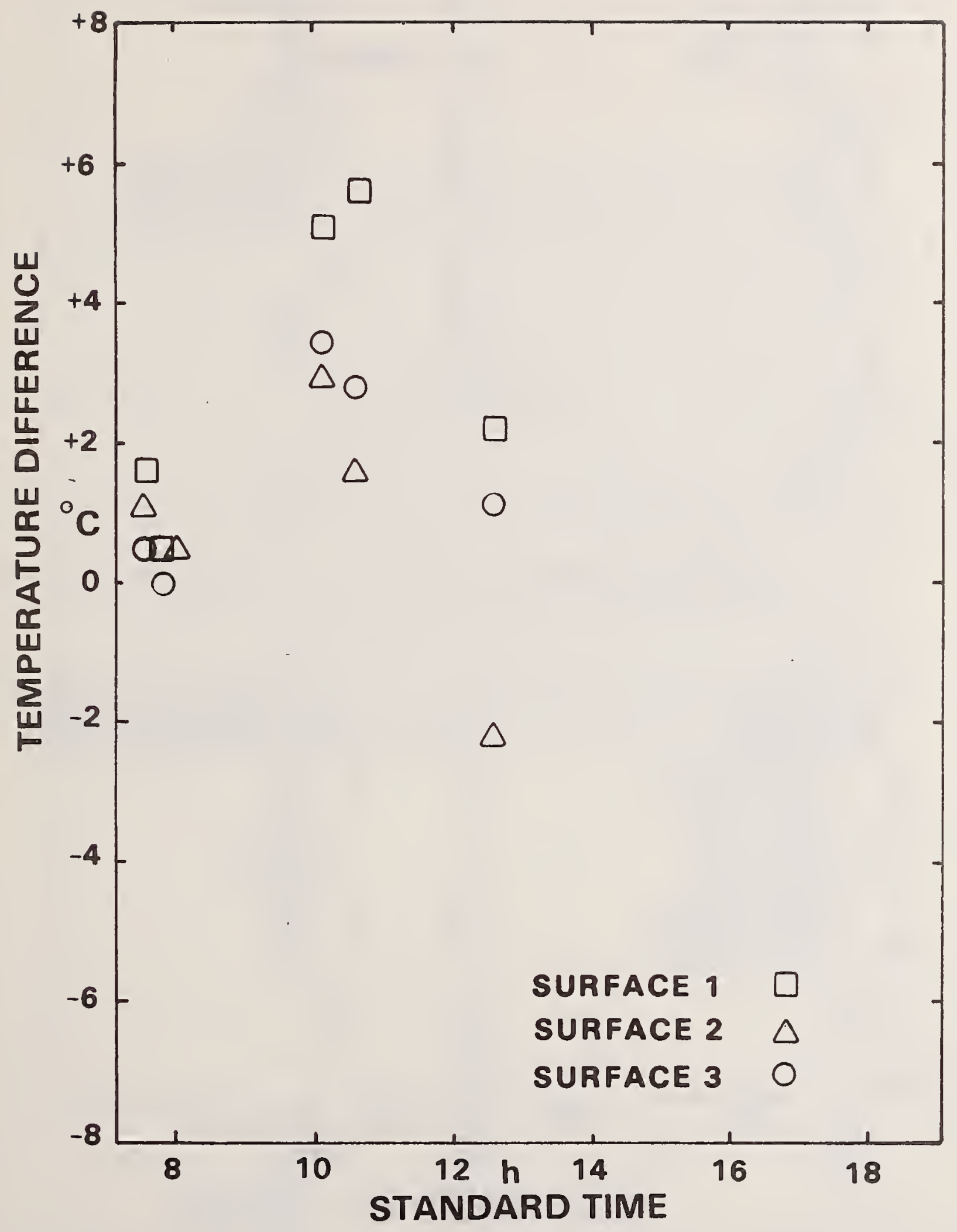

Figure 45. Surfaces $1,2,3$ north end temperature minus base temperature versus time of day, wind calm at time of measurement. Various days. 


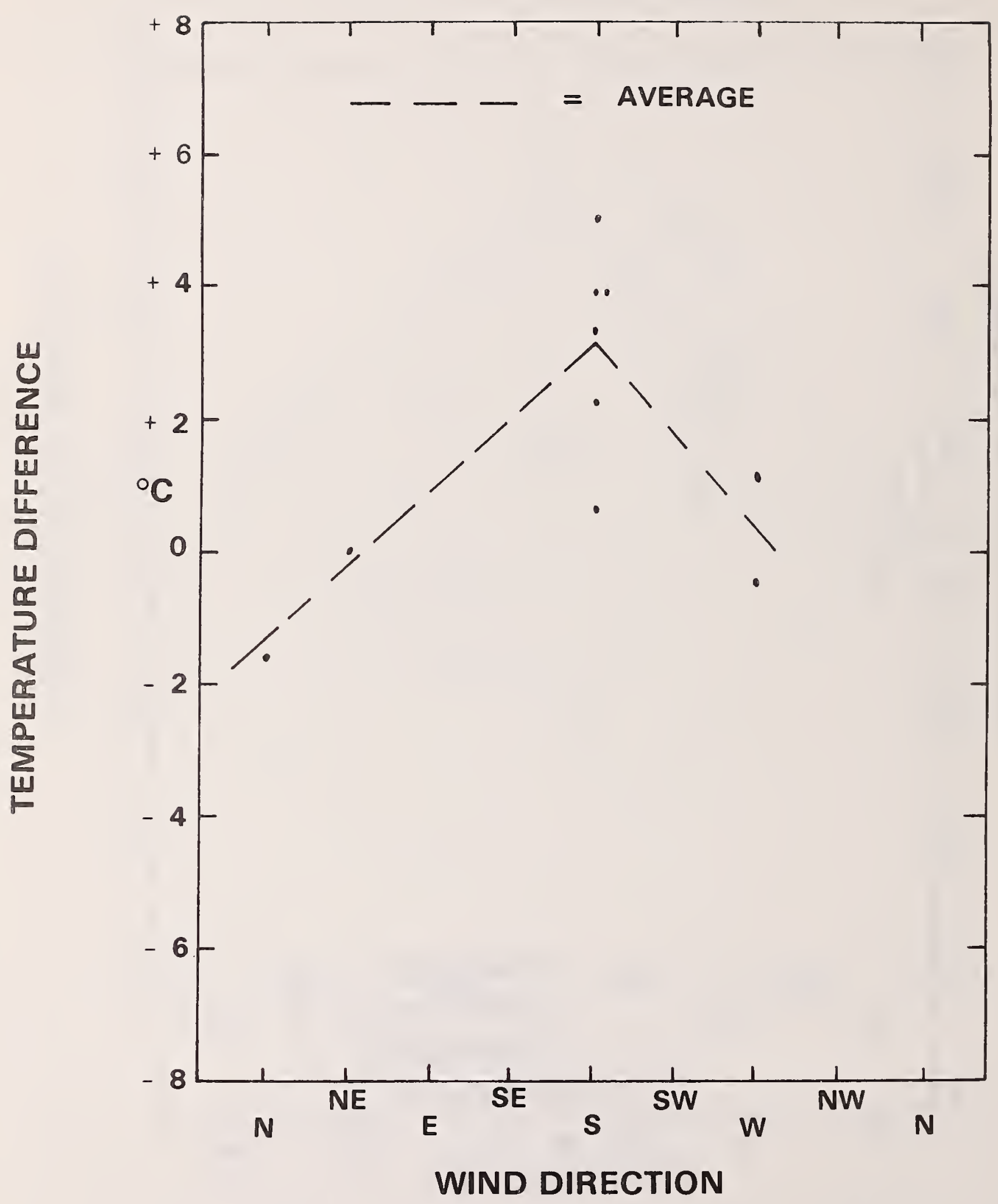

Figure 46. Surface 3 north end temperature minus surface 3 south end temperature versus wind direction, April 23 April 26, 1975. 


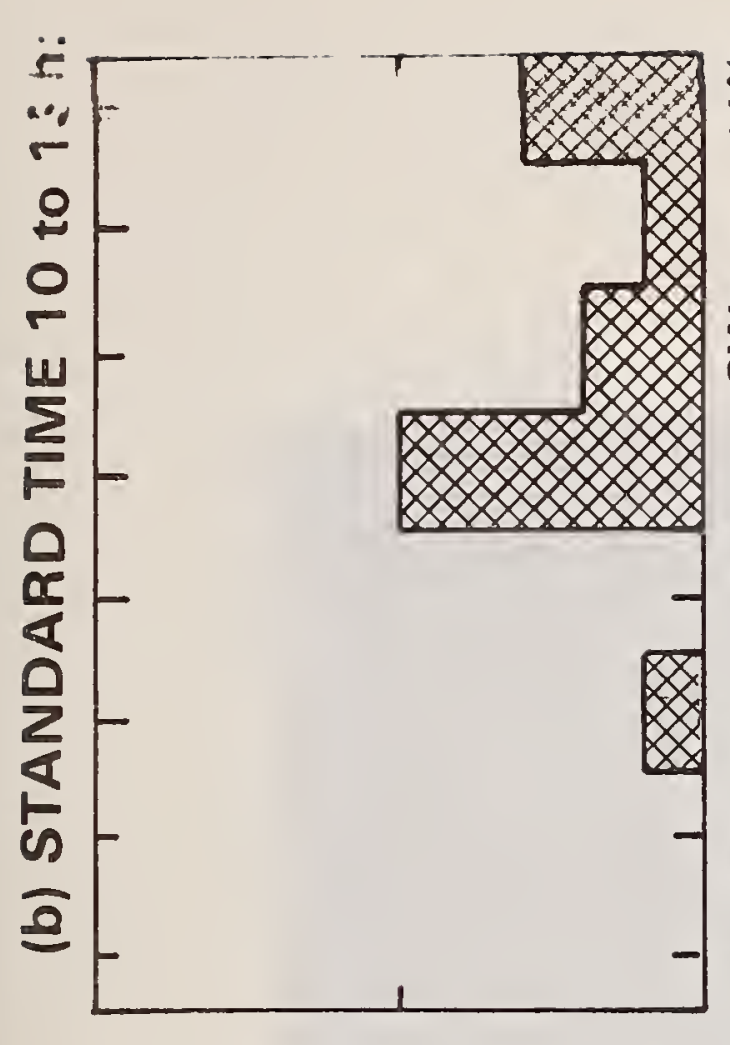

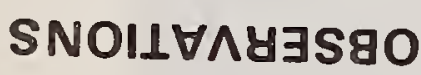

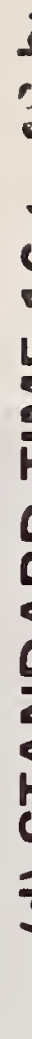

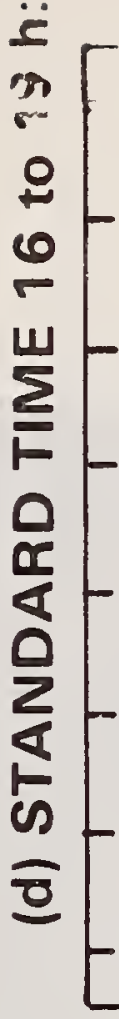

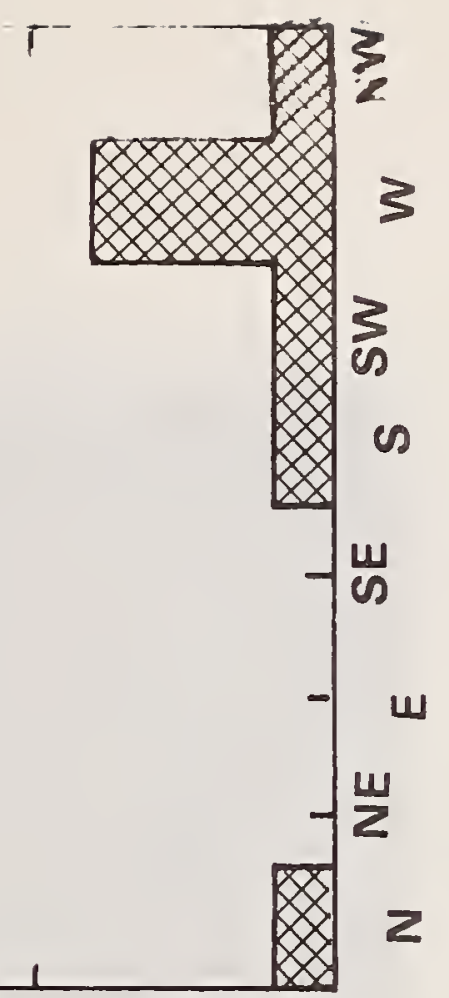

3

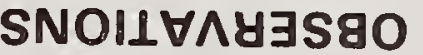

壱

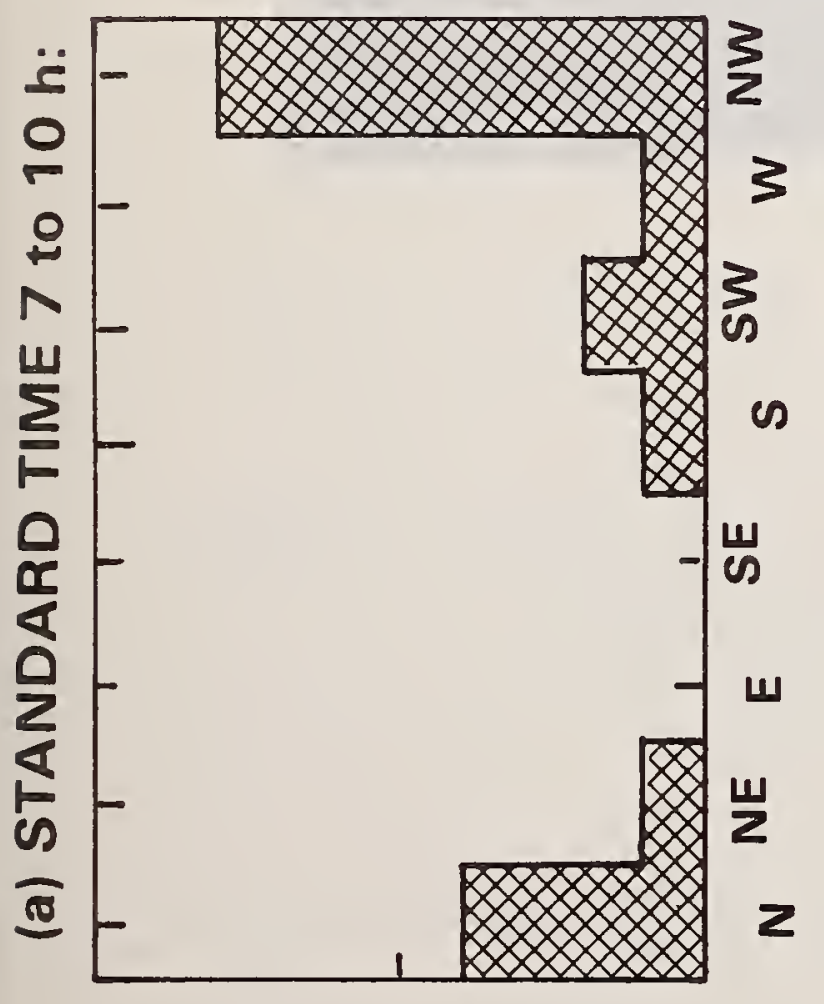

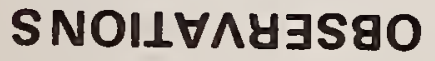

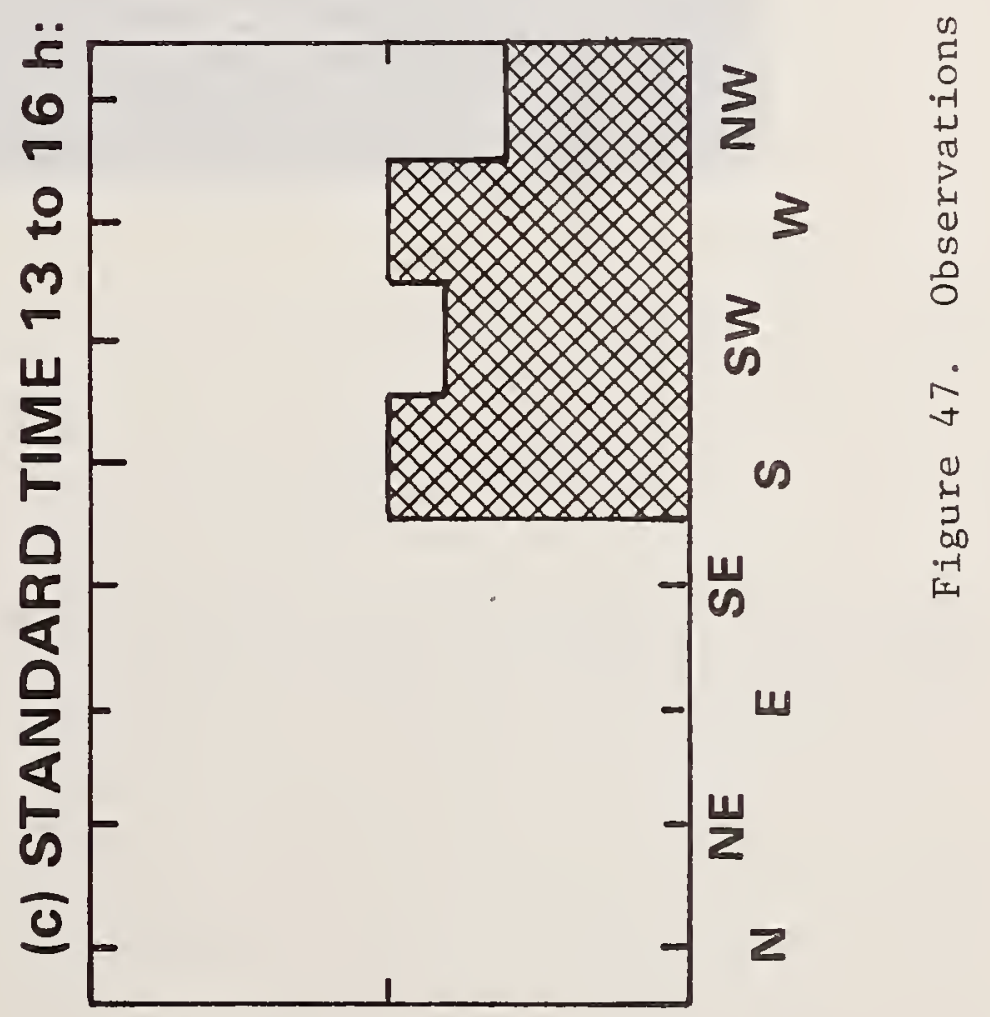




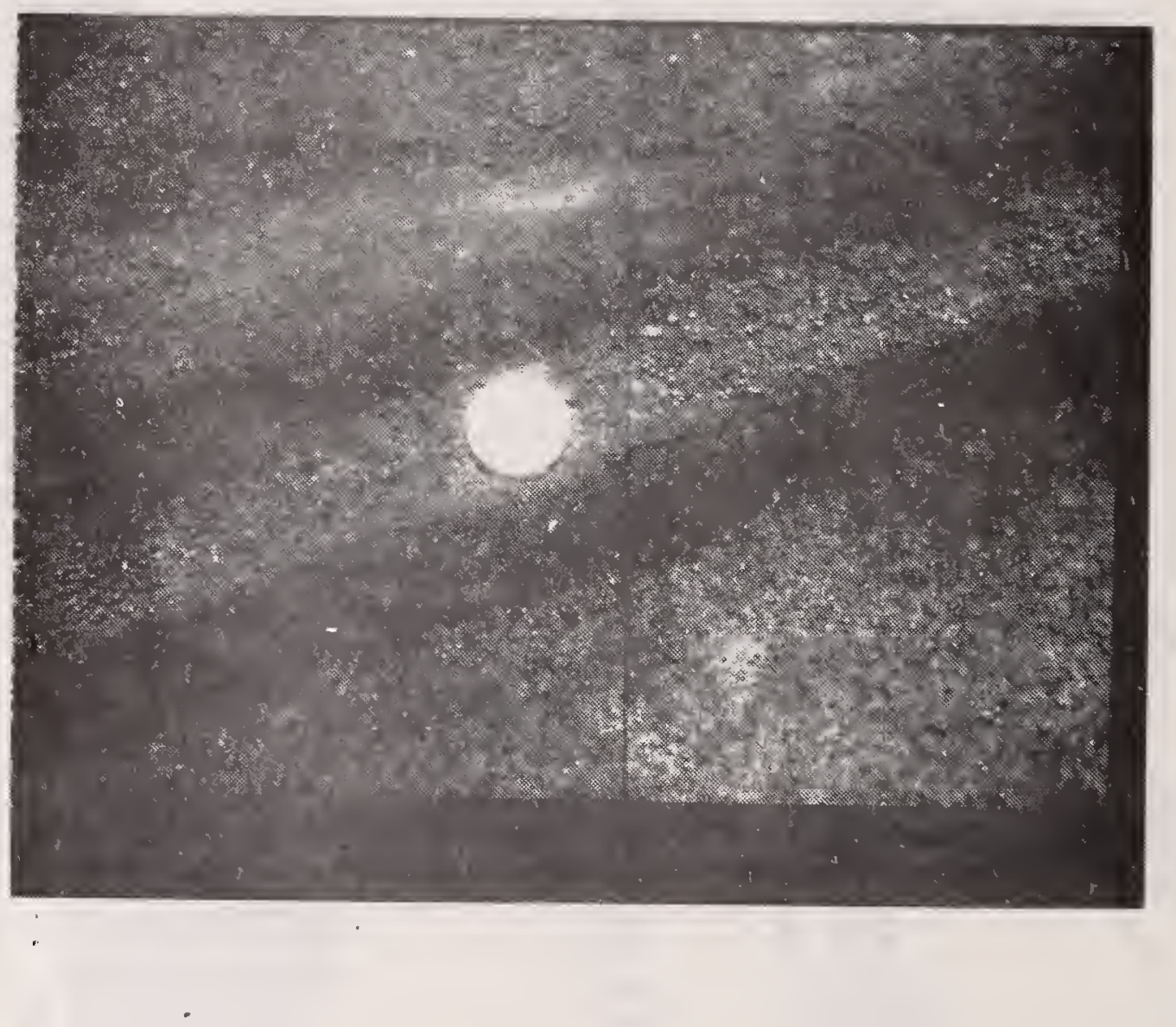

Figure 48. Texture of skid resistance surface number 1. 


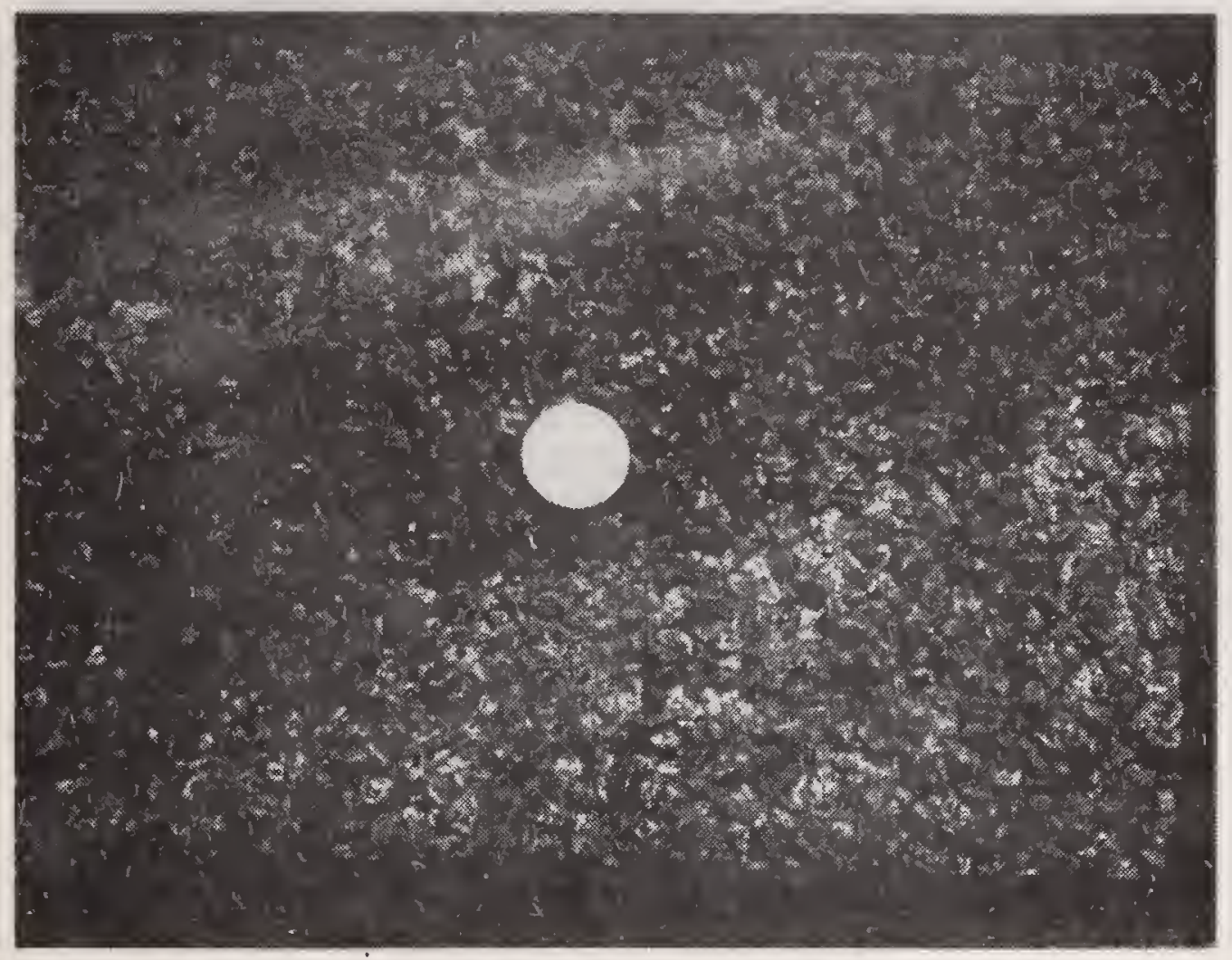

Figure 49. Texture of skid resistance surface number 2. 


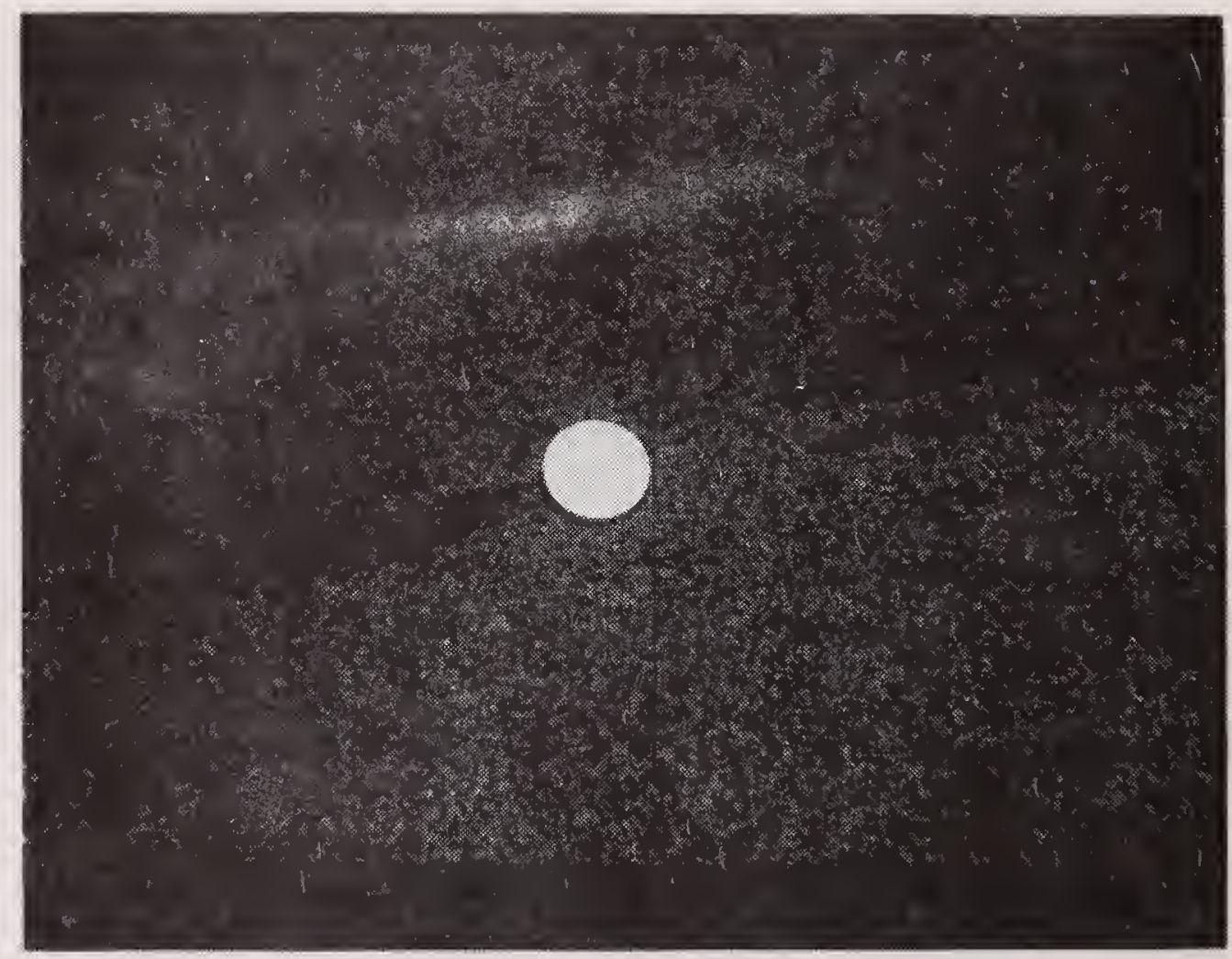

Figure 50. Texture of skid resistance surface number 3 . 


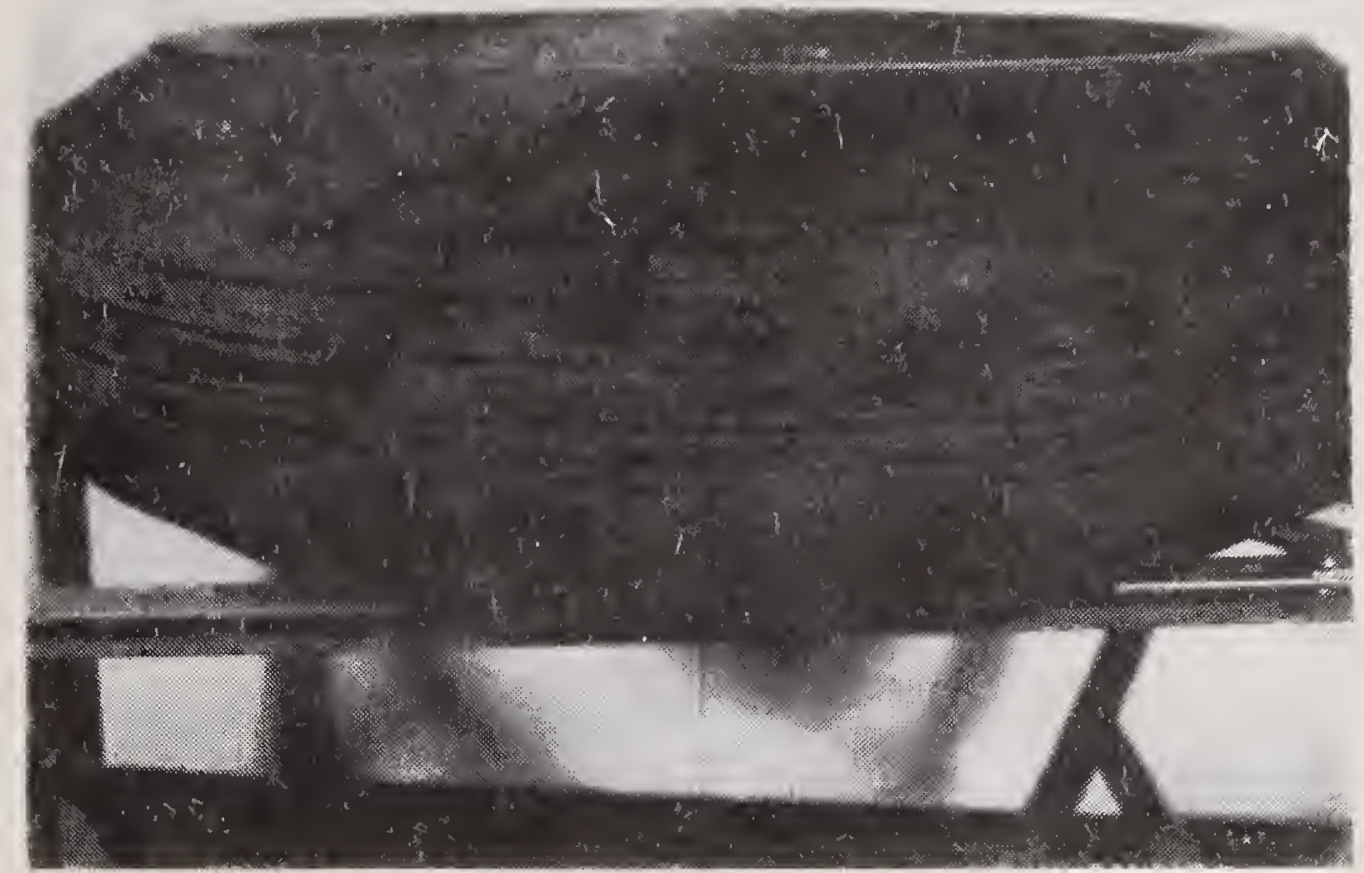

Figure 51. Texture of tire wear on surface number 1. 


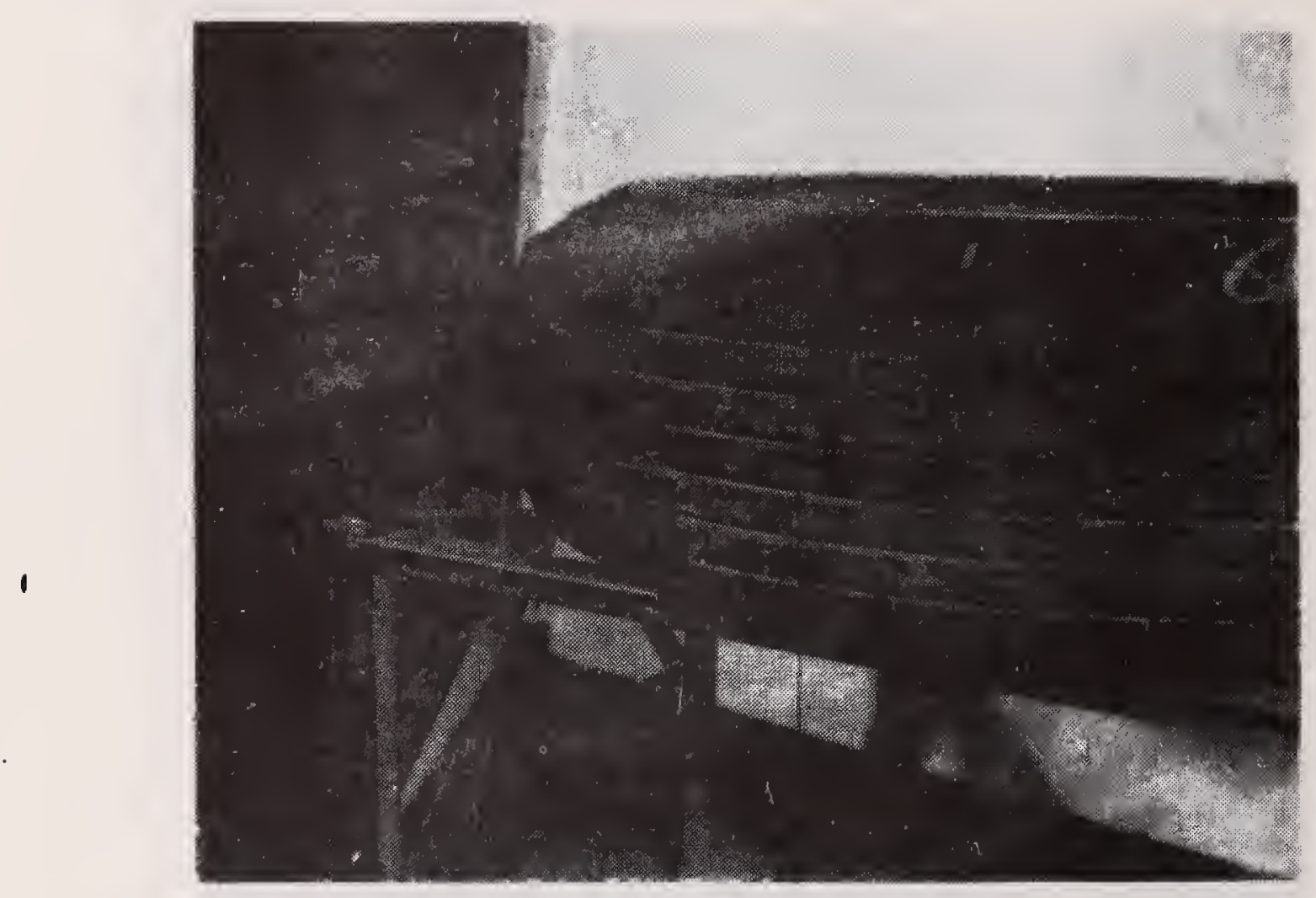

Figure 52. Texture of tire wear on surface number 2. 


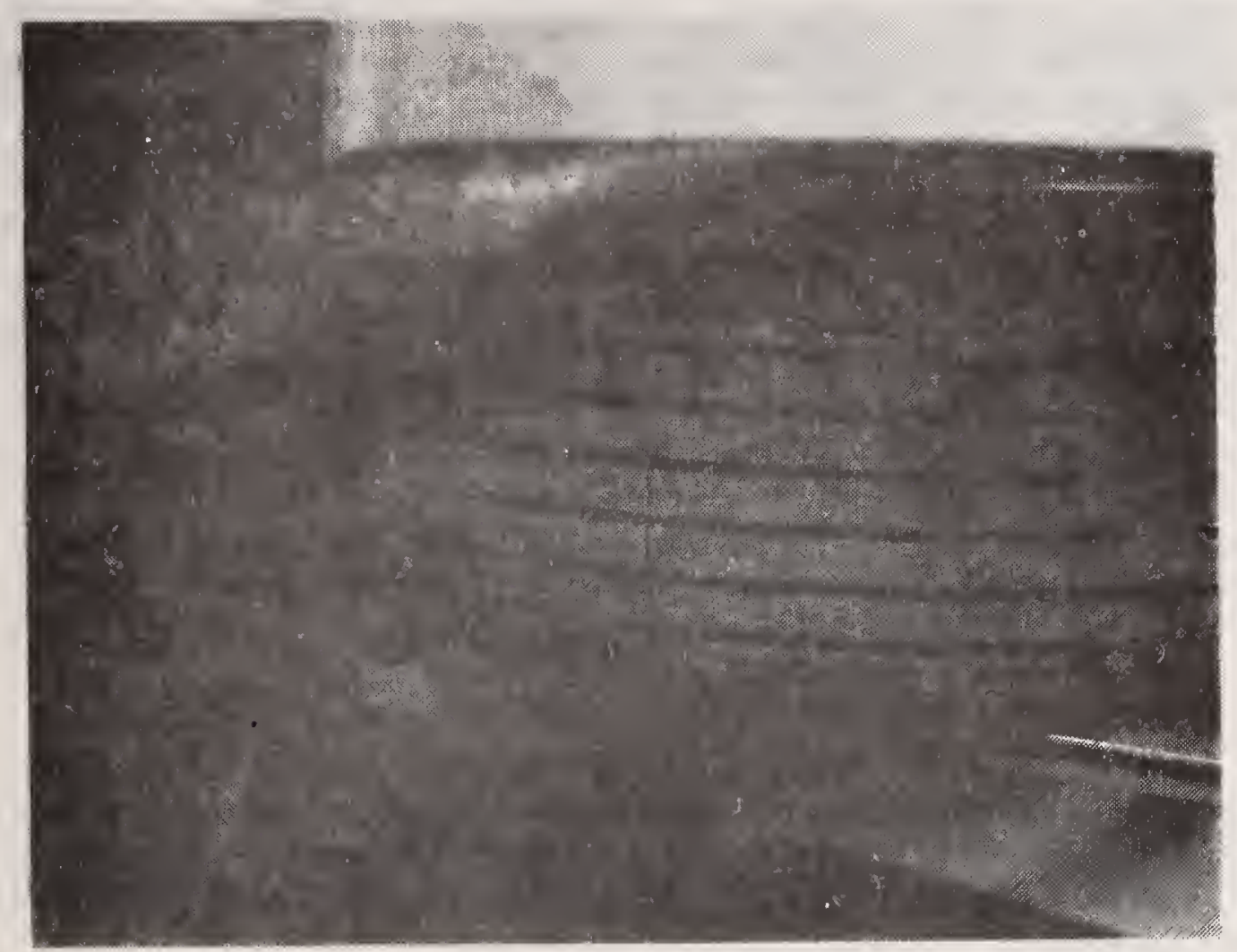

Figure 53. Texture of tire wear on surface number 3 . 
Examples of measurements from which the tire wear on surfaces 1, 2, and 3 can be estimated are shown in Figures 54, 55, and 56 respectively. A narrow white strip was painted radially on the test tire side wall at the beginning of the tire serial number. The locked position of the tire during a skid test was then related to "time" where the strip corresponds to the hour hand of a clock. The data illustrated corresponded to the tire position of $6: 30,12: 00$, and $8: 300^{\prime}$ clock on surfaces 1,2 , and 3 respectively. Tread depth measurements were made only when the test wheel was mounted on the IRS. The locked wheel position was noted as it skidded on both trailers. Consequently, the reduction in tread depth between the measurements made on lane 5 and lane 3 of surface 1 occurred in two skids, one made by the IRS and one made by the WARS. The skids occurred in the top-to-bottom order shown in the legend of the figures.

The length of the contact patch at the tire-pavement interface is nominally six inches $(15 \mathrm{~cm})$ while the measurements are made in a 0.25 in $(0.6 \mathrm{~cm})$ transverse band. There was no assurance that the tire position was in integer multiples of one-half hour increments, that the measurement band was in the center of the contact patch or that migration of the rubber did not occur as it was textured. With these qualifications the figures indicate that tire wear was least on surface 1 , the most on surface 2 and intermediate on surface 3.

\subsection{The Correlation Test Plan}

A purpose of the dynamic skid test program listed previously is to correlate the degree to which the IRS and WARS measuring system results match. The results include three sources of dispersion which degrade the correlation:

1) different time periods in which the measurements are made,

2) any nonuniformity between test tires, and

3) any nonuniformity between lanes of the test surface.

The correlation test plan is designed to measure these sources of dispersion. If their existance can be proven and quantified, their effect on the results can be taken into account to yield a more precise correlation. Knowledge of the bounds of these sources of dispersion can be used to establish an uncertainty band around the correlation result.

Statistical confidence in the results can be improved by increasing the number of tests. Confidence in the correlation of equipments is enhanced by finding consistency both in the magnitude of the results at a point, and in the first derivative of the results with respect to a test variable through that point. Confidence in the measurement results is enhanced when the data points are found to be within small intervals of variation. 


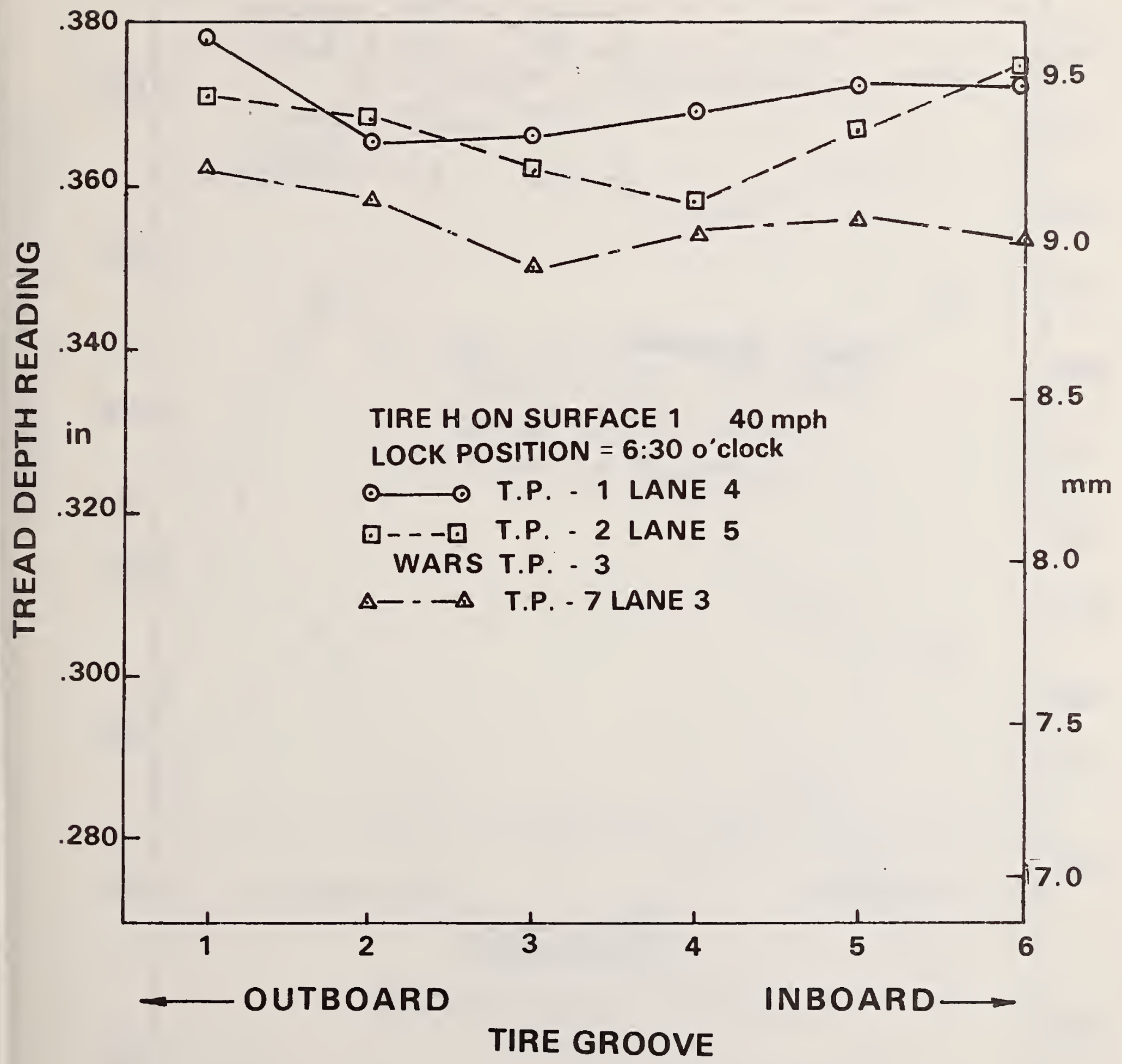

Figure 54. Tire wear on surface 1. 


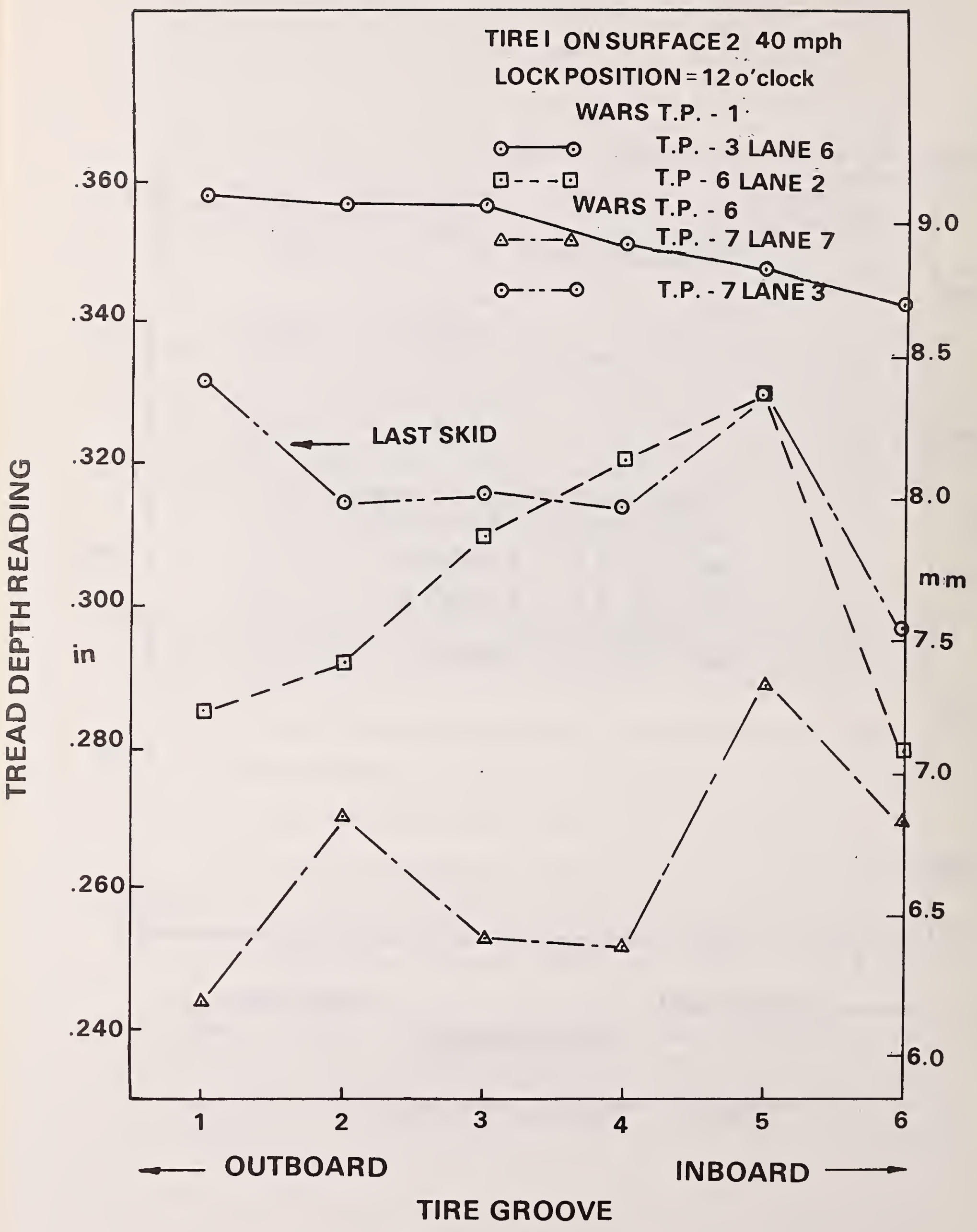

Figure 55. Tire wear on surface 2 . 


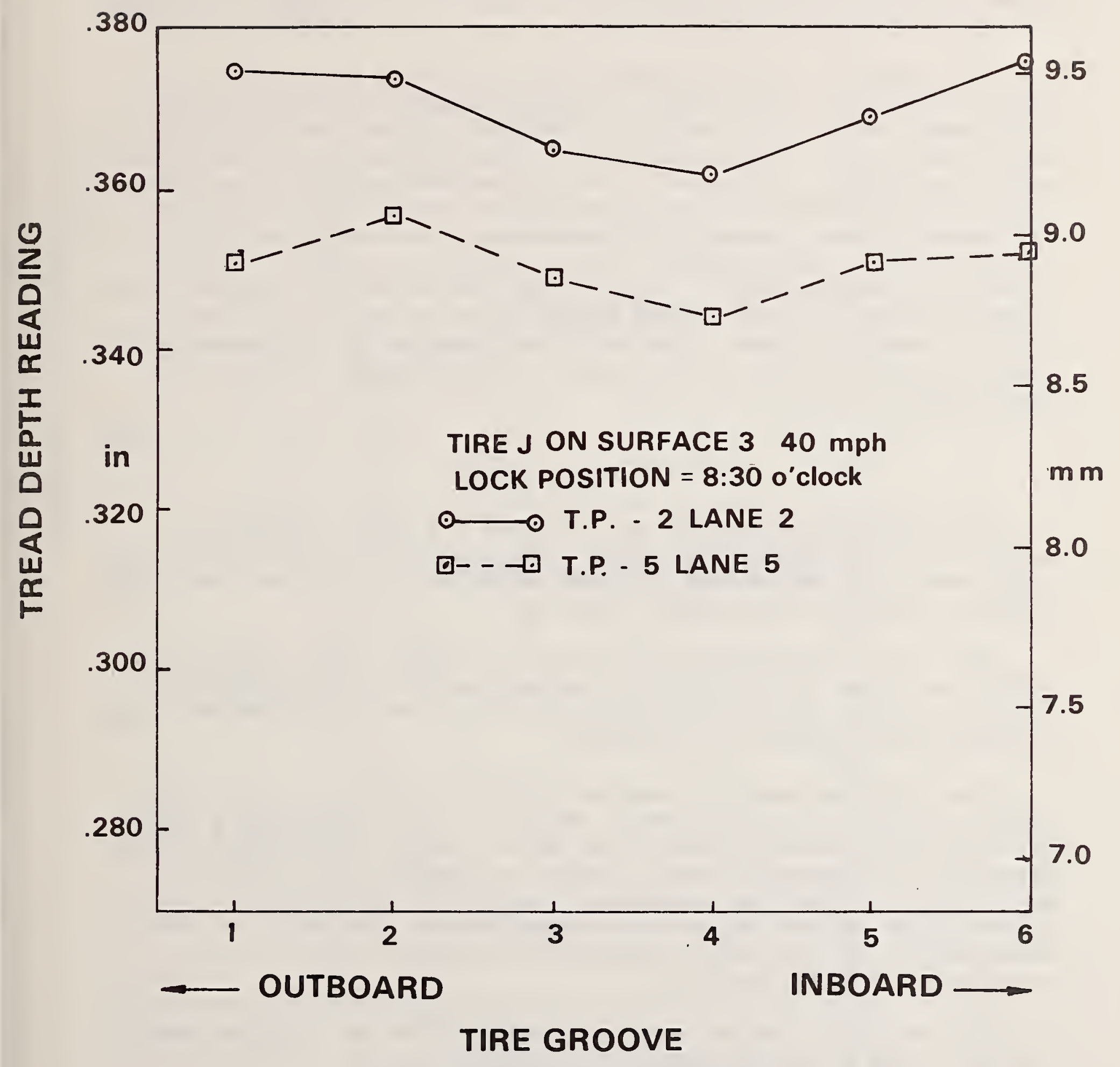

Figure 56. Tire wear on surface 3 . 
Testing of the IRS with the Central FTC (CFTC) ARS was conducted in May, 1972. A statistical analysis of the results of these tests provides a basis for computing the number of tests needed to determine the skid number within a given confidence level. Statistical inference techniques are used in the calculations [9].

The results of the calculations for one surface at the CFTC are given in Figure 57. For example, to report a mean skid number within \pm 1 skid numbers in May, 1972 would have required 185 tests on the surface by the IRS. This number of tests on the same pavement at the same speed was not practical. Consequently, the IRS has been modified, instrumentation subsystems added, and the degree of test control improved with the development of more complete test procedures. In anticipation of improved precision due to these changes, the test program was designed using the expected IRS results shown. A larger number of tests were planned for $40 \mathrm{mph}(64 \mathrm{~km} / \mathrm{h})$ than for 20 and $60 \mathrm{mph}(32$ and $97 \mathrm{~km} / \mathrm{h})$ since this is the more usual test speed. The test plan contained 210 skid measurement tests to yield an expected skid number interval of less than four $( \pm 2)$ skid numbers.

\subsection{Test .Matrix Results}

The skid resistance measurement results are given in terms of a mean value at the nominal test speed, the measured skid resistance test speed gradient through that mean value, and a 99 percent confidence interval about the mean value.

The results from measurements made at the WFTC during single time periods are shown in Figure 58 for the WARS and in Figure 59 for the IRS. The results for multiple time periods are shown in Figure 60 for the WARS and in Figure 61 for the IRS.

The deviation about the mean calculated for the set of test tires used on surface 1 from measurements made by the WARS are shown in Figure 62 and from measurements made by the IRS are shown in Figure 63. The pattern of the deviations about the mean is similar but of opposite sign. That is, while the measurement made by the WARS using test tire A-I was below the mean of the measurements made by the WARS, the measurements made by the IRS using test tire A-1 was above the mean of the measurements made by the IRS.

The deviation from the mean calculated for the set of tires used on surface 2 from measurements made by the WARS are shown in Figure 64 and from measurements made by the IRS are shown in Figure 65.

The deviation from the mean calculated for the set of tires used on surface 3 from measurements made by the WARS are shown in Figure 66 and from measurements made by the IRS are shown in Figure 67. 


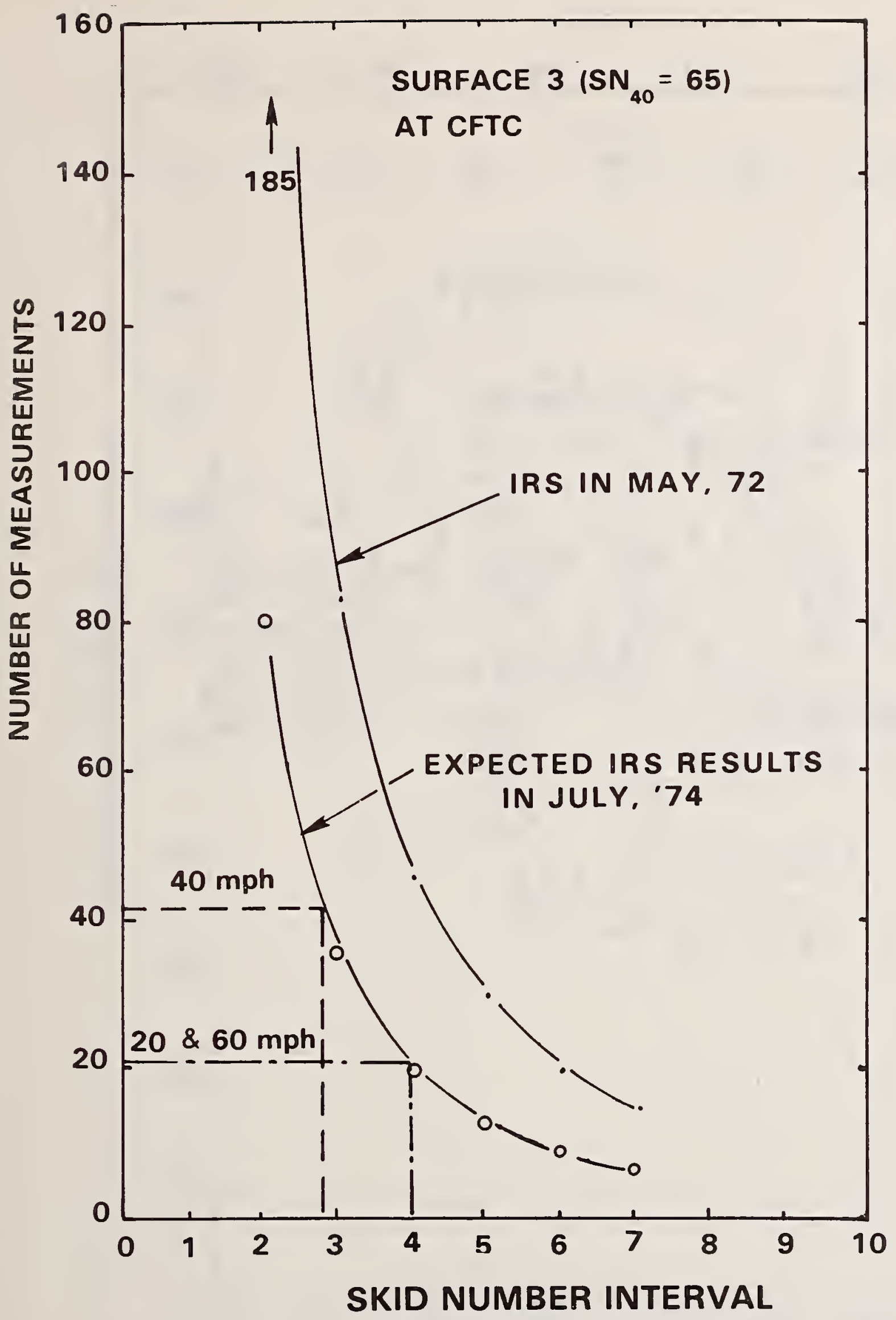

Figure 57. Confidence interval versus number of measurements. 
$\mathrm{km} / \mathrm{h}$

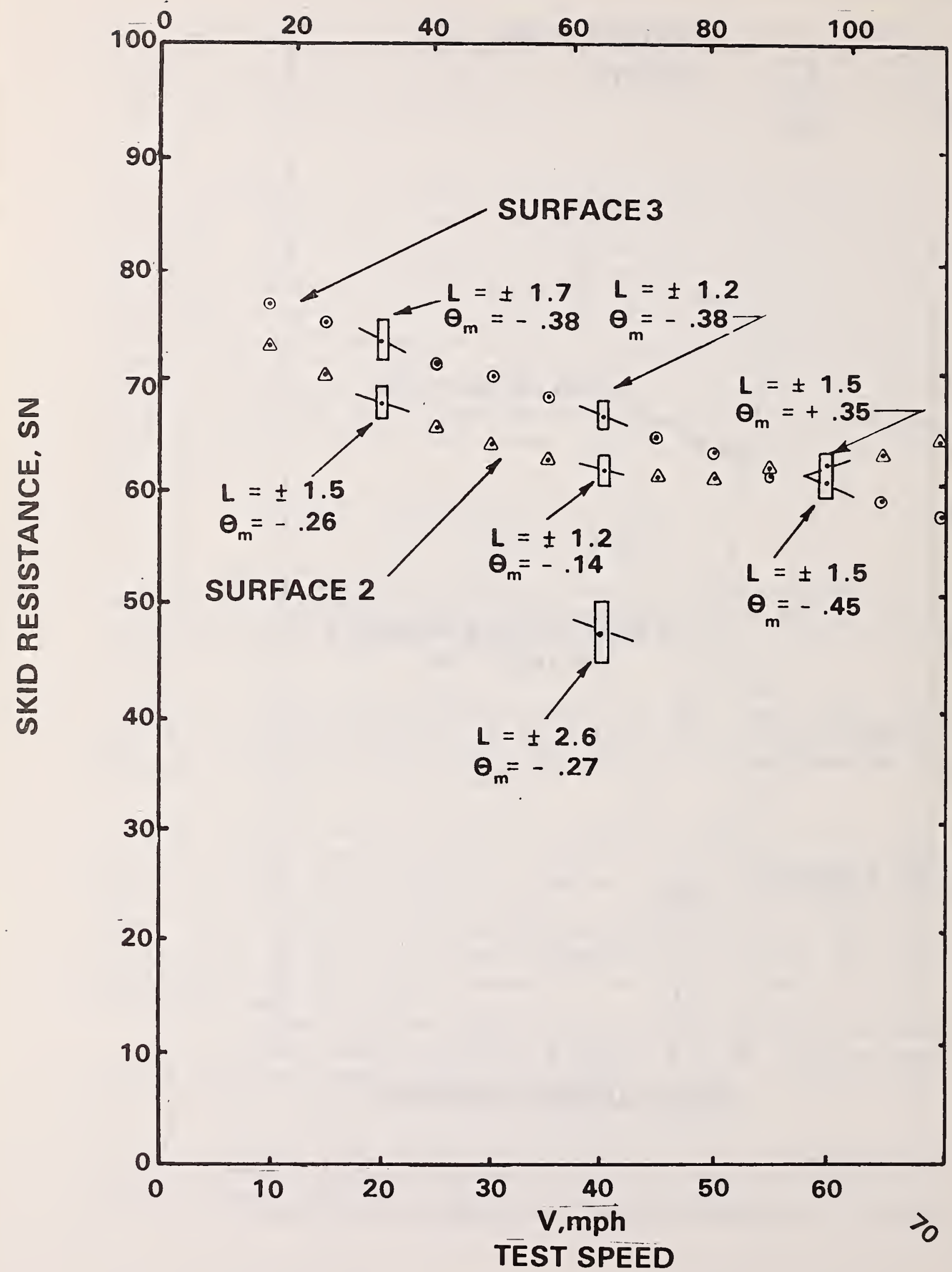

Figure 58. WARS measurement results at WFTC - spring, 1975, single time period measurements. 


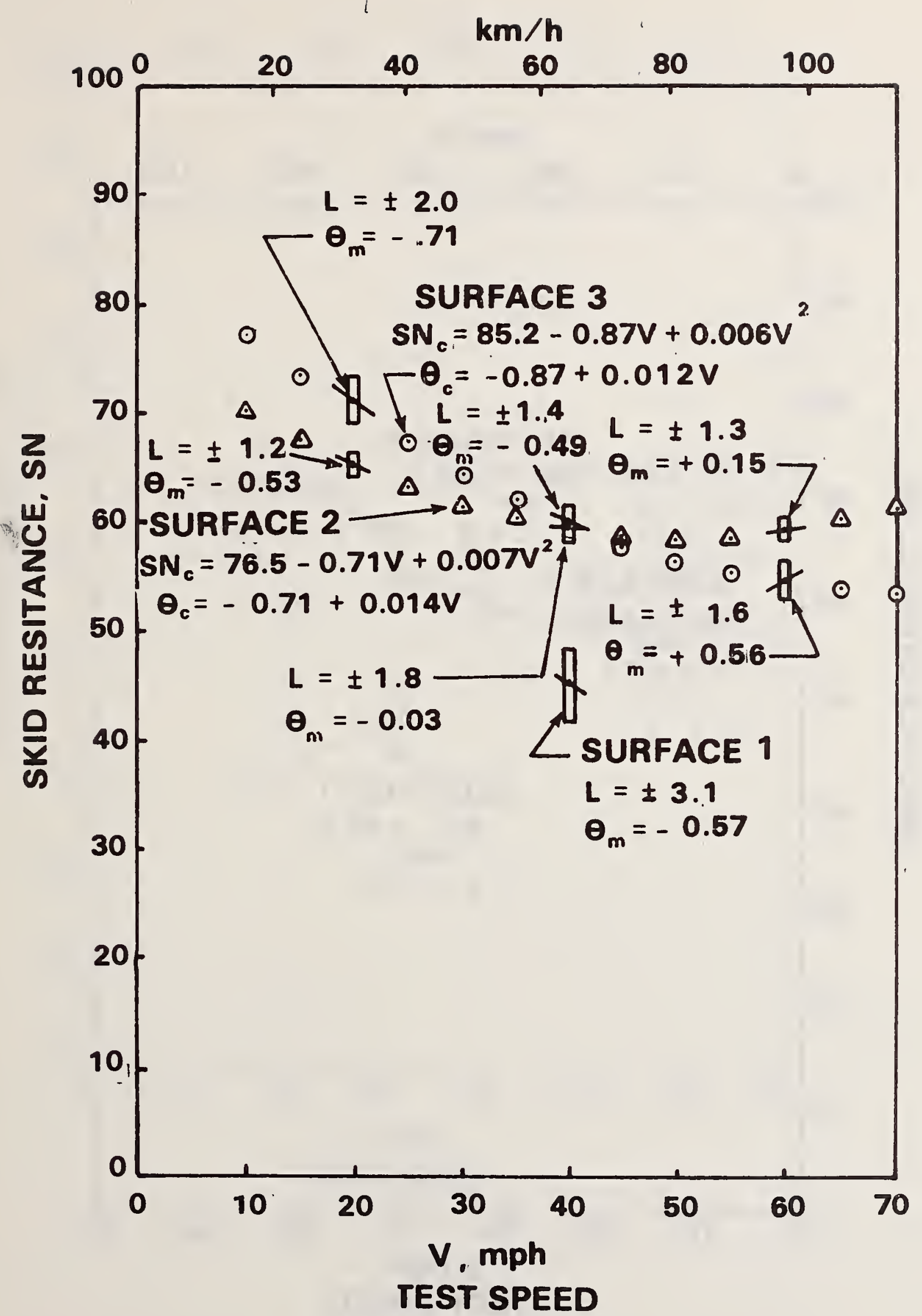

Figure 59. IRS measurement results at WFTC - spring, 1975, single time period measurements. 


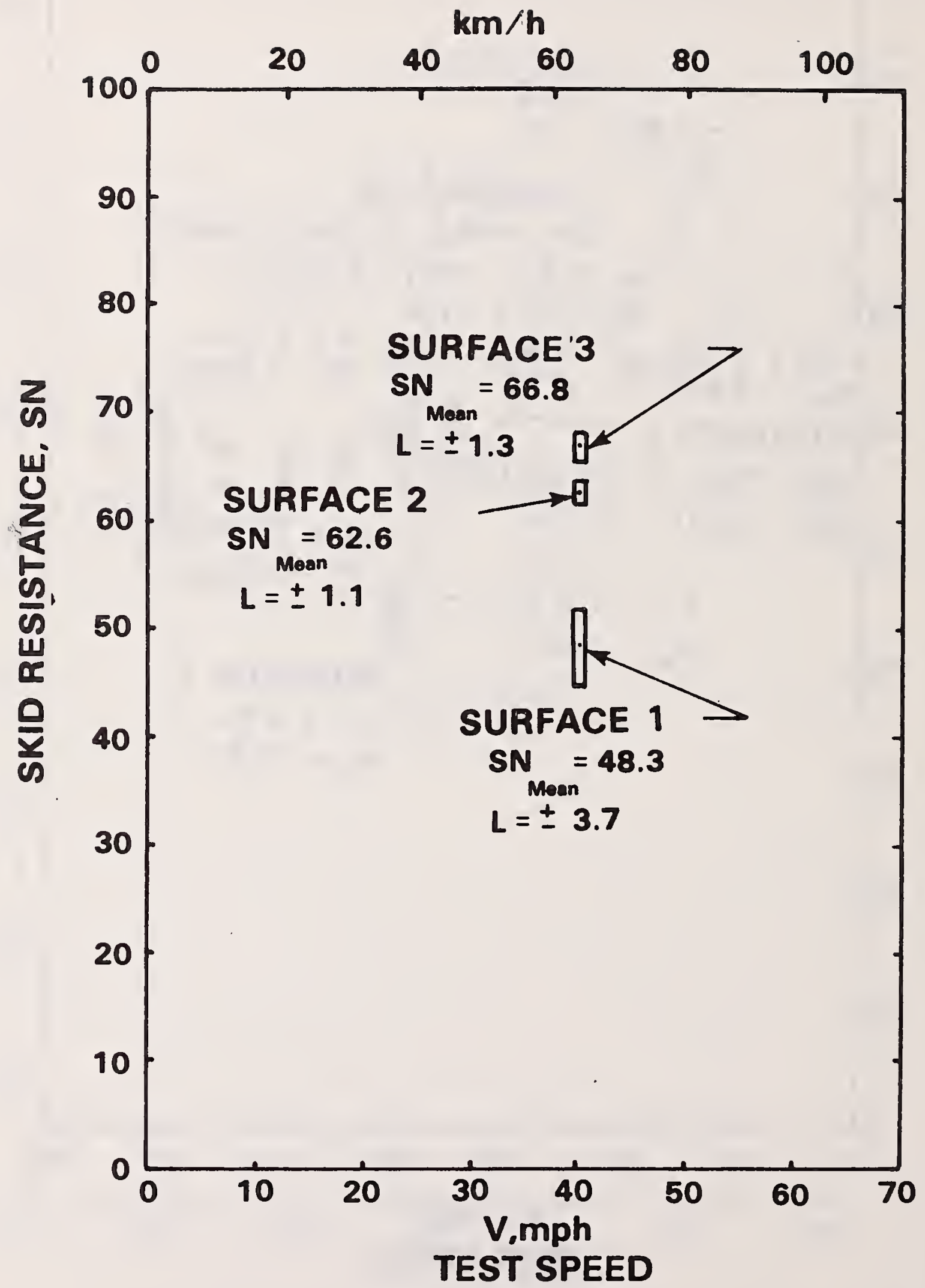

Figure 60. WARS measurement results at WFTC - spring, 1975, multiple time period measurements. 


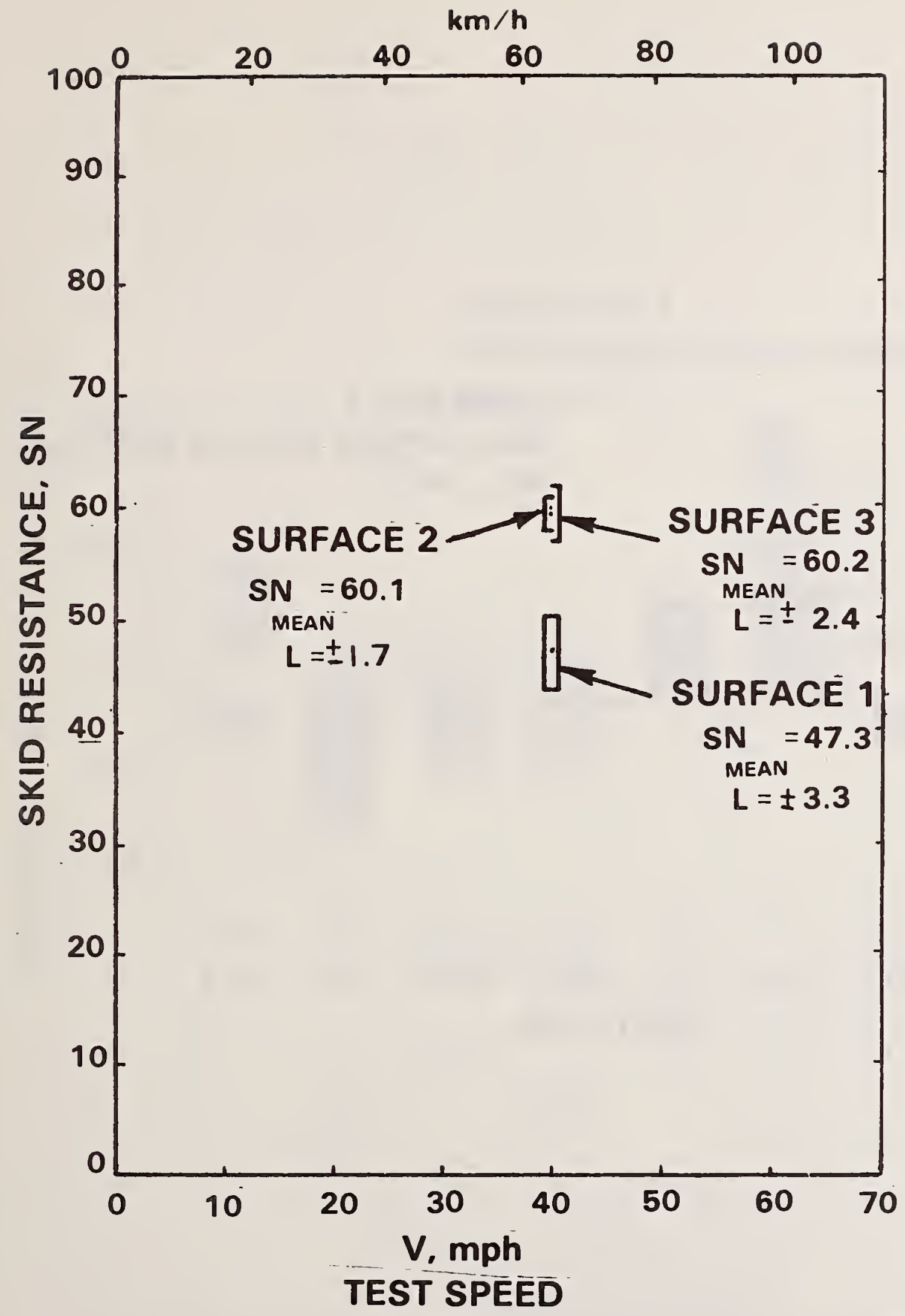

Figure 61. IRS measurement results at WFTC - spring, 1975, multiple time period measurements. 


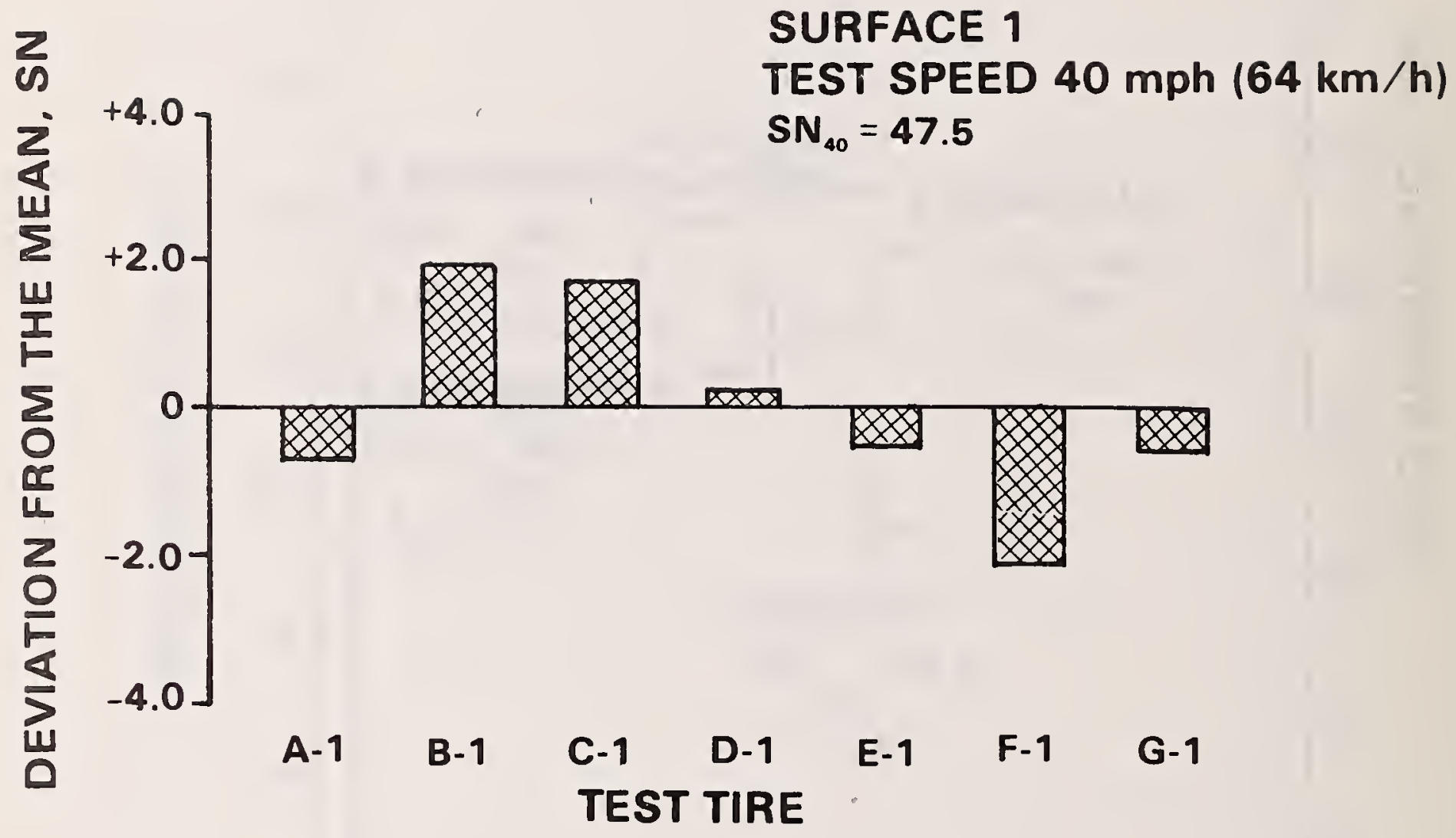

Figure 62. Deviation from the mean skid number measured by the WARS on surface 1 at the WFTC as a function of test tire. 


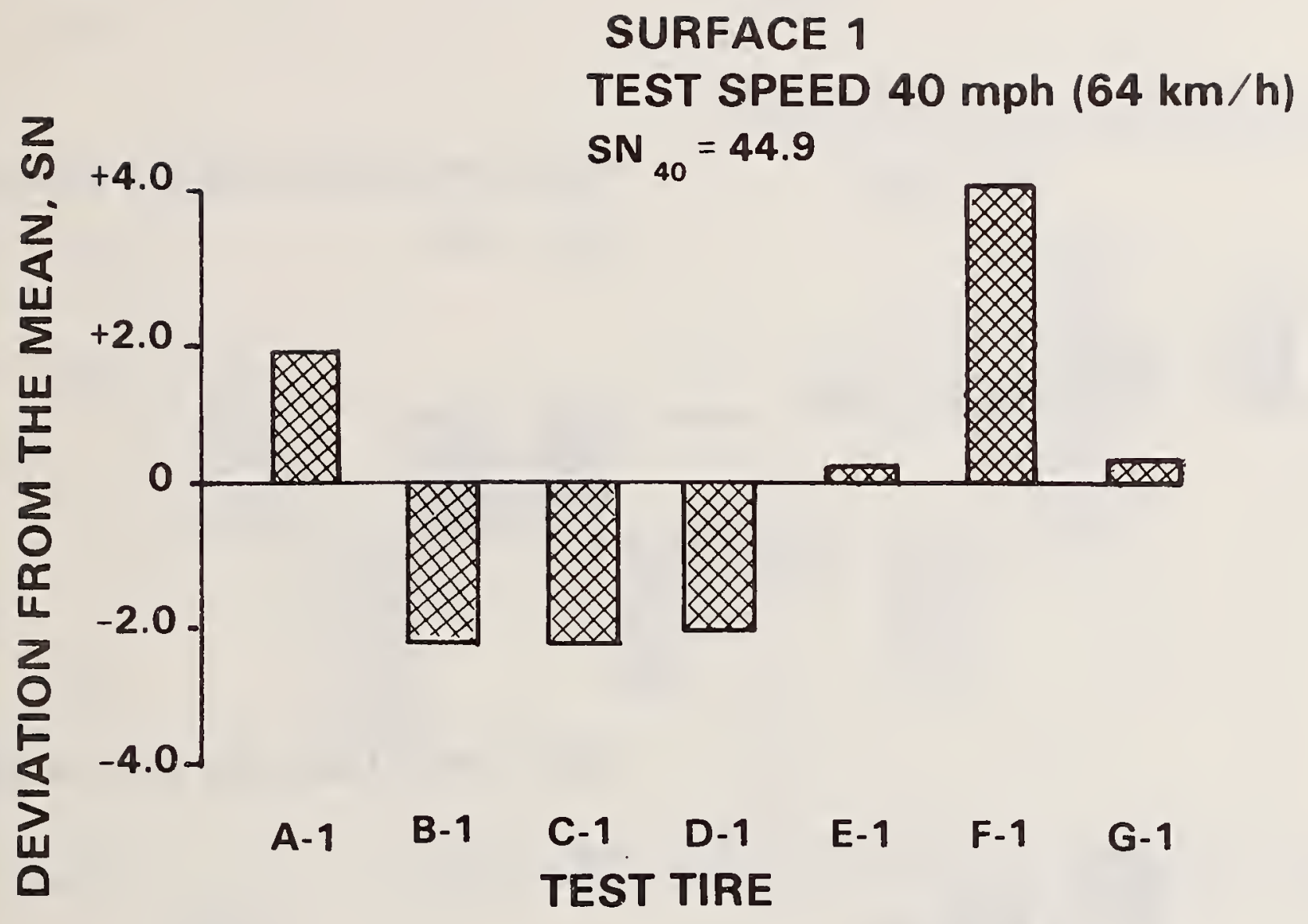

Figure 63. Deviation from the mean skid number measured by the IRS on surface 1 at the WFTC as a function of test tire. 


\section{$\mathrm{SN}_{20}=67.9$}

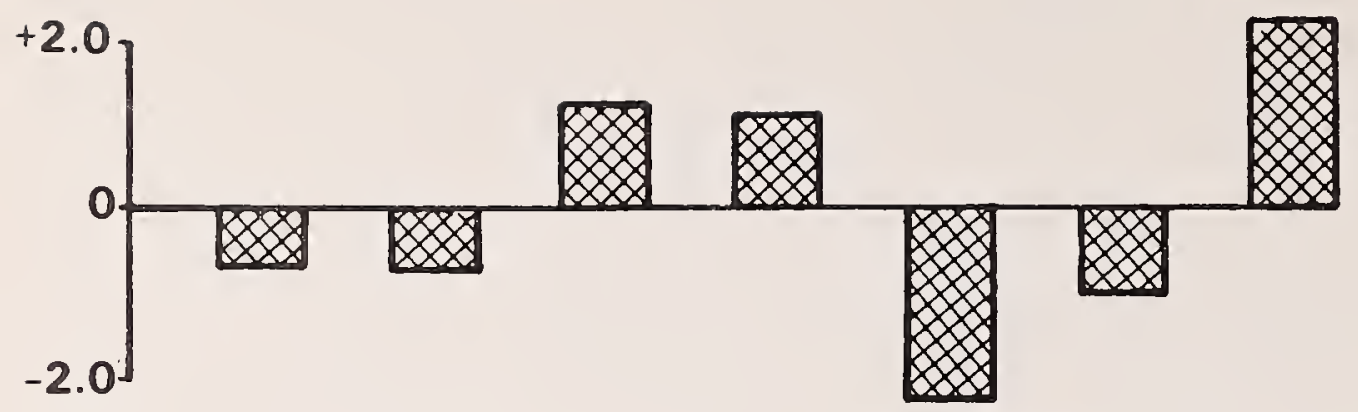

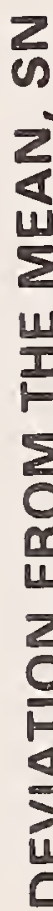

TEST SPEED $40 \mathrm{mph}(64 \mathrm{~km} / \mathrm{h})$

$\mathrm{SN}_{40}=62.0$

TEST SPEED $60 \mathrm{mph}(97 \mathrm{~km} / \mathrm{h})$

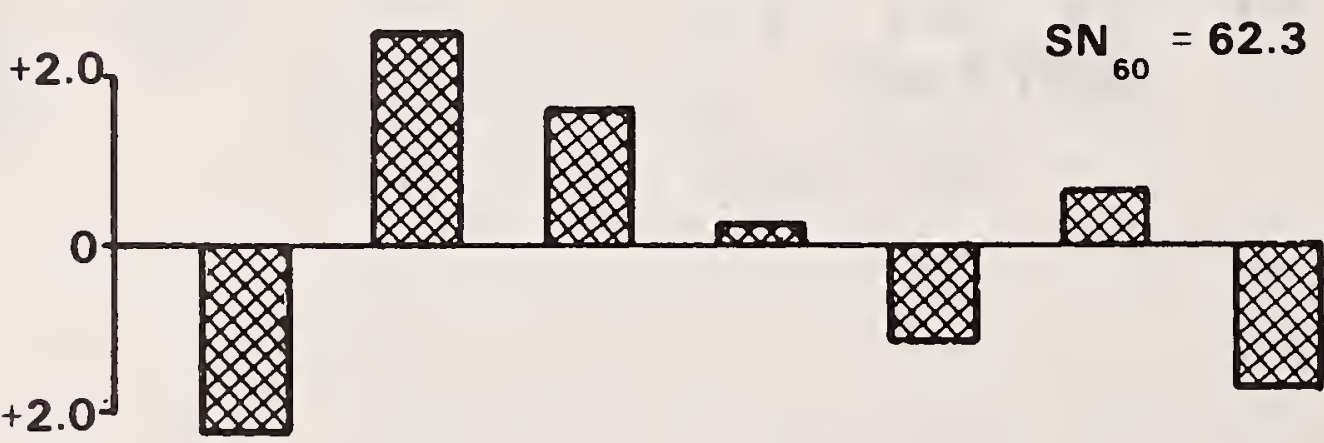

\section{$\begin{array}{lllllll}\text { A-2 } & \text { B-2 } & \text { C-2 } & \text { D-2 } & \text { F-2 } & \text { E-2 } & \text { G-2 }\end{array}$ TEST TIRE}

Figure 64. Deviation from the mean skid number measured by the WARS on surface 2 at the WFTC as a function of test tire. 


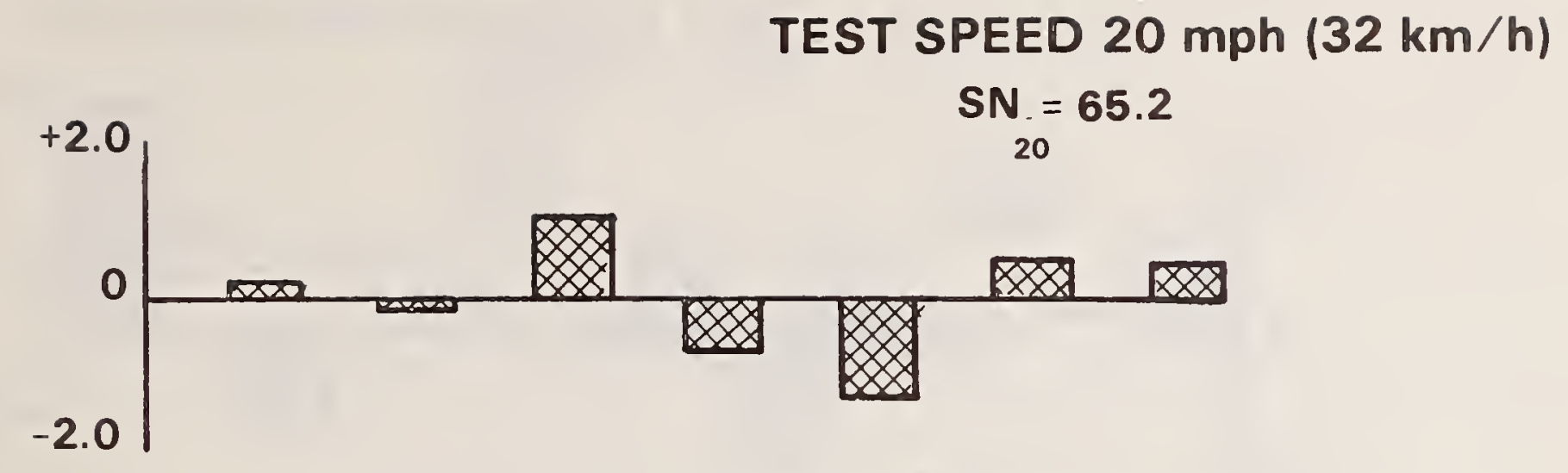

TEST SPEED $40 \mathrm{mph}(64 \mathrm{~km} / \mathrm{h})$

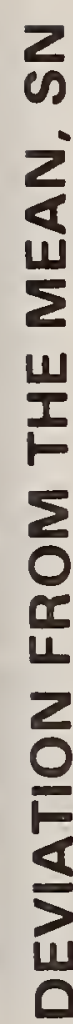

TEST SPEED $60 \mathrm{mph}(97 \ldots \mathrm{km} / \mathrm{h})$

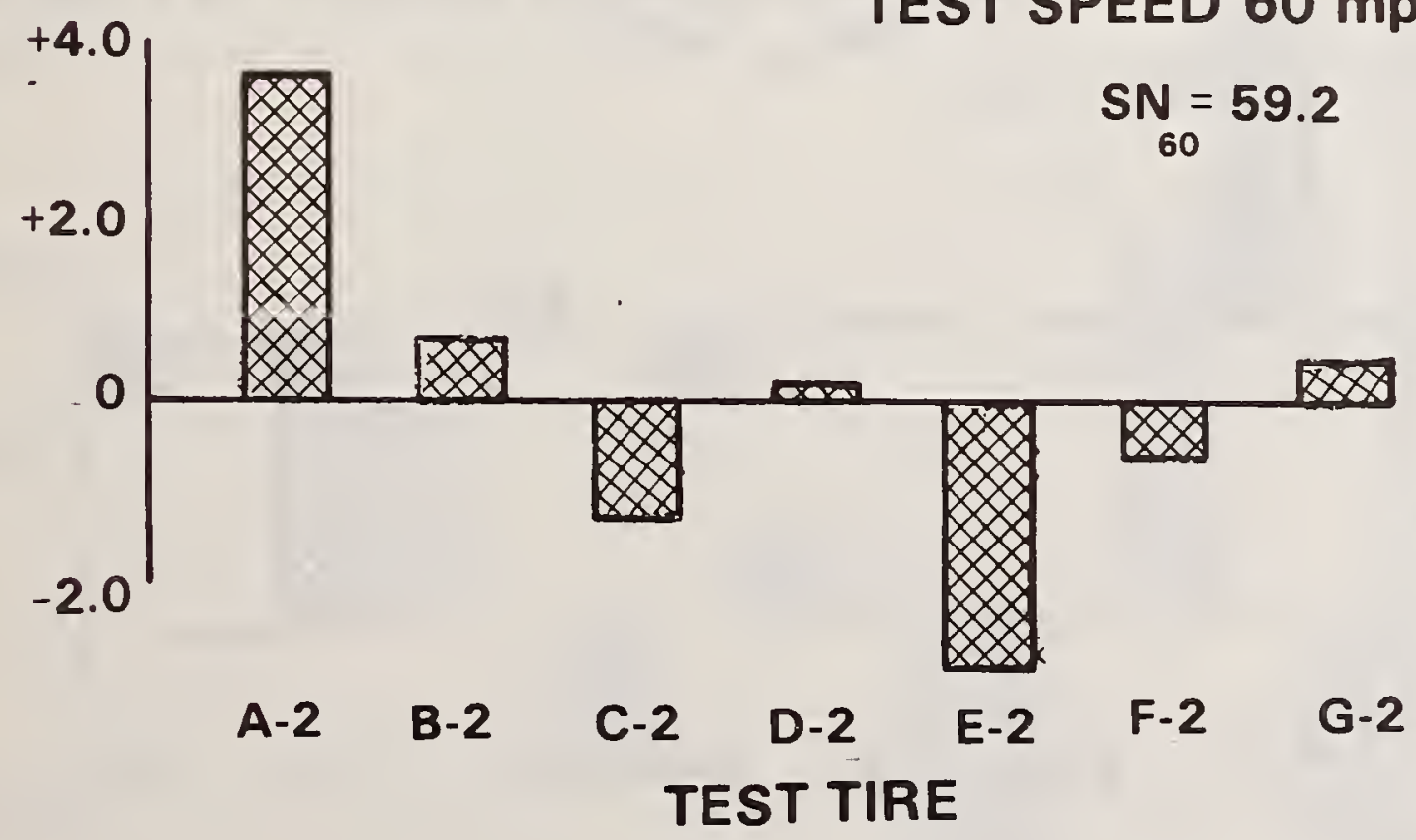

Figure 65. Deviation from the mean skid number measured by the IRS on surface 2 at the WFTC as a function of test tire. 
TEST SPEED $20 \mathrm{mph}(32 \mathrm{~km} / \mathrm{h})$

$\mathrm{SN}_{20}=73.5$

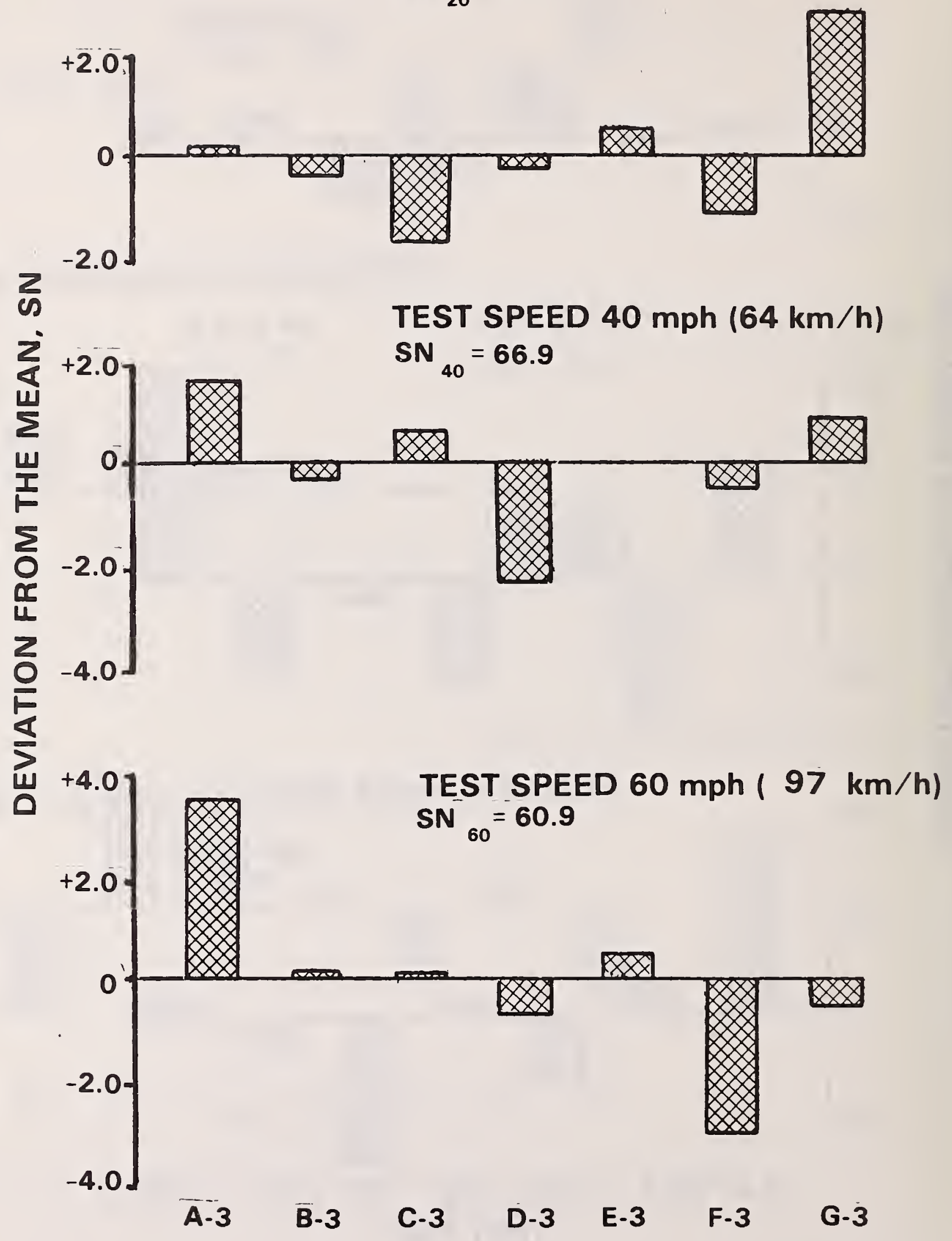

Figure 66. Deviation from the mean skid number measured by the WARS on surface 3 at the WFTC as a function of test tire. 
TEST SPEED $20 \mathrm{mph}(32 \mathrm{~km} / \mathrm{h})$ $\mathrm{SN}_{20}=70.1$
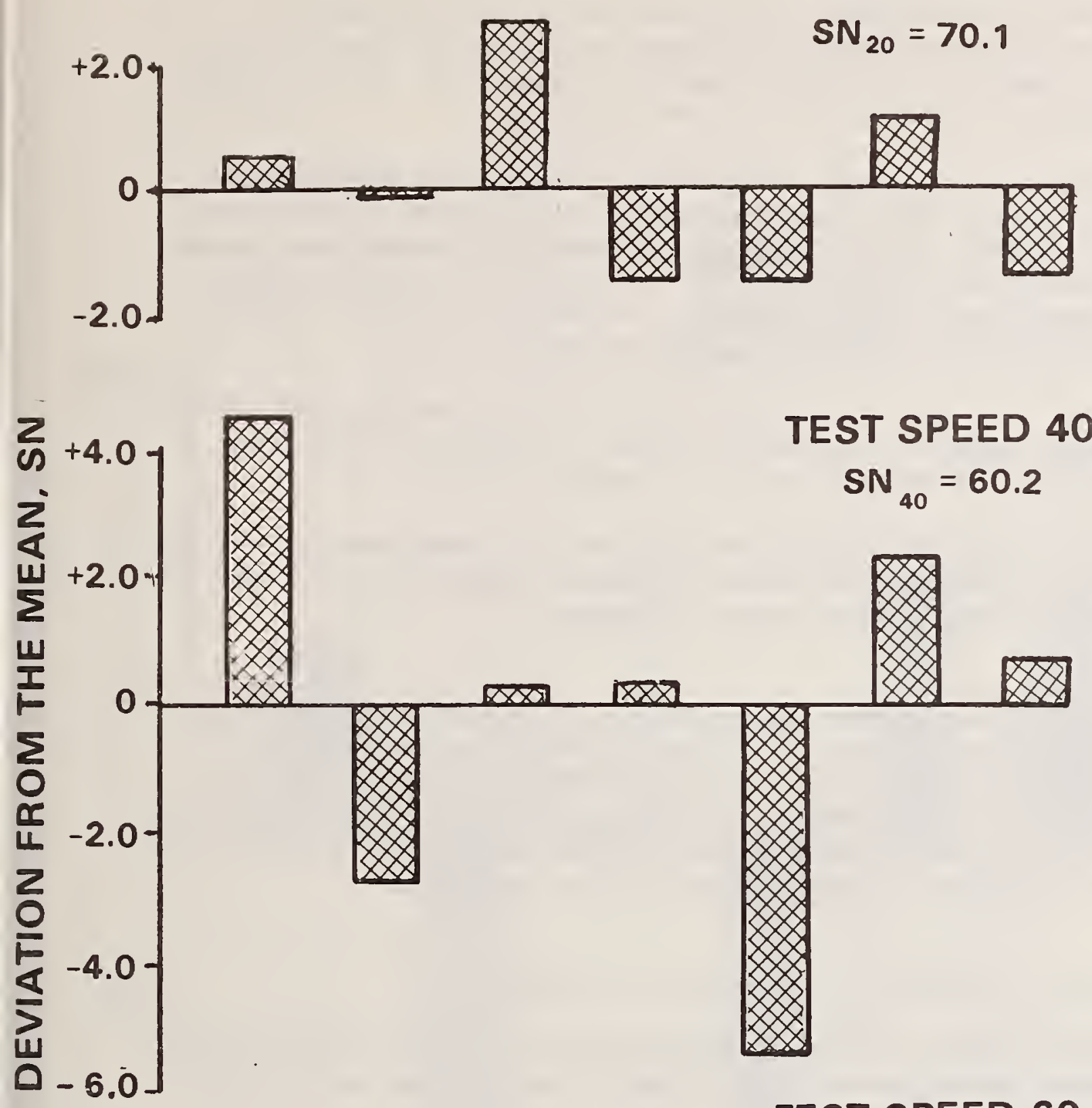

TEST SPEED $40 \mathrm{mph}(64 \mathrm{~km} / \mathrm{h})$

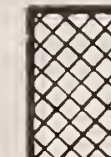

$$
\mathrm{SN}_{40}=60.2
$$

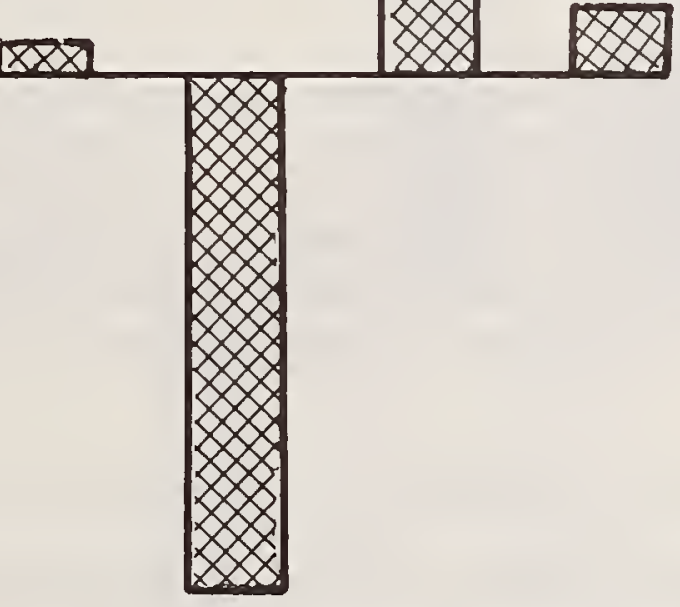

TEST SPEED $60 \mathrm{mph}(97 \mathrm{~km} / \mathrm{h}$ )

$S N_{60}=54.4$

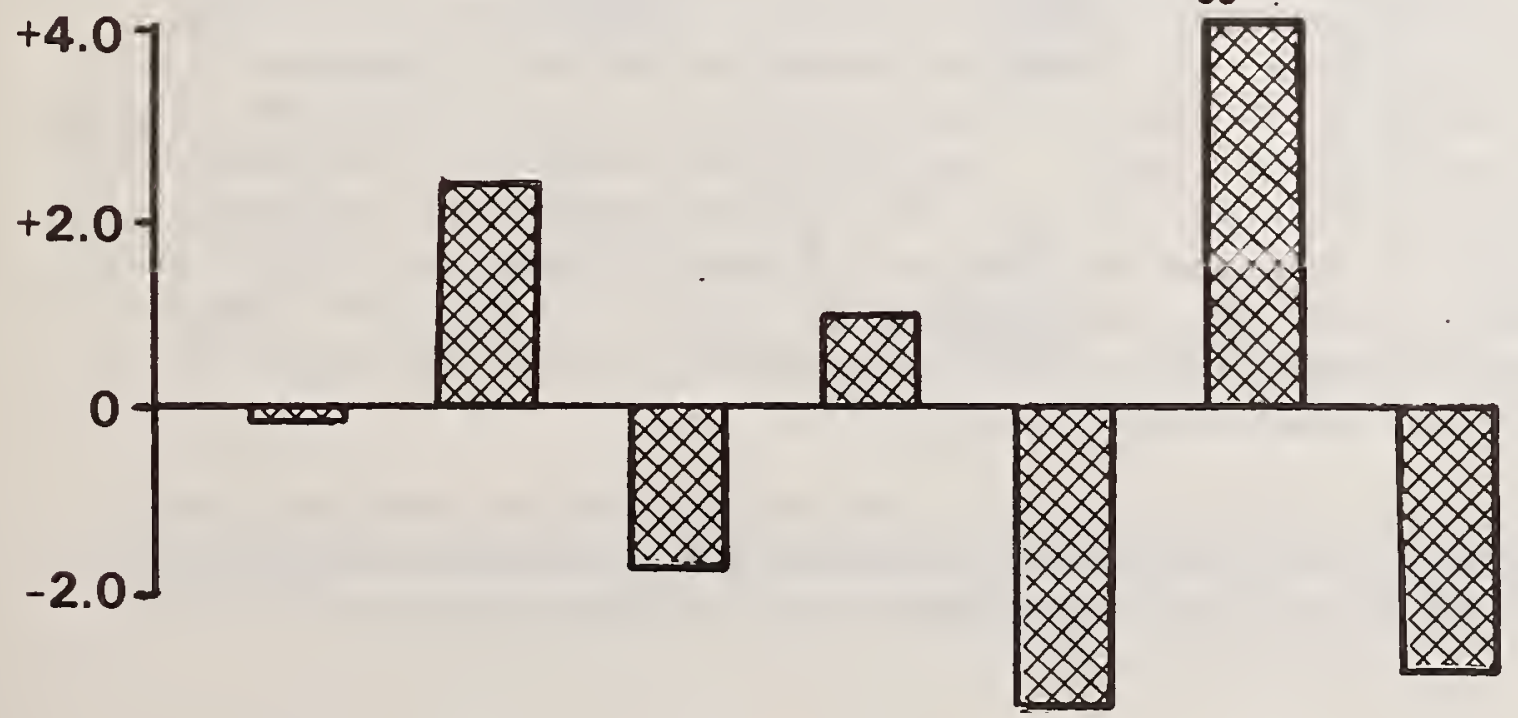
A-3
B-3
C-3
D-3
E-3
F-3
G-3

\section{TEST TIRE}

Figure 67. Deviation from the mean skid number measured by the IRS on surface 3 at the WFTC as a function of test tire. 
The deviation from the mean calculated for the lanes used on surface 1 from measurements made by the WARS are shown in Figure 68 and from measurements made by the IRS are shown in Figure 69. The relative pattern of deviation is similar for the two systems.

The deviations may be large enough to be outside the random error band of the test so that the similar patterns are evident. To reinforce the validity of the pattern of deviations it should be noted that lanes 1 thru 4 were constructed on one pass of the pavement laying equipment while lanes 5 thru 7 were constructed on a second pass. Thus there may be a discontinuity in skid resistance between lanes 4 and 5 .

The deviation from the mean calculated for the lanes used on surface 2 from measurements made by the WARS are shown in Figure 70 and from measurements made by the IRS are shown in Figure 71.

The deviation from the mean calculated for the lanes used on surface 3 from measurements made by the WARS are shown in Figure 72 and from measurements made by the IRS are shown in Figure 73.

The deviation from the mean calculated for the space of time that tests were conducted on surfaces 1,2 , and 3 from measurements made by the WARS are shown in Figure 74 and from measurements made by the IRS are shown in Figure 75. The deviation pattern is similar on surface 3 for both systems. The measurements tended to be higher at the beginning of the tests and decreased toward the end of the test period.

\subsection{Ranking of the Sources of Dispersion}

The ranking of these sources of dispersion calculated from the WARS test matrix results are given in Table 9 while the ranking calculated from the IRS results are given in Table 10 .

The sample standard deviations of skid number, with the calculated tire and lane dispersions, are listed according to test matrix in Table 11. With a few exceptions, the standard deviation of the calculated tire and lane dispersion is small compared to the standard deviation of the skid number measurement result. One exception, which is confirmed by the measurement of both systems, is the lane dispersion on surface 1 . The pattern of lane dispersion is similar for both systems on surface 1 . The results indicate that the measurements in lanes $1,5,6$, and 7 gave higher than average values while the measurements in lanes 2,3 , and 4 yielded lower than average values.

As discussed in section 3 the test program is divided into two sets of ten test matrices. One set is for the IRS, the other for the WARS. Generally, two days of testing were planned for a test matrix which 


\section{SURFACE 1}

\section{TEST SPEED $40 \mathrm{mph}(64 \mathrm{~km} / \mathrm{h})$ $S N_{40}=47.5$}

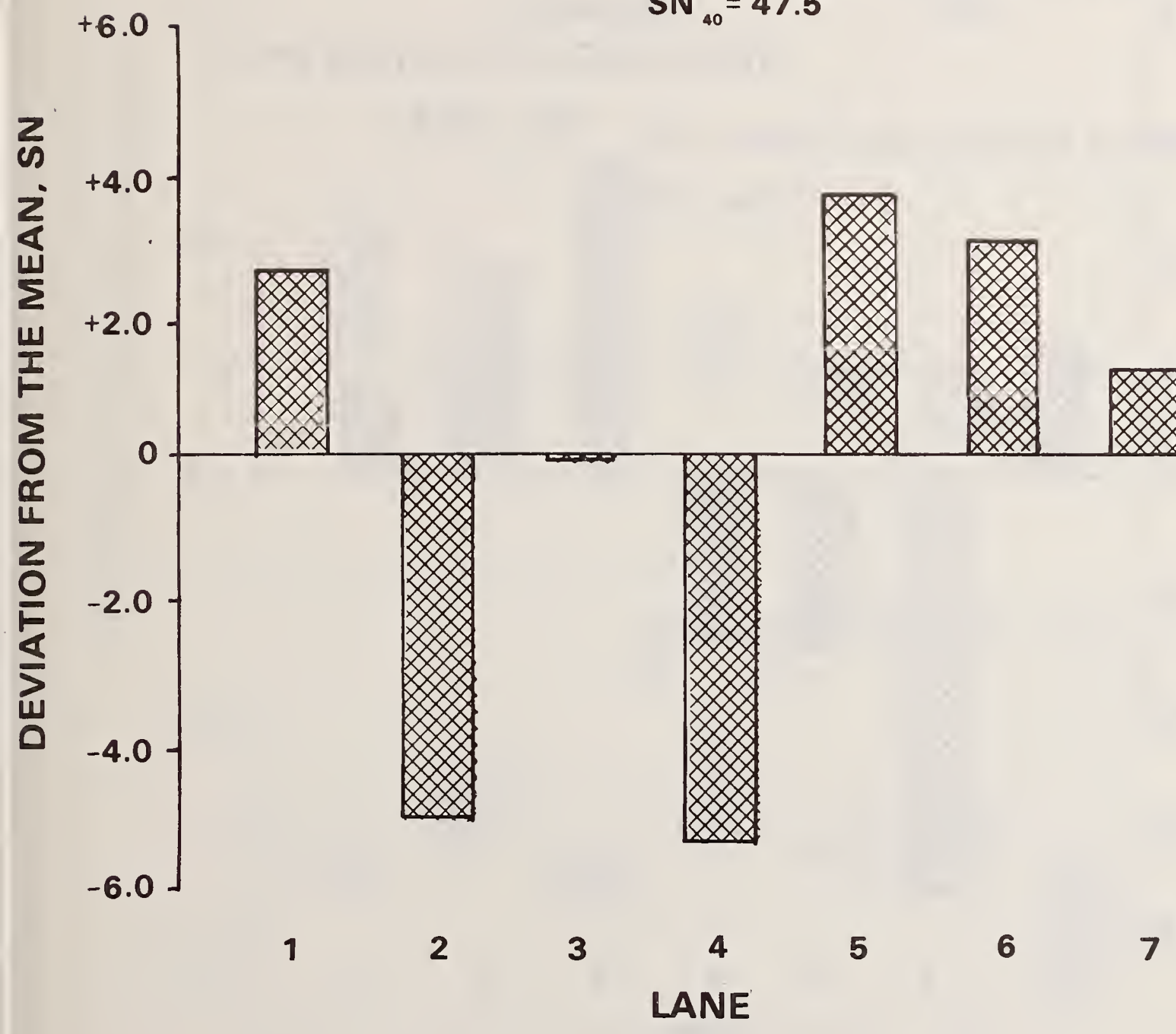

Figure 68. Deviation from the mean skid number measured by the WARS on surface 1 at the WFTC as a function of lane. 


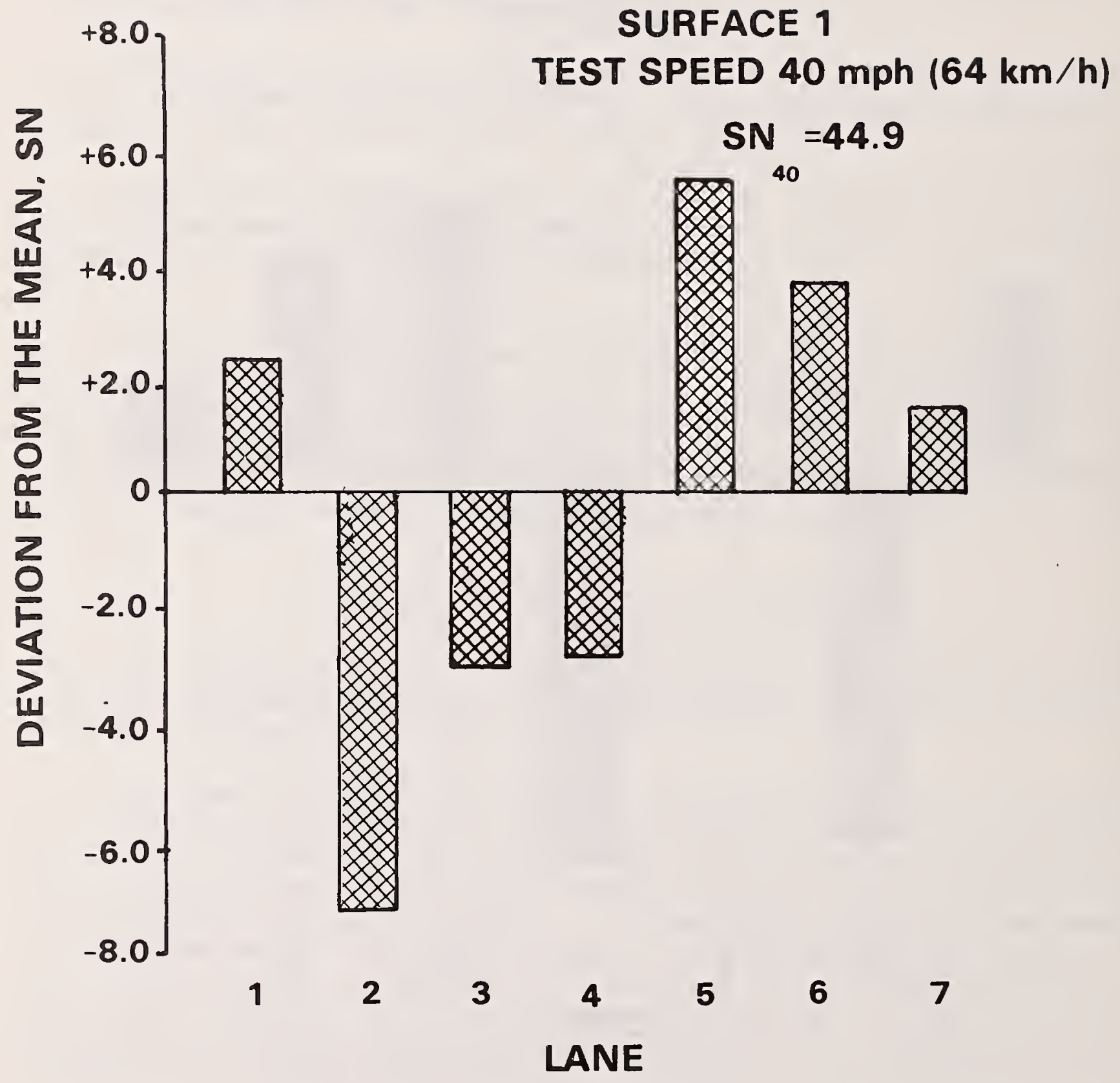

Figure 69. Deviation from the mean skid number measured by the IRS on surface 1 at the WFTC as a function of lane. 
TEST SPEED $20 \mathrm{mph}(32 \mathrm{~km} / \mathrm{h})$

$\mathrm{SN}_{20}=67.9$

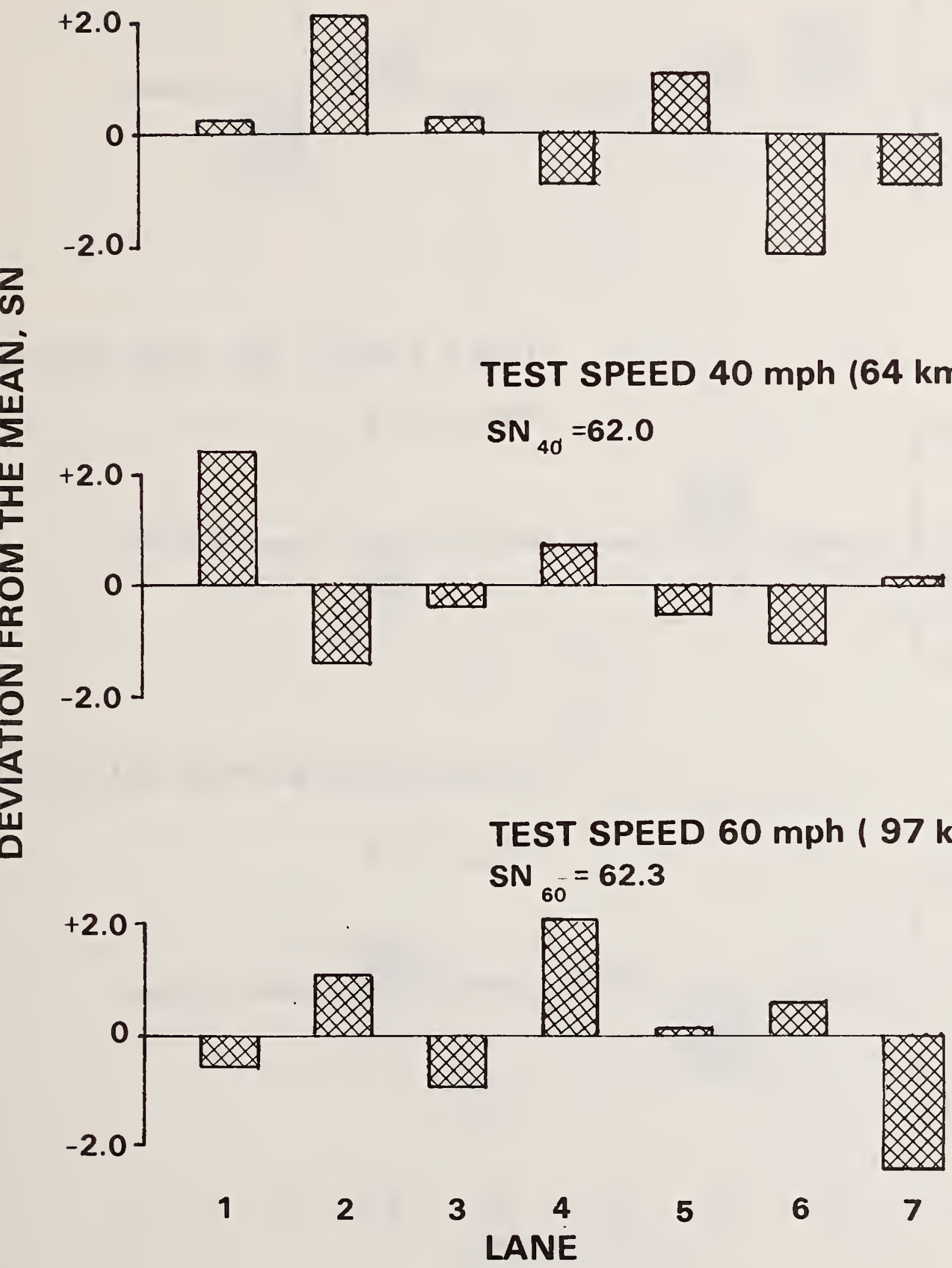

Figure 70. Deviation from the mean skid number measured by the WARS on surface 2 at the WFTC as a function of lane. 
TEST SPEED $20 \mathrm{mph}(32 \mathrm{~km} / \mathrm{h})$

$S N_{20}=59.4$

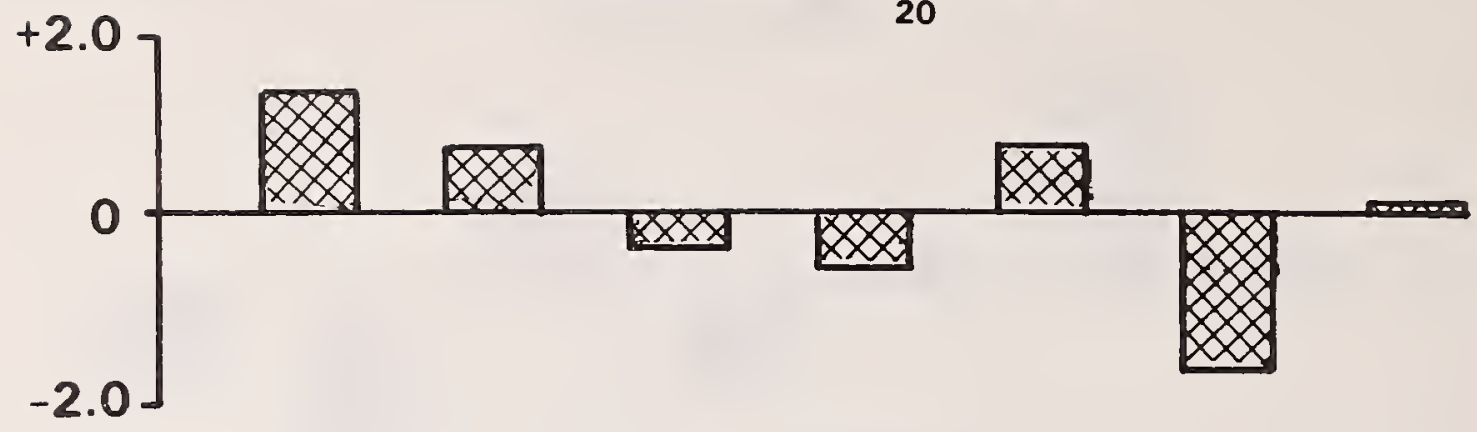

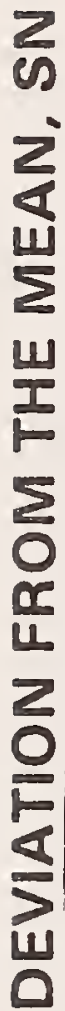

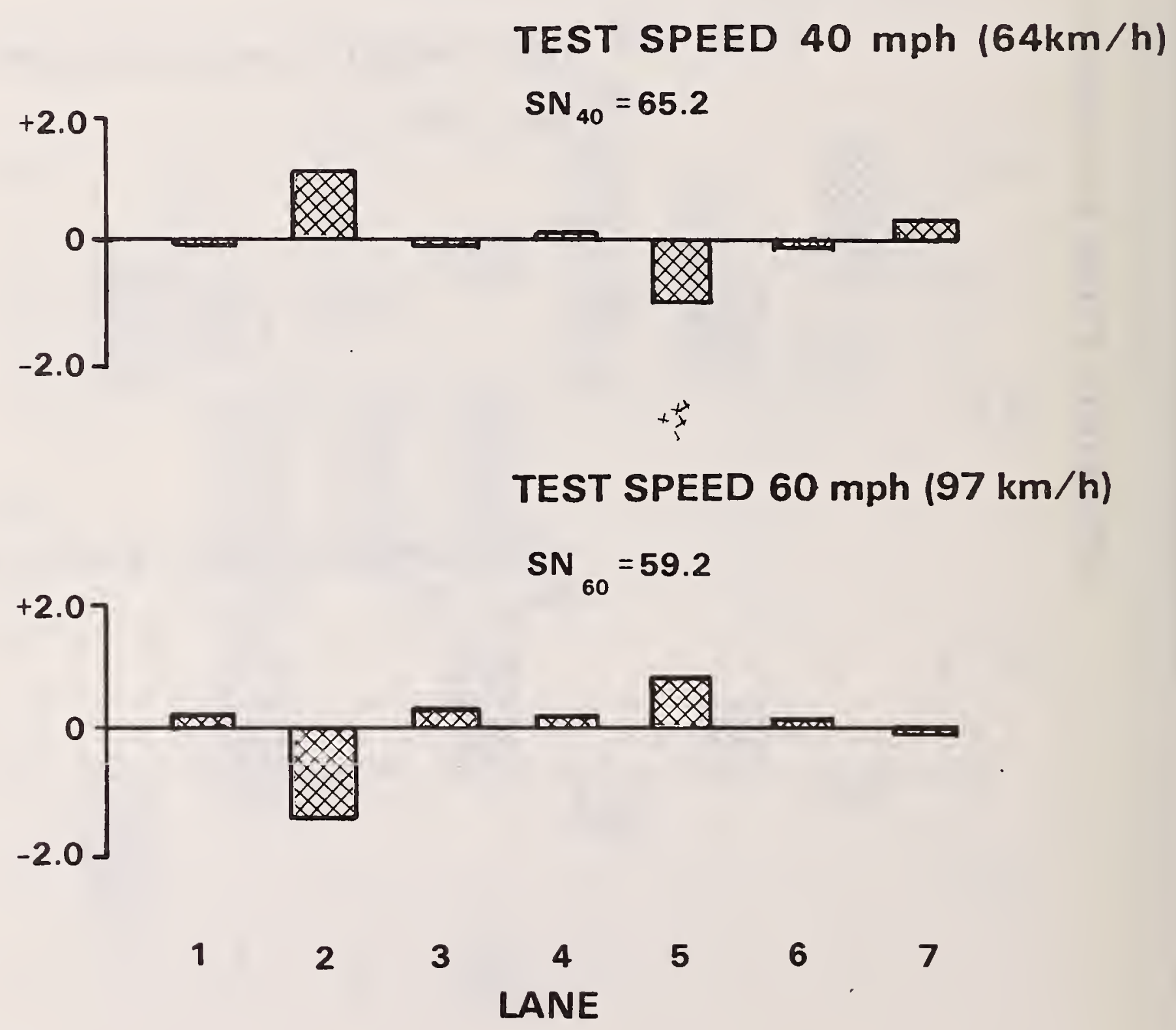

Figure 71. Deviation from the mean skid number measured by the IRS on surface 2 at the WFTC as a function of lane. 

TEST SPEED $20 \mathrm{mph}(32 \mathrm{~km} / \mathrm{h})$
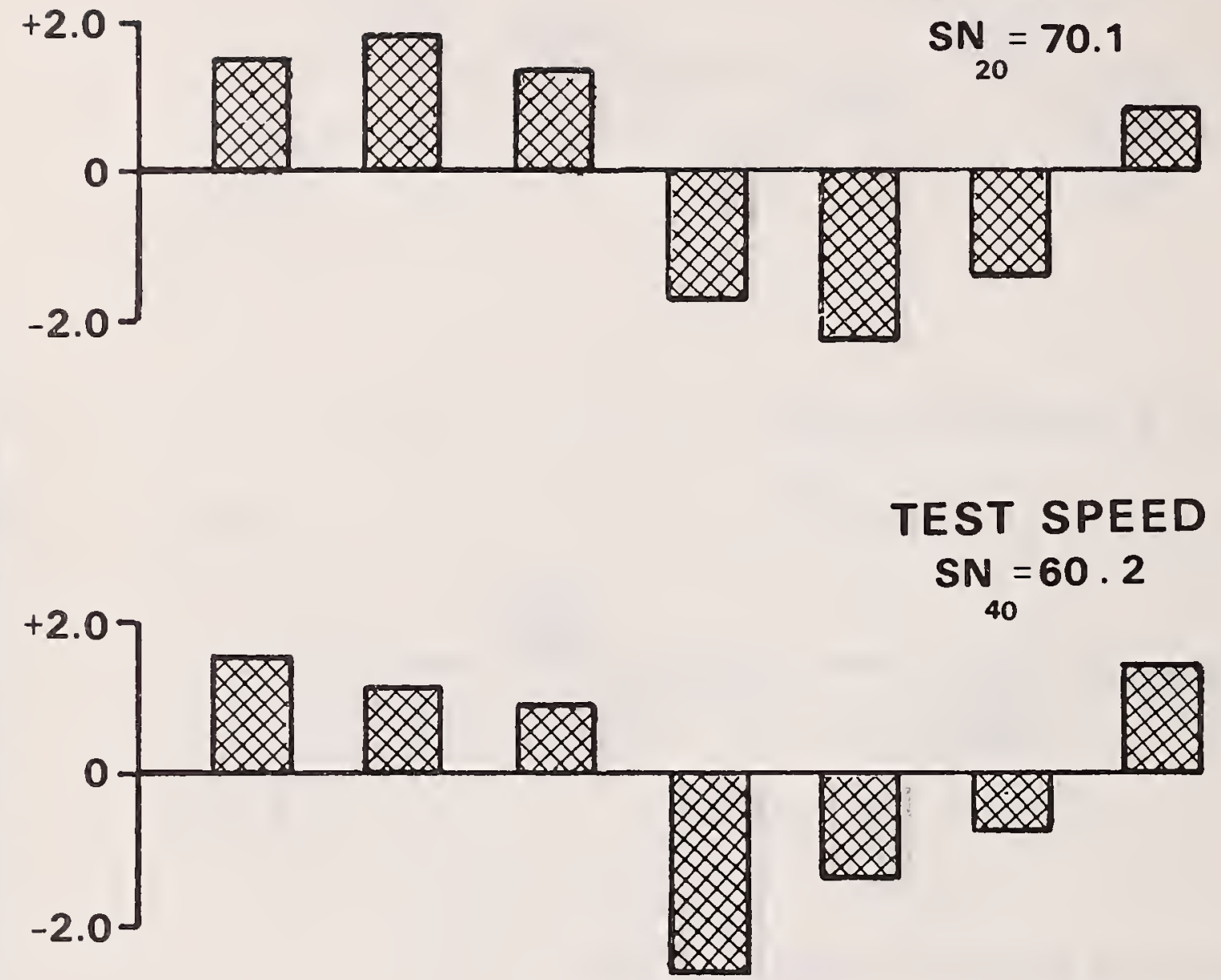
TEST SPEED $40 \mathrm{mph}(64 \mathrm{~km} / \mathrm{h})$ $S N=60.2$

$\frac{u}{2}$

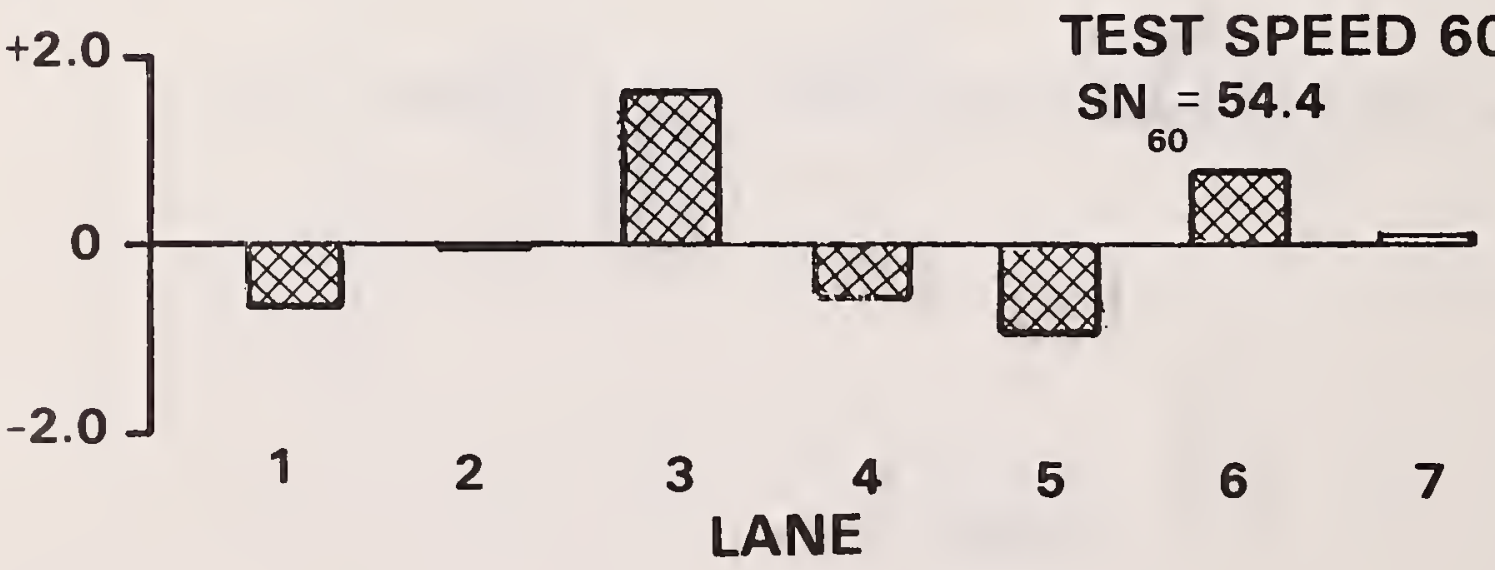

Figure 73. Deviation from the mean skid number measured by the IRS on surface 3 at the WFTC as a function of lane. 


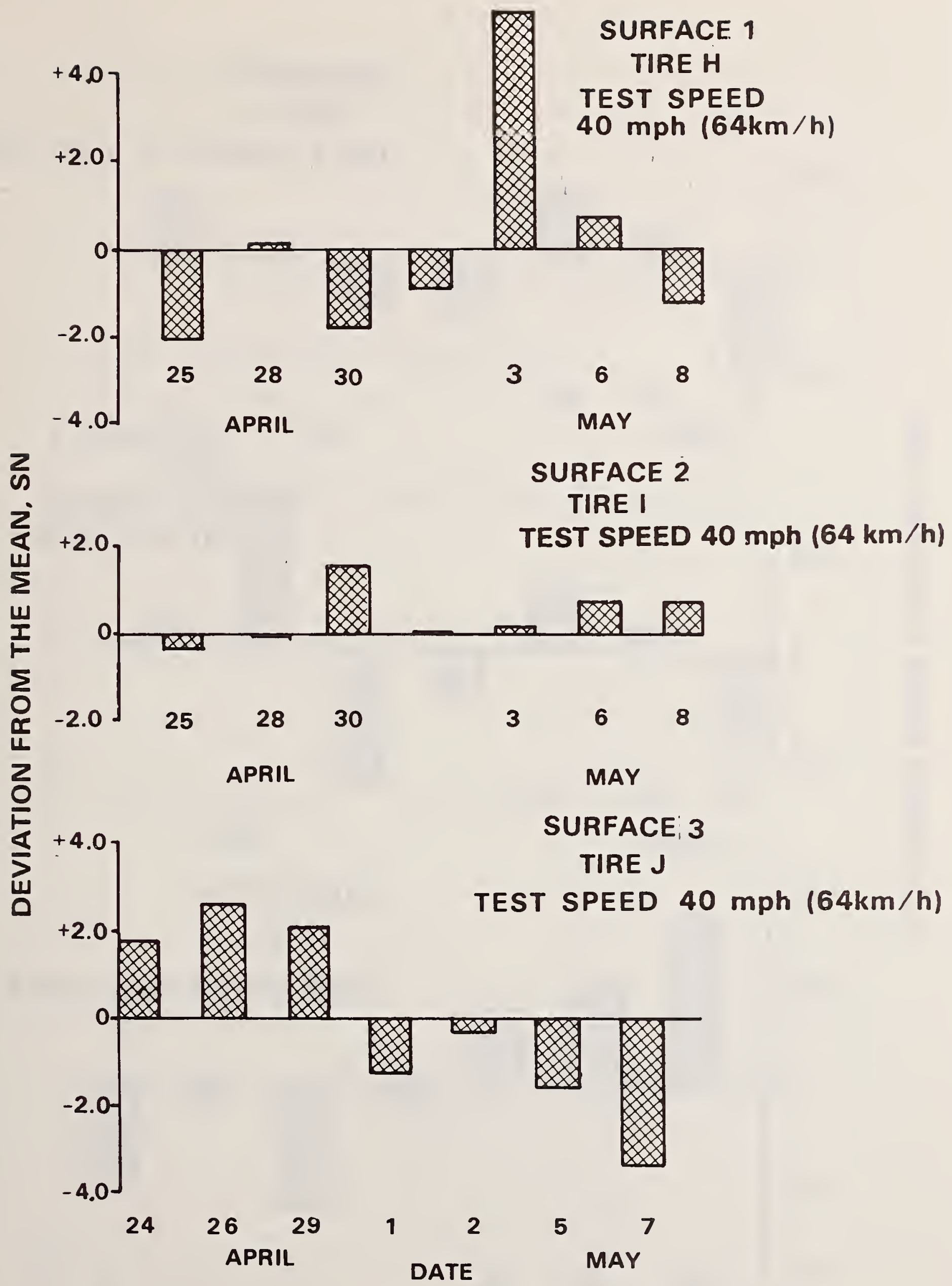

Figure 74. Deviation from the mean skid number measured by the WARS at the WFTC as a function of time period. 


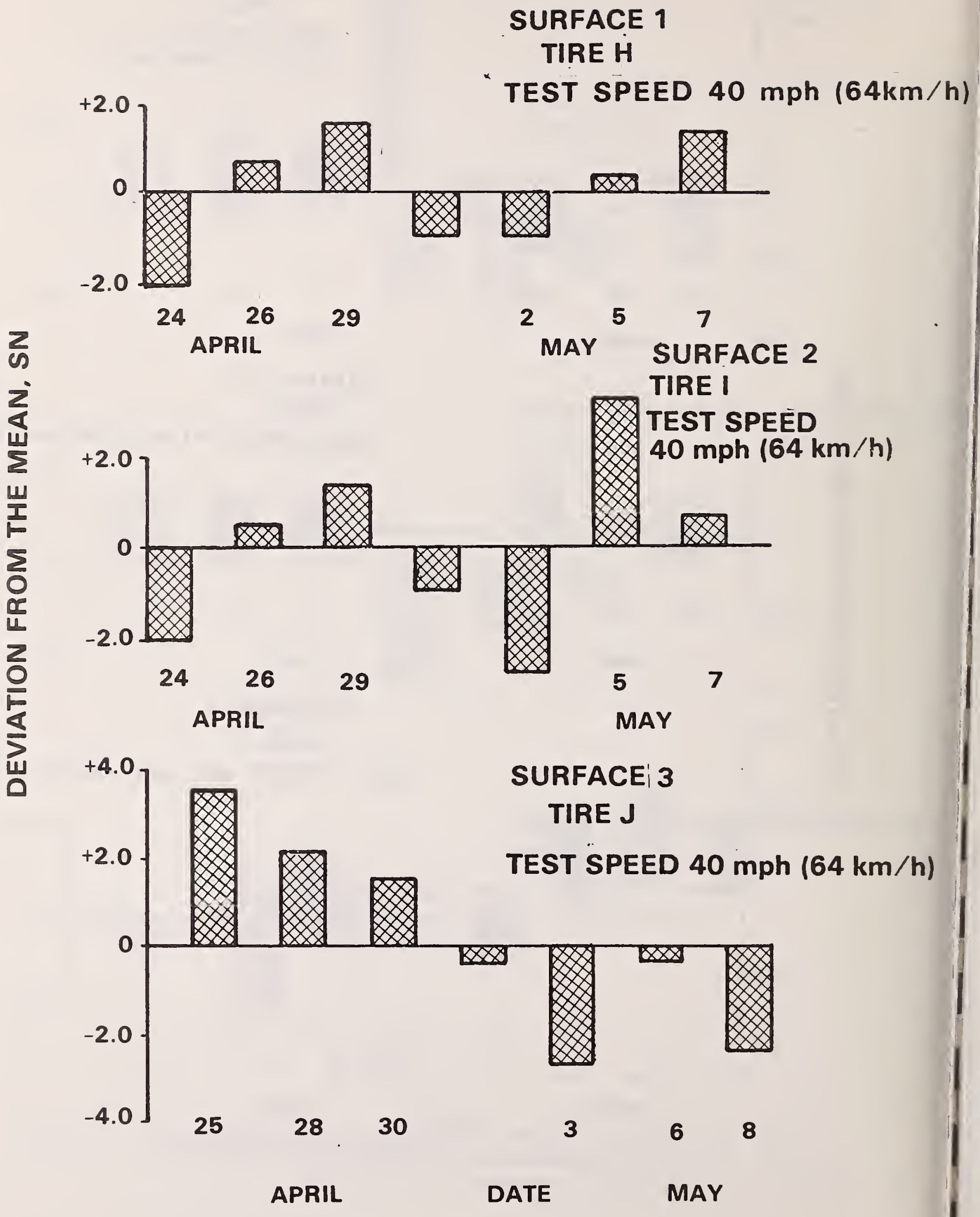

Figure 75. Deviation from the mean skid number measured by the IRS at the WFTC as a function of time period. 


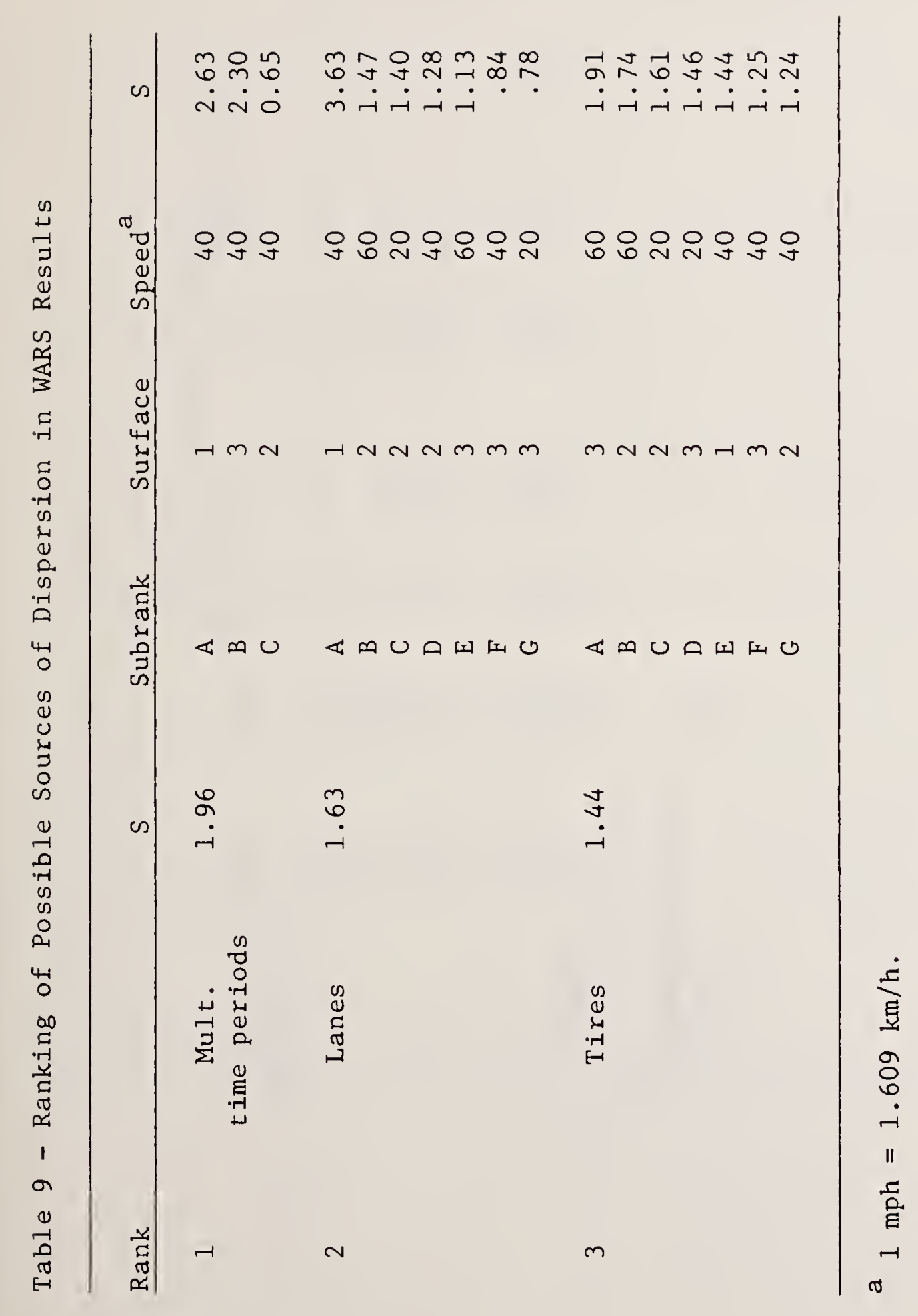




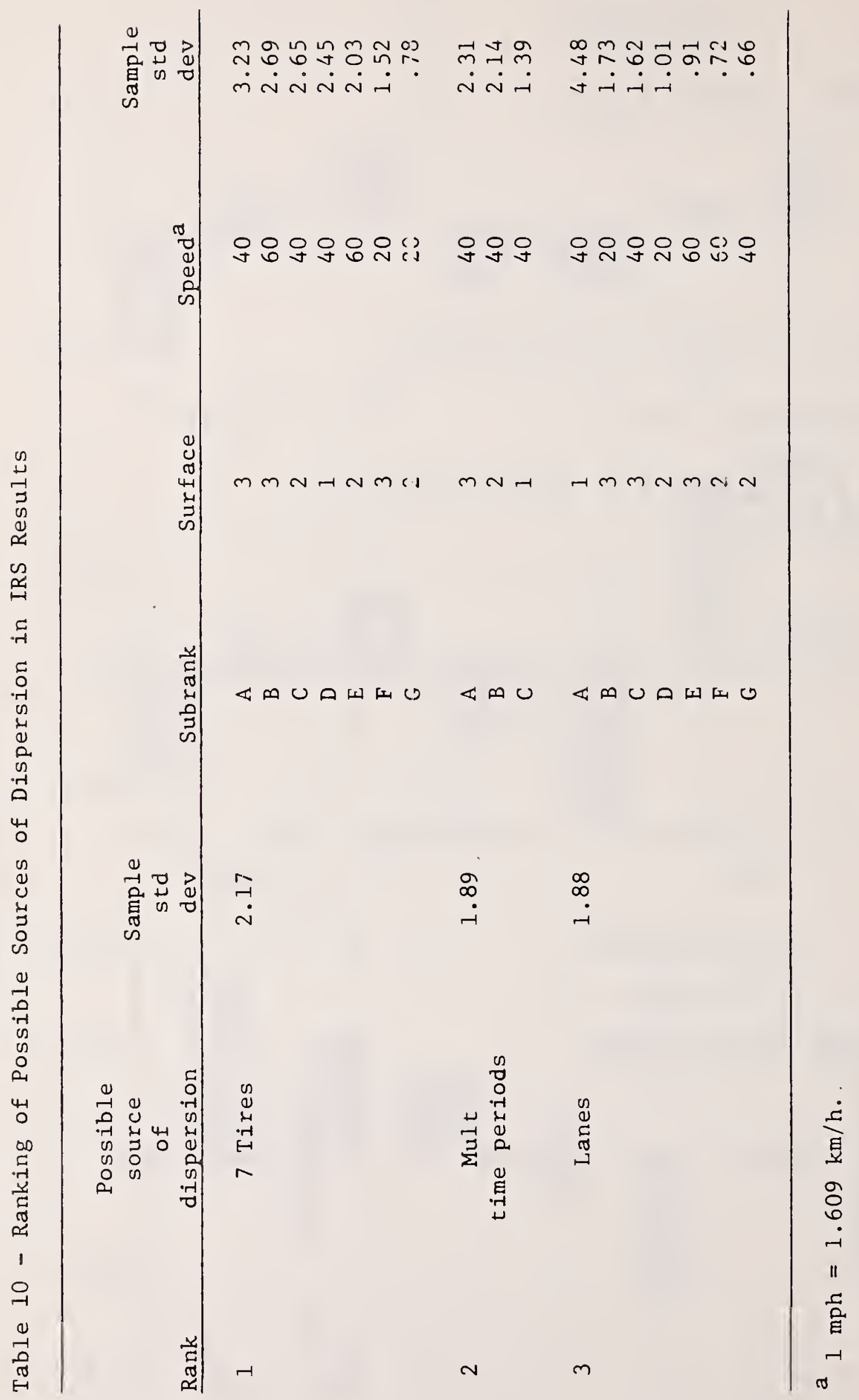




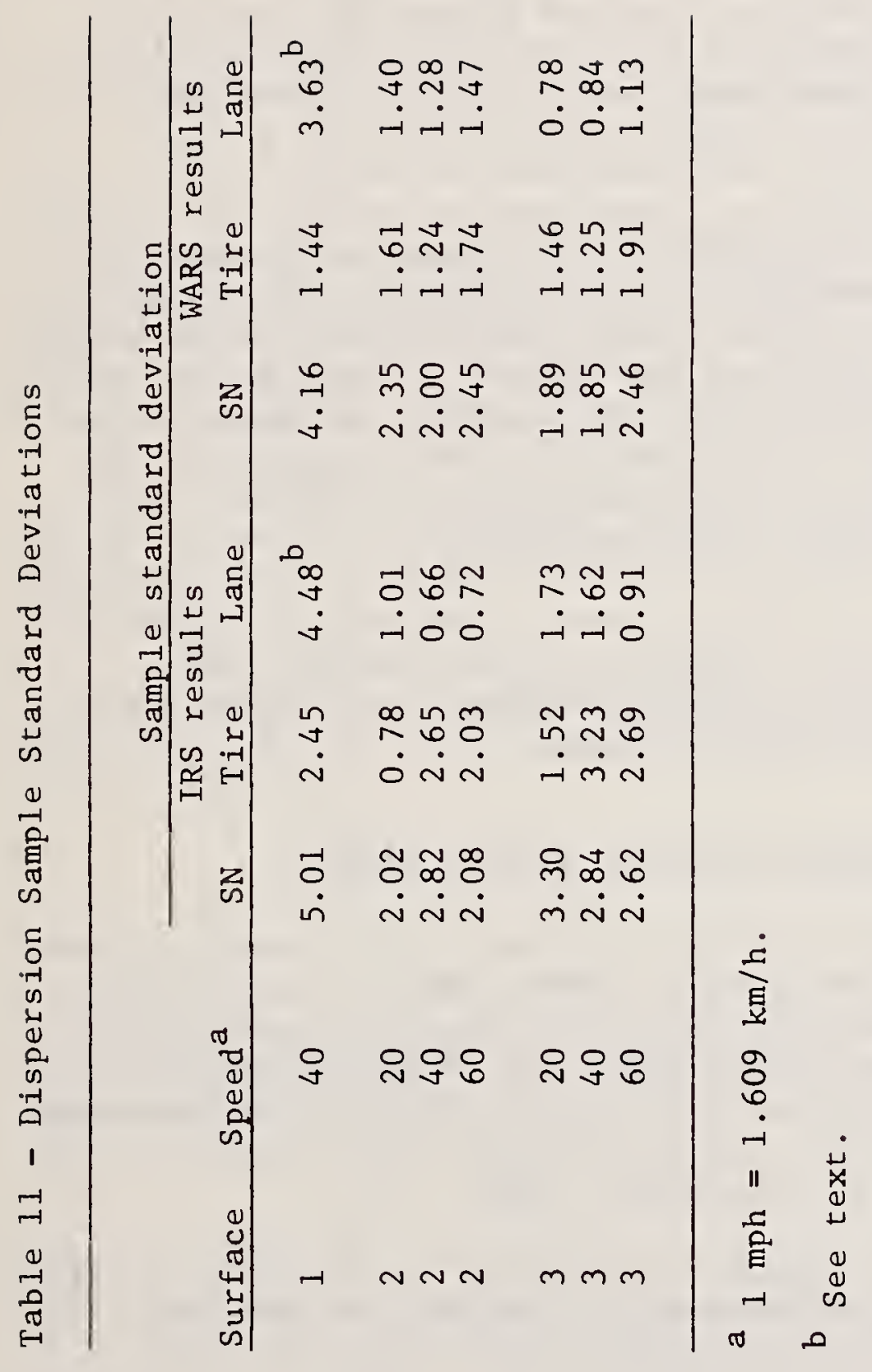


includes a share of one of the three between time period test matrices. In operation, the tests conducted on the first day were all repeated on the second day with each equipment changing test assignments on the second day. Thus, while we may expect differences in measurement between the two systems, we would not expect a difference between the average measurement made the second day from that of the first. It is therefore significant that in each of the seven two-day pairs, the average skid number measured on the second day is lower than the average skid number measured on the first day. In those instances when a portion of the second day's test program was conducted during the first day also, the second value measured on a given lane at the same speed, corrected for speed gradient, was lower than the first. When the skid measurement results are grouped by tire and date there are 37 test comparisons where the first day's result exceeds the second and 27 test comparisons where the reverse is true. When the skid measurement results are grouped by lane and date the number of test comparisons where the first day's results exceeds the second rises to 66 and there are 24 test comparisons where the reverse is true. This implies that the reduction in skid resistance value on the second day of test is associated more with the lane rather than the tire used. The average skid resistance value measured on the second day was 2.2 percent below that measured on the first day. With few exceptions, three skid tests were made per lane on the first day and three per lane on the second day.

A black film did build up on the fenders of the trailer as the skid testing progressed. This fact, in combination with the discussion above, implies the surfaces may have to be "washed" rather than "swept" to restore the skid resistance of the surfaces.

\subsection{Skid Resistance Speed Gradient}

From test data generated at largely different test speeds, we know that pavement skid resistance varies with test speed. In this section we have shown, analytically and experimentally, that the skid resistance -

test speed gradients measured, using the $2 \mathrm{mph}(3.2 \mathrm{~km} / \mathrm{h})$ differential test speeds, $\Delta S$, of the test matrix in conjunction with the differential radar system, are consistent with a continuous polynomial expression of skid resistance as a function of test speed.

The synthesis of a skid resistance expression for surface 2 at WFTC utilized the results from three test matrices measured by the IRS. The expression is:

$$
\mathrm{SN}_{\mathrm{C}}(\mathrm{V})=76.5-0.71 \mathrm{~V}+0.0070 \mathrm{~V}^{2}
$$

where $\mathrm{V}$ is the test speed in $\mathrm{mph}(1 \mathrm{mph}=1.609 \mathrm{~km} / \mathrm{h})$. 
Differentiation of this expression results in a skid resistancetest speed gradient which is also a function of test speed.

$$
\theta_{c}(V)=\frac{d(S N)}{d(V)}=-0.71+0.014 \mathrm{~V}
$$

A similar expression for the skid resistance of surface 2 at the WFTC can be synthesized from the results of three test matrices measured by the WARS. That expression is:

$$
\mathrm{SN}_{\mathrm{C}}(\mathrm{V})=79.9-0.76 \mathrm{~V}+0.0077 \mathrm{~V}^{2}
$$

Differentiation of this expression results in a skid resistancetest speed gradient which is also a function of test speed.

$$
\theta_{C}(V)=-0.76+0.0154 \mathrm{~V}
$$

The skid resistance characteristic of surface 2 as synthesized from the measurements of the IRS and the WARS are shown in Figure 76. The results show quite good agreement over the test speed range from 0 to 80 mph ( 0 to $129 \mathrm{~km} / \mathrm{h}$ ). The curves are practically parallel differing by $3.4 \mathrm{SN}$ at $0 \mathrm{mph}(0 \mathrm{~km} / \mathrm{h})$ and $4.2 \mathrm{SN}$ at $80 \mathrm{mph}(129 \mathrm{~km} / \mathrm{h})$.

The skid gradient characteristic of surface 2 as synthesized from the measurements of the IRS and WARS are shown in Figure 77 . The results show quite good agreement over the test speed range from 0 to $80 \mathrm{mph}$ ( 0 to $129 \mathrm{~km} / \mathrm{h})$.

The synthesis of a skid resistance expression for surface 3 at the WFTC utilized the results from three test matrices measured by the IRS. The expression is:

$$
\mathrm{SN}_{\mathrm{C}}(\mathrm{V})=85.2-0.87 \mathrm{~V}+0.0060 \mathrm{~V}^{2}
$$

where $\mathrm{V}$ is the test speed in $\mathrm{mph}(1 \mathrm{mph}=1.609 \mathrm{~km} / \mathrm{h})$.

Differentiation of this expression results in a skid resistancetest speed gradient which is also a function of test speed.

$$
\theta_{C}(V)=\frac{d(S N)}{d(V)}=-0.87+0.012 V
$$

An expression for the skid resistance characteristic of surface 3 at the WFTC was synthesized using the results from three test matrices measured by the WARS. The expression is:

$$
\mathrm{SN}_{\mathrm{C}}(\mathrm{V})=80.4-0.36 \mathrm{~V}+0.0006 \mathrm{~V}^{2}
$$

Differentiation of this expression results in a skid resistancetest speed gradient which is also a function of test speed. 


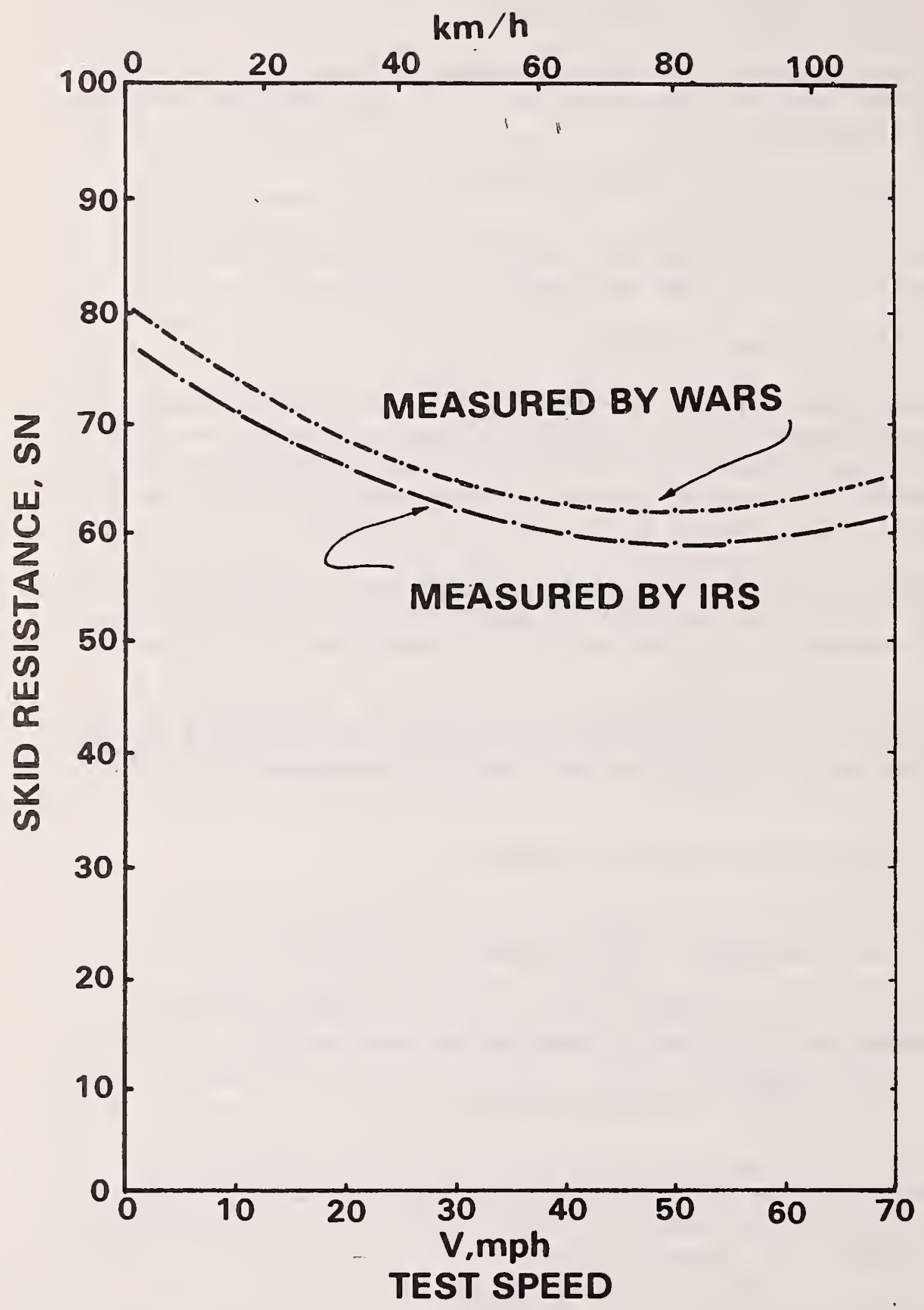

Figure 76. Skid resistance characteristic, surface 2 at FHWA, WFTC. 


$$
\theta_{c}(V)=-0.36=0.0012 \mathrm{~V}
$$

The skid resistance characteristic of surface 3 as synthesized from the measurements of the IRS and the WARS are shown in Figure 78 . The WARS results are more linear than the IRS results. Since the surface is constructed of the same aggregate as used on surface 3 at the EFTC, the results of the IRS measurements at the EFTC made in the fall of 1974 [5] are shown also. The EFTC results tend to confirm the nonlinear characteristic of the IRS results since the curves are practically parallel and also tend to confirm the higher values measured by the WARS.

The skid gradient characteristic of surface 3 as synthesized from the measurements of the IRS and the WARS are shown in Figure 79. The skid gradient results of the WARS differ from those of the IRS. The skid gradient characteristic of surface 3 at both the WFTC and the EFTC show good agreement as measured by the IRS.

Consistency of the measurements can be tested by determining the slope measured with each test matrix and comparing it with the value calculated from the formula.

For surface 2:

\begin{tabular}{cccccc} 
& \multicolumn{2}{c}{ IRS } & & \multicolumn{2}{c}{ WARS } \\
\cline { 2 - 3 } & $\theta_{c}$ & $\theta_{\mathrm{m}}$ & & $\theta_{c}$ & $\theta_{\mathrm{m}}$ \\
\hline 20 & -.43 & -.53 & & -.40 & -.26 \\
40 & -.11 & -.03 & & -.14 & -.14 \\
60 & +.13 & +.15 & & +.17 & +.35
\end{tabular}

$1 \mathrm{mph}=1.609 \mathrm{~km} / \mathrm{h}$

Both measuring systems show consistency between the measured skid gradient, $\theta_{\mathrm{m}}$, and the calculated skid gradient, $\theta_{\mathrm{c}}$.

For surface 3:

\begin{tabular}{|c|c|c|c|c|}
\hline \multirow[b]{2}{*}{$\underset{\mathrm{mph}}{\mathrm{V}}$} & \multicolumn{2}{|c|}{ IRS } & \multicolumn{2}{|c|}{ WARS } \\
\hline & $\theta_{c}$ & $\theta_{\mathrm{m}}$ & $\theta_{c}$ & $\theta_{\mathrm{m}}$ \\
\hline 20 & -.63 & -.71 & -.34 & -.38 \\
\hline 40 & -.38 & -.49 & -.31 & -.38 \\
\hline 60 & -.15 & +.56 & -.29 & -.45 \\
\hline
\end{tabular}

$1 \mathrm{mph}=1.609 \mathrm{~km} / \mathrm{h}$ 


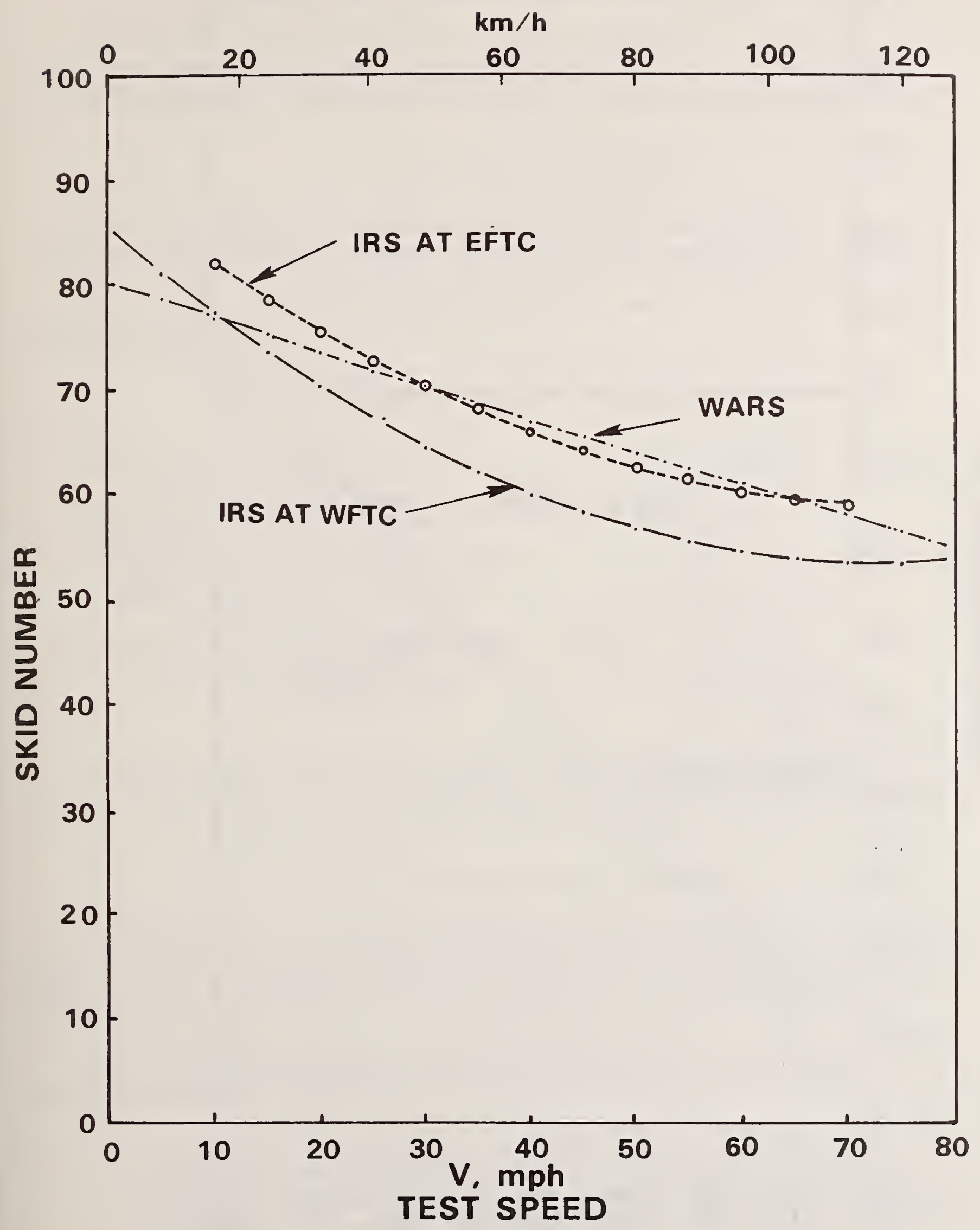

Figure 78. Skid resistance characteristic, surface 3 at FHWA, WFTC. 


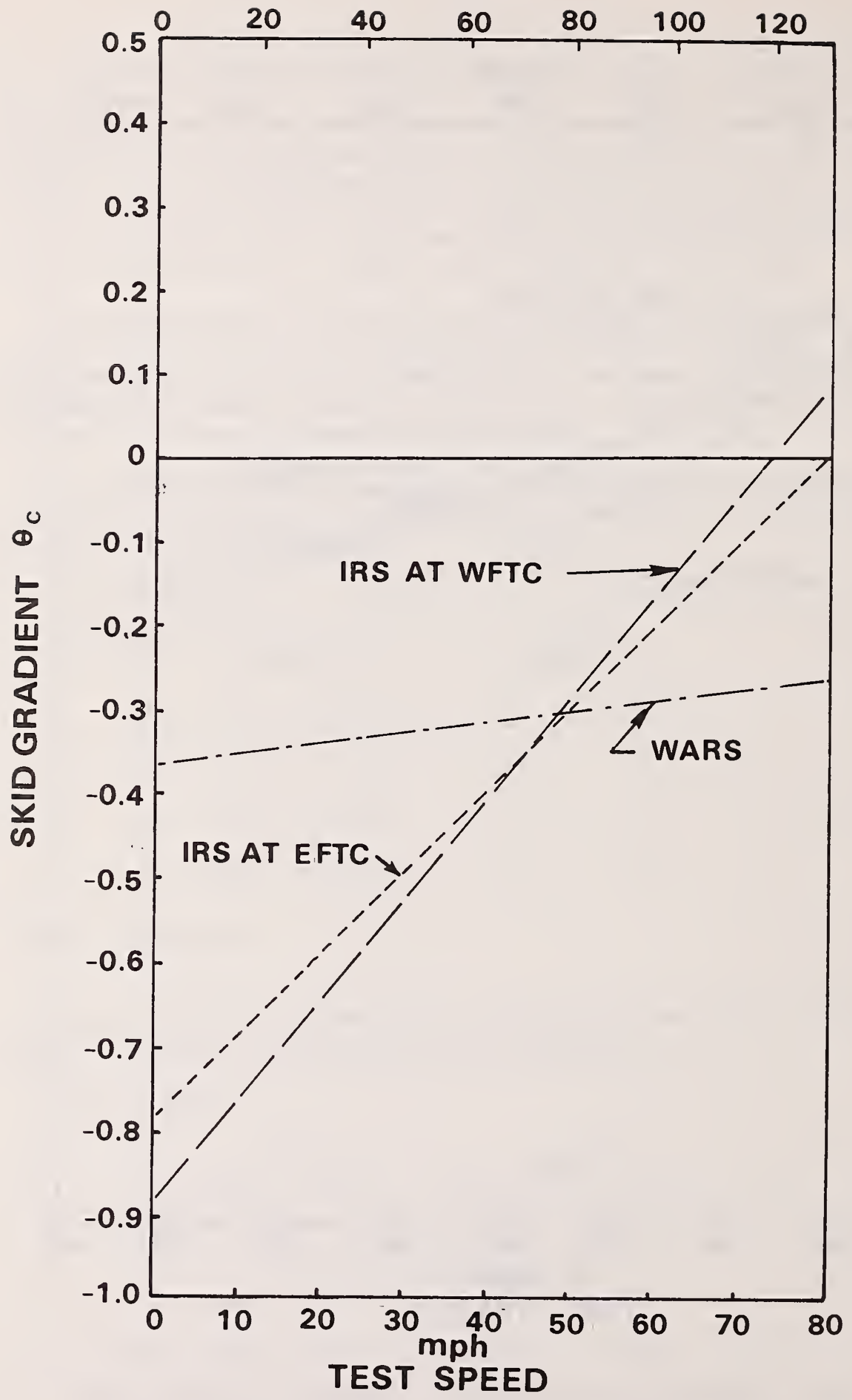

Figure 79. Skid gradient characteristic, surface 3 at FHWA, WFTC. 
The measured skid gradient $\theta_{\mathrm{m}}$, made by the IRS at $60 \mathrm{mph}(97 \mathrm{~km} / \mathrm{h})$ is not consistent with the corresponding calculated skid gradient, $\theta$. The WARS measured values are all consistent with the calculated values.

\subsection{The Correlation Equation}

The results of the dynamic skid resistance measurement test program conducted on the three surfaces at the WFTC are summarized in Table 12.

The linear correlation equation for the seven sets of single time period results is:

$$
\text { SN }_{\text {WARS }}=4.55+0.99 \mathrm{SN}_{\text {IRS }}
$$

$\begin{array}{ll}\text { Correlation coefficient } & 0.974 \\ \text { Residual standard deviation } & 2.01 \\ \text { Standard deviation of intercept } & 6.12 \\ \text { Standard deviation of slope } & 0.103 \\ \text { Standard deviation of predicted } & 1.6\left(\mathrm{SN}_{45}\right) \\ \text { value (a point on the line) } & 0.88\left(\mathrm{SN}_{50-60}\right) \\ & 1.4\left(\mathrm{SN}_{70}\right)\end{array}$

A plot of the equation and data points is shown in Figure 80 . The length of the crosses correspond to the 99 percent confidence interval, L.

\subsection{Use of the Correlation Equation}

To predict a value with 95 percent confidence limits, multiply the standard deviation of predicted values by 2.571 . To predict a value with 90 percent confidence limits, multiply the standard deviation of predicted values by 2.015 .

The correlation equation data may be interpreted as follows for 90 percent confidence limits:

\footnotetext{
"In repeated calibration of WARS using the same general procedure, the results are not expected to differ from the present calibration by more than $3.2 \mathrm{SN}$ at the low end of the calibration line $\left(\mathrm{SN}_{45}\right)$, by more than $1.8 \mathrm{SN}$ in the middle range ( $\left.\mathrm{SN}_{50-60}\right)$ and by more than $2.8 \mathrm{SN}$ at the high end $\left(\mathrm{SN}_{70}\right)$."
}

In using the calibration line, presumably WFTC personnel would like to predict IRS values from their own measurements, using 


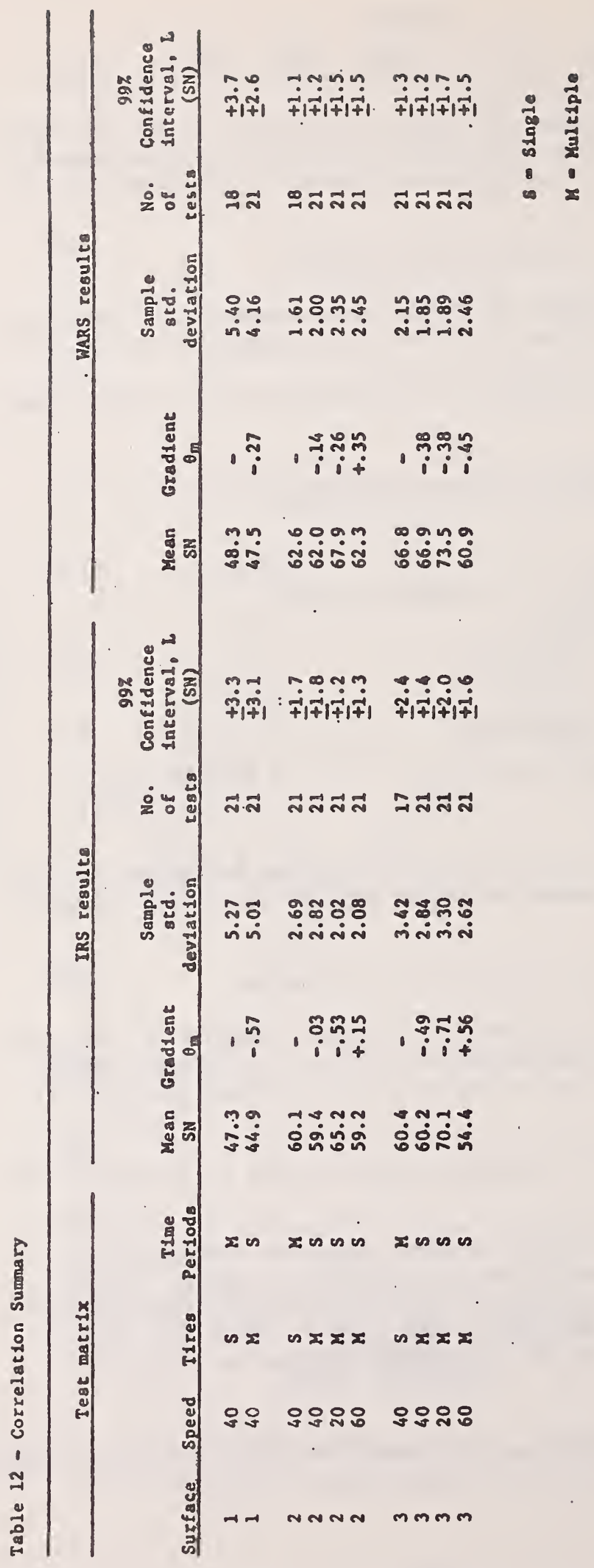




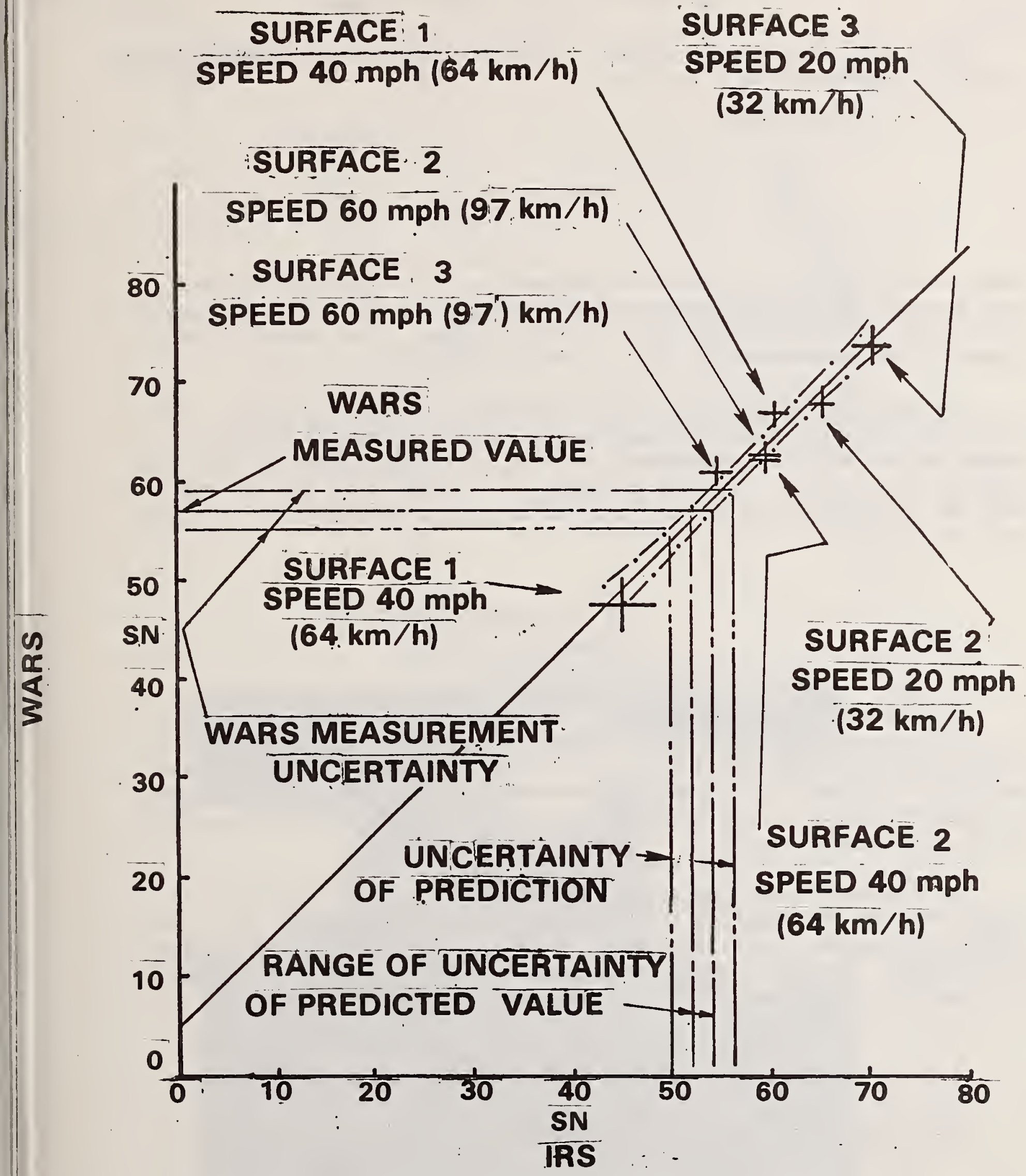

Figure 80. WARS-IRS correlation, single time period results. 


$$
\mathrm{SN}_{\text {IRS }}=-1.34+0.969 \mathrm{SN}_{\text {WARS }}
$$

The uncertainty for 90 percent confidence limits of a predicted IRS value for a given value of WARS is

SN Number

45

60

70
Uncertainty

3.4

1.7

2.6

computed as before. In addition, the random error component of WARS must also be taken into consideration. A graphical procedure is perhaps the easiest way to estimate the total uncertainty. The example shown in Figure 80 is drawn for a 90 percent confidence band.

The uncertainty given for the calibration line itself is in a sense systematic in nature from the WARS point of view, 1.e., if WARS is comparing the SN of two different surfaces, this systematic uncertainty cancels out. However, if WARS compares its results with another ARS, then the uncertainty of the two calibration lines will have to be taken into consideration.

\section{THE IRS GROUND STATION}

\subsection{Introduction}

The skid resistance measurement process includes the conversion of the measurement instrumentation outputs to skid number. Measurement precision may be degraded due to differences in judgement between data analysts. Further, the precision of repeated measurements depends upon the identification of the specific section of surface that corresponds to the skid number result.

To further improve the skid resistance measurement process in this regard the IRS was modified to include a ground station (Fig. 81). The ground station was partially evaluated during the dynamic skid testing at the WFTC. In this section, the features of the ground station and the results of the evaluation tests are given.

\subsection{Features of the Ground Station}

There are three outputs from the ground station:

1) a magnetic tape record of all the test data scaled in engineering units, preceded by

a test description. 


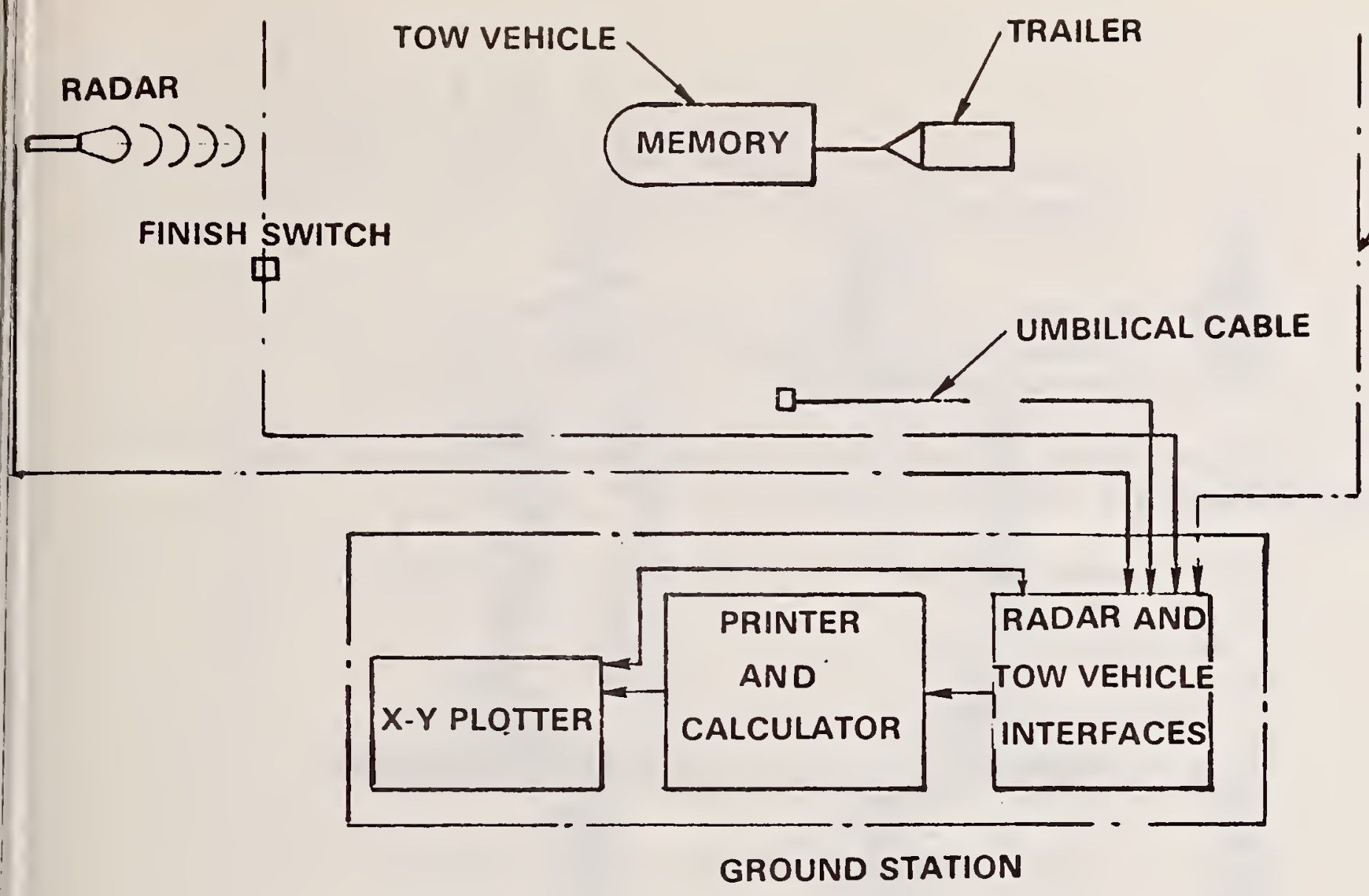

a) BLOCK DIAGRAM

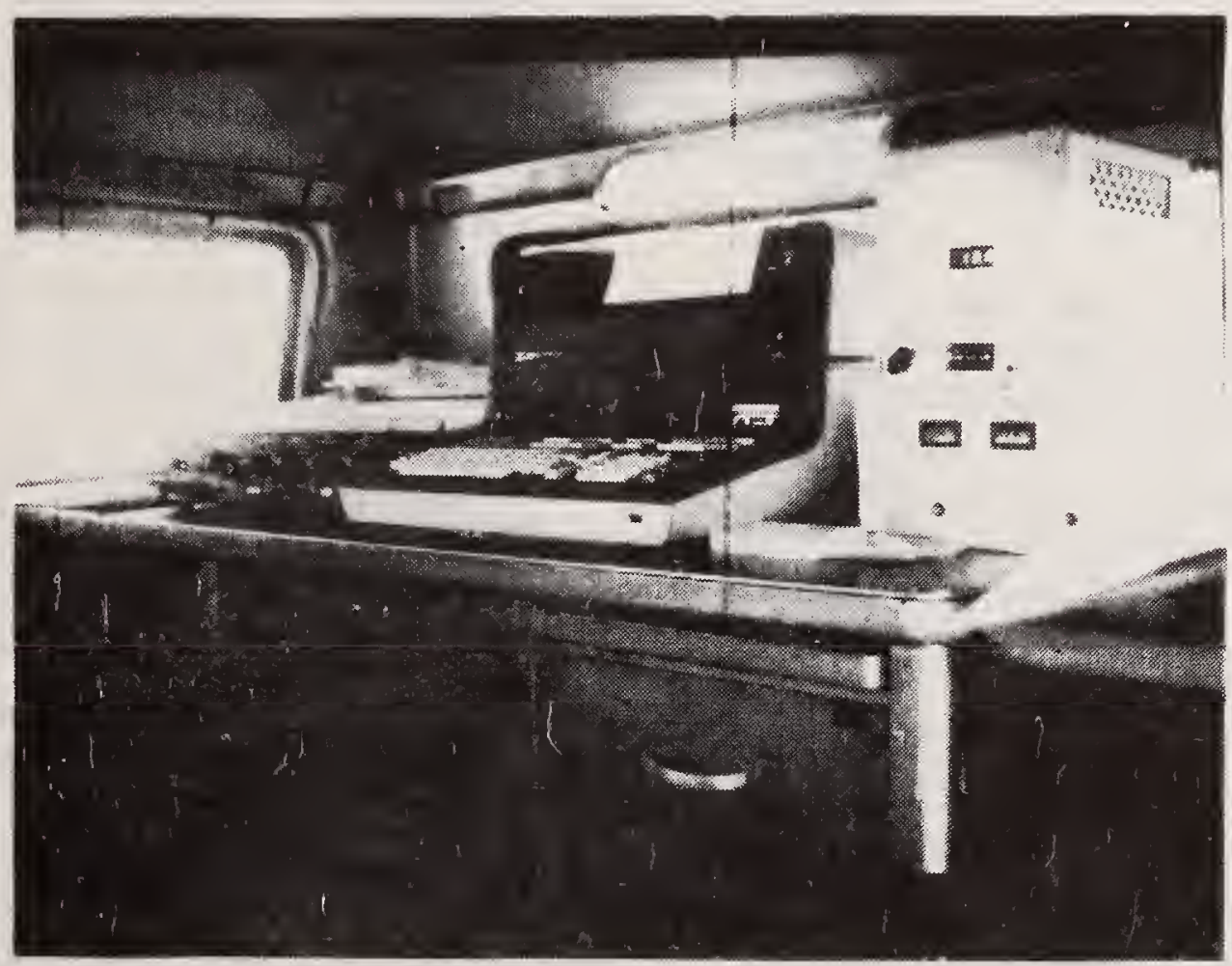

b) SET-UP WITH A VAN AT THE WFTC 
2) an automatic plot of the test variables as a function of longiludinal location on the surface, and

3) a statistical analysis of the SN results between whichever longitudinal distance limits are selected.

When test data are recalled from the magnetic tape, the ground station automatic printout includes:
a) file number,
b) date of test,
c) time of day,
d) surface number, lane number, nominal test speed,
e) skid trajectory start lane and finish lane, and
f) static test wheel load.

The on-board analog strip chart recorder plots the test variables versus time. Traction, vertical load and water flow rate are simultaneously recorded in the digital on-board memory. The momory is unloaded through the umbilical cable to the ground station. The automatic plot from the ground station records the test variables versus distance $110 \mathrm{~m}$ a start switch (Fig. 82). The start swilch is segmented such that the starting and finishing transverse location is known in one foot $(0.3 \mathrm{~m})$ increments.

As soon as the start tape switch is energized, the ground station integrates the radar speed data with respect to time to oblain the longitudinal distance coordinate of the test variable outputs.

Test speed is plotted to a resolution of $0.1 \mathrm{mph}(0.2 \mathrm{~km} / \mathrm{h})$. Water flow rate is plotted to a resolution of $0.1 \mathrm{gpm}(0.41 / \mathrm{min})$. Traction and vertical load are plotted to a resolution of $0.5 \mathrm{lbf}(2.2 \mathrm{~N})$.

The combination of lateral lane position and test parameter variations plotted as a function of longitudinal position from a known start point locates the section of surface that corresponds to the skid number result.

The data analyst is required to judge the mean value of both the traction recording and the vertical load recording over a one second interval. Previous experiments by NBS personnel, using data which had also been reduced at the CFTC, indicated that differences between data analysts can result in five percent differences in skid numbers measured. 


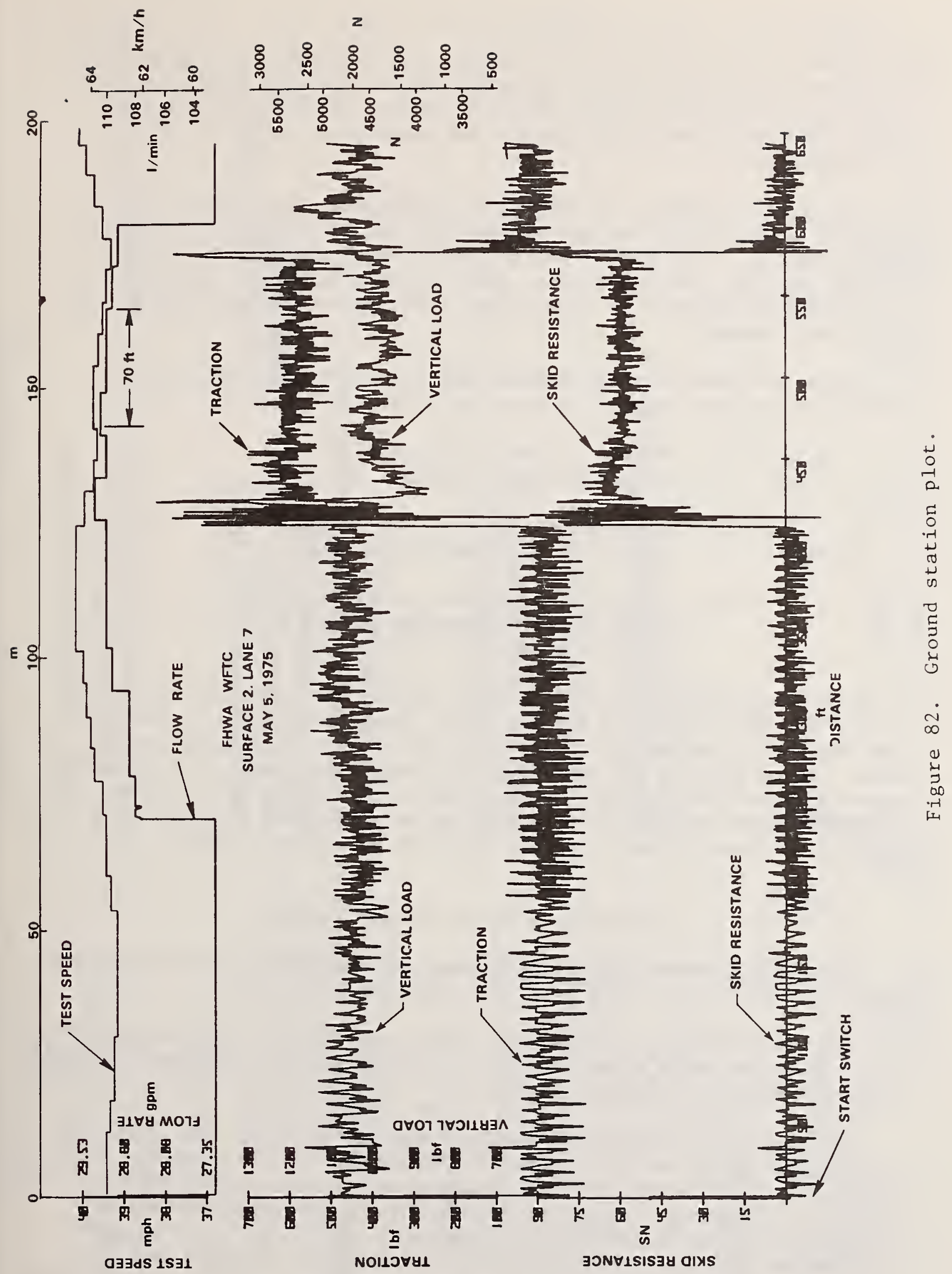


Skid number, as calculated by an analyst, is then taken as the quotient of the two mean values. The skid number values plotted by the ground station are the instantaneous quotients of the traction and vertical load. The mean value calculated by the ground station is the mean of the quotients.

Further, to comply with the ASTM method, the data analyst must use judgement to reference the one second interval to the start of steady state friction. From Figure 83, it can be shown that steady state friction does not generally start after a fixed delay in time from the start of brake application, but rather, requires more time delay at the higher test speeds.

There are three results printed automatically when the ground station statistical analysis feature is used. These are:

1) the mean value of $\mathrm{SN}$ between

two longitudinal limits,

2) the standard deviation of $\mathrm{SN}$ with respect to this mean value, and

3) the best, in a least squares sense, second degree polynomial fitted to the data between the limits.

By using this feature repeatedly, while moving the same interval length through the data, Table 13 and Figure 84 can be constructed. The location where the standard deviation about the mean is a minimum can be found. Using this as a mathematical definition of steady-state, the one second data interval can be located without the use of data analyst judgement. The corresponding second degree polynomial is given as a function of longitudinal position along the surface in Figure 85.

\subsection{Evaluation of the Ground Station}

The evaluation of the ground station was based upon a comparison of ground station results with other IRS measurements.

The data analyst established a skid number value of 59 for this test. The mean value determined by the ground station using the minimum standard deviation technique is 58.6 .

The radar was tracking the vehicle during the test. The resulting differential radar record is shown in Figure 86. The test whee1 "lock" (L) and "unlock" (U) events were marked manually after being seen visually. The ground station plot mimics the radar speed information perfectly starting at the 400 foot position. The "lock" and "unlock" event marks are also properly synchronized with the traction force trace. The radar indicates that the test speed was constant at $40.2 \mathrm{mph}$ 


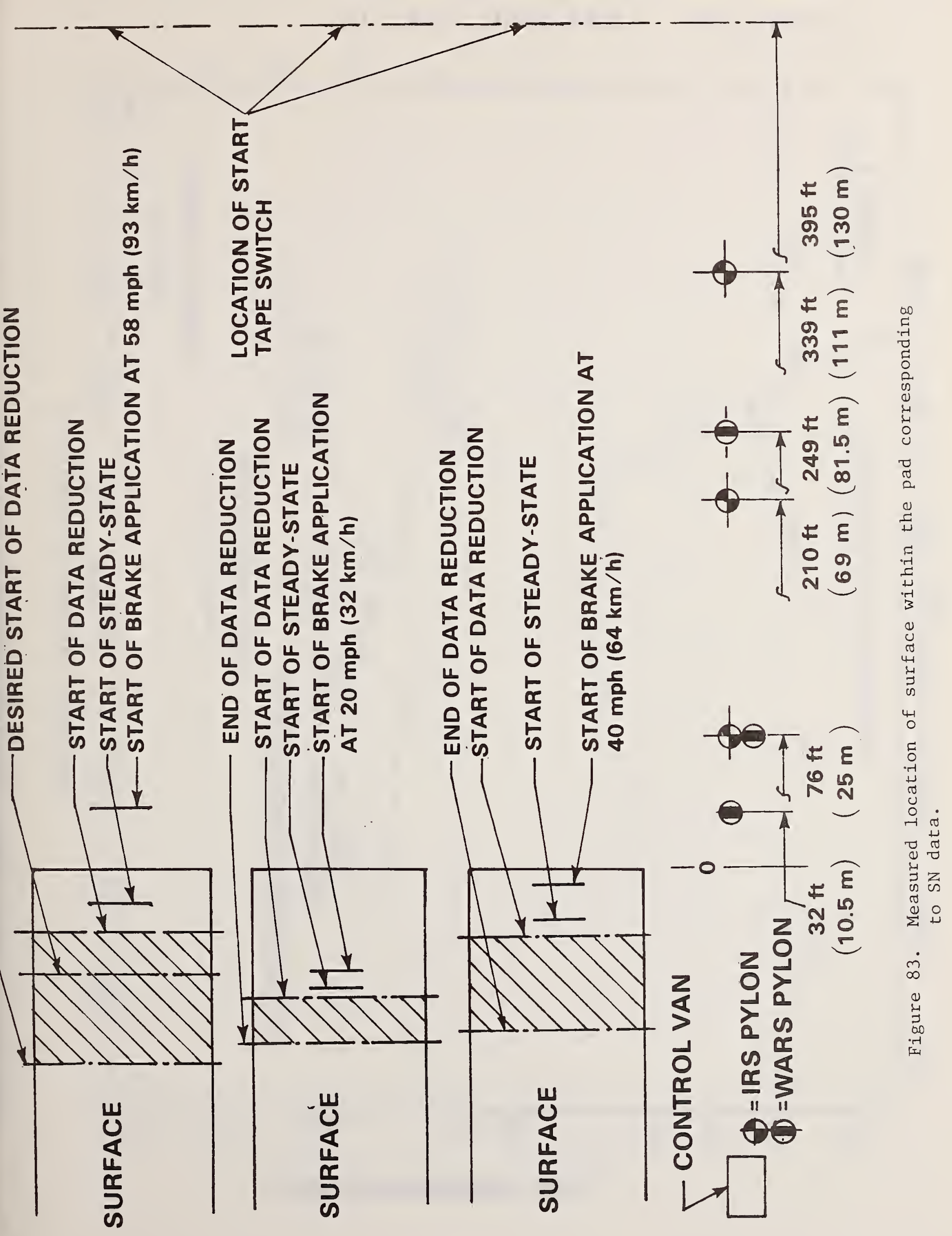




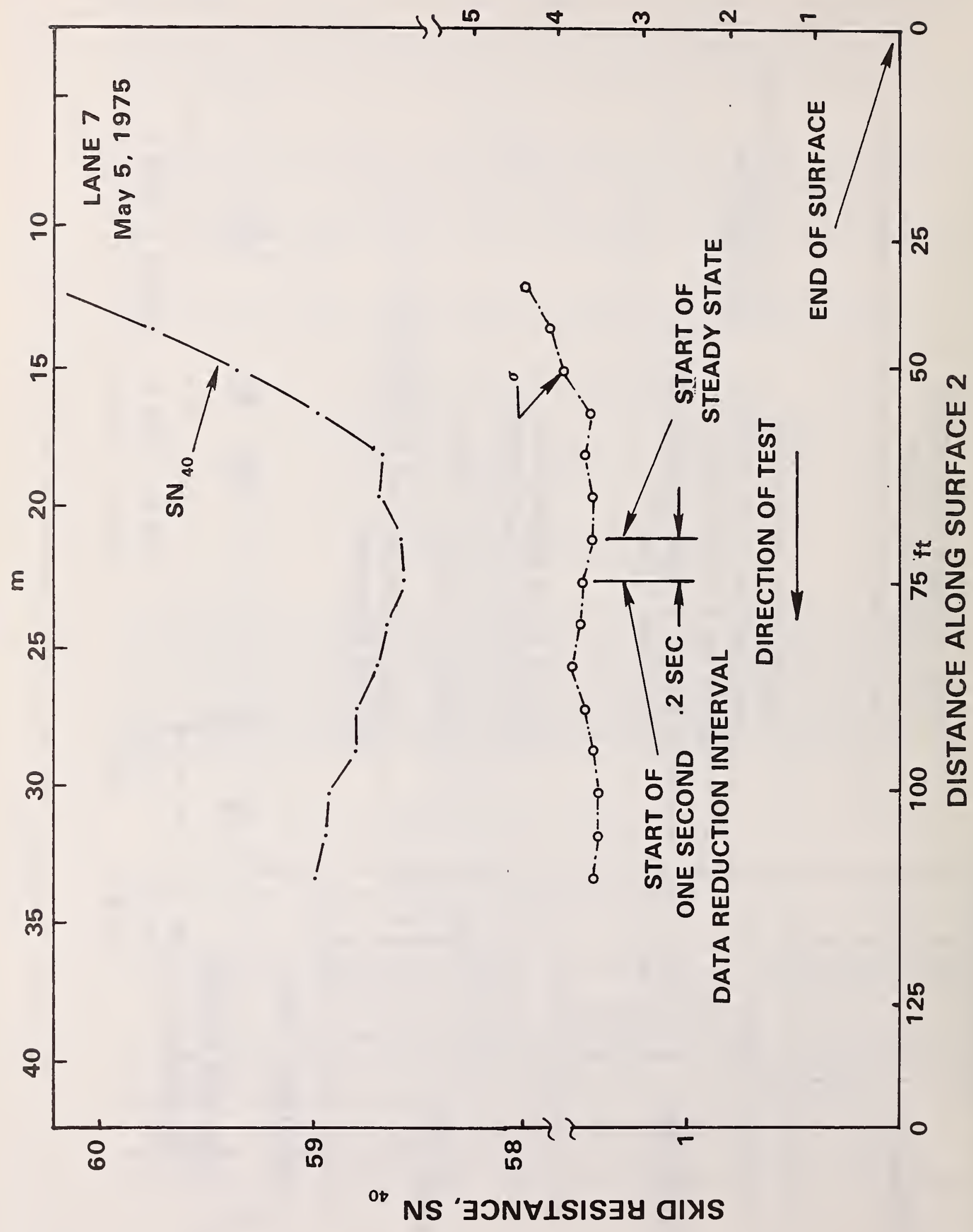




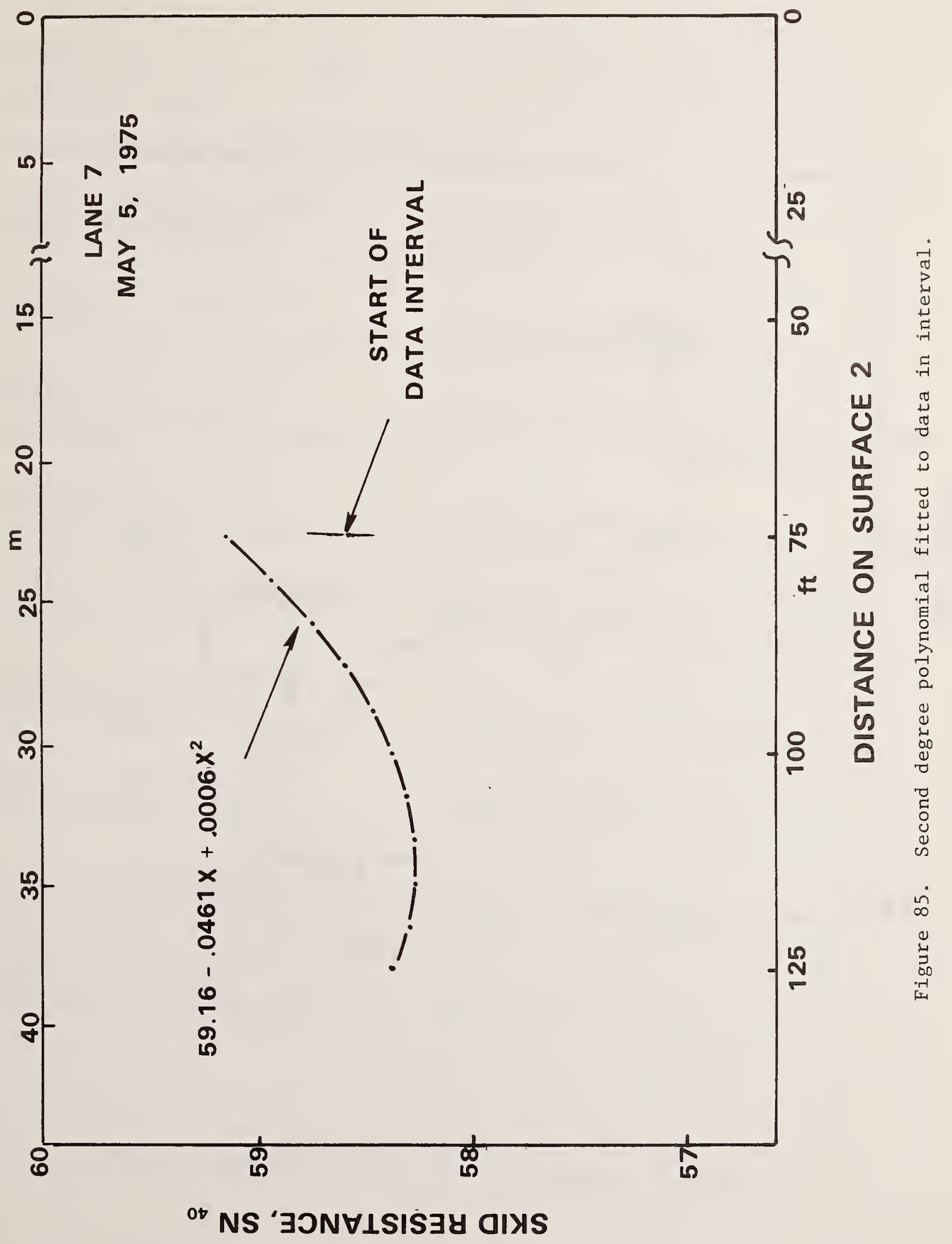




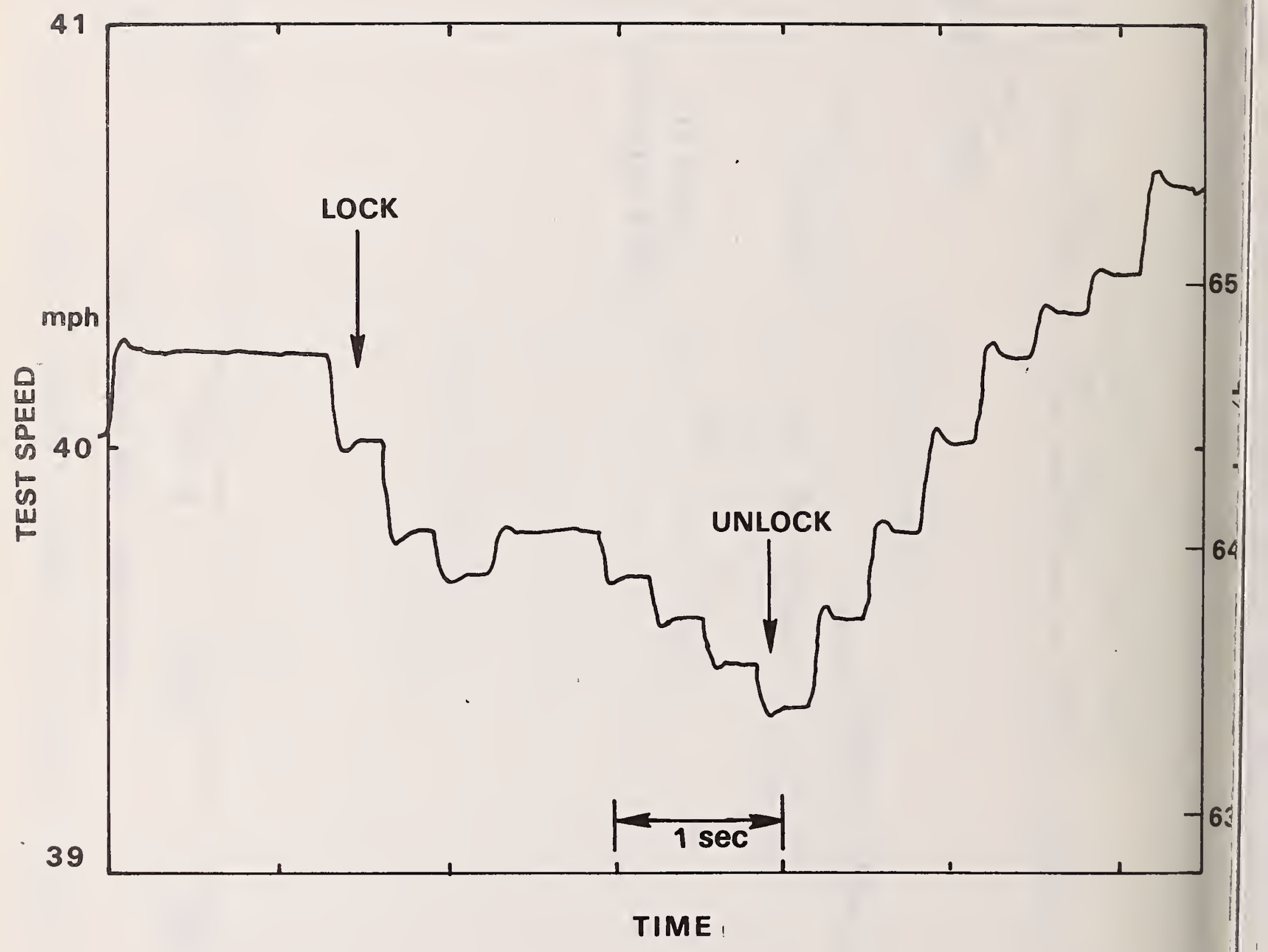

Figure 86. Differential radar system plot of test speed. 
Table 13 - Skid Number Values Computed by the Ground Station

\section{DATE: $5,5<75$ \\ TIME: 1405 \\ SIJRFACE: 2740}

INTEGRATED DISTANCE = 643.88GE1164

EHTER LIMITS?450,568.5

MEAN $=58.97529659 \quad S I G M A=3.677319464$

C.DEFFICIENTS: $(60.4922)+(-9.1003) x+(0.01823 \times 12$

ENTER LIMITS? $455,513.5$

MEAH = 58.6511967? SIGMA= 3.761497192

COEFFICIENTS: (59.9264) + (-6.6192\% +

EHTER LIMITST4E, 512.5

MEAH = 5.6.6141613 SILMA= 3.645952EIE

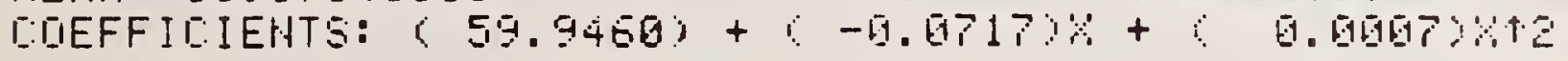

EHTEF LIMITS?4E.5.5.5.5

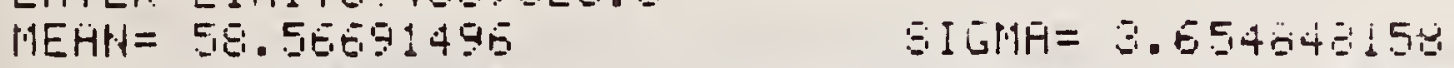

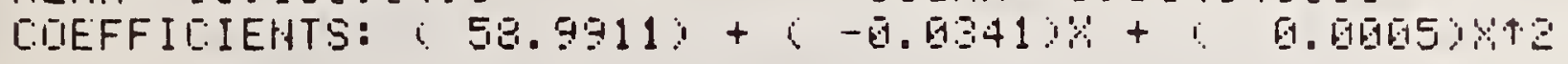

ENTEF: LINITSTHO 528.5

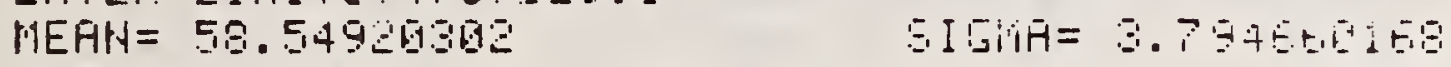

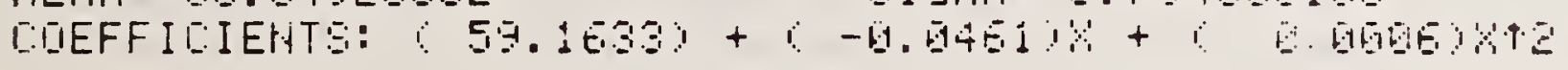

ENTEF LIMITST475.533.5

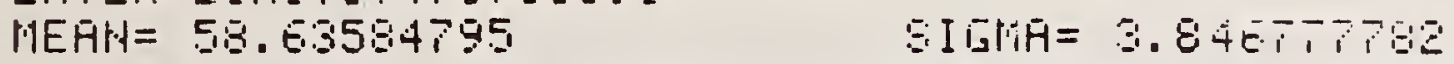

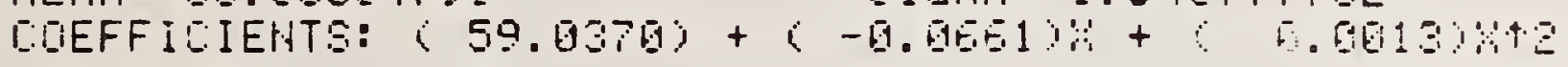

ENTEF: LINITST496, 595.5

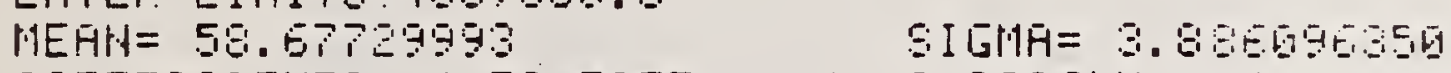

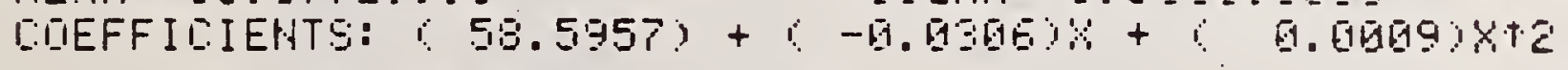

ENTEF: LIMITS:485.54:5

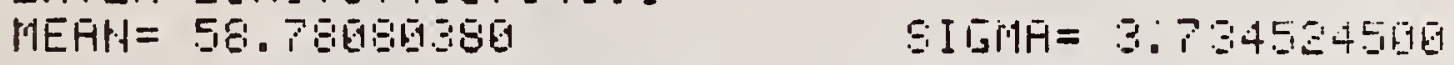

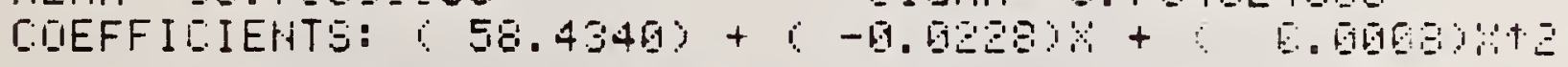

ENTER I.IMITST496, 548.5

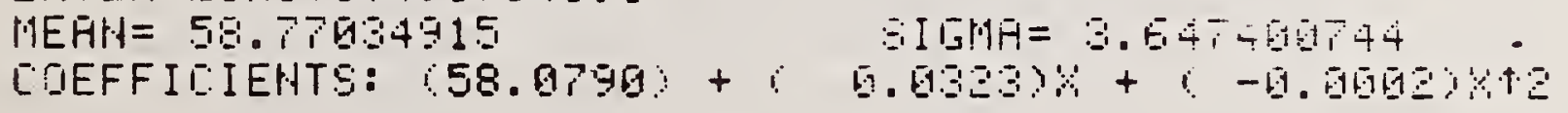


$(64.7 \mathrm{~km} / \mathrm{h})$ for approximately one second prior to wheel lock. At wheel lock the test speed was $40.0 \mathrm{mph}(64.4 \mathrm{~km} / \mathrm{h})$, declined to $39.7 \mathrm{mph}$ (63.9 $\mathrm{km} / \mathrm{h})$, recovered to $39.8 \mathrm{mph}(64.0 \mathrm{~km} / \mathrm{h})$, and declined again to $39.4 \mathrm{mph}(63.4 \mathrm{~km} / \mathrm{h})$ at wheel unlock after which the speed increased rapidly through $40 \mathrm{mph}(64 \mathrm{~km} / \mathrm{h})$. The on-board fifth wheel record is shown in Figure 87. It indicates that the speed was $40.4 \mathrm{mph}(65.0$ $\mathrm{km} / \mathrm{h}$ ) just prior to lock-up of the test wheel. The speed declined to $39.7 \mathrm{mph}(63.9 \mathrm{~km} / \mathrm{h})$ recovered to $39.9 \mathrm{mph}(64.2 \mathrm{~km} / \mathrm{h})$, and declined again to $39.5 \mathrm{mph}(63.6 \mathrm{~km} / \mathrm{h})$ just after wheel unlock after which the speed increased rapidly through $40 \mathrm{mph}(64 \mathrm{~km} / \mathrm{h}$ ). (The rapid increase is not reproduced here.) Both the radar and fifth wheel instrumentation have a digital uncertainty of $0.1 \mathrm{mph}(0.2 \mathrm{~km} / \mathrm{h})$. A comparison of the records indicates the fifth wheel instrumentation may be higher than the radar by approximately $0.1 \mathrm{mph}(0.2 \mathrm{~km} / \mathrm{h})$.

Both the ground station plot and the on-board instrumentation indicate that the flow rate was $29.1 \mathrm{gpm}(107.71 / \mathrm{min})$ when the speed was $39.8 \mathrm{mph}(64.0 \mathrm{~km} / \mathrm{h})$. The desired flow rate at $39.8 \mathrm{mph}(64.0 \mathrm{~km} / \mathrm{h})$ is $27.9 \mathrm{gpm}(103.4 \mathrm{l} / \mathrm{min})$. The flow rate may have been high by 3 percent. Since the traces are reasonably parallel, the flow rate was proportional to test speed.

There is also good agreement between time as measured on the onboard recorder, test speed, and distance as computed by the ground station. Since flow rate is recorded versus time and distance it is used for the comparison. A 1.2 second interval on the time scale corresponds to 70 feet $(21 \mathrm{~m})$ on the distance scale. This is nominally correct at $39.7 \mathrm{mph}(63.9 \mathrm{~km} / \mathrm{h})$, approximately the average test speed during the interval.

The test wheel brake application occurred at 410 feet $(125 \mathrm{~m})$ beyond the start tape, which is 5 feet $(1.5 \mathrm{~m})$ after the beginning of the test surface (see Fig. 83). This is closer to the surface beginning than desired but the average speed during the approach was low. The test tire "shudders" during the free rolling to lock-up transition. The traction force at the tire-pavement interface generates a moment with respect to the hitch which unloads the vertical force causing the trailer to bounce vertically after lock-up.

To further evaluate the ground station, a test was simulated using known inputs. The ground station radar signal input was set to 40.0 $\operatorname{mph}(64.4 \mathrm{~km} / \mathrm{h})$. The flow rate differential was set to $+0.2 \mathrm{gpm}(0.7$ $1 / \mathrm{min})$ above the set point of $28.8 \mathrm{gpm}(1061 / \mathrm{min})$. The dynamic calibrator was then cycled twice during the automatic test time interval. Each cycle generated a sequence of signals on the traction and vertical load channels which was equivalent to known values of force. The test results were then stored on magnetic tape by the ground station and plotted at a later date. The results are plotted in Figure 88 . The calculated skid number segments appear correct within the resolution of the scales. Second degree polynomials were fitted to four intervals of skid number. The fitted results are shown superimposed on the data intervals. 


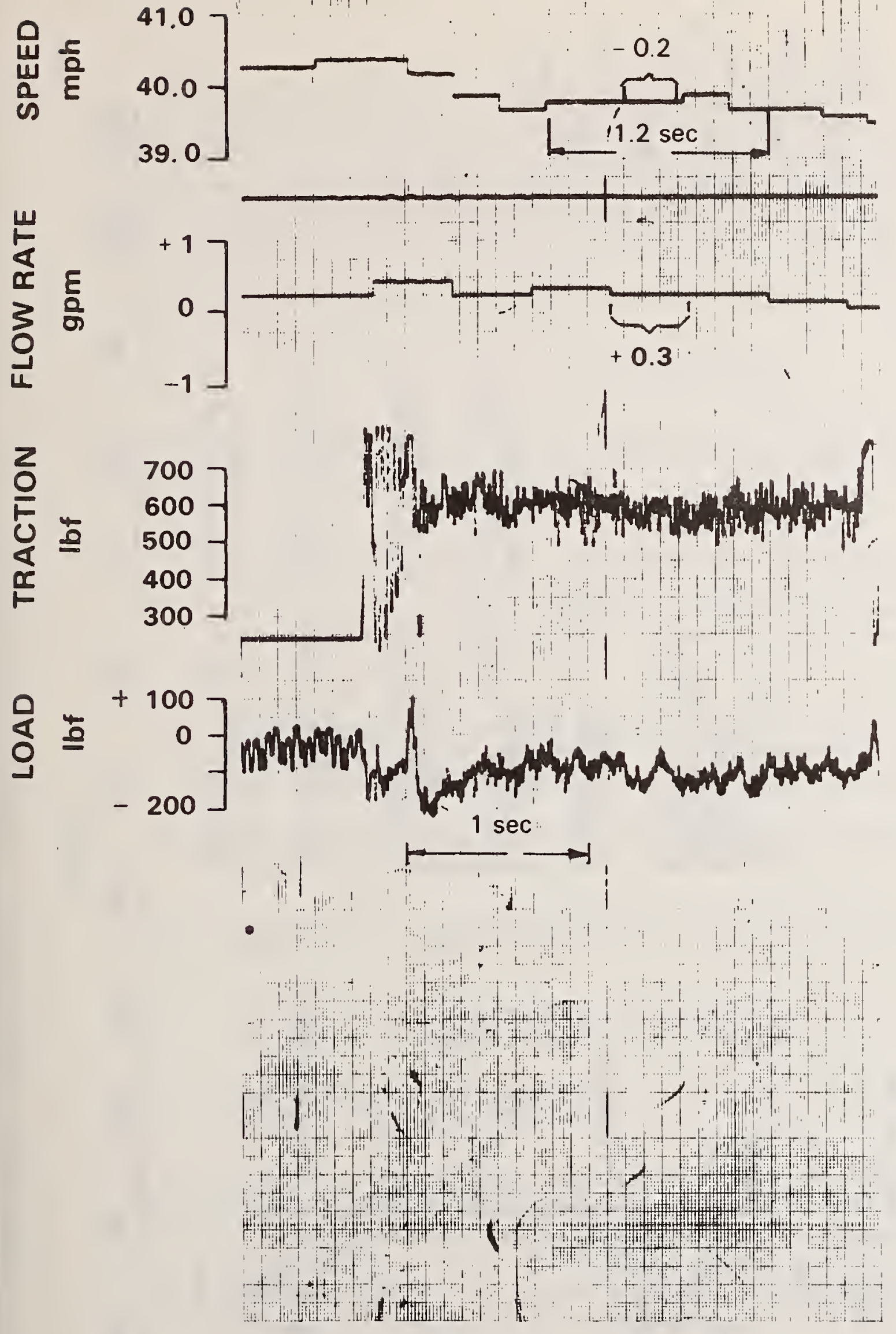

Figure 87. Plot on-board tow vehicle.

143 
In each test sequence the test tires are changed after three skid tests. There is a time delay between each set of three while the new tire is mounted, subjected to a five-mile $(8 \mathrm{~km})$ warm-up, etc. The plan is to record two of the test results on tape and to plot the three results during the time delay. In this manner, a test can be conducted every ten minutes which is compatible with the drying time of the surfaces.

The ground station performance has met the design objectives.

\section{RECOMMENDATIONS}

To improve the reliability of subsystem evaluation, skid measurement correlation results, and the convenience of conducting the tests, the following recommendations are made:

1. A measured distance for adjusting the fifth wheel system should be established at a place more convenient to the skid test surfaces, where it would be possible to make test runs in both directions, and where extended driving distance would not be required between runs.

2. The WARS speed measuring subsystem should be modified so that both the driver's aid readout and the recorded speed signal are conditioned through a single set of calibration adjustments.

3. The DDG and its method of use should be thoroughly studied and modified as necessary to improve its reliability.

4. A photographic method should be developed for determining the width of the water trace at the point that the tire enters it.

5. The change in transducer readout which occurs when the brake system is energized should be eliminated.

6. The height of the WARS flow nozzle should be reduced in compliance with ASTM E274.

7. The test tire inflation pressure should be adjusted to $24 \mathrm{psi}$ $(165 \mathrm{kPa})$ after the $5 \mathrm{mile}(8 \mathrm{~km})$ conditioning drive and immediately before the skid resistance measurement test.

8. The weighing on the force plate of the flow tank versus time should be considered by WFTC personnel as a means of measuring the average flow rate.

9. The IRS skid resistance measurement results obtained by use of the ground station should be compared to the results obtained from a data analyst. The comparison should be made for a large number of tests during the time restraints of a correlation program. 
The WARS evaluations and correlation results reported here are valid only if no modifications are made, if no changes occur in mechanical and electrical components, and if the system is operated in the same manner as it was at the time of these tests. Appendix A describes the WARS and contains a listing of the values of recognized WARS variables in effect during these tests.

It is a pleasure to acknowledge the helpful discussions and assistance of $\mathrm{Dr}$. Hsien $\mathrm{H}$. Ku concerning the statistical analysis of the test results, of Mr. W. H. Appletor and Mr. R. G. Russell in the conduct of the tests, of other members of the NBS staff, and of personnel of the FHWA Western, Central and Eastern Field Test Centers and the Federal Highway Administration for their cooperative efforts. 


\section{REFERENCES}

[1] "Standard Method of Test for Skid Resistance of Paved Surfaces Using a Full Scale Tire," Designation E274-70, Annual Book of ASTM Standards, Part 11 (American Society for Testing and Materials, Philadelphia, Pa., 1973).

[2] Watson, John R. and Cook, Larry M., "A National Program to Standardize Skid Resistance Measurements", Public Roads, A Journal of Highway Research, Vol. 37, No. 3, pp 77-80 (December 1972).

[3] Smith, L. L. and Fuller, S. L., "Florida Skid Correlation Study of 1967 - Skid Testing with Trailers," Highway Skid Resistance, STP 456 (American Society for Testing and Materials 1969).

[4] Kearns, R. W. and Ward, J. F., "A Method and Means of Calibrating an Air-Bearing Force Plate for Use with a Towed Pavement Friction Test Trailer," National Bureau of Standards (U.S.), NBSIR 75-738 (December 1974).

[5] Kearns, R. W. and Ward, J. F., "Skid Resistance Measurement Tests at the FHWA Eastern Field Test Center," National Bureau of Standards (U.S.), NBSIR 75-972.

[6] Chestnut, H. and Mayer, R. W., Solution of Linear Differential Equations, Chapter 3, Servomechanisms and Regulation System Design, Vol. 1, p 62 (John Wiley \& Sons, Inc., N.Y. 1951).

[7] Garfinkel, Mann and Youden, "Design and Statistical Procedures for The Evaluation of an Automatic Gamma-Ray Point-Source Calibrator," National Bureau of Standards (U.S.), Spec. Publ. 300, Vol. 1, 436 pages (February 1969).

[8] Mortimer, T. P. and Ludema, K. C. (University of Michigan), "The Effects of Salts on Road Drying Rates, Tire Friction and Invisible Wetness," Pavement Friction Characteristics and Water Depth, Paper 396, Highway Research Record, (1972).

[9] "Locked-Wheel Pavement Skid Trailer Correlation and Calibration Techniques," Final Report NCHRP project 1-12(2). February, 1973. (Pennsylvania State University Transportation and Traffic Safety Center). 
General Description of the Western Area Reference System

(Tow Vehicle and Trailer)

1. System Identification

1.1 System manufactured by: Ford Motor Company

1.2 Model: Arizona Proving Ground Torque Trailer System

1.3 Tow Vehicle ID Number: 000T024

1.4 Trailer ID Number: 13

2. Tow Vehicle

2.1 Make: Ford

2.2 Model year: 1974

2.3 Body style: F350

2.4 Engine: 460 with dual exhaust

2.5 Fuel tank capacity: main tank removed, auxilary 22 gallons

2.6 Seating: driver's seat only

2.7 Normal occupancy: driver only

2.8 Air conditioning: yes

2.9 Wheel base: 140.6 inches

2.10 Track: front 66.5 inches, rear 63.5 inches

2.11 Tire size: front 9.50-16.5, rear 9.50-16.5 load range $\mathrm{E}$

2.12 Rear wheels: single

3. Trailer

3.1 Construction: welded steel chassis and box with streamlined fiberglass body

3.2 Length: center of hitch to center of axle, 105.2 inches

3.3 Track: 66 inches (E 501 tires)

3.4 Suspension: leaf springs with two air spring shock absorbers at each wheel. Air springs operated at 0 psi.

3.5 Test brakes: non-retracting disk type, air-actuated hydraulic

3.6 Skid measurement transducer: left wheel, strain gaged torque tube between axle and brake backing plate

4. Pavement Wetting

4.1 Water tank capacity: 235 gallons

4.2 Pump: one gear pump, powered by drive shaft

4.3 Flow rate control: roughly proportional to speed. Coarse control by drive pulley. Fine control by means of trim valves adjusted for $20,40,60 \mathrm{mph}$

4.4 Nozzle: Pennsylvania State Type, mounting adjustable for pitch angle and height. 
5. Instrumentation

5.1 Speed: analog fifth wheel with nullmeter driver aid readout, full scale data recording readout.

5.2 Inflation: common tire gage referenced to user calibrated gage.

5.3 Data recorder: Brush, 11211128 galvanometers, filtered inputs, strip chart, two channels, light pens.

5.4 Signal amplifier, torque transducer: Daytronic model 878A.

5.5 Channel assignments: torque, speed. Comments: chart paper is 6 in wide with 100 percent channel overlap. Grid lines are recorded while paper is in motion. Timing marks are recorded at $1 / 10$ second intervals.

5.6 Transducer excitation: $3 \mathrm{kHz}$ carrier, modulated and demodulated internally in the signal amplifier.

6. Test Sequence

6.1 Sequence of events: See figure $\mathrm{Al}$

7. Crew

7.1 Driver/Operator: Eugene L. Kaylor

7.2 For further information, contact:

John L. King

Principal Investigator

Field Test and Evaluation Center for Western States

Post office Box 1031

Kingman, Arizona 86401 


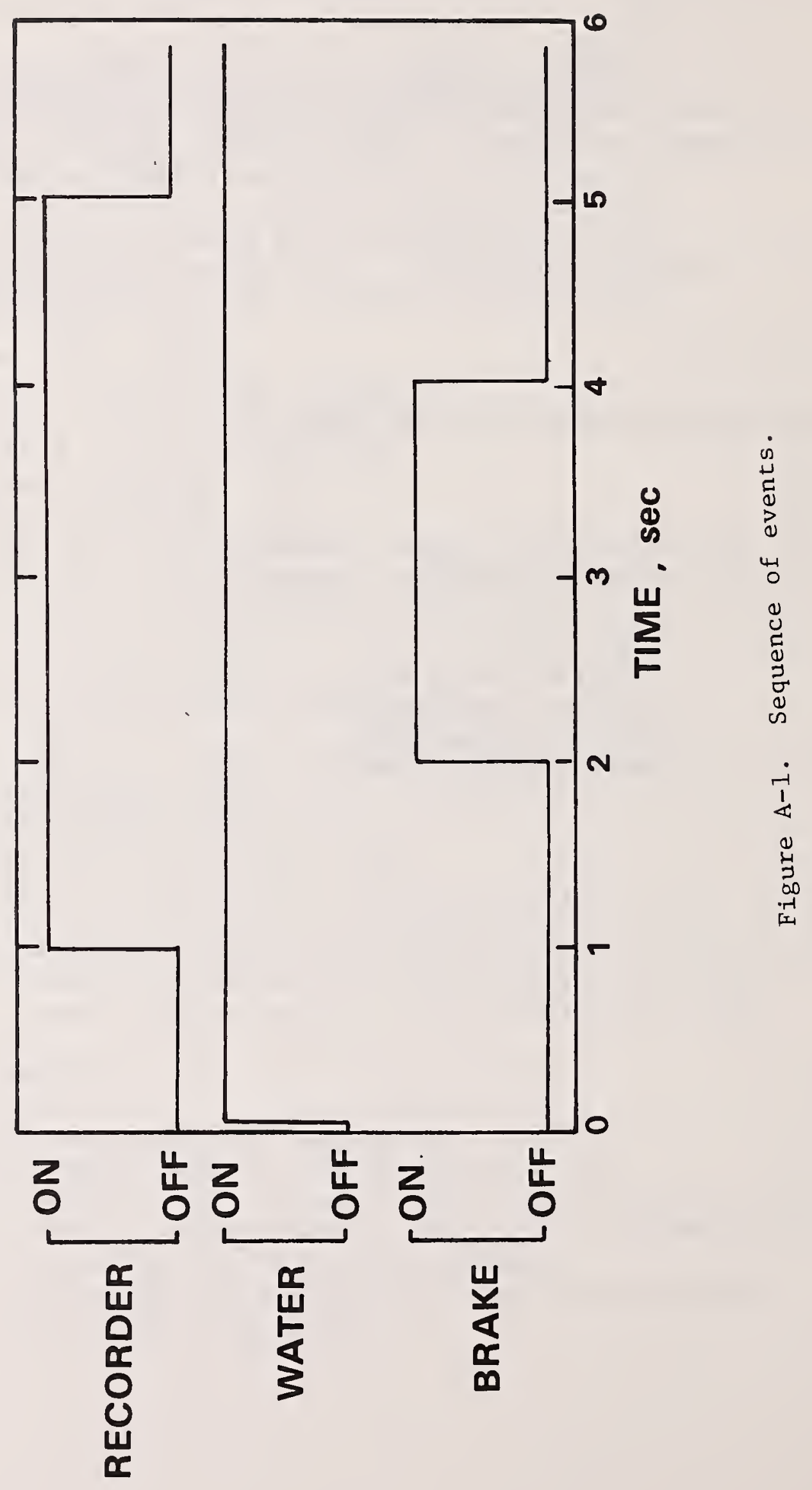


The information below represents the values of recognized WARS variables in effect during this comparison with the IRS.

1. Test tires: standard pavement test tires, G 78-15, ASTM designation E 501 .

2. Test tire inflation: 24 psi, maintained during testing.

3. Hitch height: $143 / 8$ inches from level pavement to bottom of trailer hitch flange, maintained during testing.

4. Test side of trailer: left only.

5. Calibration signal: left wheel, $865 \mathrm{lbf}$ (933 ft-1bf at $1215 / 16$ inches wheel radius).

6. Static vertical loads: left trailer wheel, 1087 lbf; right trailer wheel, 1083 lbf; hitch, 178 lbf.

7. Trailer suspension:

Tire radial spring rate $=1280 \mathrm{lbf}$ per inch

Effective damping factor (after modification):

$\zeta$ body-to-axle $=0.65$,

$\zeta$ body-to-ground $=0.42$,

$\zeta$ force plate $=0.35$.

Suspension system:

damped low natural frequency $=3.7 \mathrm{~Hz}$, damped high natural frequency $=6-8 \mathrm{~Hz}$.

Vertical frequency response on tires without suspension relative movement $=4 \mathrm{~Hz}$.

8. Consumable cargo: pavement wetting tank refilled frequently, nominally after three runs.

9. Condition of test pavements: dry before each test.

10. Flow rates: $20 \mathrm{mph}, 14.6 \mathrm{gpm} ; 40 \mathrm{mph}, 29.2 \mathrm{gpm} ; 60 \mathrm{mph}, 43.9 \mathrm{gpm}$. 
APPENDIX C

The Test Matrix

A subdivision of the test plan consists of the following test matrix:

Time Period

Surface

\begin{tabular}{|c|c|c|c|c|c|c|c|}
\hline TPEED & A & $B$ & C & 1 & $\mathrm{E}$ & $\mathrm{F}$ & $\mathrm{G}$ \\
\hline$S-\Delta S$ & 1 & 2 & 3 & 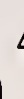 & 5 & 6 & 7 \\
\hline$S$ & 2 & 3 & 4 & 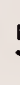 & 6 & 7 & 1 \\
\hline$S+\Delta S$ & 4 & 5 & 6 & 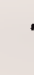 & 1 & 2 & 3 \\
\hline
\end{tabular}

Letters A thru G designate 7 tires while numbers 1 thru 7 identify the 7 lanes comprising the surface. The nominal test speed is $\mathrm{S}$, while $\Delta \mathrm{S}$ is an incremental change in the speed.

The mean of the 21 skid number measurements represents the skid number of the surface measured during the time period using the average tire at the nominal test speed. The novelty of the test matrix is that it yields the skid gradient of the surface, as well as a measure of the surface and tire nonuniformities.

Suppose we want to compare the effect of making a measurement with tire A with all the other tires. To do this effectively, we want to eliminate any measurement deviations due to skidding in different lanes and at different speeds.

Let a measurement result be represented by the notation

$$
(\mathrm{SN}+\varepsilon)_{\operatorname{LT}(S-\Delta \mathrm{S})}
$$

where:

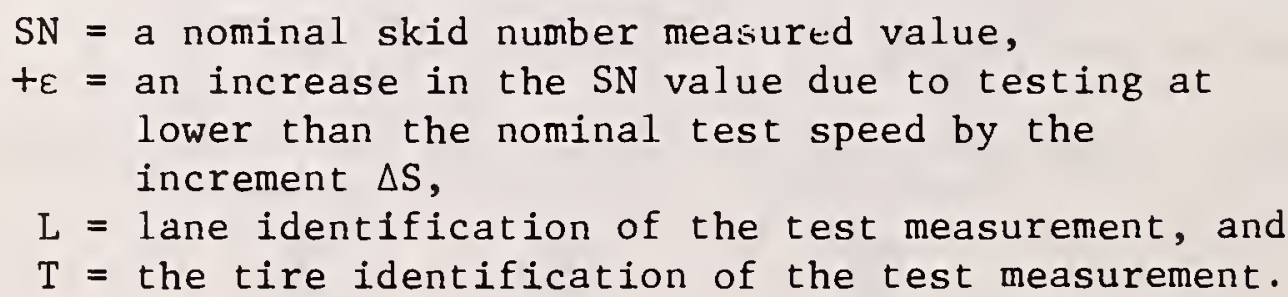


From the test matrix, tire $A$ was used in lanes 1,2 , and 4 at three different speeds. Lane 1 was used with tires $A, G$, and $E$ at three different speeds, while lane 2 was used with tires $B, A$, and $F$ at the three different speeds, while lane 4 was used with tires $D, C$, and $A$ at three different speeds.

lane

Let us write an equation for the measurement results made in each

$$
\begin{aligned}
& 2(S N+\varepsilon)_{1 A(S-\Delta S)}(S N)_{1 G(S)}-(S N-\varepsilon)_{1 E(S+\Delta S)}=\Delta_{A G E}+3 \varepsilon \\
& 2(S N)_{2 A(S)}-(S N+\varepsilon)_{2 B}(S-\Delta S)-(S N-\varepsilon)_{2 F}(S+\Delta S)=\Delta_{A B F} \\
& 2(S N-\varepsilon)_{4 A(S+\Delta S)}-(S N)_{4 C(S)}-(S N+\varepsilon)_{4 D(S-\Delta S)}=\Delta_{A C D}-3 \varepsilon
\end{aligned}
$$

where $\Delta_{\mathrm{AGE}}=$ twice the difference between using tire $\mathrm{A}$ and the average of using tires $G$ and $E$ in lane 1 ,

$\begin{aligned} \Delta_{\mathrm{ABF}}= & \text { twice the difference between using tire } A \text { and the average } \\ & \text { of using tires } \mathrm{B} \text { and } \mathrm{F} \text { in lane } 2,\end{aligned}$

${ }_{A C D}=$ twice the difference between using tire $A$ and the average of using tires $C$ and $D$ in lane 4.

Note that equations 1,2 , and 3 are each independent of lane effects. Note also that the sum of the three equations is independent of any speed effects (assuming $\Delta S$ is small). Consequently, the sum is free of both lane and speed effects. To simplify the notation, e]iminate the lane and speed variations from the sum, and we get

$$
6(\mathrm{SN})_{\mathrm{A}}-(\mathrm{SN})_{\mathrm{B}}-(\mathrm{SN})_{C}-(\mathrm{SN})_{D}-(\mathrm{SN})_{\mathrm{E}}-(\mathrm{SN})_{\mathrm{F}}-(\mathrm{SN})_{G}=\sum \Delta
$$

We may add to this equation [7], the equation

$$
(\mathrm{SN})_{\mathrm{A}}-(\mathrm{SN})_{\mathrm{A}}=0
$$

which simply says that the skid number without lane and speed dispersion is equal to the skid number measurement using tire A without lane and speed dispersion with no measurement error. Then

$$
7(\mathrm{SN})_{\mathrm{A}}-\left\{\mathrm{SN}_{\mathrm{A}}+\mathrm{SN}_{\mathrm{B}}+\mathrm{SN}_{\mathrm{C}}+\mathrm{SN}_{\mathrm{D}}+\mathrm{SN}_{\mathrm{E}}+\mathrm{SN}_{\mathrm{F}}+\mathrm{SN}_{\mathrm{G}}\right\}=\sum \mathrm{A}
$$


Now, the measurement performance with tire a can be compared with the performance of all the other tires by writing

$$
\begin{aligned}
\mathrm{SN}_{\mathrm{A}} & =\sum_{i=\mathrm{A}}^{\mathrm{G}} \frac{\mathrm{SN}_{i}}{7}+\frac{\sum \Delta}{7} \\
& =\quad \begin{array}{l}
\text { mean of al1 } \\
\text { measurements }
\end{array}+\sum \Delta
\end{aligned}
$$

In a similar manncr, the test matrix can be rearranged to vield, for example, the measurement performance on lane 1 compared with the performance on all the other lanes. The resuits are then a measure of surface uniformity. 
From the test matrix, tire $A$ was used in lanes 1,2 , and 4 at three different speeds. Lane 1 was used with tires A, G, and $E$ at three different speeds, while lane 2 was used with tires $B, A$, and $F$ at the three different speeds, while lane 4 was used with tires $D, C$, and $A$ at three different speeds.

lane

Let us write an equation for the measurement results made in each

$$
\begin{aligned}
& 2(\mathrm{SN}+\varepsilon)_{1 \mathrm{~A}(\mathrm{~S}-\Delta \mathrm{S})}-(\mathrm{SN})_{1 \mathrm{G}(\mathrm{S})}-(\mathrm{SN}-\varepsilon)_{1 \mathrm{E}(\mathrm{S}+\Delta \mathrm{S})}=\Delta_{\mathrm{AGE}}+3 \varepsilon
\end{aligned}
$$

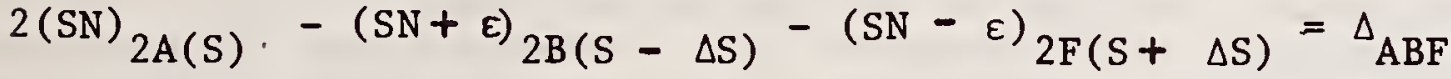

$$
\begin{aligned}
& 2(S N-\varepsilon)_{4 A}(S+\Delta S)-(S N)_{4 C(S)}-(S N+\varepsilon)_{4 D}(S-\Delta S)=\Delta_{A C D}-3 \varepsilon
\end{aligned}
$$

where $\Delta_{\mathrm{AGE}}=$ twice the difference between using tire $\mathrm{A}$ and the average of using tires $\mathrm{G}$ and $\mathrm{E}$ in lane 1 ,

${ }_{\mathrm{ABF}}=$ twice the difference between using tire $\mathrm{A}$ and the average of using tires $B$ and $F$ in lane 2, $\begin{aligned} \Delta_{\mathrm{ACD}}= & \text { twice the difference between using tire } \mathrm{A} \text { and the average } \\ & \text { of using tires } \mathrm{C} \text { and } \mathrm{D} \text { in lane } 4 .\end{aligned}$

Note that equations 1,2 , and 3 are each independent of lane effects. Note also that the sum of the three equations is independent of any speed effects (assuming $\Delta S$ is smal1). Consequently, the sum is free of both lane and speed effects. To simplify the notation, e]iminate the lane and speed variations from the sum, and we get

$$
6(\mathrm{SN})_{\mathrm{A}}-(\mathrm{SN})_{\mathrm{B}}-(\mathrm{SN})_{C}-(\mathrm{SN})_{D}-(\mathrm{SN})_{\mathrm{E}}-(\mathrm{SN})_{\mathrm{F}}-(\mathrm{SN})_{\mathrm{G}}=\sum \Delta
$$

We may add to this equation [7], the equation

$$
(\mathrm{SN})_{\mathrm{A}}-(\mathrm{SN})_{\mathrm{A}}=0
$$

which simply says that the skid number without lane and speed dispersion is equal to the skid number measurement using tire $A$ without lane and speed dispersion with no measurement error. Then

$$
7(\mathrm{SN})_{\mathrm{A}}-\left\{\mathrm{SN}_{\mathrm{A}}+\mathrm{SN}_{\mathrm{B}}+\mathrm{SN}_{\mathrm{C}}+\mathrm{SN}_{\mathrm{D}}+\mathrm{SN}_{\mathrm{E}}+\mathrm{SN}_{\mathrm{F}}+\mathrm{SN}_{\mathrm{G}}\right\}=\sum \Delta
$$


Now, the measurement performance with tire A can be compared with the performance of all the other tires by writing

$$
\begin{aligned}
& \mathrm{SN}_{\mathrm{A}}=\sum_{i=\mathrm{A}}^{\mathrm{G}} \frac{\mathrm{SN}_{i}+\frac{\sum \Delta}{7}}{} \\
&=\begin{array}{l}
\text { mean of all } \\
\text { measurements }
\end{array}+\sum \Delta \\
& \frac{7}{7}
\end{aligned}
$$

In a similar manncr, the test matrix can be rearranged to yield, for example, the measurement performance on 1 ane 1 compared with the performance on all the other lanes. The resuits are then a measure of surface uniformity. 


\section{NATIONAL BUREAU OF STANDARDS DEPARTMENT OF COMMERCE WASHINGTON, D.C. 20234}

10. I'rojucel/Tnsk/Work lait No. 2130440

11. Contract/Cirant No.

1-1-1261

13. 'Type of Repore \& Period Covered Fina 1

March-April, 1975

14. Sponsoring Agency code.

Federal Highway Administration

Office of Development

Washington, D. C. 20590

16. ABSTRACT (A 200-word or less factual summary of most significant information. If document includes a significant bibliography or literature survey, mention it here.)

The Federal Highway Administration (FHWA) is developing a program to improve the method of measuring wet weather pavement skid resistance (SN) and to reduce the variation in results. At the national level, an interim reference system (IRS) is maintained and operated by the National Bureau of Standards. At the regional level, an area reference system (ARS) is maintained and operated at each FHWA field test center. Intencomparisons between these reference systems and the highway measuring systems at the state leve1, provide measurement assurance.

In this report, the first correlation results between the IRS and the western ARS (WARS) are given: $\mathrm{SN}_{\text {WARS }}=4.55+0.99 \mathrm{SN}_{\text {IRS }}$ where the computed standard deviation of a mid-range predicted value is $1 \mathrm{SN}$. SN is described as a function of test speed, V, in $\mathrm{mph}(1 \mathrm{mph}=1.609 \mathrm{~km} / \mathrm{h}):$ for surface $2 ; \mathrm{SN}(\mathrm{V})=76.5-0.71 \mathrm{~V}+0.0070 \mathrm{~V}^{2}$ and the speed gradient is $\frac{\mathrm{d}(\mathrm{SN})}{\mathrm{d}}=-0.71+0.014 \mathrm{~V}$.

The test program Is explained from test preparations, tuning and calibration of subsystems, thru dynamic measurement of the surfaces. Controlled and uncontrolled variables are identified, discussed, and in some cases, experimentally verified. A ranking of the sources of dispersion is given. A discontinuity in SN of surface 1 is identified due to the unique test plan. A ground station for improved SN calculation precision and on-site statistical analysis is found to meet design objectives.

17. KEY WORDS (six to twelve entries; alphabetical order; capilalize only the first letter of the first key word unless a proper name; separated by semicolons) Accident reduction, skidding; correlation, skid resistance; highway safety; measurement, skid resistance; pavement, skid resistance; pavement wetting system; tire-pavement interface forces; wet pavement.

18. AVAILABILITY [X] Unlimited

[ For Official Distribution. Do Not Release to NTIS

[] Order From Sup. of Doc., U.S. Government Printing Office Washington, I).C. 20402, SI) Cat. No. C.13

[X Order From National Technical Information Service (NTIS) Springficld, Virginia 22 I 51

\begin{tabular}{|l|c|}
\hline $\begin{array}{l}\text { 19. SECURITY CLASS } \\
\text { (THIS REPURT) } \\
\text { UNCL ASSIFIED }\end{array}$ & 165 \\
\hline $\begin{array}{l}\text { 20. SECURITY CLASS } \\
\text { (THIS PAGE) }\end{array}$ & 22. Price \\
UNCLASSIFIED & $\$ 6.75$ \\
\hline
\end{tabular}



NBSir 76-1134 cancel

(to be issued after $9 / 178$ with a new number) 
